Sebastian Odzuck

\title{
The Priority of Locomotion in Aristotle's Physics
}

\section{Ebook}

\section{Vandenhoeck \& Ruprecht}




\section{VYR}

(c) 2014, Vandenhoeck \& Ruprecht GmbH \& Co. KG, Göttingen ISBN Print: 9783525253069 — ISBN E-Book: 9783647253060 


\title{
Hypomnemata \\ Untersuchungen zur Antike und zu ihrem Nachleben
}

\author{
Herausgegeben von \\ Ewen Bowie, Albrecht Dihle, \\ Dorothea Frede, Hans-Joachim Gehrke, Günther Patzig, \\ Karla Pollmann, Christiane Reitz, Christoph Riedweg, Gisela Striker
}

Band 196

\section{Vandenhoeck \& Ruprecht}


Sebastian Odzuck

\section{The Priority of Locomotion in Aristotle's Physics}

\section{Vandenhoeck \& Ruprecht}




\section{Verantwortliche Herausgeberinnen: Dorothea Frede und Gisela Striker}

Bibliografische Information der Deutschen Nationalbibliothek

Die Deutsche Nationalbibliothek verzeichnet diese Publikation in der Deutschen Nationalbibliografie; detaillierte bibliografische Daten sind im Internet über http://dnb.d-nb.de abrufbar

ISBN 978-3-525-25306-9

ISBN 978-3-647-25306-0 (E-Book)

Umschlagabbildung: Sanitarium Charleroi, Christian Odzuck, Collage, $18 \mathrm{~cm} \times 24 \mathrm{~cm}, 2013$ C) 2013 VG Bildkunst, Bonn.

Gedruckt mit freundlicher Unterstützung der Geschwister Boehringer Ingelheim Stiftung für Geisteswissenschaften in Ingelheim am Rhein.

(C) 2014, Vandenhoeck \& Ruprecht GmbH \& Co. KG, Göttingen / Vandenhoeck \& Ruprecht LLC, Bristol, CT, U.S.A. www.v-r.de

Alle Rechte vorbehalten. Das Werk und seine Teile sind urheberrechtlich geschützt. Jede Verwertung in anderen als den gesetzlich zugelassenen Fällen bedarf der vorherigen schriftlichen Einwilligung des Verlages. - Printed in Germany.

Gesamtherstellung: $\oplus$ Hubert \& Co, Göttingen

Gedruckt auf alterungsbeständigem Papier. 


\section{Contents}

Acknowledgements . . . . . . . . . . . . . . . . 9

1. Introduction $\ldots \ldots \ldots \ldots \ldots \ldots$

2. The importance of the primary kind of change . . . . . . . 14

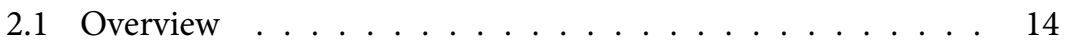

2.2 The arrangement of the Physics . . . . . . . . . . . . 15

2.2.1 First option: Books VI-VIII as the treatise On Change 18

2.2.1.1 Andronicus . . . . . . . . . . . . . . . . . . . 19

2.2.1.2 Theophrastus' letter . . . . . . . . . . . . . . . 19

2.2.1.3 References in Aristotle . . . . . . . . . . . . . 21

2.2.1.4 Eudemus . . . . . . . . . . . . . . . . 21

2.2.2 Second option: Books V-VIII as the treatise $\mathrm{On}$

Change ................ 22

2.3 The eight books of the Physics _ . . . . . . . . . . . 25

2.3.1 Physics I-IV: Examining change for the sake of understanding nature . . . . . . . . . . 25

2.3.2 Physics V-VIII: The general analysis of change . . . . 27

2.4 Physics VIII . . . . . . . . . . . . . . . . . . . . . 31

2.4 .1 Overview . . . . . . . . . . . . . 31

2.4.2 The argument of Physics VIII . . . . . . . . . . . 31

2.4.3 The importance of the primary kind of change . . . . 34

2.5 Conclusion . . . . . . . . . . . . . . . . 40

3. Change in quality and quantity of living beings depends on locomotion, but not vice versa . . . . . . . . . . . . . . . 42

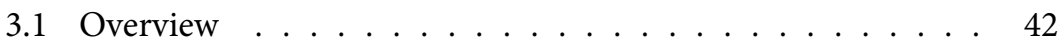

3.2 Growth and diminution presuppose alteration . . . . . . . 44

3.2.1 Growth presupposes alteration . . . . . . . . . 45

3.2.2 Diminution presupposes alteration . . . . . . . . 48

3.3 Alteration presupposes locomotion . . . . . . . . . . . . . 49

3.4 Does locomotion precede all occurrences of change in quantity? . . . . . . . . . . . . . . . . 53

3.5 The reason for the restriction of the argument's scope . . . . 58 
3.6 The sense of priority $\ldots \ldots \ldots 7 \ldots$

3.7 Conclusion . . . . . . . . . . . . . . . . . . . . 69

4. Locomotion necessarily accompanies each of the other kinds of change, but not vice versa . . . . . . . . . . . . . . . . 71

4.1 Overview .................. 71

4.2 What changes in quantity changes with respect to place . . . 73

4.2 .1 Overview . . . . . . . . . . . . . . . 73

4.2.2 What is growing moves to a larger place . . . . . . 74

4.2.3 Change in place implies no change in the spatial order of the subject's parts . . . . . . . . . . . . . 78

4.2.4 A possible objection . . . . . . . . . . . . . . 81

4.2.5 Compatibility with the irreducibility of the kinds of change ................. . . 85

4.2 .6 Conclusion . . . . . . . . . . . . . . . . 88

4.3 What undergoes generation or corruption changes with respect to place . . . . . . . . . . . . . . . . . . . 89

4.3 .1 Overview . . . . . . . . . . . . . . 89

4.3.2 Generation and corruption in virtue of aggregation and segregation . . . . . . . . . . . . 90

4.3.3 What aggregates or segregates must change with respect to place . . . . . . . . . . . . . . . . 96

4.3.4 Conclusion . . . . . . . . . . . . . . . . . . . 97

4.4 What changes in quality changes with respect to place . . . 98

4.4 .1 Overview . . . . . . . . . . . . . . . 98

4.4.2 What does it mean that condensation and rarefaction are principles of quality? . . . . . . . . . . . 100

4.4.3 Every alteration involves a change in the four basic qualities . . . . . . . . . . . . . . . 104

4.4.4 Every change in the four basic qualities involves condensation or rarefaction . . . . . . . . . . . 108

4.4.5 Condensation and rarefaction are forms of aggregation and segregation . . . . . . . . . . 110

4.4.6 What changes in quality changes with respect to place 112

4.4 .7 Conclusion . . . . . . . . . . . . . . . . . 113

4.5 Conclusion . . . . . . . . . . . . . . . 113

5. All changes depend on the first locomotion, but not vice versa . . 115

5.1 Overview . . . . . . . . . . . . . . . . . 115

5.2 The unity of the eternal change . . . . . . . . . . 118

5.2.1 Two ways in which change may be eternal . . . . . 118

5.2.2 Why the eternal change must be one and continuous . 121 
5.2.3 The criteria for being one continuous change . . . . 123

5.2.4 What is better is the case in nature . . . . . . . . 127

5.3 Locomotion alone can be one and eternal . . . . . . . 130

5.3.1 None of the other three kinds of change can be one and eternal . . . . . . . . . . . . . . 131

5.3.2 Only circular locomotion can be one and eternal . . . 134

5.4 Locomotion has ontological priority . . . . . . . . . . 137

5.4 .1 Ontological priority . . . . . . . . . . . . 137

5.4.2 A third sense in which locomotion is ontologically prior . . . . . . . . . . . . . . 139

5.5 Conclusion . . . . . . . . . . . . . . . . . . 142

6. Locomotion has temporal priority . . . . . . . . . . . . 144

6.1 Overview . . . . . . . . . . . . . . . . . . . 144

6.2 Locomotion has priority in time, since it is the only change eternals can undergo . . . . . . . . . . . . 146

6.3 Objection: Locomotion is the last of all changes in perishable things . . . . . . . . . . . . . . . . 148

6.4 Coming to be presupposes an earlier locomotion . . . . . . 150

6.5 The locomotion of the sun as a cause of generation . . . . 154

6.6 Conclusion . . . . . . . . . . . . . . . . 162

7. Locomotion is prior in essence . . . . . . . . . . . . . 164

7.1 Locomotion is prior in essence, since it is last in coming to be . . . . . . . . . . . . . . . . . . 164

7.1 .1 Overview ................... . 164

7.1.2 The reversed priority claim . . . . . . . . . . 166

7.1.3 A different use of the term 'locomotion' . . . . . . . 172

7.1.4 Does locomotion come to things last? . . . . . . . . 175

7.1.4.1 Capacities of the soul . . . . . . . . . . . . 176

7.1.4.2 Priority in essence of the locomotive capacity . . . . 179

7.1.5 Another sense of priority in essence . . . . . . . . 182

7.1.6 Conclusion . . . . . . . . . . . . . . . . 184

7.2 Locomotion alone preserves its subject's essence . . . . . . 186

7.2 .1 Overview . . . . . . . . . . . . . 186

7.2.2 Locomotion does not change its subject's being . . . 188

7.2.3 Locomotion preserves its subject's essence best . . . . 190

7.2.4 Making $x$ depart from its essence by being part of a change in essence? . . . . . . . . . . . . . . 195

7.2.4.1 Alteration as part of a change in essence . . . . . . 195

7.2.4.2 Growth and diminution as part of change in essence . 199 
7.2.4.3 Locomotion as a part of a change in essence? . . . . . 201

7.2.5 Change in quality or quantity in principle may result in a change in essence . . . . . . . . . . . . 202

7.3 Conclusion: Locomotion's priority in essence . . . . . . . 207

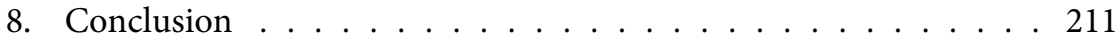

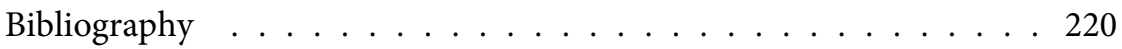

List of Abbreviations . . . . . . . . . . . . . . . 223

Index Locorum . . . . . . . . . . . . . . . . . . . . . 221

Index Nominum $\ldots \ldots \ldots \ldots . \ldots \ldots$

Index Rerum . . . . . . . . . . . . . . . . . . . . 221 


\section{Acknowledgements}

This book is a slightly revised version of my dissertation, which was accepted at the Humboldt Universität zu Berlin in 2012. Above all, I would like to thank my three supervisors Jonathan Beere, Ben Morison, and Christof Rapp. My dissertation benefited greatly from working under their guidance and I am most thankful for the generous support they have given me in many different respects both while I was working on this project and afterwards. I was especially fortunate to have had the opportunity to continually work with Ben Morison while on a short stay in Oxford, during several months at Princeton, and - despite being on the other side of the Atlantic - from my desk in Erlangen. Our conversations and his numerous comments and suggestions greatly improved my work both in detail and from a broader perspective and I am very grateful for his support and encouragement.

I also want to take this opportunity to thank Friedemann Buddensiek for his constant support over the past few years and for helping me start my inquiry into the priority of locomotion in the first place. Jacob Rosen, in addition to discussing various ideas, read and critiqued an earlier draft of chapter 7 and helped me clarify important points made there. Joshua Crone read the entire work and made many helpful suggestions, for which he has my sincere thanks. I am indebted to many other people for comments and help of various kinds: Andreas Anagnostopoulos, Stephen Hamilton, Hendrik Lorenz, Marko Malink, Henry Mendell, Roman Rüttinger, Pieter Sjoerd-Hasper, and the audiences at Berlin, Göttingen, Princeton, and Würzburg to whom I had the opportunity to present parts of my work. I wish to thank my fellow doctoral students in the Ancient Philosophy program in Berlin as well as my colleagues first in Munich and later in Göttingen for making my time and work in these places so pleasant.

I wrote my dissertation as a doctoral fellow at the Excellence Cluster Topoi in Berlin and am thankful for its generous support. I would also like to thank the editors of this series, in particular Dorothea Frede and Gisela Striker, for accepting my book for publication.

I am especially grateful to my wife, Eva Odzuck, for her provocative claims about Aristotle (and other things), continuous support and patience, and much more, from the beginning right to the very end. Finally, I would like to thank my parents for all they have given me. This book is dedicated to them. 


\section{Introduction}

What is the connection between a living being coming to be, a blade of grass growing, a leaf changing colour, and my walking from here to there?

In each of the four examples a change is described, yet the way in which the respective subject changes is different in all four cases. In fact, each of the examples stands for one of the four respects in which according to Aristotle change ( $x^{\prime}\left(\nu \eta \sigma \iota \varsigma / \mu \varepsilon \tau \alpha \beta \sigma \lambda \eta^{\prime}\right)$ may occur. ${ }^{1}$ Something $x$ may change in

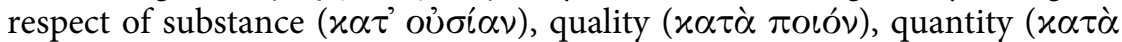

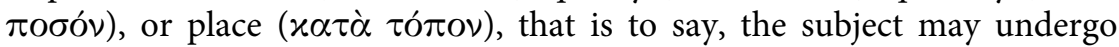

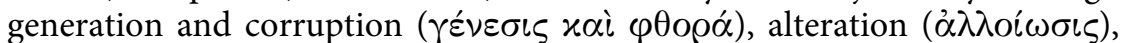

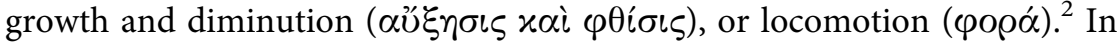
Book VIII of the work which we call the Physics, but also in other places, Aristotle claims that of these four types of change the latter, i. e. locomotion, in general should be considered the most important and primary $(\pi \rho \omega \tau \eta$ $\tau \tilde{\omega} \nu \chi \iota \nu \dot{\eta} \sigma \varepsilon \omega \nu)$, in that it has priority over the other types in different ways ${ }^{3}$, which for instance finds its expression in the fact that according to Aristotle there is no change in quality, quantity, or substance without locomotion, while the converse does not hold. ${ }^{4}$

1 Aristotle often uses both $x^{\prime}(\nu \eta \varpi \iota \varsigma$ (motion) and $\mu \varepsilon \tau \alpha \beta \circ \lambda \eta$ (change) in referring to the four different kinds of change he thinks exist. In Phys. V 1 and 2, however, he explicitly distinguishes the terms from one another: $x_{i} \nu \eta \sigma \iota \varsigma$ only covers the three kinds of non-substantial change, namely change in place, quality, and quantity, while $\mu \varepsilon \tau \alpha \beta o \lambda \eta \dot{~ i s ~ u s e d ~ a s ~ t h e ~ m o r e ~}$ general term, and stands for all of the four kinds of change, i. e. for the non-substantial kinds as well as for change with respect to substance (see Phys. V 1, 225a34-b3, V 2, 226a23-25 and

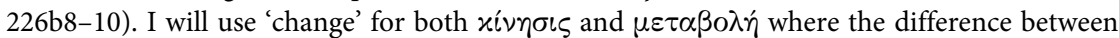
the terms is of no importance, and render xivnoıs as 'non-substantial change' when the context suggests that $x^{i} \nu \eta \sigma \iota \varsigma$ is restricted to this sense. For more on the different uses of xiv vs. $\mu \varepsilon \tau \alpha \beta 0 \lambda \eta$ see for instance Ross (1936), 7-8, and Waterlow (1982), 93-95.

2 For the four kinds of change see for instance Phys. III 1, 200b33-201a1, and more generally V 1-2.

3 See for instance Phys. VIII 7, 260b15-19, and 261a27. In Phys. VII 2, 243a39-40 and Phys. VIII 7, 260a26-29, Aristotle claims that locomotion is primary with respect to the nonsubstantial types of change. See also Phys. IV 1, 208a31-32 where Aristotle points out that

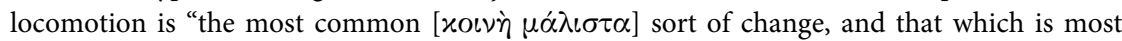
properly [ $\chi \cup \rho \iota \tau \alpha \dot{\alpha} \tau \eta]$ so called" (Transl. Morison $(2002), 11$.) Something similar is said in Phys. VIII 9, 266a1-2. For more on the connection between the fact that $\varphi$ ood is the primary and most common kind of change see Morison (2002), 13-15.

4 See Phys. VIII 7, 260b26-29. 
With respect to this claim one may wonder first of all why one of these four kinds is held to be more important than the others, or even why it should be fundamental to them, as the stated claims seem to suggest. Furthermore, it is far from obvious why locomotion is held to be this primary kind; for locomotion, one might object, requires a subject that can change with respect to place and therefore, it would seem, locomotion clearly presupposes and in this sense depends on a preceding change in substance, namely the coming-to-be of its respective subject. This, however, would then seem to contradict the priority claim, i. e. Aristotle's thesis about change in place being prior to the other kinds of change.

Although this claim is made elsewhere in Aristotle and obviously seems to be of importance to him, it has not yet been subject to a detailed study. ${ }^{5}$ As I intend to show, for various reasons it has been ignored and even considered as being of "small general interest". ${ }^{6}$ In this study I will therefore present a detailed examination of this claim as it is laid out in Phys. VIII 7, the only place in which Aristotle deals with it systematically and where different arguments for, as well as possible objections against, this far from self-evident assumption are discussed. The questions that serve as a starting point for my inquiry and that therefore will guide my discussion are the following: What does it mean to say that locomotion is prior to other kinds of change, and why is this important? Why does Aristotle think locomotion has this special status, and are his reasons good ones?

My thesis is that Aristotle rightly claims that locomotion has ontological, temporal and essential priority over the other kinds of change, which amounts to the claim that the occurrence of any change belonging to one of the other kinds in different respects presupposes locomotion. In this way Aristotle reaches the goal toward which the discussion of the priority claim tends, namely to establish that the change caused directly by the first unmoved mover can only be locomotion, i. e. a change in place. In order to show this I will proceed in the manner outlined below.

My first step will be to analyse the context in which the arguments for the priority of locomotion are presented (chapter 2). This will help us develop an understanding of what it may mean to say that locomotion is primary and what Aristotle's motivation might have been for making this claim, given that the discussion of the priority claim certainly plays an essential characteristic role in the context of Phys. VIII 7. Only if these points are clear will we be able to analyse and evaluate the arguments presented for the claim in step two, where I will argue that the discussion of

5 The priority claim is also made for instance in GC II 10, 336a18-20 and Met. XII 7, 1072b8-9, and-at least indirectly-in 1073a12.

6 Ross (1936), 93. For more on this see section 2.4.3, esp. p.36, n. 79. 
the primacy of locomotion in the Physics is part of Aristotle's larger project of developing a general theory of the phenomenon of change. More specifically, by belonging to Book VIII of this work, the discussion fulfils the essential task of providing justification for a claim whose truth is presupposed by the whole theory developed in Phys. VIII, a claim which, however, is far from obvious. A part of this important task, I will argue, is carried out by Aristotle, who shows that locomotion is the primary kind of change in different respects, and that therefore the eternal change which is directly caused by the first unmoved mover can only be locomotion.

In the five chapters following this preparatory work I will present a detailed, step-by-step analysis of each of the five different arguments presented for the priority claim in Phys. VIII 7. My examination of the different arguments will follow their order of appearance in VIII 7. The first three of these arguments, I will claim, show that locomotion is ontologically prior to the other kinds of change in different respects, while the fourth and fifth make clear that it is also prior in time and in essence, respectively. As we will see, most of these arguments are rather compressed, but at the same time presuppose the reader's acquaintance with the larger theoretical background sketched out for instance in the De Anima, the De Generatione et Corruptione, as well as in other parts of the Physics. Consequently, understanding and evaluating the five arguments often involves discussing relevant points of these theories.

I shall start by discussing the first of these arguments (260a26-7b). In this argument Aristotle, as I will argue, shows that locomotion has ontological priority in that change in quality and quantity occurring in living beings depends on change in place, because both always presuppose the occurrence of a preceding locomotion, but not vice versa (chapter 3 ).

In the next step I will examine the second argument (260b7-15), which presents another way in which locomotion has ontological priority, namely in virtue of the fact that locomotion always accompanies every other kind of change, while the converse does not hold. For, as I will show, undergoing any of the three remaining kinds of change implies that parts of the respective subject change in place (chapter 4 ).

This will be followed by my analysis of the third argument (260b15-29), which discusses the third way in which locomotion is ontologically prior. According to this argument locomotion is ontologically prior, I will claim, because it is the only type of change that in principle can be eternal and therefore at least in this respect seems to be the only possible candidate for the eternal change responsible for the occurrence of the other types, while itself not presupposing the occurrence of some other change (chapter 5).

Next, I will present my reading of the fourth argument (260b29-a12). I will argue that Aristotle, by once again making use of the fact that in principle locomotion alone can be eternal, makes clear that it also has temporal 
priority, although there are facts that seem to contradict this assumption (chapter 6).

This will be followed by my examination of the last of the five arguments (261a13-23). I will argue that Aristotle makes clear that locomotion is prior in essence by means of two sub-arguments, the first presenting reasons for the claim that locomotion has this kind of priority with respect to perishable self-movers like animals, while the second showing the same with respect to eternal things that may function as the causes of change in other things. The reason for this, I will point out, lies on the one hand in the fact that locomotion is prior in essence in living things, since having locomotion is more important for being what they are according to their form than having any of the other types of change, while the second sub-argument makes use of the fact that locomotion alone completely preserves its subject's essence and, thus, is the only change eternal things can undergo (chapter 7).

My final step will be to give an overview of the results of my study and evaluate what they may imply for the larger context of Phys. VIII as well as for Aristotle's general theory of the phenomenon of change (chapter 8). 


\section{The importance of the primary kind of change}

\subsection{Overview}

Making sense of and evaluating the arguments that are presented for the priority claim in Phys. VIII 7 first of all presupposes an understanding of what Aristotle means by saying that change of place is primary and of why he makes that claim at all. In order to arrive at such an understanding, however, one needs to look at the context in which the discussion of the priority claim is embedded. For, Aristotle certainly had very good reasons for framing this discussion in its respective context in such a way that it fulfils its specific role in the whole of the argumentation. In this chapter, I will therefore analyse the context in which the arguments for the claim that change in place is prior to the other three kinds of change are presented.

I will argue that this examination of the context shows that the systematic discussion of the priority claim in Phys. VIII 7 plays a crucial role in the theory developed in the whole of Book VIII. This theory is supposed to account for the existence of change in the cosmos as one observes it day by day. Part of this theory is that for there to be change there must be a first unmoved mover that acts as the principle of all change in the cosmos by causing one single eternal change. I will argue that this theory presupposes the primacy of locomotion. That is to say, if the arguments presented for the priority claim fail, then the theory, too, may no longer hold. A part of this essential task is performed by Aristotle, who shows that locomotion is prior to the different types of change in different respects and that therefore the eternal change which is directly caused by the first unmoved mover can only be locomotion. This step is necessary, however, in order to make clear that it is possible for a change that fulfils the criteria of being the sole eternal change that has its direct source in the first unmoved mover to exist at all as the theory developed in Phys. VIII presupposes. In order to show all of this I will take the following steps.

The discussion in Phys. VIII 7 on the one hand is embedded in the larger context of the book that today we call Aristotle's Physics. Since this book as we have it today was not arranged by Aristotle himself and originally consisted of more or less independent treatises, I shall first of all examine the original context of the discussion of the priority claim in Phys. VIII. Based on a variety of sources, I will argue that this discussion needs to be considered as a part of a larger project dedicated to a general examination of 
change in that it originally comprised part of a formerly independent treatise which focused primarily on this phenomenon and that consisted of books V, VI, and VIII of the Physics (2.2).

My next step will be to show that this observation is also confirmed by a closer look at the actual content of Phys. V-VIII, since Aristotle in these books indeed aims at developing a general theory of change. As I will make clear, the discussion of the priority claim, in virtue of belonging to Physics VIII, is a part of Aristotle's explanation that accounts for the existence of any and all change in the cosmos (2.3).

Against this background I will analyse the specific role which the discussion of the priority claim in Phys. VIII 7 plays in Book VIII of the Physics. I will argue that without what is presented in VIII 7, the theory developed in the six preceding chapters, namely that change is eternal and that there must be a first unmoved mover, would not hold. For this to be possible Aristotle needs to show, I will argue, that there is a type of change that fulfils the criteria of being a change which has its direct source in the first unmoved mover. The first step of this important task is taken by showing that locomotion is primary and therefore is the only of the four kinds of change capable of fulfilling these criteria (2.4). My final step will be to summarize the results of this chapter (2.5).

\subsection{The arrangement of the Physics}

I will now take a closer look at the context in which the discussion of the priority claim in Phys. VIII 7 is embedded in Physics VIII. Aristotle surely had good reasons to inquire into the primary kind of change in the specific context of this book. Only if we understand why this discussion is presented here, how it is connected to its context, and what role it plays in the text as a whole, will we be able to grasp the significance of the discussion of the primary kind of change, and what it is supposed to show.

Book VIII is generally seen as the part of Aristotle's Physics in which the work "reaches its culmination", as the "crowning achievement of his theory of nature" , or as the book that presents "theorems [...] which hold together the whole doctrine of nature". ${ }^{3}$ This might suggest that the last book brings the whole of the Physics to its intended end and accomplishes

1 Ross (1936), 85.

2 Graham (1999), ix. Wagner (1967), 278, uses a similar expression by stating that "Buch VIII den krönenden Abschluß der Physikvorlesung bringen sollte".

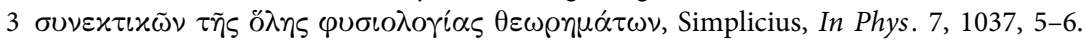
(Transl. Hagen (1994)). 
the theory of nature which Aristotle had developed step by step in previous books; however, this view, as we shall see, is not unproblematic if we keep in mind how the book which we today call the Physics came down to us, and if we take a closer look at its content.

At the same time it was pointed out that Book VIII has a special status among the eight books of this work, since introducing the theory of a first and eternal unmoved mover goes beyond what usually belongs to the scope of natural philosophy and in this sense was even taken to mark the transition from philosophy of nature to metaphysics. ${ }^{4}$ Yet, the question exactly what role Book VIII plays in the Physics as it has come down to us, that is, its connection to the seven preceding books may not be easily answered and in fact has been the subject of scholarly debate since ancient times.

One reason for this certainly lies in the fact that the arrangement of the eight books into one work which we today call the Physics was not, as scholars seem to agree, accomplished by Aristotle himself. ${ }^{5}$ As I will show in more detail later, it is for this reason that one first of all has to become clear on the question which of the different books in fact need to be considered as the closer context of Book VIII. Traditionally, the form and composition of the work called $\Phi v \sigma \iota x \grave{\eta} \dot{\alpha} x \rho o ́ \alpha \sigma \iota \varsigma$ was taken to be the outcome of the editorial work done by Andronicus of Rhodes. According to Porphyry ${ }^{6}$ Andronicus was the first to collect and edit Aristotle's writings, which, as the traditional view holds, eventually led to the Corpus Aristotelicum as we now have it.?

Based on the testimonies of Strabo and Plutarch ${ }^{8}$, the traditional view argues that Aristotle's so-called esoteric writings ${ }^{9}$ were ultimately brought

4 For the latter see Jaeger (1955), 314-315, who argues that Book VIII in this sense "steht außerhalb der Physik" and occupies an exceptional position, as it belongs to natural philosophy in one sense, but to the field of metaphysics in another. Also von Arnim (1931), 30, Wagner (1967), 275, Zekl (1988), XXXVI, Graham (1999), xiii-xiv, and Flashar (2004), 263, emphasize the special status of Book VIII. Apart from these observations, which are based on the content, Book VIII is taken to be a later addition to the other books, for instance by Jaeger (1955), 314-315, and Ross (1936), 10.

5 See for instance Jaeger (1955), 315, Wagner (1967), 277-278, Brunschwig (1991), 24-25, and Barnes (1997), 65-66. Yet, as Brunschwig (1991), 28 and 36, correctly indicates, this does not necessarily imply that Aristotle did not have an overall plan for the Physics in mind.

6 Porphyry was instructed by his teacher Plotinus to arrange and edit his writings after his death, and for this reason put them into a systematic order, since prior to this the only order they had was that of their publication. In chapter 24 of his Life of Plotinus Porphyry writes that in his work on Plotinus' writings he imitated Andronicus of Rhodes who "divided the works of Aristotle [...] into treatises, collecting related material into the same place" (Vit. Plot. 24, 6-11, Transl. Barnes (1997), 37).

7 See for instance Düring (1957), 413-25. Also Barnes (1997), 37-39.

8 See Barnes (1997), 2-3.

9 The so-called esoteric writings of Aristotle were only used in the Lyceum, the school 
to Scepsis in Troad by Neleus, who took over the library of his teacher Theophrastus, who again was a close disciple of Aristotle and his successor in the Lyceum. In Scepsis these texts were stored and hidden in a cave, and for this reason were accessible neither to the Peripatetics nor to anyone else, and consequently fell into oblivion until they were rediscovered and brought back to Athens. Eventually, they were transferred to Rome where Andronicus of Rhodes used the manuscripts for his edition and catalogues of Aristotle's works. ${ }^{10}$

There are reasons for rejecting the thesis of Andronicus' editorship, or at least for suspecting that the role he played in the arrangement of the Corpus Aristotelicum was of much less importance than Porphyry's statement seems to imply and the traditional view assumes. ${ }^{11}$ However, I will not say anything more about this question here, since, as I intend to show, the question whether Andronicus was the originator of the Corpus' arrangement does not contribute anything to determining the context of Physics Book VIII. What we have to keep in mind, however, is that the arrangement of the Corpus Aristotelicum, i.e. also that of the eight books of our Physics, was not accomplished by Aristotle.

Apart from the question what scholars think about how exactly the Physics came down to us, a consensus exists that what we call the Physics today consists of at least two originally independent parts: a treatise dealing primarily with the principles of nature and another which focuses on examining the phenomenon of change. ${ }^{12}$ Yet, scholarly debate has persisted since antiquity on which books of the Physics these treatises consisted of and

founded by Aristotle, and treated philosophical problems in all their depth. In contrast to the less technical exoteric writings, the esoteric ones were not written for a broader audience. Apart from a few exceptions, only the esoteric writings have come down to us (see Brunschwig (1991), 21-22).

10 For this see Düring (1957), 413-25. See also Brunschwig (1991), 22-23, and Barnes (1997), 28-31, who both criticize this view for several reasons.

11 See Brunschwig (1991), 28, who argues that, despite what the traditional view claims, Aristotle's esoteric writings were available to scholars even before Andronicus' edition of Aristotle's works. Barnes (1997) goes further and calls Andronicus' activity "at best amateur tinkering rather than genial construction" (65) without any significance for Aristotelian scholarship, as his edition involved the publication of faulty manuscripts, even though the important ones were available to scholars throughout the entire period (see 65-66).

12 See for instance Wagner (1967), 275, Brunschwig (1991), 28-32, Barnes (1997), 34-36, 59-61, Morison (2002), 13, n.11. Note that different names are used for the first work. For instance, as Barnes (1997), 66, n. 279, points out, Simplicius uses different names in order to refer to what he takes to be this first part of the Physics, i.e. Books I-V. Sometimes he calls it

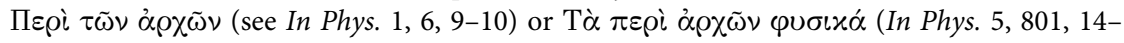

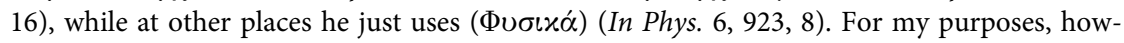
ever, it is only important that there are at least these two different parts, the second of which is called On motion, no matter what the name of the first is. 
which of them therefore have to be considered as the contextual background to which Phys. VIII originally belonged. The answer to this question, however, could clearly have an impact on what one thinks is the task of Book VIII and thus on one's reading of the discussion of the primary kind of change within it, since Aristotle certainly had good reasons to present this book in its specific context.

In general, one can distinguish between two different answers that have been given to this question. ${ }^{13}$ The first holds that the cut between the two works lies between Physics V and VI, while the second argues that the dividing line needs to be drawn after Book IV. Since what needs to be considered as the context and intellectual background of Physics VIII depends on which of the two answers we prefer, i. e. which of the seven preceding books we take to belong to the same treatise as Book VIII, I will now take a closer look at these two options. I will argue that the second option is more appropriate than the first.

\subsubsection{First option: Books VI-VIII as the treatise On Change}

The first answer may be found in Simplicius' introduction to his commentary on Physics VI. In these introductory remarks Simplicius presents what he says is the common view held by the Peripatetics, namely that the first

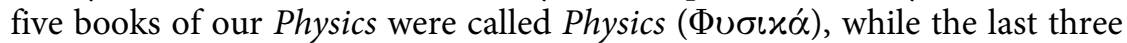

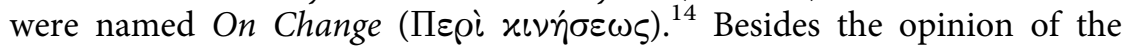
Peripatetics which, of course, does not necessarily have to be identical with Aristotle's even if he reported it correctly, Simplicius provides other reasons for this assumption.

He gives four reasons for dividing the Physics after Book V. He refers (1) to the authority of Andronicus, who according to the tradition arranged and divided the books in this way when he edited Aristotle's writings. He also claims (2) that Theophrastus shared this view, and (3) that it is also supported by Aristotle himself when he refers to his own works. Finally, (4) Eudemus, too, appears to have divided the Physics in the same way as Andronicus and Simplicius. I shall examine the different reasons in more detail now and argue that, contrary to what Simplicius states, they may, but certainly do not have to speak for the assumption that the essential cut between the two parts of the Physics needs to be made after Book V.

13 See Brunschwig (1991), 28-33.

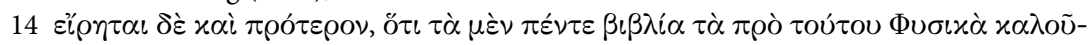

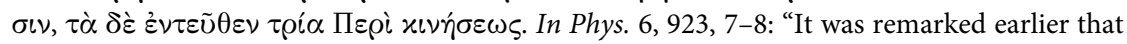
they call the five books before this one [scil. Book VI] the Physics, and the next three On Motion." (Transl. by Konstan (1989)) For the names of the different works see p. 17, n. 12. 


\subsubsection{Andronicus}

Simplicius claims that besides the Peripatetics, Andronicus, too, divides the Physics in the manner described above. There are two different ways in which these remarks may be understood: (1) either Simplicius, as some scholars took it, is merely reporting Andronicus' view and his reasons for holding it, or (2) he is presenting Andronicus' view and, since he himself endorses this position, is also presenting additional arguments for it. ${ }^{15}$ Which of these two options is correct, however, is irrelevant to the task of determining whether one should divide the Physics as indicated in Simplicius' introductory remarks. If the reasons presented by Simplicius for doing so are good ones, it does not matter who their originator is. The mere fact, however, that Andronicus also divided the Physics the same way as the Peripatetics does not make this position any more likely-especially if one takes into account that there are serious doubts about the true role which Andronicus played in the Aristotelian scholarship of his time. ${ }^{16}$

\subsubsection{Theophrastus' letter}

According to Simplicius, Theophrastus, Aristotle's disciple and successor as head of the Lyceum, also thought that the first five books were called Phy-

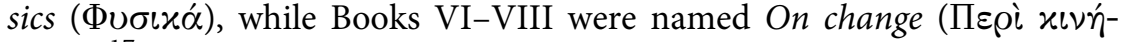
$\sigma \varepsilon \omega \varsigma) .{ }^{17}$ Simplicius attempts to prove this by presenting a part of a letter from Theophrastus to Eudemus in which the former seems to refer to a section from Book V and speaks of this part as belonging to the Physics ( $\dot{\varepsilon} x$ $\tau \tilde{\omega} \nu$ $\Phi v \sigma \iota x \tilde{\omega} \nu) .{ }^{18}$ Therefore, Simplicius seems to think, Theophrastus took

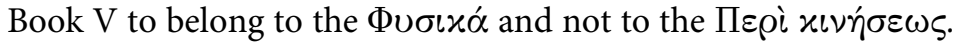

It has been doubted whether the letter quoted here really existed. Rather, it has been argued, Simplicius is merely continuing to present what Andronicus stated, who cited a letter supposedly written by Theophrastus, although Simplicius himself did not have access to the letter. This would weaken the support for Simplicius' claim about the correct division of our Physics.

15 See Düring (1957), 417, who claims position (1) and Barnes (1997), 35-36, who argues against that claim and thinks that there is no indication that Simplicius is citing Andronicus here.

16 See p. 17, n. 11.

17 See In Phys. 6, 923, 9-11.

18 See In Phys. 6, 923, 11-16. 
But even if, as has been pointed out, Simplicius were not just citing Andronicus here ${ }^{19}$, or in the best-case scenario Simplicius is citing a letter really written by Theophrastus, what help would this section be in deciding whether Simplicius' division is correct?

In order to answer this question it is important to understand what the name Tò $\varphi v \sigma \iota x \grave{\alpha}$ may refer to in general. Aristotle himself uses this label in very different ways. Ross lists all of them and comes to the conclusion

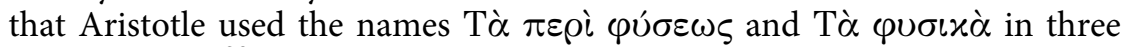
different ways. ${ }^{20}(1)$ There is a narrow usage of T⿳亠丷厂 $\varphi v \sigma \iota x \grave{\alpha}$ which refers to a group of writings that at least included Books II and III, while Books VI and VIII did not belong to this group. (2) According to Ross, these terms also had an intermediate meaning for Aristotle and referred to the work that today we call the Physics, either with or without Book VII. (3) The two terms were also used in a broad sense that besides the two parts of the Physics also included all of the writings that belonged to the science of nature, for instance the De Caelo, the De Generatione et Corruptione and the Meteorologica. ${ }^{21}$

This is something which Simplicius himself was well aware of, which makes it surprising that he draws the aforementioned conclusion from the letter supposedly written by Theophrastus. For, on the very next page of the introduction to Book VI, Simplicius himself points out that the Peripatetics used the term Tò $\varphi v \sigma \iota x \alpha ́$ in a narrow and in a broad sense, that is, on the one hand for Books I-V, while on the other hand, more generally, for the whole of Physics as the science of nature ${ }^{22}$, also encompassing works like the De Anima, De Caelo, and so forth. Since the context of Theophrastus' letter is lacking we are not able to decide whether he is using the broad, intermediate or the narrow meaning of Physics here. He might think that

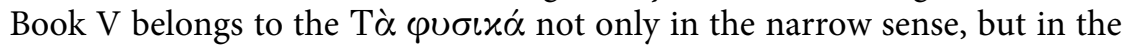
other two senses as well. Thus, even if the letter is genuine, it does not show that Book V indisputably belongs to the $\Phi v \sigma \iota x \alpha$ in the narrow sense and

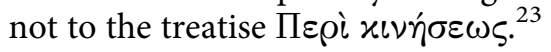

19 See Barnes (1997), 35-36.

20 See Ross (1936), 2-3.

21 Note, however, that the references Ross presents for the third meaning, as he himself points out, do not show unambiguously that this broad meaning of $\tau \grave{\alpha} \varphi v \sigma \iota x \alpha ́$ or $\tau \grave{\alpha} \pi \varepsilon \rho \grave{\imath}$

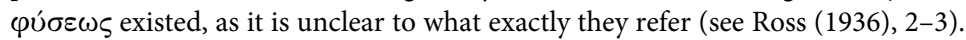

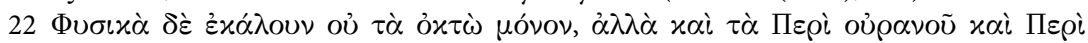

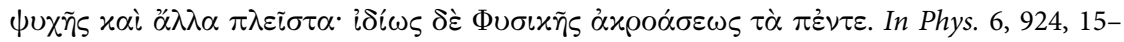
16: "They called Physics not only the eight books but also On the Heavens and On the soul and many more; but in the narrow sense the five of the Lecture on Physics." (Transl. Barnes (1997), 68).

23 Therefore, Moraux (1973), 115, is also wrong when he reads this passage in Simplicius as a proof of the division of the Physics as suggested by Simplicius. 


\subsubsection{References in Aristotle}

Simplicius also refers to Aristotle himself in order to show that his claim about the two parts of our Physics is correct. For this reason he cites three places in Physics VIII where Aristotle refers to sections belonging to Books

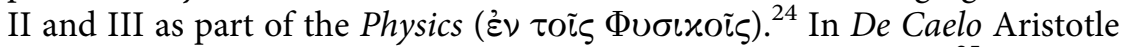
refers to two places in the work On Change, both from Book VI. ${ }^{25}$ The passages to which Simplicius points here show the following: first, Aristotle would also say that the book which today we call the Physics consists of different works or parts, one of them being a work which he here calls T $\grave{\alpha}$

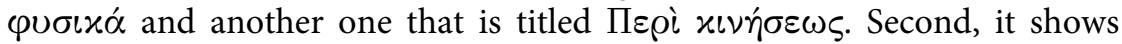
that Books II and III are parts of the treatise which is called Physics and is separate from Book VIII. Thirdly, Book VI belongs to On Change. All of this fits well into Simplicius' theory. However, it does not tell us anything about whether Aristotle thought Book V belongs to the treatise on Physics or to the one On Change. The same is true of the other cases where Aristo-

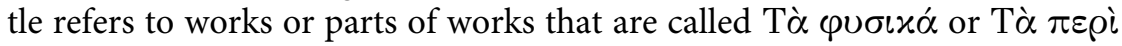

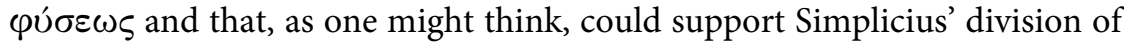
the Physics; but as Ross points out correctly, none of them shows that Simplicius' view is right. ${ }^{26}$ Hence, even the references made by Aristotle himself do not necessarily provide any further support for Simplicius' view.

\subsubsection{Eudemus}

The last piece of evidence that Simplicius presents for his division of the eight books into five books of Physics and three On Change is a passage from a lost biography of Eudemus, another important disciple of Aristotle, that was written by an unknown author named Damas. ${ }^{27}$ According to this

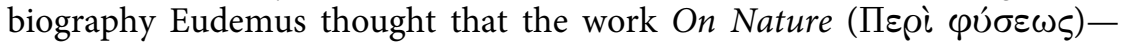
the name here is obviously being used in its intermediate or broad meaning - had a part that consisted of the three books On Change, which for Simplicius, following Andronicus, could only refer to Books VI, VII and VIII. Yet, without any further context this passage supports Simplicius' claim only to a certain degree. This passage merely tells us that Eudemus thought that the

24 See In Phys. 6, 923, 16-924, 5. The sections from Phys. VIII are 251a8-10, 253b7-9, and 267b20-2; for Books II and III they are 202a7-8, 192b20-2/200b12-13, and 204a34$206 \mathrm{a} 8$.

25 See In Phys. 6, 924, 5-12. The passages in Cael. are 272a28-31 and 275b21-3; those in Phys. VI are 233a31-4 and 266b25-7.

26 See Ross (1936), 3.

27 See In Phys. 6, 924, 12-14 (=Fr. 1 in Wehrli (1955)). On Damas see Wehrli (1955), 78. 
Physics encompass a part named On Change which itself consisted of three books, but we are not told which of the eight books these are.

What then do we learn from the points discussed above on Simplicius' introduction to Physics VI? We learn that Simplicius, following Andronicus, thought that Books I-V belonged to a work called the Physics and Books VI-VIII to one named On Change. We have seen that this does not follow necessarily from the arguments Simplicius presented here ${ }^{28}$, although this evidence certainly does not contradict his and Andronicus' way of dividing the Physics. Yet, this is not enough to show that Andronicus' and thus Simplicius' view is to be preferred over the second option according to which also Book V belongs to the treatise On Change.

Indeed, the arguments given all are based on remarks which Aristotle, Theophrastus, and Eudemus made or supposedly made about the different books of the Physics, yet the arguments make no reference to the actual content of these books, and do not propose any division based on that content. As we will see later on, the reader of the Physics, however, would hardly assume that Books V and VI belong to formerly independent treatises: Aristotle, to name just one example, starts Book VI by picking up terms that had just been introduced and discussed in Physics V 3 and that are of utmost importance for the discussion in Book VI, which obviously continues Aristotle's inquiry. But this is something of which Simplicius, too, is very aware. For, at the end of his introduction he points to the close connection between Books V and VI with respect to their content so as to show that they are arranged in the correct order. ${ }^{29}$ This, however, does not really fit with his claim that the formerly separate first part ends with the fifth book.

\subsubsection{Second option: Books V-VIII as the treatise On Change}

The connection which Simplicius sees in content and line of thought between Books V and VI, rather would seem to support the second way of answering the question where the cut between the Physics and the treatise On Change lies, namely between Books IV and V. The earliest known proponent of this view seems to be Nicolaus of Damascus. ${ }^{30}$ Later, it was also held by Porphyry and Philoponus. ${ }^{31}$ In addition, although he obviously holds another view in his commentary on the Physics, Simplicius, too,

\footnotetext{
28 For this see also Ross (1936), 1-3.

29 See In Phys. 6, 924, 16-23.

30 See Lulofs (1969), F.15 and 130-131, and Barnes (1997), 36.

31 For Porphyry see Simplicius In Phys. 5, 802, 7-13. For Philoponus In Phys. 1, 2, 16-17. Ross (1936), 3, also takes this to be correct view.
} 
argued in his commentary on De Caelo that this was the right way of dividing the Physics. ${ }^{32}$

But there appears to be a problem with this division. It looks as though it is compatible with all the statements about the arrangement of the books that were presented by Simplicius in order to support his and Andronicus' view; all but one: as we have seen, Damas reports that according to Eudemus the treatise On Change consists of three books. Dividing the Physics after Book IV however, would imply that the work On Change consists of Books V-VIII, i.e. of four rather than three books. Yet, there is another statement by Eudemus which tells us something about the structure of our Physics. Eudemus who, as already mentioned, was a direct disciple of Aristotle, did not consider Book VII to be a genuine part of the Physics. ${ }^{33}$ Ancient commentators and modern scholars, too, for several reasons take Book VII to be a later misplacement of either a formerly independent treatise, an earlier version of Book VIII, or some collection of notes on the topic of change. ${ }^{34}$ However, it is correct to say that Book VII is related in a certain way to Book VIII ${ }^{35}$ and, as it deals with change in general, rather belongs to the part of the Physics which was called On Change than On Nature. The mere fact that it is related to Phys. VIII in content, however, implies neither that Aristotle himself considered it to be a necessary part of the treatise On Change, nor that he intended to place it between Book VI and VIII. For, as I will show, Book VII interrupts the line of thought that connects VI and VIII and therefore certainly was not a part of the treatise On Change, although the points discussed in Book VII clearly are closely connected to those dealt with in the On Change. ${ }^{36}$ This then lead Simplicius

32 See In Cael. 1, 226, 19-23, where Simplicius claims that Aristotle called the first four books On Principles and the remaining four On Change ( $\pi \varepsilon \rho \grave{\alpha} \dot{\alpha} \rho \chi \tilde{\omega} \nu \tau \dot{\alpha} \tau \varepsilon \delta \sigma \alpha \rho \alpha \pi \rho \tilde{\omega} \tau \alpha$

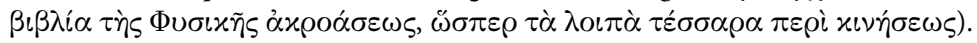

33 See Simplicius In Phys. 7, 1036, 11-15. See also Jaeger (1955), 312, Brunschwig (1991), 27, and Barnes (1997), 61.

34 According to Simplicius, who himself holds that VII does not fit in its context, Alexander, Eudemus, and Themistius also seem to have thought this way (In Phys. 7, 1036, 8-17) (and, indeed, Themistius' paraphrasis of Phys. VII is rather short in comparison to that of the other books). See also Ross (1936), 15-17, Mansion (1946), 14-15, Jaeger (1955), 312, Wagner (1967), 275, and Brunschwig (1991), 27, 31, for the claim that Physics VII must be a misplacement.

35 See Waterlow (1982), 236, n.22, and Wardy (1990), 114-116, who argue that Physics VII provides support for an assumption on which the theory developed in Phys. VIII 1-6 relies. One could further add that VII 2 is the only place where Aristotle systematically discusses the claim that the non-substantial kinds of change presuppose that the changer and the subject of the change come into contact, an assumption clearly presupposed by the first of the five arguments for the priority claim (see section 3.3, esp. p.50-51).

36 For instance Book VI ends with the remark that it remains to be shown that there is 
to assume that Book VII was placed between VI and VIII because it was considered to be related (oixعĩov) to the arguments presented in Book VIII. ${ }^{37}$

This then was the cause of the confusion on where the division between On Nature and On Change needs to be made: it seems that Andronicus, or whoever was responsible for the division, divided the whole of the Physics in the wrong way, as they falsely took Book VII to belong between Books VI and VIII and wanted this division to accord with Eudemus' statement that the original treatise On Change consisted of three books. ${ }^{38}$ If one knows that Book VII was not an original part of the work, it becomes clear that the Physics needs to be divided after Book IV rather than where Andronicus and Simplicius suggest. ${ }^{39}$

Based on the testimonies presented in this section one has to conclude that the dividing line between the two works of which our Physics (at least) consisted needs to be drawn after Book IV. Since Book VII has to be considered a misplacement, the treatise On Change most likely comprises Books V, VI and VIII. Situating the discussion of the primary kind of change in Book VIII accordingly makes it a part of the larger project for the examination of the phenomenon of change that the treatise On Change performs.

Yet, thus far I have only taken a look at different testimonies that may be read as suggesting different ways of dividing the Physics. My intention was to show first of all that these testimonies rather speak against what seems to be Andronicus' division. Of course, it is an examination of the content of Books V, VI and VIII that should finally help us decide whether Philoponus' position is correct. Therefore, I will now have a look at these books in greater detail and present what is of importance with respect to the current discussion. As we will see, from this perspective as well, it is clear that Books V, VI and VIII belong together.

one single change that is everlasting (see VI 10). Book VIII then starts by asking whether change is eternal and by finally arguing for the claim that it indeed is and that therefore one single everlasting change must exist, if there is to be any change at all.

37 See In Phys. 7, 1037, 3.

38 See Brunschwig (1991), 31. Wehrli (1955), 78, at least points in this direction by mentioning that, even though this is rather implausible, Damas in the fragment of his biography of Eudemus might have been referring to Books V, VI and VIII when speaking of the "three books On Change".

39 Another source of information about the composition of the Physics is the ancient catalogues on Aristotle's works. There are three such lists, all of which may be found in Düring (1957): by Diogenes Laertius, Hesychius, and Ptolemy. Since the conclusions that may be drawn from an examination of these catalogues, as Ross (1936), 5, puts it, are "highly conjectural" and do not really show which of the two views is the right one, I will not discuss them here in more detail. 


\subsection{The eight books of the Physics}

\subsubsection{Physics I-IV: Examining change for the sake of understanding nature}

The Physics as it has come down to us basically needs to be considered as a work that develops the fundamental principles which govern the natural world and with which the student of nature has to be acquainted in order to carry out more specific inquiries. ${ }^{40}$

In Physics II Aristotle, therefore, raises the question what nature ( $\varphi \dot{\sigma} \sigma \varsigma$ ),

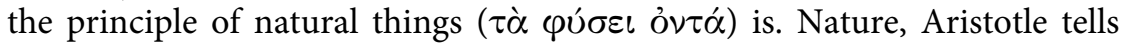
us, is a source of change ( $\dot{\alpha} \rho \chi \hat{\eta} \chi \iota \nu \dot{\eta} \sigma \varepsilon \omega \varsigma)$ and rest inside the thing that has this nature. ${ }^{41}$ For instance all living beings, but also the elemental bodies like earth, water, fire, and air, contain the principle of change within themselves. ${ }^{42}$ Since nature is explained by referring to change, the student of nature has to grasp what change (and rest) is in order to understand what nature is. ${ }^{43}$ Accordingly, Aristotle develops a definition of change, but also points out that several other terms need to be examined that are commonly thought necessary for understanding what change is. For this reason the remainder of Book III and the whole of Book IV discuss the concepts of the

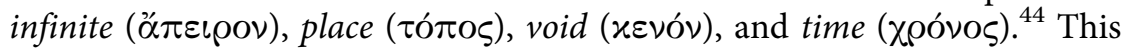
is consistent with the fact that the first four books of the Physics originally formed an independent treatise On Nature that dealt with nature and its principles.

Again, the student of nature needs to deal with change in order to understand what nature is. Therefore, at first glance it might look as though Books V-VIII also continue the task of inquiring into the phenomenon of change in order to understand nature as a principle of change and rest, since we find a thorough examination of change in the four remaining books of the Physics. Yet, it is most likely that Aristotle thought differently. This can be seen from the fact that he points out that first $(\pi \rho \tilde{\omega} \tau o \nu)$ one

40 Wagner (1967), 287, thinks that the Physics need to be understood as a "Naturlehre" that is fundamental to the other more specific areas. Also Wieland (1992), 18-19, states that the Physics in no way deals with specific natural things, but only with the general principles of natural things and for this reason may even be called a metaphysical inquiry. Morison (2002), 1-2, finally argues that the Physics accordingly need to be considered as a philosophical inquiry that however is "in part using empirical data" (1).

41 See Phys. II 1, 192b13-23, and Phys. III 1, 200a12-13.

42 See Phys. II 1, 192b9-13.

43 See Phys. III 1, 200a12-15.

44 Aristotle lays out this plan in Phys. III 1, 200b12-25. The infinite is discussed in III 48 , place in IV 1-5, the void in IV 6-9, and time in IV 10-14. 
needs to determine what change is ${ }^{45}$ and after that the same is necessary for the related concepts of the infinite, place, and so forth. ${ }^{46}$ Thus, Aristotle obviously considers his discussion of the definition of change to be completed when he moves on to his inquiry into related concepts that need to be examined in the same fashion. But if Aristotle has already presented a definition of change that seems to serve the purpose of understanding nature, what is his reason for taking up the topic of change once again in Books V-VIII? This might lead one to conclude that even though we now know those aspects of change that are important for dealing with nature as a principle of change and rest there are still many things about change which have not been examined so far and need further investigation, because they were not necessary for understanding nature as a source of change as presented in the first half of what we call the Physics.

But one also cannot deny that there, of course, is a close connection between what goes on in the first and the second half of the Physics. Both are pieces of Aristotle's natural philosophy, or more precisely, of a work that serves as a kind of preliminary to any more specific inquiry into natural phenomena. ${ }^{47}$ However, the only way in which the books On Change may be understood as a follow-up to Book IV, is in that they also deal with change and take for granted certain things that were said about this phenomenon in the previous books. For instance, they do not present a new or different definition of what change is, but obviously work with the one developed in Book III. ${ }^{48}$ Moreover, this definition seems to include or at least foreshadow certain aspects of change that Aristotle unfolds and develops fully in the later books.

Again, despite this close relation, Aristotle has different reasons for examining change in the second part of the Physics, which is why one may not argue that the treatment of change from Book $\mathrm{V}$ onwards continues the inquiry that was started in the first half of the Physics. If one thinks that the analysis of change in V-VIII is done for the sake of understanding what nature is, one needs to explain what exactly these books contribute to the

45 See Phys. III 1, 200a25.

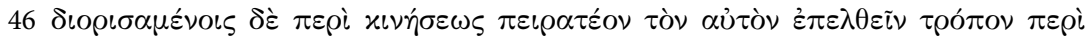

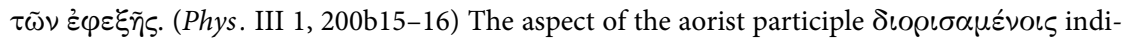
cates that the defining of change is completed and hence needs to precede the examination of the other terms. In addition, also the fact that the definition of the four named concepts should be executed in the same way as it was done for change, presupposes that the definition of change is accomplished before trying to find one for the related concepts. Hardie \& Gaye (in Barnes (1984)), Carteron (1952), Wagner (1967), Hussey (1983), and Zekl (1987) translate this passage accordingly. Also Brunschwig (1991), 30, points out that the plan laid out at the beginning of Phys. III is fulfilled at the end of Book IV.

47 See Phys. IIII 1, 200b24-25. See also p. 25, n. 40.

48 See for instance Phys. V 2, 224b10-11, and VIII 1, 251a8-10. 
understanding of $\varphi \dot{\sigma} \sigma \iota \varsigma$ as the source of change ( $x^{\prime} \nu \eta \sigma \iota \varsigma$ ) in natural things, since this was the reason for developing an understanding of what change is

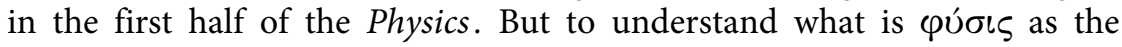
source of change in natural beings it is not necessary, for instance to discuss an important question raised at the end of Phys. VI and taken up again and discussed in full detail in Phys. VIII, namely how there could be a change that is eternal without being composed of other changes.

This observation, but also the fact that all tasks that were laid out before are completed at the end of Phys. IV, supports the claim that Aristotle had good reasons for letting the first part of the eight books of Physics, i.e. the formerly independent treatise On Nature, end with Book IV as is suggested by the testimonies discussed above. The books On Change examine this phenomenon not only for the sake of understanding what nature is, but, as I will now show, present a more general theory of this phenomenon.

\subsubsection{Physics V-VIII: The general analysis of change}

At the beginning of Physics Book V Aristotle does not tell us anything about his motivation for treating of the subject that he deals with in Book V and the following books, nor does he lay out his plan for the subsequent chapters. It becomes clear, however, that in the last books of the Physics he is interested in presenting a general analysis and discussion of change and its presupposition, a discussion that goes beyond what was said about the phenomenon in the previous books. For, while On Nature primarily deals with change only insofar as it is important in gaining an understanding of nature as the source of the change that things have within them, the treatise On Change aims to develop a general understanding of change as a fundamental phenomenon in the cosmos that is graspable through scientific inquiry. This of course does not mean that the analysis of change conducted in Phys. V-VIII does not contribute anything to a further understanding of nature, only that change in these books is not examined primarily and merely for the sake of understanding nature as a source of change.

In Book V Aristotle starts making preparations for this project by first of all developing fundamental notions and drawing distinctions that are essential for working with the phenomenon of change and hence for the subsequent discussion. In the beginning of this book, therefore, Aristotle analyses different ways in which things are said to change, and what factors determine every change ${ }^{49}$. He then shows that there are exactly the four different kinds of change, namely change in quality, quantity, place, and substance

49 In Phys. V 1, 224a21-22, Aristotle explicitly points out that his starting point is everything which changes ( $\tau \grave{\partial} \mu \varepsilon \beta \dot{\alpha} \lambda \lambda \lambda_{0 \nu} \pi \tilde{\alpha} \nu$ ) in general. 
(V 1-2). ${ }^{50}$ This argument, combined with the definition of change developed in Book III $^{51}$, enables Aristotle to claim that his discussion so far has made clear what change is, how many different kinds of change there are, and what their basic characteristics are. ${ }^{52}$ In the remaining chapters of this book the rest of the concepts that are necessary for developing a general theory of change and that are of essential importance for the inquiries in Books VI and VIII are analysed. Aristotle therefore discusses the different ways in which changes or parts thereof can be related to each other (V 3). The most important of these concepts is the notion of continuity, without which for instance the refutation of Zeno's paradoxes in Books VI, as well as the discussion of the eternal kind of change in VIII would be impossible. ${ }^{53}$ Also, the analysis of the features that are responsible for a change's unity (V 4), and of ways in which changes or states of rest are contrary to each other (V 5-6) are of utmost importance for the project Aristotle pursues in Book VIII. ${ }^{54}$

Building on what was discussed in the previous book, in Physics VI Aristotle elaborates on one of the main features that change, time and magnitude have in common, namely that they are continuous, and he systematically works out what this implies for change. This enables him to repel the threat of Zeno's paradoxes and to establish a coherent theory of change that allows for a scientific understanding and treatment of this phenomenon and that thus lays the basis for a science that deals with everything in nature that is subject to change. However, the inquiry in Book VI does not end with the refutation of Zeno's paradoxes, but continues afterwards in Phys. VI 10 with a discussion of whether something indivisible can undergo change and whether infinite change exists. Although both problems play an important role in the discussion in Physics VIII, it is especially the latter, as

50 The different ways in which $x$ is said to change are essential to the arguments for the priority of locomotion; see for instance section 4.2.2, esp. p.77-78. That all arguments presuppose that there are exactly four kinds of change is clear from the fact that in all but the first one Aristotle argues that locomotion is the first of these four types, that is, if there were other kinds of change the arguments couldn't possibly succeed in showing that locomotion of all kinds of change is primary.

51 See Phys. V 1, 224b10-11, where Aristotle refers to the definition of change that was presented in Phys. III.

52 See Phys. V 2, 226b16-17.

53 For the latter for instance see my discussion of the third argument (esp. section 5.2.1) where it also becomes clear that the argument also presupposes knowledge of the other terms presented in Phys. V 3, e.g. of that of $\varepsilon \varphi \varepsilon \xi \tilde{\eta} \zeta$.

54 This, for instance, becomes clear in my presentation of the third argument (esp. section 5.2.3). There Aristotle shows that the only change capable of forming an eternal unity is circular locomotion, since it can do so without being composed of parts that are contrary to one another. 
we will see, that will be essential for understanding what significance lies in inquiring into the primary kind of change at all, and, in fact, the question is taken up again at the beginning of Book VIII. Between outlining the task of examining whether one eternal change can exist and carrying out this task we find Book VII.

The fact that Book VII interrupts the line of thought connecting Book VI and VIII-along with other arguments we have already considered - suggests that Book VII needs to be considered as a misplacement. ${ }^{55}$ This possibility becomes even more likely when the reader tries to relate what was done in Physics V and VI to Book VII. Although the topics discussed there certainly are related in a way to what goes on in Books V, VI and VIII, Phys. VII in itself does not seem to be structured by a plan that connects it to what is done in the two books prior to it and to the next and final book, but rather gives the impression of being more a collection of different thoughts on certain aspects of change than a systematic inquiry. As was noted, neither does the beginning of Book VII fit with the end of Book VI, nor does its end fit with the beginning of Book VIII. ${ }^{56}$ At best one might consider it a kind of digression that interrupts the examination started in Physics V, continued in VI and concluded in Book VIII. Therefore, even if some scholars are correct in assuming that Book VII relates to Book VIII by providing support for the argument for the first unmoved mover, this still would not imply that the appropriate place for Book VII is between VI and VIII. ${ }^{57}$

Book VIII, however, is again closely connected with the inquiry begun in Book V and continued in VI. As we have already seen, it relies on the discussions contained in these books. Without having followed this discussion the reader is prepared neither to understand what Physics VIII is supposed to show and hence the significance of the claim that locomotion is primary, nor how the arguments for this claim work. ${ }^{58}$ In addition, the argument begins more or less directly where the discussion in Phys. VI ended, namely by picking up the question whether there can be one change that is eternal and by showing later on that, as Phys. VI 10 already suggested, this change can only be circular locomotion. ${ }^{59}$

For, as stated in the next section in greater detail, Phys. VIII starts by showing that the phenomenon of change must have always existed, which finally will lead to the assumption that there must be one eternal change

55 See the beginning of section 2.2 .2 and p. 23, n. 34, again.

56 See Ross (1936), 15.

57 See p. 23, n. 35 .

58 See p. 28 n. 50,53 , and 54.

59 See Phys. VI 10, 241a26-b20, and Phys. VIII, 2, 252b7-12. For the claim about circular locomotion that is made in Phys. VI 10 see 241b18-20; Aristotle shows in Phys. VIII 8 that only this kind of change may be eternal. 
and that there needs to be a first unmoved mover that is the source of this eternal change and, by extension, of all change in the universe. By doing so Aristotle shows that the general and consistent theory which was developed in Books V and VI can be applied successfully to the whole of the cosmos in order to give a final causal explanation of the occurrence of change as we observe it day by day and by systematically working out the implications and presuppositions of the empirical fact that change exists.

To put it in other words: in Phys. V Aristotle develops the concepts necessary for a general explanation of the theory of change. Against this background, Phys. VI, by presenting a consistent theory of the phenomenon of change, is then able to show that change is an appropriate object of scientific inquiry, although there are powerful objections against this claim. In contrast to these two rather abstract discussions, in Book VIII Aristotle applies this theory of change to the cosmos and shows that it may account for the empirical fact that change exists. Based on his general theory devel-

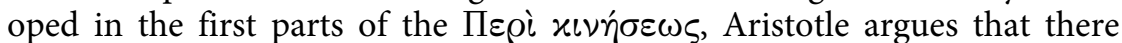
must always have been change in the cosmos and that there needs to be a first unmoved mover that is the source of all change in the universe.

This enables Aristotle to provide an adequate causal explanation of any change in the cosmos and to show that his theory of change as a scientifically graspable phenomenon as presented in Phys. V and VI that may serve as the basis for any further inquiries by the student of nature is also compatible with a consistent theory of change in the cosmos. In this sense, however, Phys. VIII not only is closely connected to the discussion presented in Phys. V and VI, but by presenting the theory of the first unmoved mover, that is, the eternal primary cause and principle of all existing change, it leads the discussion

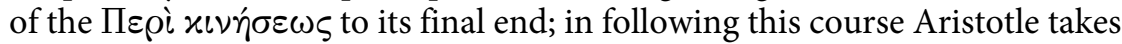
his discussion of sublunary change as far as it can go by introducing the unmoved mover, an object that in a certain sense rather falls within the scope of metaphysical inquiry. ${ }^{60}$ One needs to have all this in mind when discussing the arguments for the priority claim later on, and in fact we will see that the claim that locomotion is the primary kind of change can only be under-

60 In this respect at least one may agree to Jaeger (1955), 314-315, who claims that Phys. VIII in a certain sense "steht außerhalb der Physik". Something similar is stated, for instance by Graham (1999), ix, who thinks that Phys. VIII on the one hand is a piece of natural philosophy, that on the other hand also deals with "the metaphysical presuppositions of physics", by which he refers to the introduction of the first unmoved mover. He even goes as far as saying that Phys. VIII therefore needs to be considered as "a bridge between physics, cosmology, metaphysics, and theology" (xvi). I agree that what is said in Phys. VIII in a certain respect connects natural philosophy to these other areas of philosophy, yet, as I have stated, it is of utmost importance that Aristotle is interested in giving an explanation of the existence of change in the first place, which then may or may not involve establishing such points of connection. 
stood within the larger context of the argument that Aristotle is developing in Book VIII to account for how change as a phenomenon we are acquainted with by experience can exist in the way we observe it.

\subsection{Physics VIII}

\subsubsection{Overview}

In this last section I will examine what role the arguments presented for the priority claim play in the context of Physics VIII. For, only if one knows what this discussion in Phys. VIII 7 aims at and why Aristotle is interested in showing the truth of this claim can one understand what it stands for and evaluate the arguments presented for it in an appropriate way. As I shall explain in this section, Aristotle needs to show the truth of the priority claim in order to be able to provide evidence for an assumption which he made implicitly in the discussion of Phys. VIII 1-6 and on which the theory developed there essentially depends, namely the premise that against all possible objections there exists one single change that is eternal and that fulfils all other criteria required of a change whose direct source is the first unmoved mover.

In order to show this I will first of all outline the basic argument presented in Phys. VIII 1-6. I will argue that Aristotle in these chapters develops a theory according to which change is eternal and that in order to account for this fact the necessary existence of an unmoved mover needs to be presupposed (2.4.2). My second step will then be to examine the importance of the arguments for the primacy of locomotion, and by extension of the whole discussion stated in Phys. VIII 7-9 into which they are embedded. I will show that these chapters present a justification for assumptions whose truth is presupposed in the discussion in Phys. VIII 1-6 and without which this theory would not hold (2.4.3).

\subsubsection{The argument of Physics VIII}

In Book VIII of the Physics Aristotle, by building on the preparatory work done in Books V and VI, aims to develop a theory that explains how the fundamental phenomenon of change exists in the way in which we experience it in the world. ${ }^{61}$ This is done by showing that all changes may be

61 Accordingly, I agree with Ross (1936), 85, who states that the object of Phys. VIII basically is "to account for the presence of movement in the world and for its having the characteristics it has." 
traced back to an ultimate source of change that is (at least partly) responsible for any occurrence of each of these changes and furthermore that any subject undergoing a change as a part of the cosmos is embedded into a larger framework of manifold causal relations. ${ }^{62}$ This means Aristotle spells out what principles must underlie the assumption that there are things that change in different ways, but are also capable of being at rest-something we experience every day. ${ }^{63}$ He holds the view that both change and rest are basic constituents of our world and are accepted unquestioningly by every student of nature. ${ }^{64}$ Therefore, I conclude that Phys. VIII is not primarily about proving the existence of a first unmoved mover, or even god, although it is sometimes read this way, but only shows the necessary existence of this entity for the sake of presenting a causal account of change in the cosmos. ${ }^{65}$

At the beginning of Phys. VIII Aristotle emphasizes that the assumption underlying all natural philosophy is the undeniable fact that change exists. ${ }^{66}$ Starting from this assumption Aristotle in the first chapter of Physics VIII

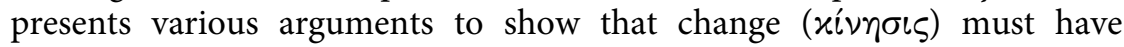
always existed, and did not come to be or cease to exist at some point in time, as some of his predecessors claim. Change in fact needs to be eternal and imperishable. ${ }^{67}$ In the course of this discussion, in Phys. VIII 2, three problems concerning the claim about the eternity of change are raised, although not all of them are solved, a fact that will be of importance later on. ${ }^{68}$

After having argued for the eternal existence of change in the first two chapters of Book VIII, Aristotle discusses what this implies for the way

62 Therefore, I think that von Arnim (1931), 52, is correct in holding the view that Phys. VIII is supposed to show "die kausale Einbezogenheit der Selbstbewegung der Lebewesen in die kosmische Bewegungskausalkette".

63 See Phys. VIII 3, 253a23-b2. There Aristotle states among other things that the assumption that there is no change is absurd and contrary to all basic experience (253a32b2). Later on in Phys. VIII 3, 254a27-30, he also presents an argument showing that everyone, even those who reject this claim, in fact implicitly presupposes that there is change.

64 See previous footnote and Phys. VIII 3, 253b2-6 as well as 254a35-b4.

65 Thus, I do not agree with Solmsen (1961), 270, who takes it that "Aristotle's objective in this Book is to establish the existence of the Unmoved Mover, his God, who is the cause and fountainhead of all movements in the Cosmos." Yet, I agree with both Lang (1981), 328, and Flashar (2004), 263, who both state that Phys. VIII does not aim at showing the existence of a first unmoved mover, but only proves its existence insofar as this is able to account for the existence of change in the cosmos.

66 See n. 63 and 64 of this chapter.

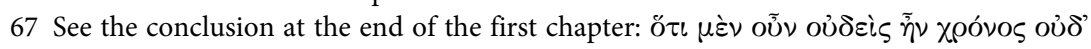

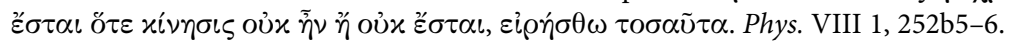

68 See Phys. VIII 2, 252b9-28. 
change may or may not occur in the cosmos. He first of all rejects the theory that everything is always changing, and, again, the theory claiming that there is no change at all and everything is at permanent rest. ${ }^{69}$ The only plausible options, he argues, are either (1) that all things are sometimes in motion and sometimes at rest, or (2) that besides the things that are changing between change and a state of rest, there are some things that are always undergoing change and others that are always at rest. It is the task of Phys. VIII 4-6 to examine which of these two options is correct. ${ }^{70}$

In Phys. VIII 4 Aristotle begins this task by establishing the claim that for whatever is changing there must be some cause of this change ${ }^{71}$ : either what is changing is itself the cause of its change, i.e. a self-mover, or its change is caused by some other thing. Phys. VIII 5 then directly continues this train of thought and shows that each thing that is in the state of change, but is not a self-mover, must have a first cause of change that is a self-mover ${ }^{72}$, which, as Aristotle points out in this context, may be further analysed into a moving and an unmoving part ${ }^{73}-\mathrm{a}$ step that is essential for the further development of the argument. This line of reasoning is then completed in Phys. VIII 6, where Aristotle shows that for the stated reasons there must be one unmoved mover that is the source of all change. ${ }^{74}$ This unmoved mover is eternal and causes an eternal change that is always one and the same, i. e. not composed of different changes, and therefore continuous as a whole. ${ }^{75}$ By establishing the theory of the necessary existence of the first unmoved mover, Aristotle seems to have finished his examination, as the task which was set out at the end of Phys. VIII 3 is accomplished: according to this theory developed throughout chapters $1-6$, it is clear now that in the cosmos there are things that are always undergoing change, others that are always at rest, and still others that are sometimes at rest and sometimes undergoing change. ${ }^{76}$

Contrary to what one might expect, however, Aristotle's inquiry does not end after Phys. VIII 6, but continues by arguing first of all that locomotion is the primary of the four kinds of change (VIII 7) and that circular locomotion is the primary type of locomotion and the kind of change that alone

69 See Phys. VIII 3, 254a35-b4.

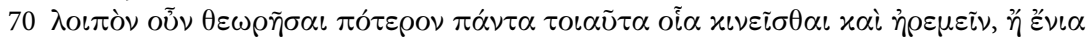

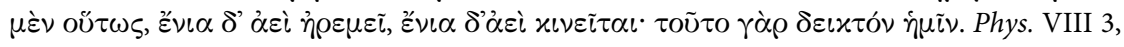
254b4-6.

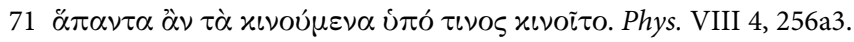

72 See Phys. VIII 5, 258b4-9.

73 See Phys. VIII 5, 258a1-2.

74 See for instance Phys. VIII 6, 259a6-13, and 259a13-20.

75 See Phys. VIII 6, 259a13-20, and 260a17-19.

76 See Phys. VIII 6, 260a11-19. 
can be eternal (VIII 8-9). In the last chapter Aristotle closes the discussion by arguing for another claim that seems to be presupposed by the theory developed in Phys. VIII 1-6, namely that the first unmoved mover does not have parts or any spatial extension and only for this reasons is capable of persistently causing the occurrence of the same change, i. e. the eternal circular locomotion of the outermost heavenly sphere (VIII 10).

As we have seen so far, the context of Aristotle's arguments for the claim that change in place is the primary kind of change in Phys. VIII 7 is a discussion which shows that change must always have existed and in connection with which he develops his theory of the necessary existence of a first and eternal unmoved mover. My next step will be to examine the way in which the latter is connected with the question of the primary kind of change.

\subsubsection{The importance of the primary kind of change}

In what follows I will argue that the examination of the question which is the primary kind of change and the arguments presented for the claim that this change must be locomotion plays an important role in the whole of Book VIII of the Physics. For, the discussion in Phys. VIII 7-9, of which this inquiry is a necessary part, provides essential support for the theory that change exists eternally and that there must be a first unmoved mover by backing up an assumption presupposed by this theory, despite serious objections against it. The assumption that Phys. VIII 7-9 show to be true is that there is a kind of change that can be eternal, primary and one without being composed of other changes.

That this is Aristotle's motivation for treating of the question which is the primary kind of change becomes clearer upon closer examination of the beginning of Phys. VIII 7, that is, of the introductory remarks which open the discussion of the primary kind of change. Here is the passage in full:

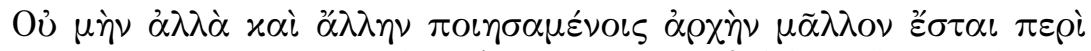

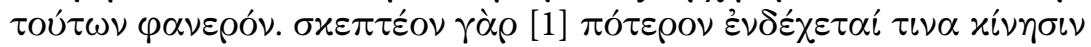

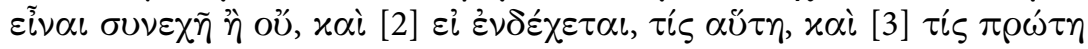

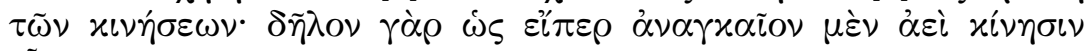

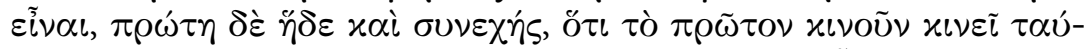

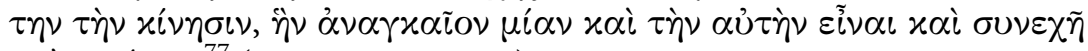

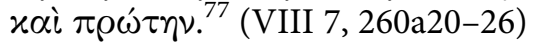

77 All translations are my own, unless noted otherwise; yet, I made extensive use of the different translations that are listed in the bibliography. 
Nevertheless, more will be clear about these matters, for those who make another start. For it must be examined [1] whether it is possible that there is a change which is continuous or not, and, [2] if it is possible, which one this is, and [3] which is primary among the changes. For it is clear that if indeed there always must be change, and this change must be primary and continuous, then the first mover causes this change, which must be one and the same and continuous and primary.

With these remarks, Aristotle sets out the task of the following chapters: we have to examine ( $\sigma \chi \varepsilon \pi \tau \varepsilon$ ov) the three stated questions in order to gain a better understanding of "these matters".

But why should these questions be asked, and in what way could they be of interest to us? Aristotle does not really explain this here. Nor do the lines following these questions make things much clearer; they only indicate that the treatment of these questions stands in a close relation to what was discussed in the previous chapters, namely, his claims that change needs to be eternal, and that there must be a first unmoved mover which is the cause of all change. The "matters" which are supposed to become clearer by examining the questions, therefore, would seem to be certain parts of this theory that were discussed in the preceding chapters.

Yet, against the background of Phys. VIII 1-6, one is puzzled even more about Aristotle's statement what has to be done next, because it seems that Aristotle's inquiry came to an end in VIII 6. After all, he claims there that the goal he set in VIII 3 has been reached, since by developing the theory of the first unmoved mover it was shown that the second of the two stated options must be true, that is, there are three different kinds of things: things that are always undergoing change, others that are always at rest, and still others that are sometimes changing and sometimes at rest. ${ }^{78}$

But despite this claim, Aristotle does not end his examination at all, but continues, as some matters that were treated before now obviously need to be made clearer by taking another starting point ( $\left.\dot{\alpha} \lambda \lambda \dot{\eta} \dot{\alpha} \rho \chi \hat{\eta}^{\prime}\right)$. This start seems to be made by raising and then answering the three stated questions that have to be examined, and in Phys. VIII 7-9, indeed, all three of them are addressed. The questions are:

1. Is it possible that there is a continuous change? (260a21-22)

2. If there is a continuous type of change, which type is it? (260a22-23)

3. Which is the primary kind of change? (260a23-24)

78 See Phys. VIII 3, 254b4-6, and the concluding remarks of VIII 6, 260a11-19, which make clear that Aristotle thinks he has fulfilled the task set out in VIII 3. 
Yet, Aristotle does not really make clear what his motivation is for asking these three questions, one of which concerns the primary kind of change. This probably is also the reason why none of the commentators, with one exception, seems to be able to give an appropriate answer to the question about Aristotle's motivation. ${ }^{79}$ As I will show, one can only understand the importance of all three of these questions by looking at them in conjunction. I will argue now that the treatment of these questions, taken as a whole, provides essential support for the theory that was developed in VIII $1-6$, insofar as it shows the truth of an assumption on which this theory is essentially based, namely that there is a change that is eternal and one and that in other respects is an appropriate candidate for the eternal change whose direct source is the first unmoved mover, although it is far from obvious that this is the case.

First of all, it might seem puzzling, or even absurd, that Aristotle raises question (1), i.e. asks whether there can be a change that is continuous. Since as Aristotle shows in Phys. VI every change is continuous, and in fact it is this essential feature of the phenomenon of change which enables him to rebut Zeno's paradoxes and to establish that change is a proper object of scientific inquiry. But why then should we deal with this question at all?

The answer is that the term 'continuous' here, as in other places, clearly is not used in the sense defined in Phys. V 3 and VI 1. As I will show later on in my discussion of the third argument, being continuous here rather stands for being eternal. ${ }^{80}$ The first question, accordingly, asks whether there is a change that can be eternal.

79 Themistius, In Phys. 8, 225, 11-16, Philoponus, In Phys. 8, 895, 4-5, and Simplicius, In Phys. 8, 1264, 23-27, seem to think that Aristotle raises these questions in order to show again what was shown before, namely that what is directly changed by the first unmoved mover needs to undergo change eternally. In other words Aristotle makes "these matters" clearer by showing parts of what he has already demonstrated in Phys. VIII 6 once again, but by means of another argument; this would imply that the section started by these introductory remarks is more or less superfluous. Ross (1936), 92 and 709, on the one hand, correctly points out that the treatment of the first two questions is crucial insofar as they answer a previous objection. As to the question which is the primary kind of change and the answer arrived at, Ross, on the other hand, points out that, as it is "of small general interest", no further discussion is needed (92-93), while in his commentary he at least admits that it may be important insofar as it tells us "what is the nature of the movement imparted by the first mover" (709); yet, he does not say what role this may play in the argument of Phys. VIII. Wagner (1967) and Graham (1999) in their commentaries do not say anything about the question why Aristotle is interested in what the primary kind of change is and which role the examination of this question plays or might play in Phys. VIII. As I shall show, only Aquinas offers a possible explanation for Aristotle's treatment of the three questions, see p.39, n. 88.

80 For this see section 5.2. 
That this must be the question that Aristotle has in mind and that is of utmost importance to him is clear for the following reason. As Aristotle states in Phys. VIII 6 the change which the unmoved mover directly causes must be one and eternal, in the sense that this change cannot merely be eternal by being composed of a number of different changes. ${ }^{81}$ But it was pointed out for instance in Phys. VI 10, and also in Phys. VIII 2 that a single change cannot take an infinite time, i.e. be eternal; in fact, this was the first of the three objections against the claim of the eternity of change Aristotle himself raised in VIII 2, and for which he said a solution needs to be found later on. ${ }^{82}$ For every change is a change from something into something, that is, it has a definite starting and end point, and in this way is limited and occurs in a limited amount of time. ${ }^{83}$ What is limited in this way, however, cannot be eternal. ${ }^{84}$ This, however, would clearly contradict the claim in Phys. VIII 6 that the change which the first unmoved mover causes as the primary source is one, i.e. non-composed, and eternal. ${ }^{85}$

Yet, what is stated in Phys. VI 10 and VIII 2 is not Aristotle's last word on this problem-rather, he already indicates in both places that there may be a solution to this problem that he will present later. And in fact, although there are compelling arguments against this claim, as we will see, it will indeed become clear that such an eternal change exists. At the beginning of Phys. VIII 7 Aristotle, therefore, does what he announced in Phys. VIII 2 and finally takes up the question whether it is possible for one single eternal change to exist, for, as we have seen, this is what is clearly presupposed by the theory developed in the discussion in Phys. VIII 1-6. Posing the first of the three questions-and showing that there is a positive answer to it, of course-is therefore crucial for the theory of the eternity of change and that of the necessary existence of a first and eternal unmoved mover.

Yet, obviously it is not enough to know that an eternal and continuous change can exist; as Aristotle pointed out, two more questions need to be examined in order to achieve more clearness about the things said thus far. ${ }^{86}$ Question (2), that is, the first of the two remaining ones, presupposes

81 See Phys. VIII 6, 259a13-20.

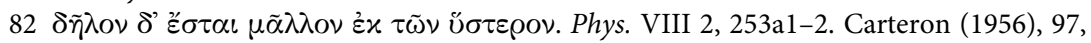
therefore, is clearly wrong when he states in his overview of the arguments of Phys. VIII that this objection is refuted in VIII 2; as I will show later on, this is done in the discussion of Phys. VIII 7-8.

83 See Phys. VI 10, 241a26-b11, and VIII 2, 252b9-12, according to which a change is

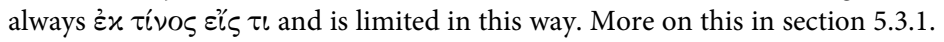

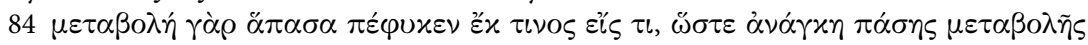

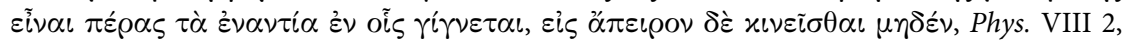
252b10-12.

85 For this claim see 259a13-20.

86 See Phys. VIII 7, 260a20-23. 
a positive answer to question (1) and asks which kind of change can be eternal. Question (3), then, asks which kind of change is the primary one. Understanding why Aristotle is interested in this last question will certainly tell us something about the role played by the arguments that are presented in order to show that the answer to this question can only be locomotion. Yet, as I have already pointed out, this can only be understood by looking at the three questions in conjunction.

The answer to the first and the second question is presented in parts of Phys. VIII 7 and 8 by showing that the only change that can be eternal without being composed of other changes is a special kind of change in place, namely circular locomotion. ${ }^{87}$ Thus, it is made clear at the end of Phys. VIII 8 that there can be one single change that is eternal, and furthermore that the change must be this special type of locomotion. According to the theory developed in the previous chapters, this must be the change of which the first unmoved mover is the cause.

Yet, Aristotle still seems to think that for some reason it has not been satisfactorily shown that the change which is caused directly by the first mover can only be circular locomotion, although this is the only type of change that can be one and eternal. The reason for this is that the change, which in virtue of having its direct source in the first mover may be called primary, not only needs to be non-composite, one and eternal, but also has to fulfil other criteria. As we will see, one of these criteria is for example that this change must be able to occur independently from the other kinds of change, and as the first existing change cannot presuppose the existence of any other change that causes it, or without which it could not occur. That this is far from self-evident is shown later on by Aristotle when for instance he raises the objection that one might think that in order for something $x$ to undergo locomotion, the subject $x$ of this change in place first of all needs to come to be so that in this sense there could be no occurrence of a change in place without a preceding generation ( $\gamma \varepsilon \dot{v} v \sigma \iota \varsigma)$. If this were true, then the first of all changes that according to Phys. VIII 6 is the cause of all other changes certainly could not be locomotion. Yet, since locomotion again is the only possible type of change that can be eternal, one might then come to the conclusion that Aristotle's theory about there being a first mover that needs to cause one single eternal change in order for change to be eternal must be wrong, since it leads to absurd consequences. Therefore, Aristotle will somehow have to show among other things that, contrary to what one may think, this objection does not threaten his theory. In fact, Aristotle will argue that locomotion, in contrast to each of the other kinds

87 The arguments are presented in 261b28-265a12. 
of change, does not entail the occurrence of some other change, but that to the contrary none of these other types can occur without locomotion.

In addition, the change which has its primary source in the first unmoved mover must be of such a kind that it can be undergone by that which is directly changed by the first unmoved mover, i.e. the imperishable and eternal outermost sphere of the heavens. As we will see, this special kind of change, despite being a change, can therefore only change its subject in a way that is compatible with the fact that its subject as an imperishable and eternal thing must not alter or change anything of what it is. In Phys. VIII 7 Aristotle will argue that this is possible for locomotion alone, which is another reason why it is the only appropriate candidate for this very special first change.

The discussion in Phys. VIII 7-9, in which the answers to all three questions are given, therefore aims as a whole at establishing that the only kind of change that can be eternal without being composed of different changes, i. e. circular locomotion, also has all of the other characteristics which the change that is directly caused by the first unmoved mover needs to have because it is the primary kind of change in all important respects. ${ }^{88}$ In Phys. VIII 7, the chapter on which my study will focus, Aristotle first of all shows that of the four kinds of change, change in quality, quantity, place, and substance, locomotion is the primary one (260a20-261a26). At the end of the same chapter and throughout the whole of Phys. VIII 8 he then presents arguments for the claim that a change in place alone, i.e. circular locomotion, can constitute one single change that is eternal. In Phys. VIII 9 he ultimately demonstrates that circular locomotion is prior to the different types of change in place, thus making it clear that the primary kind of change and that which can be eternal are one and the same. If the discussion stated in Phys. VIII 7-9 is successful, then Aristotle indeed provides the lacking justification for the assumption which Phys. VIII 1-6 presupposes and on which the whole theory developed there relies, namely that there is one single change that fulfils all the criteria of the change caused by the first unmoved mover and that therefore may itself be responsible for any other changes that occur in the cosmos.

An essential part of this inquiry, is the discussion that I will focus on in my study, that is, the discussion of the claim that of the four kinds of

88 That this is what Aristotle has in mind is indicated by 260a23-26, where the connection between the primary kind of change and that which may be "continuous", i.e. eternal, is made; this is pointed out by Aquinas, In Phys., L. VIII, 1. XIV, 1086, who states that Aristotle in these lines makes clear that the primary change and the eternal one must be one and the same although this may be doubted. He does not, however, explain why exactly they should be identical. Nevertheless, his remark certainly is very helpful in making sense of these introductory remarks. 
change locomotion is the primary one and that for this reason the change which has its primary source in the first unmoved mover can only be locomotion.

\subsection{Conclusion}

What has this chapter, which dealt with the context of the arguments for the priority claim, shown?

In examining different testimonies that tell us something about the way in which the book we call the Physics of Aristotle was originally arranged, it first of all became clear that Book VIII of this book, together with Books V and VI, most likely formed a formerly independent treatise named On Change. In contrast to the preceding books of the Physics, which go back to at least one other treatise called On Nature and which dealt with the principles of nature, this treatise focused on examining the phenomenon of change in general. The discussion of the primary kind of change in Book VIII accordingly has to be considered as a part of this larger project for examining change.

This observation was also confirmed by the fact that with respect to the content of these books Aristotle's goal in Phys. V-VIII is to develop a general theory of change: after basic concepts that are necessary for this enterprise are analysed and the phenomenon of change is established as an object accessible to scientific inquiry in Phys. V and VI, Book VIII completes the inquiry by developing a theory that, based on the work done in Phys. V and VI, can account for the empirical fact of the existence of change in the cosmos by showing that change must be eternal and that all changes have their common principle in a first unmoved mover.

Finally, I made it clear that Aristotle's question which kind of change is primary, as it is raised and discussed in Phys. VIII 7 plays a crucial role for the argument of Book VIII. Together with the rest of what is discussed in chapters 7-9 the arguments provide essential support for the theory of the eternity of change and the necessary existence of a first unmoved mover which is the source of all change in the universe, a theory that was developed in the first six chapters of Phys. VIII. For, only if the arguments for the claim that locomotion is the primary kind of change are successful can Aristotle show that there can in fact be this one single eternal change whose existence the theory presupposes, because by making clear that the type of change which is primary and the change which can be eternal are one and the same Aristotle proves that there is a change that, besides being eternal, in virtue of belonging to the primary kind of change also fulfils the other criteria for being the change which is directly caused by the first unmoved 
mover. By showing that locomotion has primacy over the other three kinds of change Aristotle therefore provides reasons why this eternal change can only be locomotion.

Contrary to what the literature suggests, the discussion of the question which kind of change is primary, is therefore essential not only for what goes on in Phys. VIII, but also for Aristotle's larger project of developing a general theory of change, a project which comes to an end in this last book of the Physics.

But now that the significance of inquiring into the primary kind of change and of showing that it must be locomotion has become clear, I will turn to the discussion of the first argument for the priority claim. 


\section{Change in quality and quantity of living beings depends on locomotion, but not vice versa}

\subsection{Overview}

Aristotle presents his first argument for the priority of locomotion in the following lines:

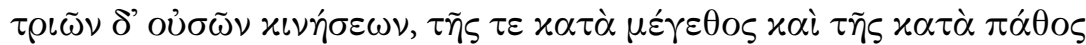

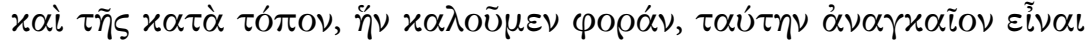

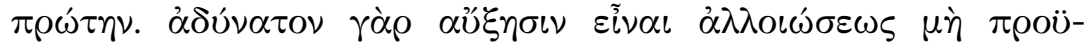

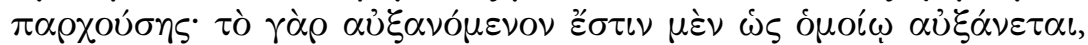

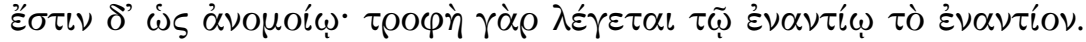

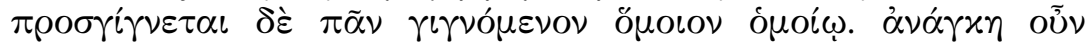

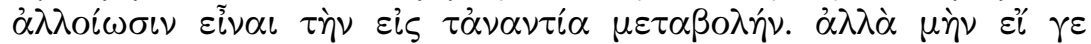

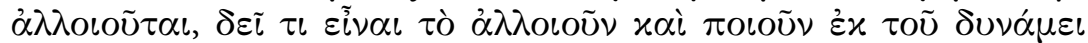

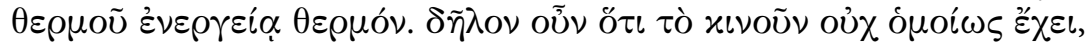

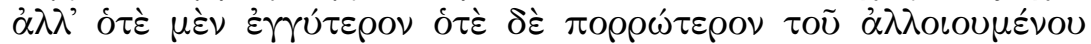

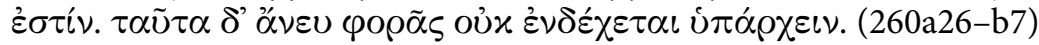

As there are three kinds of non-substantial change, that with respect to magnitude, that with respect to quality, and that with respect to place, which we call locomotion, this [last] one must be primary. For it is impossible that there is growth without a preceding alteration. For what grows in one way grows by what is like, but in another way by what is unlike. For the contrary is said to be food for the contrary. But everything is added to its like by becoming alike. Therefore, the change between the contraries must be an alteration. Surely, if something is altered, there needs to be something that alters the thing and which makes it [change] from potentially hot to actually hot. So, it is clear that the mover does not [always] hold the same relation [to what is altered], but sometimes is nearer and sometimes farther away from what is altered. But this cannot be without locomotion.

According to my reading, Aristotle in this argument is showing that locomotion in a certain respect has ontological priority over the other two kinds of non-substantial change, i.e. change in quantity and quality. As we will see, something $x$ is ontologically prior to $y$, if and only if for $y$ to be there must be $x$, but not vice versa. Or, to put it in other words, $y$ cannot be with- 
out $x$, while $x$ can be without $y$, so that the relation between $x$ and $y$ in this sense may be described as an asymmetric relation of ontological dependency. At first glance the passage seems to suggest that Aristotle is presenting an argument for locomotion's general ontological priority over the other two kinds of non-substantial change. But I will show that in fact when one looks at it more closely, it becomes clear that Aristotle is only arguing here for the claim that locomotion has this kind of priority with respect to special cases of these changes, namely change in quantity and quality as they occur in living beings. According to my reading the argument therefore shows that any growth, diminution, and alteration that occurs in a living organism necessarily needs to involve some preceding locomotion, while the converse does not hold.

It is important for Aristotle to make clear that this is the case, since based on what is stated in certain passages of Phys. VIII one might think that the processes that animals as self-sustaining organisms seem to undergo at certain times or even persistently-growth for instance-precede locomotion or even might be necessary for locomotion to occur in general. This, however, clearly would contradict the claim that locomotion in general has priority over the other kinds of change. Therefore, Aristotle is showing in this first argument that any change in quantity as well as any alteration that occurs in a living being presupposes a preceding locomotion, not necessarily of that which changes in quantity or quality, but in general of something that may or may not be identical with the subject of these other two changes. But by showing that in this sense change in place is necessary for the other types of change to occur, I will argue, it is established that change in place has ontological priority over the other two kinds of non-substantial change with respect to changes in living beings, but also with respect to any other changes of which animals as self-movers may be a cause. As I will show, this amounts to saying that any occurrence of the other kinds of change that is caused by a sublunary source of change always implies a preceding locomotion, while the occurrence of a locomotion does not necessarily entail any of the other two kinds of change.

The basic structure of the argument presented by Aristotle for the priority of locomotion over change in quantity and quality is this:

(1) The occurrence of growth as well as diminution for which living beings are responsible presupposes a preceding alteration.

(2) The occurrence of alteration presupposes a preceding locomotion.

(3) Hence, growth, diminution, and alteration for which a living being is responsible presuppose a preceding locomotion.

In order to fully understand whether and, if so, in what way the argument makes clear what Aristotle aims to show, a more detailed analysis of the 
argument is necessary. I will proceed in the following way: I will start by examining the first of the two premises on which the argument is based, namely that change in quantity, i. e. growth and diminution, presupposes a preceding alteration (3.2). Then I will deal with the second premise, which is that alteration cannot occur without a preceding locomotion (3.3). After that I will show that the argument, contrary to what one might expect, does not show locomotion's general priority over any kind of change in magnitude, but only with respect to growth and diminution as they occur in living beings and for which they are responsible insofar as they have a soul. I will argue that the argument, nonetheless, not only makes clear that locomotion must be prior to the changes in quality or quantity to which living beings are subject in the stated sense, but also with respect to all other changes that are caused by a living being (3.4). Next I will show that Aristotle has very good reasons to focus on changes that are caused by living beings (3.5). For, by doing so he rejects a possible objection against the priority claim, since the argument he presents makes clear that change in place-in the sense relevant for this argument-has ontological priority over change in quality and quantity in living beings, although there seem to be reasons to think differently (3.6). My last step will be to summarize the results of this chapter (3.7).

\subsection{Growth and diminution presuppose alteration}

The passage cited above begins by introducing the claim that the argument is supposed to establish. Of the three kinds of non-substantial change that exist, that is, of "that with respect to magnitude, that with respect to quality, and that with respect to place, which we call locomotion, this [last] one must be primary."1

The first argument that Aristotle makes in order to justify the claim ( $\gamma \alpha \dot{\alpha} \rho)$ that locomotion is prior to change in quantity and quality is that there can be no growth ( $\left.\alpha u^{\prime} \xi \eta \sigma \iota \varsigma\right)$ without a preceding alteration $\left(\dot{\alpha} \lambda \lambda \operatorname{li}^{\prime} \omega-\right.$ $\sigma \iota \varsigma){ }^{2}$ By 'growth' Aristotle is obviously referring here to change in magnitude, i. e. growth and diminution, in general. This is clear because the argument for which this statement serves as one of the premises is supposed to show that locomotion ( $\varphi \circ \rho \alpha$ ) is prior to change in magnitude ( $\varkappa \alpha \tau \grave{\alpha}$

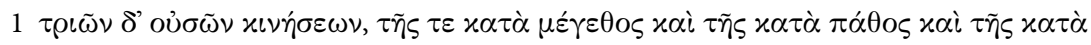

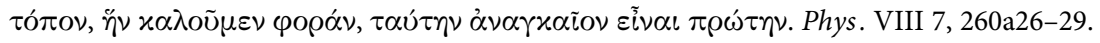

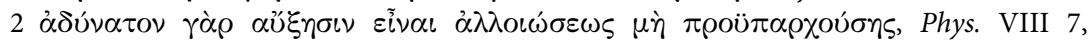
260a29-30: "For it is impossible that there is growth without a preceding alteration." 
$\mu \varepsilon ́ \gamma \varepsilon \theta \varsigma)$ in general, as he pointed out just two lines earlier. ${ }^{3}$ Accordingly, it would make no sense if Aristotle argued for the assumption that only growth, that is, increase in size, presupposes alteration, since this would not lead to the conclusion that locomotion-in virtue of being necessary for an alteration to occur and thus being prior to it-is prior also to change in magnitude. ${ }^{4}$ Therefore, the claim that serves as the first premise of the argument and for which Aristotle is actually arguing here is that both growth and diminution presuppose alteration, although only the reasons for making this assumption with respect to growth are explicitly stated. I will now present the argument for the claim that growth presupposes alteration (3.2.1) and afterwards give reasons why this is also true of diminution (3.2.2).

\subsubsection{Growth presupposes alteration}

The argument presented for the claim that growth presupposes a preceding alteration basically is that growth of organisms always occurs through the addition of something to that which is growing, in the sense that food is taken in and by undergoing certain changes becomes a part of the body. This process of transformation of food necessarily involves alteration. As we will see, something similar also takes place in the case of diminution. For this process occurs by means of removal of some material from that which is shrinking. Furthermore, this process of separation, I will argue, necessarily involves alteration.

In 260a30-33 Aristotle explains why growth cannot occur without alteration and states four points from which this is supposed to become clear: (1) growth on the one hand takes place "by what is like" (óoí $\omega$ ), but on the other hand "by what is unlike" ( $\alpha$ vouoi $\omega){ }^{5}$ The reason presented for the former is that (2) "the contrary is said to be food for the contrary" the argument given for the latter is that (3) the addition that is part of any growth occurs by "like becoming alike." 7 Besides, (4) the change between contraries that is involved in this process must be an alteration. ${ }^{8}$ All this as

3 See Phys. VIII 7, 260a26-29.

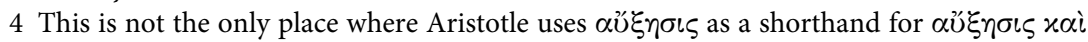
$\varphi \theta i \sigma ı$. See for instance GC I 5, 320a8, where Aristotle introduces the kind of change discussed now merely as $\alpha \bigcup \xi \xi \eta \sigma \varsigma$ and asks how it differs from the other kinds of change.

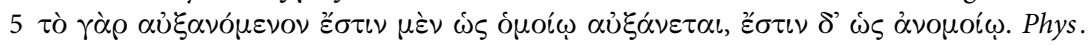
VIII 7, 260a30-31.

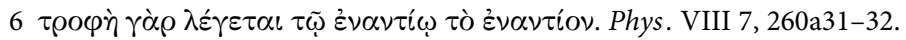

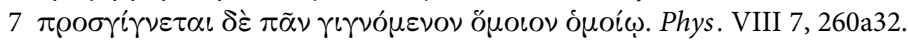

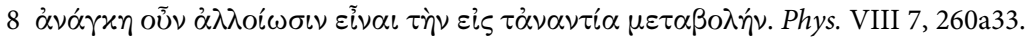


it is stated here still does not make clear in what way change in magnitude presupposes alteration and, indeed, it seems that Aristotle presupposes that the reader is acquainted with his understanding of growth as it is laid out in GC I 5 and de An. II 4, because there the same claims are made in the context of a more detailed explanation of what happens when growth occurs. ${ }^{9}$

According to the account in GC I 5, a process of growth may be explained in the following way. All growth occurs in virtue of something being added. ${ }^{10}$ What is added-this is called food ( $\tau \rho \circ \varphi \eta$ ) -is contrary to that to which it is added, in the sense that for example moist food is added to something dry, the flesh of the growing thing. ${ }^{11}$ The food is unlike that to which it is added, since it is different and a separate thing that is characterised by contrary qualities. This is the reason for claiming (2), that is, for saying that the contrary, i. e. the moist food that is added, is food for its contrary, namely for the dry flesh to which it is added and which it increases in size. ${ }^{12}$ In this way claim (2) is plausible, since it refers to the fact that the food is unlike the body of which it is supposed to become a part in the process of growth.

But as claim (1) asserts, growth does not only occur in virtue of "what is unlike", but at the same time takes place through "what is like". While the former was explained by the fact to which claim (2) referred, the latter will become clearer by what is stated in claim (3), which says that "everything is added to its like by becoming alike." What Aristotle means to say here is that in order for something to grow, that which is added and that, as we have seen, is unlike the growing thing needs to be transformed so that it may become an integral part of that to which it is added. The food therefore in principle needs to be capable of becoming a part of the whole to which it is added. The food that is supposed to make an animal grow, for instance, must potentially be flesh, although in the moment it is consumed it still is something else and unlike flesh. ${ }^{13}$ One could say that the food needs to be of such quality that it can be assimilated by the growing thing's body. Hence, when an infant swallows a stone, this does not lead to growth, i.e. to the stone's integration into the infant's body, for the stone is not potential flesh in the sense that it cannot be transformed into a part of the infant's body. A piece of apple that I feed the infant, however, by means of digestion

9 For claim (1) see GC I 5, 322a 4 f., for claim (2) 321b35-322al, for claim (3) 322a5f., and for claim (4) 322a1-3. For Aristotle's account of growth in living organisms as it is presented in de An. II 4 see 416a19-b31.

10 See GC I 5, 321a18-22 and 321b22-24.

11 See GC I 5, 321b35-322a3.

12 See GC I 5, 321b35-322a3.

13 See GC I 5, 322a5-6 
can be transformed into flesh and in this sense is potentially like that to which it is added.

In the sense stated above, therefore, the food which is added is actually something unlike the growing thing, but also is potentially something like the growing thing, which is exactly what claim (1) says. ${ }^{14}$ That this must be what Aristotle has in mind here becomes even more clear in a passage from de An. II 4, where it is stated that the food, "insofar as it is undigested, is the contrary for the contrary, but insofar as it is digested, is the like for the like." ${ }^{15}$ This, however, is a short reformulation of what I just stated, namely that growth indeed seems to take place by means of that which is like andat the same time, yet in another respect-unlike the growing thing.

But in order for the growth to occur the nourishment's potential of being like that to which it is added has to be actualised. In terms of Aristotle's explanation from GC I 5, the food, among other things, needs to be changed from moist to dry, that is from the quality by which it is characterised into this quality's contrary. A change from a quality to its contrary, however, is an alteration. ${ }^{16}$ Since, as we have seen, such a change needs to occur when the food is transformed in order to become an integral part of the body, Aristotle correctly makes claim (4), i. e. that this change ( $\left.\mu \varepsilon \tau \alpha \beta \rho \lambda \eta^{\prime}\right)$, which involves a change between these contraries can only be an alteration $\left(\dot{\alpha} \lambda \lambda \operatorname{oi}^{\prime} \omega \sigma \iota \varsigma\right){ }^{17}$

Therefore, Aristotle rightly claims that an alteration, at least in the stated case, has to precede growth in the sense that before the material becomes a part of the body by being integrated into it, it must first undergo an alteration. One way to think of this in Aristotelian terms would be the following: in order for the growth of the animal to take place, food has to be digested, that is, turned into blood and later for instance into the homoeomeres of flesh or bone. This involves an alteration, since this process, parts of which involve the change from wet to dry, takes place by concoction $(\pi \varepsilon \dot{\varepsilon} \psi \iota \varsigma)$, i. e. the heating of the food. ${ }^{18}$

Hence, every process of growth which works in this way has to be preceded by an alteration. In this way Aristotle shows that this is what must happen whenever an animal grows; yet, he does not make clear that its decrease in size, i.e. diminution, also presupposes alteration in the stated

14 See GC I 5, 322a5-6.

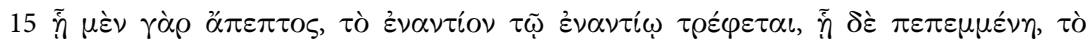
ŏ

16 See for instance Phys. V 2, 226b1-3, GC I 4, 319b8-12, where $\alpha \lambda \lambda$ oí $\omega \sigma \iota \varsigma$ is defined as the change between contrary qualities of some $x$. The example that in GC I 5 is given for this change is that of nourishment being changed from wet to dry (see 322a1-3).

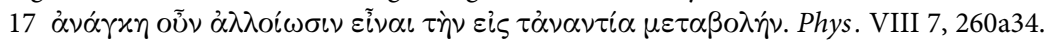

18 See PA II 3, 650a2-6. 
way. As I have pointed out, change in magnitude, however, includes both growth and diminution. ${ }^{19}$ For this it remains to be shown that not only growth, but also diminution requires an alteration in order to occur. Otherwise, Aristotle could not claim that change in magnitude-about which he is obviously speaking here-presupposes alteration and hence locomotion. $^{20}$

\subsubsection{Diminution presupposes alteration}

Aristotle does not spell out explicitly how diminution occurs. According to GC I 5 something grows by means of some thing's acceding to the growing thing, while something diminishes by some thing's leaving the body. ${ }^{21}$ Even though Aristotle does not say this explicitly, he seems to think that growth and diminution work according to the same principles, since diminution may be considered as a reversed form of growth, so to speak. If this is correct, that which is leaving the body, a portion of flesh or tissue for example, needs to become separated from the portion of flesh of which it is a part. This detachment, or, to put it in Aristotelian terms, the process of turning something that is like that of which it is a part into something that-at least to a certain degree-is unlike this stuff, presupposes an alteration. Furthermore, this alteration needs to occur before the actual occurrence of the diminution, since the part cannot be dissolved out of the continuous whole, thereby making this whole become smaller, until it is altered in the necessary way. An example of this would be a part of flesh that is detached from the living tissue and that by this process ceases to be like the actual flesh of the body and turns into some other material that is transported out of the body after the change. ${ }^{22}$ The following example could serve as an analogy: suppose, for instance, I take a candle or a piece of wax and start heating a part of it by means of another other candle that is burning. A part of the wax will become warmer and warmer through my heating and at some point a certain portion of the wax will turn into liquid and finally will be

19 See Phys. V 2, 226a29-32, and GC I 5, 320a8-10.

20 Philoponus, Simplicius, Aquinas, Ross (1936), Wagner (1967), Zekl (1988), and Graham (1999) do not say anything about this. Either they-without making it explicit-do not think that this a problem and presuppose that it is clear that diminution takes place according to the same principles as growth, or they are unaware of this problem.

21 See GC I 5, 321a3-5 and 321b12f.

22 The 'flesh' by being detached from the organism's tissue stops being flesh in the strict sense, as this presupposes being part of a living body's flesh; in the same sense Aristotle would say that a chopped off hand is no longer a hand, since being a hand presupposes being part of a living human body. 
separated from the solid piece of wax in form of a drop. For this process of separation to occur, however, an alteration needs to take place in order to dissolve a part of the wax from this continuous whole. In a similar way, I take it, alteration is involved in the process of diminution in living organisms. Therefore, it is clear that not only growth, but also diminution presupposes the occurrence of alteration.

Yet, one could think of a different case of diminution as it occurs with respect to living things and for which one should also be able to explain to what extent this process involves alteration: as I age and decrease in size, this, for instance, may also involve some of my hair, i.e. some part of my body, falling off. But in what way would this involve an alteration? For the hair, merely by falling off, certainly does not alter. Yet, it seems nonetheless that even in this case one has to presuppose that an alteration is necessarily involved in this process, insofar as the root of my hair, which is a part of the tissue of the skin on my head, needs to become loose in order to become separated from the tissue so that the hair can finally fall off. In this respect the case clearly is no different from that in which flesh is detached from the tissue by which it is surrounded in other instances of diminution. Although it is correct that the hair itself does not alter, there certainly is an alteration involved. Accordingly, in this case as well, the occurrence of a preceding alteration needs to be presupposed. One must conclude, then, that not only growth, but also diminution presupposes the occurrence of alteration.

This assumption is also a reasonable one from our point of view. For, although we might not agree to how exactly the change in quantity occurs, we certainly would also say that any process of growth and diminution in organisms necessarily involves some process in which that which is added or taken away, or some part of that which is changing in size, needs to be altered.

\subsection{Alteration presupposes locomotion}

Now that it has become clear in what way Aristotle is correct to claim the first premise, i.e. that there must be an alteration prior to change in magnitude, I will now examine the second premise on which the argument is based and the reasons that are presented for this assumption. The premise states that prior to any alteration a locomotion needs to occur. ${ }^{23}$ The argu-

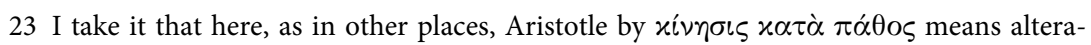
tion in general and not only in those cases in which an affection is altered. In GC I 4 for instance alteration $\left(\alpha \lambda \lambda \alpha^{\prime} \omega \sigma \iota \varsigma\right)$ is explicitly defined as the change of a subject that "changes

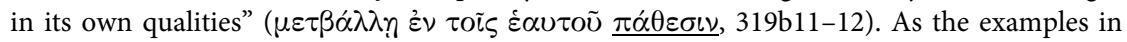
GC I 4 clearly indicate, apart from one exception, the cases of change in its $\pi \alpha \theta \varepsilon \varepsilon \iota \nu$ pre- 
ment for this claim basically seems to be that what makes the subject of the alteration alter, the alterer so to speak, needs to change its distance with respect to the subject in doing so. This, however, clearly involves locomotion. But let us look at the relevant passage (260b1-5) in more detail.

Aristotle starts by pointing out that whenever an alteration occurs, i.e. something is altered, then there must necessarily be something which

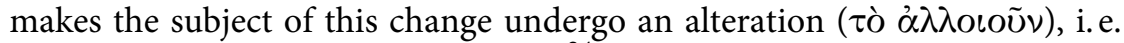
something one might call the alterer. ${ }^{24}$ This makes use of a principle that Aristotle for instance states in Phys. VIII 4, namely that whatever undergoes a change must be caused to do so by something. ${ }^{25}$ Since alteration is a change, this must also hold true for alteration. Alteration is a change with respect to quality, which in this case implies that the subject needs to be caused to change with respect to a quality. Suppose, for instance, something changes from being cold to being hot. This means that the alterer needs to change what is undergoing this alteration from being potentially hot to becoming actually hot. ${ }^{26}$ This, however, Aristotle claims, cannot happen without locomotion. ${ }^{27}$ As we will see later on, this is what shows the priority of locomotion.

But what is the reason for making the claim that locomotion is necessarily involved in this process, and in what way does the change from cold to hot presuppose locomotion? The reason Aristotle seems to have in mind is this: any alteration, also that in which something cold is turned into something hot, involves a change in distance between what alters and what is altered, i. e. a change in place of either the alterer, the altered thing, or both. This is necessary, since, as Aristotle claims in Phys. VII 2, for an alteration to occur, what alters and what is altered need to be in $\operatorname{contact}^{28}$, or to put it

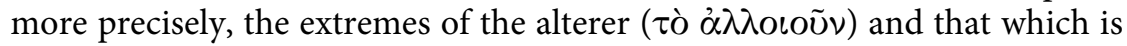

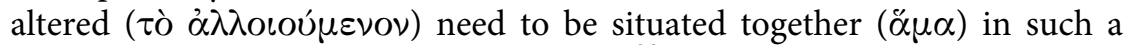
way that there is nothing between them. ${ }^{29}$ One could also say that both

sented here cover the whole spectrum of alterations that one would expect to be covered against the background of the discussion of quality in Cat. 8. I will say more about this in section 4.4.2 in the chapter on the second argument for the primacy of locomotion; see esp. p. 100, n. 70, and p. 103, n. 83).

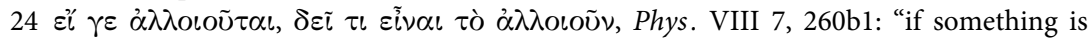
altered, there needs to be something that alters the thing".

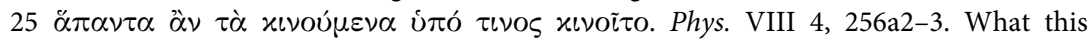
implies is discussed in more detail at the beginning of VIII 5. For the principle that any change must be caused by something see also Phys. VII 1, 241b34-35.

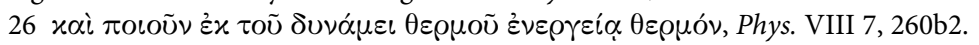

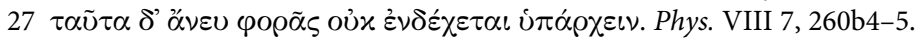

28 For the claim see Phys. VII 2, 244b2-5 and 245a10-11. The whole argument for this claim is presented in $244 \mathrm{~b} 2-245 \mathrm{a} 10$.

29 Again, I take this not only to be true for changes with respect to affections, but for any 
things are touching each other, and indeed the relation of two things touching $(\check{\alpha} \pi \tau \varepsilon \sigma \theta \alpha \iota)$ each other is defined in Phys. V 3 with respect to the things' extremes being situated together. ${ }^{30}$ But for two things to come into contact implies that they have to come closer to each other, and accordingly either one or both of them have to change place. It is for this reason that Aristotle is able to state that the alterer "does not [always] hold the same relation [to what is altered], but sometimes is nearer and sometimes farther away from what is altered." ${ }^{31}$ In order for that which is hot to impart its heat to some other thing that is cold, the two things have to move towards each other and touch. This change in place necessarily needs to occur before the alteration in the sense that the alterer and what is altered are in contact only after locomotion has occurred. ${ }^{32}$

If one takes it that the example of the cold becoming hot refers to the process in which food is heated in order to become a part of the body (and that in this way the thought from the first part of the argument is continued), then one could explain what happens in this way: ${ }^{33}$ the food, as that

alteration in general. For, as I shall argue in the next chapter, Aristotle clearly holds the view that every alteration involves a change with respect to the subject's affections. For instance he thinks that health is connected to heat (see Phys. IV 3, 210b24-27) and therefore also that a change from being healthy to being sick - which according to Cat. 8 would count as a change in a $\varepsilon \xi_{\llcorner\zeta}$, i. e. in quality-involves the subject's change with respect to the qualities of hot and cold. This is also clear from the fact that any alteration may be partly characterised as a

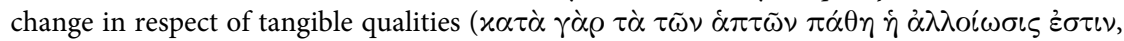
GC II 4, 331a9-10), that again may be explained in terms of the four basic qualities of hot, cold, dry, and moist. I will argue for the claim that alteration in general involves a change in the respective thing's affection later on in section 4.4.3.

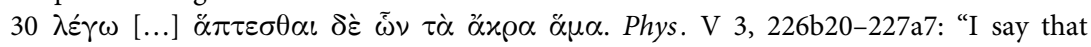
things are touching if their extremes are together."

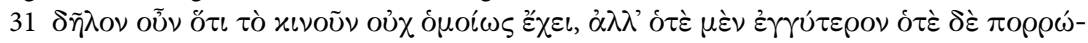

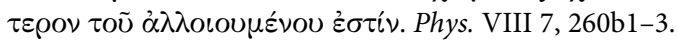

32 In fact it is not only the case for alteration that what causes the respective change ( $\tau$ ò

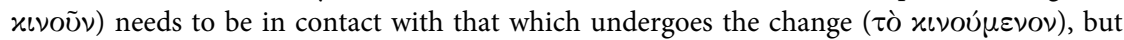
also for locomotion (243a11-244b2), and for growth and diminution (see 245a11-16), that is, for all three kinds of non-substantial change (243a34-35). It is puzzling that Aristotle does not simply make use of this fact to show that change in magnitude also presupposes locomotion in the same sense as alteration does. The only reason I can think of is that Aristotle for some reason not only wants to show that locomotion is prior to change in quality and quantity, but also that alteration is prior to growth and diminution.

33 This is what Simplicius, In Phys. 8, 1265-1266, thinks. One could also think, however, that Aristotle, by using the pair of hot and cold, is referring to two of the four basic qualities which, apart from dry and moist, (which as we saw are used in the explanation of growth in GC I 5 and $d e A n$. II 4) are involved in any alteration, as they characterise the basic material components of all composite substances in the sublunary sphere. (For more on this see my discussion of the second argument, esp. section 4.4.3). 
which needs to be altered in order to be absorbed by the body, needs to be moved to the place where digestion occurs and there come in contact with a source of heat which turns the food from cold to hot so that it can be cooked and turned into blood.

Yet, is it really necessary that alteration always involve a change in place? Suppose there is a case in which the contact that is necessary for alteration does not need to be established, since it is already the case that what will become an alterer later on and the future altered thing already are in contact and in fact always have been in contact. Accordingly, it appears, no locomotion would be necessary if one were to alter the other. For, when at some point one of the two things starts to impart heat to the other thing, which is cold, and by doing so alters the adjoining thing with which it is in contact, it seems that it is possible for a change from hot to cold to occur without locomotion.

But this objection could be rejected in the following way. In the stated case the alterer itself must be hot in order to change the other thing from cold to hot. Either the alterer has always been hot, or it became hot at some point. In the first case there simply would be no alteration. For, if both things have always been in contact and the alterer has always been hot, then it would not make sense to say that the alteration starts at a specific point; rather, if this were the case, the other thing would also always have been hot itself (provided, of course, that what is supposed to be altered here is not affected suddenly by some other source of change.) In the case where the alterer becomes hot at some point in time, there must be some other alterer which is responsible for this change from hot to cold. But in order for that to take place the future alterer and what changes it from cold to hot also need to come in contact with each other first. Since every change needs to have a cause, this then would either lead to an infinite chain in which one thing alters the next, or to claiming that this change can be traced back to a first unmoved mover. As we know from the discussion in chapters 5 and 6 of Phys. VIII, Aristotle has very good reasons to reject the first and to favour the second option. ${ }^{34}$ That the first change, of which the unmoved mover is the direct cause and that must be eternal, cannot be alteration is shown by Aristotle in Phys. VIII $8^{35}$; this, however, would be necessary for the aforementioned objection to work. Therefore, it is clear that the case stated above is not a real objection against the claim that any alteration presupposes the occurrence of a locomotion in virtue of the fact that the alterer and what is altered need to move together in order to touch each other.

34 See Phys. VIII 5, 256a4-21, and VIII 6, 259a6-20.

35 The reason in short is that alteration cannot be this first everlasting change, as it cannot be eternal; as a change between contraries it is limited and must come to a halt at some point. See Phys. VIII 7, 261a31-261b3. 
As it is clear now that alteration indeed presupposes that locomotion precedes it in the sense stated above, it is also clear that the same is true for the cases of growth and diminution discussed here. For, as we have seen, these changes in quantity cannot come about without an alteration that occurs before the actual growth or diminution. Therefore, we can conclude that change in magnitude and quality in this way presuppose locomotion. This, however, Aristotle thinks, shows that of the three non-substantial kinds of change, change in place must be the primary one.

\subsection{Does locomotion precede all occurrences of change in quantity?}

As we have seen, Aristotle's argument indeed seems to show that for there to be alteration, i.e. change in quality, as well as growth and diminution, that is, change in magnitude, some kind of change in place has to be presupposed. But we need to be clear about how to understand this: as we have seen this does not necessarily mean that the subject of the change in quality or quantity changes in place, but merely that something which may or may not be identical with the subject of these changes needs to undergo a change with respect to place in order for growth, diminution, or alteration to occur. To put it more generally, this means that where there is any change in quality or quantity of $x$, there must also be a change in place of some $y$, although $y$ does not have to be identical with $x$.

This, Aristotle appears to think, makes clear that of the three kinds of non-substantial change, namely of change with respect to magnitude ( $x \alpha \tau \dot{\alpha}$

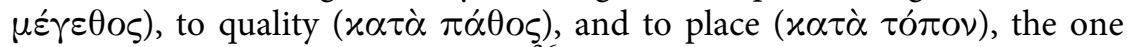
that we call locomotion is primary. ${ }^{36}$ But as I will now show there is a reason to think that only a rather more limited claim follows from the argument, and that Aristotle, therefore, might not succeed in showing what he is supposed to show.

The reason is that Aristotle appears to claim that locomotion is prior to any change that occurs with respect to the subject's magnitude in general, whereas this argument only seems to show this to be true with respect to special cases of this kind of change, namely growth and diminution as they occur in living organisms, since this is clearly indicated by the way in which growth is explained in Phys. VIII 7. ${ }^{37}$ This criticism appears to be justified,

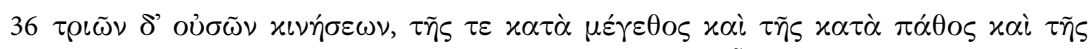

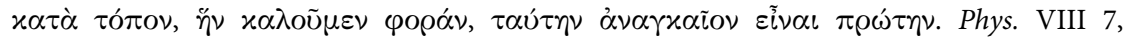
260a26-31.

37 For this criticism see Wagner (1967), 688 and 691. It is clear that Simplicius, In Phys. 8, 1265, 26-28, thinks that Aristotle is not speaking about change in magnitude here in general, 


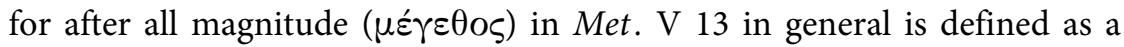
quantum $(\pi 0 \sigma o ́ \nu)$ that is measurable and can be divided into continuous

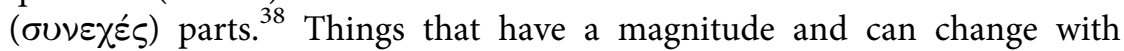
respect to it would then include for instance all kinds of living organisms, but also things like a lump of clay, a stalactite or a certain quantum of water or air. According to this general definition of magnitude-and this seems to be the point of the aforementioned criticism-all cases in which such things change with respect to their size would count as instances of a change in magnitude, and not only the special case of growth and diminution in living beings. But if Aristotle's argument really is supposed to show that locomotion is prior to any change in magnitude, but only presents reasons for this being true in the special case of growth and diminution in animals, then the argument, it seems, fails. That Aristotle's argument refers solely to changes in magnitude of living beings is clear not only from what is said in Phys. VIII 7, but also from the fact that the characterisation of growth there is a short version of what is stated in GC I 5 and parts of de An II $4 .{ }^{39}$ This, it appears, would be highly problematic, as it is far from clear, not to say wrong, that all instances of change with respect to magnitude in generalincluding the cases I just mentioned-occur in the way Aristotle explained growth in the first argument for the primacy of locomotion. Suppose, for instance, a puddle increases in size and becomes larger as it rains. To put it more generally, in this case a portion of water changes with respect to its magnitude by more water being added to it. In this case there certainly is no need for the raindrops that are added to the puddle to undergo an alteration in the way presented in the argument in order to become a part of the puddle and to be absorbed by the whole in the same way that food is transformed and integrated into the body. Another example which shows the same would be that of a river which changes in magnitude over the year: in

but rather more with respect to its role in nature ( $\varphi v \sigma \iota x \omega \tau \varepsilon \rho o \nu)$, which means in a sense that excludes other cases of change in magnitude. Graham (1999), 121, in this argument also understands $\alpha u \xi \eta$ бıৎ in the restricted biological sense, but does not seem to think that this is a problem.

38 See Met. V 13, 1020a7-11.

39 This for instance is obvious from the fact that in de An. II 4 Aristotle explains one of the essential characteristics of growth in general, namely that it occurs in one sense by what is like, in another sense by what is unlike, with reference to the fact that the food which is unlike at the beginning by being digested becomes like that to which it is added (see my discussion in section 3.2.1 and de An. II 4, 416b6-7). That the account of growth presented in GC I 5 is restricted to cases of the growth of living organisms, although it is also considered as a change in magnitude there (320a13-14) is pointed out for instance by Joachim (1922), 110, who

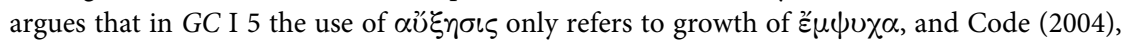
171 , who claims that growth is treated in GC I 5 not as increase in size in general but rather as a "kind of natural phenomenon". 
spring, for instance, when the snow is melting, rivers usually become broader and in this sense increase in size. For once the snow starts to melt, additional water may flow into the rivers, making them become larger. Yet, as in the case of the enlargement of the puddle, the water which flows into the river does not have to undergo any sort of alteration in order to become a part of the river. ${ }^{40}$ As a last example of an increase in quantity that does not involve an alteration of that which is added, one could also refer to the case of blowing up a balloon: the more air I blow into the balloon, the more its size will increase. Yet, the air which I blow into the balloon does not have to alter in order to become a part of the air in the balloon. More examples like this could be added.

Accordingly, I think it is correct that Aristotle in the first argument understands change in magnitude, i. e. growth and diminution, as the kind of change in size that living things undergo. However, this seems not only true for this passage, but for many others as well. As I see it, Aristotle in general considers change in quantity not merely as some process involving increase and decrease in size, but primarily as such cases in which a living organism grows and diminishes. For, besides the fact that it is clearly stated in the De Anima that only things that have a soul, i.e. living things, can be subject to growth and diminution, that is, change in quantity, in the proper sense, this is also what is implied by the way in which growth and diminution are described in Phys. V 2 and VI 10. For in the first of these two pas-

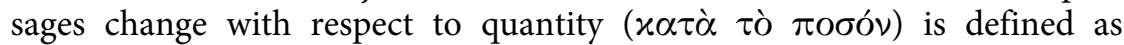

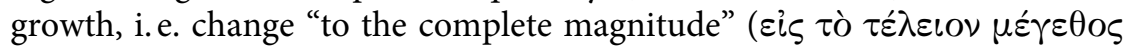
$\left.\alpha u \xi_{\eta} \sigma \iota \varsigma\right)$, and as diminution, i.e. change away from this magnitude ( $\dot{\varepsilon} x$

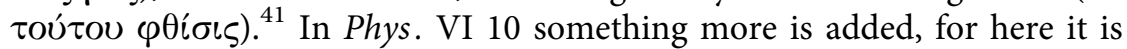
stated that growth aims at reaching the complete magnitude that is specific

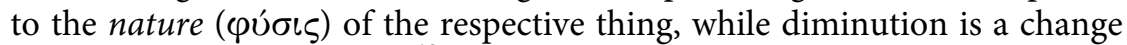
away from this magnitude. ${ }^{42}$ Both passages clearly indicate that change in quantity for Aristotle is not merely becoming larger or smaller in some sense, but rather needs to be understood primarily as a change with respect to a certain goal and nature. Yet, one certainly cannot say that whatever

40 The melting of the snow, of course, involves an alteration, namely the heating of a portion of snow, yet, when what was formerly snow and now is water flows into the river, the portion of water does not have to change in quality; it does not matter whether the increase in size occurs by the water from molten snow, or by rain, or by a factory letting its effluent flow into a nearby river-whenever water is added to a river, i. e. a large portion of water, it does not have to alter beforehand.

41 See Phys. VIII 7, 260a29-32.

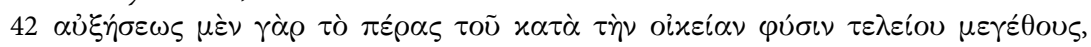
$\varphi \theta i \sigma \varepsilon \omega \varsigma \delta \dot{\varepsilon} \dot{\eta} \tau o u ́ \tau O u$ हैx $\sigma \tau \alpha \sigma \iota \varsigma$. Phys. VI 10, 241a33-b2: "the limit of growth is to be found in the complete magnitude proper to the nature of the thing, while the limit of diminution is the loss of such magnitude." (Transl. Hardie \& Gaye with mod.). 
changes in size also has a nature and a size that is specific to it. It is true that a stalactite, for instance, may be said to change with respect to its magnitude like the aforementioned puddle, but there is no magnitude that is specific to either of them. ${ }^{43}$ Living beings, by contrast, have a nature that is a source of their respective changes in place, alteration, growth and diminution. ${ }^{44}$ And, thus, it is primarily with respect to such beings that Aristotle speaks about change in quantity, i. e. growth and diminution.

But although Aristotle indeed seems to think of change in quantity primarily as a change that occurs in living things, it is nonetheless true that a change with respect to quantity in general encompasses more cases than merely the growth and diminution of living organisms. For, as is stated in Phys. III 1 and V 2 change in quantity basically is change with respect to a certain category possessed by every bodily thing, namely that of quantity. ${ }^{45}$ Thus, the argument that is supposed to show that locomotion in general is prior to change in magnitude and quality in that it necessarily precedes them needs to show that locomotion is also prior to changes in magnitude undergone by non-living things. The question, however, is whether Aristotle really wants to show what he appears to claim in 260a26-29, namely that locomotion is prior to change in magnitude without qualification, or whether he is employing the narrow sense of change in magnitude and rather aims at showing that locomotion is prior to this special kind of change in magnitude, since this for some reason is of special importance to him. I take it that the latter is the case and that Aristotle, as I will now show, has good reasons for proceeding in this way. In what follows I will present what I think these reasons might be.

Every living being in virtue of having a nature $(\varphi v ́ \sigma \iota \varsigma)$ and a soul $\left(\psi \cup \chi \eta^{\prime}\right)$ to a certain degree is the principle or source $(\dot{\alpha} \rho \chi \hat{\eta})$ of the changes that it undergoes and that are an essential part of its being a living organism. For something that has a nature has within itself the source, or at least a source, of these kinds of life-specific changes. ${ }^{46}$ Having a soul is what distinguishes living beings from lifeless things, and accordingly in this sense is also described as a principle or source of all the different changes and activities that are specific to living beings. ${ }^{47}$ The soul in this sense is responsible for

43 This is also the reason why fire, although one may say that it for example grows in a certain sense when I add additional wood, strictly speaking does not do so. Its growth is infinite ( $\alpha$ ư $\xi$ 416a15-18.

44 See Phys. II 1, 192b13-15.

45 For the fact that the different kinds of change are derived from the different categories, see Phys. II 1, 220b26-201a9, and V1, 225b5-9 and V2 in general.

46 See Phys. II 1, 192b13-15.

47 This can be seen for instance in de An. II 2 where the soul is explicitly called a source 
instance for certain changes with respect to quantity, quality, and place. ${ }^{48}$ This seems to be reasonable, since it is a fact that an animal like for instance a kitten obviously grows, regulates its body temperature and-at least at a certain point of its development-is capable of walking from the sofa to the feeding dish when hungry. As I will show later on, this, of course, does not mean that the cat in virtue of having a soul may be the source of all these different changes in an identical way.

As we have seen, this is different for inanimate things which do not have a nature. As an inanimate thing qua the respective thing that it is does not have a source of change within itself, it cannot cause or be responsible for its own change in this sense. That this is what Aristotle thinks is clear from De Motu Animalium 4, where he explicitly states that all inanimate or "lifeless things are moved by something else" and that "the origin for all the things moved in this way is something that moves itself." 49 The same claim is made again in $M A 6 .^{50}$ But there it is also stated that only living things can be responsible for the changes inanimate things undergo, for apart from certain other changes in the universe, like the eternal movement of the stars, for instance, and the changes caused by them, all changes are caused by living beings. ${ }^{51}$ This passage, therefore, shows that Aristotle thinks that in this way all changes undergone by inanimate things, apart from the abovementioned exceptions, can be traced back to a living being as the cause of the change. ${ }^{52}$ And this is plausible, since apart from what happens

$(\dot{\alpha} \rho \chi \dot{\eta})$ of the different kinds change and of activities specific to things that have life (see for instance de An. II 2, 413a20-25 and 413b11-13). In this way for instance plants have the source of their own growth within themselves (see de An. II 2, 413a25-28).

48 Apart from what I just said in n. 47 this becomes even more clear from PA I 1, 641b48. There it is stated that for each of the three non-substantial kinds of change that a living thing may undergo as a part of its life specific activities there is a corresponding part of the soul that may be considered as a source for the respective change ( $\iota\left\llcorner\dot{\eta} \sigma \varepsilon \omega \varsigma \dot{\alpha} \rho \chi \eta^{\prime}\right)$. In this sense, for instance, "of growth the origin is the part which is present even in plants, of alteration the perceptive part, and of locomotion some other part, and not the rational." ( $\alpha \lambda \lambda^{\prime}$

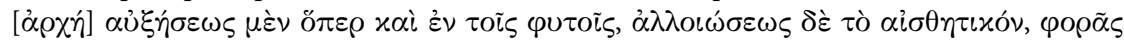

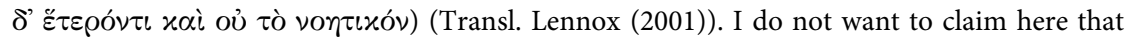
the soul is the only source for all the different changes a living being undergoes and that in this sense have their origin in it; yet, Aristotle clearly thinks that changes like growth and diminution, certain alterations and, of course, locomotion in a certain sense have their principle in the soul. I will say more on this later on in section 7.1.4.

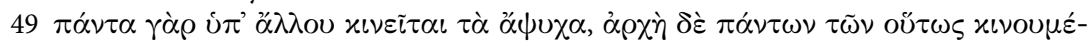

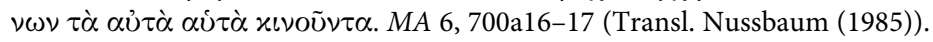

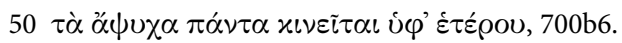

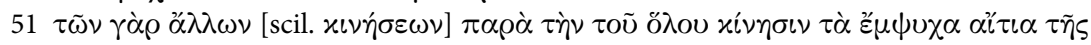

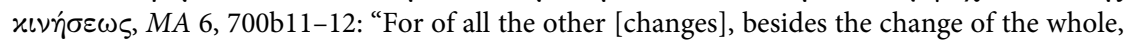
the living things are the cause of the change."

52 See MA 6, 700a6-12. 
in the superlunary sphere, only living beings strictly speaking can be sources of change, as only they can actually be responsible for initiating their own changes, unlike the inanimate elements whose movement depends in some way on an external agent (as Aristotle explains in Physics VIII 4). ${ }^{53}$ This, however, is also in accordance with the basic idea stated by Aristotle just two chapters before the discussion of the priority of locomotion in Phys. VIII 5; for there he argued that any kind of change is either self-caused by that which is undergoing this change, or that this change can be traced back to some other self-mover. ${ }^{54}$ The only things in the sublunary sphere that are self-movers, it seems, are living beings. As the passage from the $M A$ therefore pointed out correctly, all changes that do not have their cause in something from the superlunary sphere will necessarily have their source of change in a living being.

All this, of course, has implications for the interpretation of the argument as a whole, because it clearly shows that locomotion must be prior to the other non-substantial kinds of change not only with respect to living beings, but also to all other changes that have their cause in a living being. That is to say, if locomotion is prior with respect to all changes of which a living thing may be the source, then the same must be true for all other changes which are caused by this being. Accordingly, any change in magnitude that is caused either directly or through a number of intermediate steps by a living being must also in the end be preceded by locomotion. Thus, it is correct to say, at the very least, that locomotion necessarily precedes any change in quantity and quality that a living being undergoes in the sense stated above or that is undergone by something else in virtue of a living being's causing of this change.

\subsection{The reason for the restriction of the argument's scope}

This, of course, does not show that $\varphi$ oó is prior to change in quality and quantity in general, although this seems to be what is claimed at the beginning of the passage in 260a26-29, because, as we have seen, besides the changes that are caused by living things, there are still other kinds and causes of change in the cosmos.

However, as I said before, this is not what the argument is primarily about, although Aristotle does not make this explicit. Part of the project

53 As is pointed out in Phys. VIII 4, 255a5-7 and 255b29-31, the elemental bodies, which at least according to Phys. II 1,192b8-15, have a nature, cannot be called self-movers in the strict sense. For more on this see Nussbaum (1985), 322-323.

54 See Phys. VIII 5, 256a13-21 and 256b1-3. 
aimed at showing the primacy of locomotion is to compare locomotion to the other kinds of change in different respects, and here it seems that Aristotle, as we have seen, is focusing for some reason on the role locomotion plays in living things insofar as they may be the source of certain changes. This also explains why the substantial change of generation-in contrast to the following four arguments-is not compared to locomotion here, although it certainly will be necessary to make clear that change in place is also prior to generation if the thesis that locomotion has priority over all other kinds of change is to hold. ${ }^{55}$ But since a living being cannot be responsible for its own coming to be, generation is simply irrelevant to showing that locomotion is presupposed by any change of which the animal may be the source. What Wagner in his criticism therefore takes to be a weakness of the argument, namely its focusing on processes of growth and diminution in living beings, indeed seems to be necessary in order to show what Aristotle wants to show here. ${ }^{56}$ Aristotle has to focus on the special kinds of change in magnitude, since, as I will now show, it is unclear or might even seem wrong that locomotion is also prior with respect to these special cases of change. In what follows I will therefore present different reasons that may have compelled Aristotle to focus on quantitative change in living organisms in this first argument.

First of all it is important to see that the very fact that living beings by having a nature and a soul are responsible for their growth and alteration seems in a certain sense to create a problem for the claim that locomotion is primary, a problem that Aristotle has to face. For, one might think that growth and alteration in living things for this reason can occur independently of locomotion-after all, their nature and soul are sources of this living thing's own changes, and hence of their growth and alteration. Yet, it might then turn out that growth or alteration in such living beings is prior, or at least not posterior to locomotion, which would both contradict the priority claim as it is stated by Aristotle. If this really were the case, one could rightly object that locomotion against this background surely appears to be a bad candidate for the primary kind of change. I will now show that this possible objection first of all may seem to arise in particular with respect to plants or other non-locomotive animals and that this might make

55 Accordingly Wagner (1967), 688, is mistaken when he claims that it is clear for Aristotle that change in substance cannot be the primary kind of change since this process does not occur in the supra-lunar sphere. For this does not fit with the fact that Aristotle (as Wagner, 690, is well aware of!) in the fourth argument argues against the claim that generation is primary and also shows in the second argument that locomotion has priority over generation and corruption.

56 See Wagner (1967), 688. 
one think that Aristotle in this first argument is trying to establish that locomotion is primary specifically with respect to all changes that occur in living beings and accordingly focuses here on discussing the special case of organic change in quantity.

According to the De Anima a plant's soul has the nutritive capacity that, among other things, is responsible for the plant's growth. ${ }^{57}$ It is the nature of a plant to have such a source of its own growth within itself. And indeed it is a fact that we see plants growing, i.e. changing in magnitude. Yet a plant, does not have the capacity for locomotion, i.e. cannot move from point A to point B of its own accord. ${ }^{58}$ But if the plant is not even capable of causing a change in place, one might wonder in what way locomotion should be presupposed by and in this sense prior to the growth of the plant. The same case can be made for other living beings beside plants that do not have the capacity to move themselves from point $A$ to point $B$, such as for example animals like sponges. But in order to show that locomotion is primary in general among the different kinds of change, Aristotle needs to make clear that it is primary in the important case of changes that have their source in living beings. For, as we have seen, it seems that they are responsible for all changes in the sublunary sphere apart from those, of course, which have their source in superlunary causes. Accordingly, one might think that Aristotle by means of the first argument is attempting to show that change in place is primary in all living beings, although one could rightly object that some living beings do not even have the capacity to cause locomotion. If Aristotle is successful in rejecting what seems to be an objection, then it appears that, with respect to all changes caused by such sources, locomotion must nonetheless be prior to them.

Yet, there is a problem with thinking that this is what Aristotle intends to show by means of the first argument. The reason, as I will now show, is that although non-locomotive living beings have a nature, they strictly speaking cannot be considered self-movers. This becomes clear in the third of the three possible objections against the claim that change must always exist, objections that are stated in Phys. VIII 2 and that I have already mentioned in a previous chapter. ${ }^{59}$ In this objection-let us call it the third eternityobjection-Aristotle raises a problem that, as we will see, is related to the point in question in different respects and will help us to better understand Aristotle's motivation for focusing on cases of growth in living beings. The objection makes use of the fact that animals as self-movers can be observed to move suddenly from one place to another, although previously in a state

57 See for instance de An. II 2, 413a25-b1.

58 See de An. II 2, 413a31-b1.

59 See section 2.4.3. 
of rest and, one might think, not having undergone any prior change. ${ }^{60}$ The problem with this assumption is that it might suggest that-contrary to what Aristotle just stated in Phys. VIII 1-something $x$ may start to change, although it was neither undergoing a change before, nor was this sudden locomotion caused by some other cause external to $x$, such that the observed change in place appears to take place without a cause. ${ }^{61}$ From the answer presented to this problem in Phys. VIII 2 and VIII 6 only the following is of importance for my purpose at this point: Aristotle states that it is incorrect to assume that an animal prior to moving could have been in a state of perfect rest, although it might seem so at first glance. For, as he points out, living things, or at least parts thereof, are constantly undergoing certain changes, even when in what appears to be a state of rest. ${ }^{62}$ The changes an animal undergoes constantly include, for example growth, diminution and respiration ${ }^{63}$, i.e. such that are necessary for this being to sustain itself as a living organism.

Apart from this, however, in the third eternity-objection another point is discussed which poses a serious problem to what I have just presented as the reason for Aristotle's motivation in dealing with a restricted understanding of change in magnitude in the first argument for the priority claim. As I have stated, one might think that the first argument ultimately aims at showing that locomotion, with respect to the changes caused by a living being either directly or indirectly, is ontologically prior. Yet, in order to do so, it seems Aristotle needs to show that locomotion is prior in all living beings, including in less-obvious cases, like that of plants or other living beings that are not even capable of locomotion. Therefore, one might conclude, Aristotle in the first argument focuses on cases of growth that occur in living beings and shows that changes in quality and quantity as they take place in living things, including non-locomotive ones, necessarily involve some preceding locomotion, but only in the sense that something, yet not necessarily the growing or altering thing, needs to undergo a change in

60 For this third objection see Phys. VIII 2, 252b17-28, VIII 2, 253a7-21, and VIII 6, 259b1-20.

61 See Phys. VIII 2, 253a8-11 and VIII 6, 259b1-6.

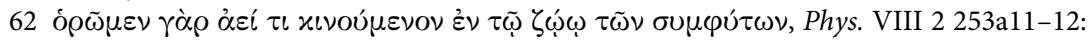
"for we observe that there is always some connatural part of the animal organism changing" (Transl. Morison (2004), 68) My understanding of this passage is essentially based on Morison (2004) who argues in his paper that the discussion of the third eternity-objection does not contradict Aristotle's view that animals are self-movers and that the orthodox view is therefore wrong which reads this passage as suggesting that Aristotle thinks that none of the changes animals undergo are actually self-caused.

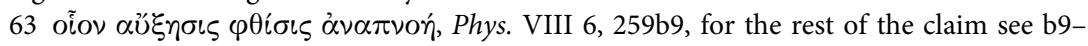
11. 
place; in this sense it would then be clear that locomotion is primary with respect to changes in non-locomotive beings as well.

Although the argument certainly would yield the stated conclusion, this cannot be Aristotle's reason for making it. For, in the discussion of the third eternity-objection he explicitly says that of the different changes that occur in living things only the change a living being undergoes with respect to place is a self-caused change, since the cause of the other kinds of change that an animal is constantly undergoing lies not in the respective living being but rather in something in its environment or at least something that in some other way was originally external to it. ${ }^{64}$ Therefore, only those beings that can perform locomotion in this sense are to be considered selfmovers. But since only self-movers, can serve as the cause of other changes, plants and all other non-locomotive living things cannot directly cause other changes that occur in the sublunary sphere ${ }^{65}$ Hence, what seems to be an objection against Aristotle's priority claim at first glance turns out not to be. Consequently, there must be another reason why Aristotle focuses on cases of natural growth in the first part of the argument.

Against the background of what we have just seen, it seems that there is another way in which the first argument could be read as Aristotle's answer to what might be another possible objection to the priority claim. The objection is this: although there is no problem with non-locomotive living things, since they are not self-movers, a similar case could be made with respect to beings that are self-movers. For living beings that are self-movers grow in a similar manner to that of plants, and therefore one might think that growth is in some sense prior to locomotion in such living beings, which again would contradict the priority claim. This would be a real problem, since it would show that locomotion is a poor candidate for the primary kind of change with respect to living things that are self-movers, which as we have just seen, are central to the occurrence of all change in the

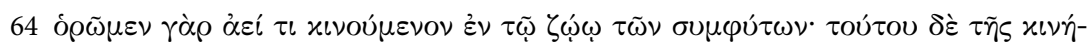

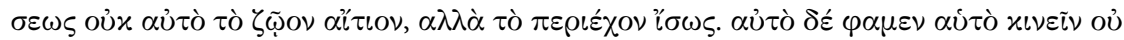

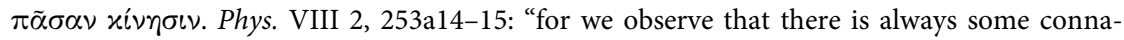
tural part of the animal organism changing, and the cause of the change of this is not the animal itself, but, perhaps, its environment. Moreover, we say that the animal itself originates not all of its changes but [only] its locomotion" (Transl. Morison (2004), 68). This thought is reiterated in Phys. VIII 6, 259b6-7. For reasons why Aristotle indeed holds the view that animals with respect to their locomotions are self-movers in the strong sense see Morison (2004), 71-78.

65 This is clear from the discussion in Phys. VIII 5, where Aristotle states that any change may be traced back to a first mover who causes this change and that this must be a selfmover. As we have just seen, however, non-locomotive beings are not self-movers. See Phys. VIII 5, 256a13-21, and 256b1-3. 
sublunary sphere that is not caused by some superlunary source of change. Accordingly, the priority claim would not hold for any of these changes.

One might conclude that the aforementioned problem exists, since in the discussion of the third eternity-objection it was pointed out that one of the changes that is always occurring in animals-even when they do not perform locomotion and are in a state of rest in this respect-is growth. ${ }^{66}$ But if growth is indeed occurring constantly in animals, it would be a much better candidate for the primary kind of change in living beings than locomotion, which only occurs from time to time. Growth occurs throughout the process by which every living thing comes to be, and as we have seen it is explicitly stated in Phys. VIII 6 that it even occurs when animals seem to be in a state of rest. If this is true, then Aristotle indeed needs an argument which shows that not growth, but locomotion is primary in living beings that are self-movers, which then would be the reason why Aristotle restricts the first argument to cases of organic change in magnitude; for, again, this argument shows that any occurrence of such a change in living beings presupposes that some locomotion has taken place beforehand.

But upon deeper reflection it becomes clear that this, too, may not be Aristotle's motivation for presenting the first argument. First of all it seems that growth cannot occur constantly, for then anything that grows, one might think, would do so ad infinitum, which strikes not only Aristotle as absurd. But in Aristotle's discussion of growth in GC I 5 it seems that he nonetheless thinks that growth in some sense occurs all the time, yet without the growing subject, a man for instance, ending up being a giant. As we have seen in my reconstruction of the first half of the first argument, growth takes place in virtue of something being added to that which is growing, something which needs to be transformed in order to become a part of the body. As stated in GC I 5, Aristotle seems to think that in living beings there is a persistent cycle of new material being incorporated into the body, and of older material leaving it, or as Aristotle puts it with respect to the process in which a portion of flesh is incorporated into the body, "some flows away and some comes in". ${ }^{67}$ This assumption is also very plau-

66 See p. 61, n. 63.

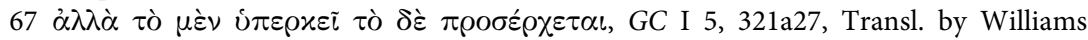
(1982) with mod. That this is the idea underlying this statement is pointed out by Williams (1982), 110, who in his commentary states that "the living eye will be subject to a constant renewal of its matter" and in this sense changes persistently by something flowing away and something else coming in new. This view is shared by Buchheim (2010), 356-8, who points out that Aristotle in this passage is referring to the idea of an equilibrium of acceding and departing material in living bodies, or, to be more precise, of a "Fließgleichgewicht ständig werdender und vergehender Stoffe, aus denen ein lebendiger Organismus sich zusammensetzt" (357). 
sible from today's point of view: a living being's body is renewed part by part in its lifetime several times over, in order to prevent decay. But for this reason one might also think that growth really occurs in this way all the time without the subject actually increasing in size, since for material that is added, other material is taken away.

Yet, even if Aristotle indeed seems to think that this process is going on in living beings, this does not imply that it is a process of growth and hence that growth is always occurring in living beings. For, as Aristotle points out in GC I 5, the process of material being added to the respective thing is not only a part of growth, but also of nutrition. ${ }^{68}$ Yet, in contrast to the process of nutrition, Aristotle clearly does not think that growth goes on constantly, for "a thing is nourished as long as it is maintained in existence even if it gets smaller, but is not always in process of growing." ${ }^{\prime 29}$ The persistent process of material 'flowing out' and new matter coming in therefore may only be the necessary function of any self-sustaining living organism, a function called nutrition, which, as Aristotle points out, despite being closely related to growth, is not identical with this process. ${ }^{70}$ There is no reason to assume then that growth is always occurring. It certainly is one of the processes that may occur alongside other important processes that an animal undergoes constantly while in a state of rest. Therefore, the fact that growth as stated in the third eternity-objection is one of the processes that, taken together, are always occurring when an animal seems to be at rest is not a problem for the priority claim, for this does not imply that growth is going on constantly and therefore growth may not be a better candidate for the primary kind of change than locomotion.

But as I will now show, the discussion of this last point has brought us closer to what Aristotle's motivation really is for giving the first argument and for focusing on non-substantial changes as they occur in living beings in the first half of it. For there is still one more reason to think that growth in living beings might be prior or at least not posterior to locomotion, which, as I have already stated, would contradict the priority claim. Again, the solution of the third eternity-objection in Phys. VIII 2 and 6 states that when an animal seems to be in a state of rest, i. e. is not undergoing locomotion, it, in fact, is undergoing different changes, at least with respect to some of its parts. Accordingly, when an animal causes itself to change in place, this locomotion is preceded by changes that occur in the state of rest pre-

68 See GC I 5, 320a20-27.

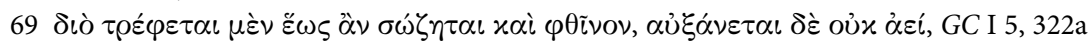
24-26. Transl. Williams (1982).

70 See GC I 5, 320a25-26, where Aristotle points out that nutrition (

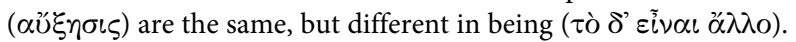


vious to the locomotion, and one of these changes that obviously may occur prior to this act of locomotion, as we have seen, is growth. In this sense growth-but also all the other changes the living being undergoes in this state of 'rest' - is prior to this locomotion. Moreover, one could even go a step further and say that, at least in certain cases, without these changes locomotion could not occur. For, as Morison has pointed out in his discussion of the passage from Phys. VIII 2 and 6, Aristotle thinks for instance that these changes are necessary in a sense for a sleeping animal to wake up and start to change place: ${ }^{71}$ the animal, after having ingested some food, digests the food while sleeping and distributes the nourishment to the respective parts of the body. Growth may occur, one might add, but after the distribution the animal wakes up and performs locomotion. ${ }^{72}$ If this is the case, then one indeed might raise the objection that this example clearly shows that locomotion in living beings certainly does not have primacy. As I have already said before, this would be a serious problem for Aristotle's priority claim, as it then would not hold with respect to all changes that have their cause in sublunary sources of change, since animals, as the only proper self-movers and hence as the only proper sources of chains of change, are central to those changes. Aristotle, therefore, clearly needs to provide an appropriate answer to this objection. However, this answer, as I have shown, is presented in his first argument. There it is made clear that any growth, diminution, and alteration, when they occur in living things, necessarily presupposes some preceding locomotion; but, as I said before, this does not need to be the locomotion of that which grows, and it suffices for Aristotle to show that none of these other changes can occur without some change in place in order to show that locomotion is primary among the three kinds of non-substantial change.

That this is Aristotle's motivation for presenting this specific argument, is of course not clear at first glance from the passage in which the argument is stated, when viewed in isolation. Aristotle does not explicitly formulate there what I take to be the possible objection against the priority claim that he is thinking of. But a reader who has the discussion of the third eternityobjection and the solution that I have just outlined in mind, and who is now confronted with the claim about locomotion's general priority indeed might wonder how this claim fits with the fact that the self-caused locomotion of an animal is preceded by, and according to the discussion might in some cases even be caused by, these other changes that occur in animals as self-sustaining organisms; after all, the solution to the third eternity-objection in Phys. VIII 6 is given only two Bekker pages before the presentation

71 See Morison (2004), 69-70.

72 For this example see Phys. VIII 6, 259b11-13. 
of the first argument for the priority of locomotion in Phys. VIII $7 .^{73}$ And, as I have stated in the introduction, the discussion of the priority claim is essentially connected with the theory developed in the first six chapters of Book VIII, according to which change needs to exist eternally and there must be a first eternal unmoved mover to which all changes in the universe may be traced. Aristotle thus rightly thought that it is important to deal with this objection, which arises from the discussion that was just completed in Phys. VIII 6. Therefore he starts with this rather specific argument before going into the details of the more general arguments for locomotion's priority. This is made still clearer by the fact that the argument offers a tailor-made solution to the objection that is raised against the priority claim: the way in which change in magnitude and quality is explained makes it obvious that Aristotle is clearly referring here to processes of change that occur in living beings.

For the aforementioned reasons it is therefore correct that the argument does not show that locomotion is primary to all kinds of change, but as we have seen, this is because it gives an answer to a specific objection which, if not faced would have seemed to contradict the priority claim. That the argument is so specific is not a problem, since the argument needs to be considered as one of many steps towards the goal of showing that locomotion is primary to all kinds of change. And, in fact, this argument is the first of five arguments that are supposed to establish locomotion's general priority and, hence, to show that this must be the kind of change which is caused directly by the first unmoved mover.

This is also what one has to have in mind when reading the corollary stated after the argument (260b5-7). Here the claim is made that if, as Aristotle argued in the first two chapters of Phys. VIII, change is eternal, then locomotion, as the primary kind of change, must also be eternal. But from the fact that alteration and change in quantity presuppose change in place only in the restricted sense that something must change place before an animal can engage in alteration or growth, it does not follow, of course, that locomotion must be the eternal motion. Aristotle is certainly aware of this, for otherwise he would have stopped after the first argument, as there would be no need to present four more arguments for the priority claim. In addition, as I already mentioned, nothing has been said thus far about the relation between change in place and change in substance, i.e. generation and corruption; but this, as we shall see, will be done later on. The argument presents one of the reasons why locomotion is correctly called primary and therefore-from what we have seen so far-is a good candidate

73 The last discussion of the third eternity-objection is stated at VIII 6, 259b1-20, while the discussion of the first argument for the priority claim starts at VIII 7, 260a26. 
for the kind of change that is eternal and has its direct source in the first unmoved mover.

The way in which I think the corollary should be read then is this: what we have seen in this argument, namely the fact that alteration, growth and diminution presuppose locomotion in the manner described, is one expression of the fact that locomotion is primary. If change is eternal and if locomotion indeed has priority over the other kinds of change-and the argument shows that we have very good reasons to think so-then locomotion, as the primary kind of change, must also be this eternal change. ${ }^{74}$

\subsection{The sense of priority}

Now that this has been made clear, it is important to understand which sense of priority with respect to locomotion this argument establishes. For as we know from the treatment of priority in Cat. 12 and Met. V 11 the word prior $\left(\pi \rho\right.$ có $\left._{\varepsilon} \rho \circ \nu\right)$ is used in a number of different ways. Aristotle himself does not use any specific name for it here, nor does he say which of the different senses of priority is established in this context, but merely claims that change in place, which we also call locomotion, needs to be 'primary', without adding any further qualifications. ${ }^{75}$ This is not the case for the last three of the five arguments, for which Aristotle explicitly points out which kind of priority he thinks each of the arguments shows with regard to locomotion. ${ }^{76}$ Yet, in what sense Aristotle thinks locomotion is shown to be prior by this argument can be seen by the way in which the relation between the three types of non-substantial change is characterised in the argument.

We have seen that locomotion is prior to the other two kinds of non-substantial change in living beings in the sense that locomotion needs to precede the other two in order for them to occur. Therefore, one might think that the kind of priority discussed here is temporal priority, since locomotion, as I have shown, in fact must take place before the alteration occurs and hence before the change in magnitude. Yet, this is certainly not the

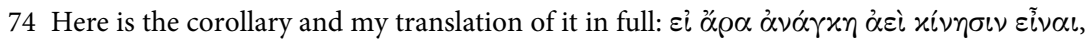

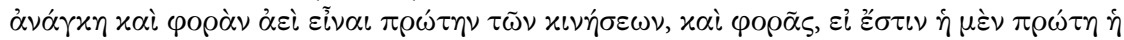
$\delta$ ' $\delta \sigma \tau \dot{\varepsilon} \rho \alpha, \tau \dot{\eta} \nu \pi \rho \dot{\omega} \tau \eta \nu$. Phys. VIII 7, 260b5-7: "Therefore, if there always must be change, then locomotion as the primary of the changes must also always be, and of locomotion, if there is a primary and a secondary kind, the primary one."

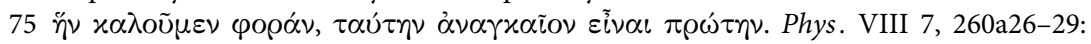
"the one which we call locomotion must be primary."

76 See Phys. VIII 7, 260b16-19. 
most important way in which locomotion is prior, according to the argument. For what Aristotle seems to emphasise in particular is that without alteration there is no change in magnitude and without locomotion, again, alteration cannot come about. ${ }^{77}$ This stresses the fact that the occurrence of locomotion is a necessary requirement for either of the other two kinds of change in living beings, i.e. they cannot occur without it. In this way the sense of priority shown here seems to be one that is also discussed in the third argument for the priority of locomotion and which I will call ontological priority in this context. ${ }^{78}$ Something $x$ is ontologically prior to $y$, if and only if for $y$ to be there must be $x$, but not vice versa. ${ }^{79}$ In other words, $y$ cannot be without $x$, while $x$ can be without $y$. This kind of relation between $x$ and $y$ might be described as an asymmetric relation of ontological dependency. This fits very well with what I just said: locomotion has ontological priority over change in quality and quantity, since the latter two cannot exist without the former. Yet, although Aristotle has clearly shown this, and in which sense this is the case, he has not said anything explicitly about the fact that locomotion does not presuppose the occurrence of any of the other kinds of change. ${ }^{80}$ But this is not entirely clear, because it seems there are cases that show that locomotion also depends on the occurrence of some other kind of change.

For instance, one might say that it is necessary that I eat food and digest it in order to be able to walk around. For, if I do not eat I will at some point become too weak to walk around. As Aristotle has shown, the digestion of food necessarily involves an alteration, so that it seems that locomotion in this sense cannot occur without it. Moreover, something similar seems to hold true with respect to growth: the fact that living things need to develop muscles and limbs, i. e. need to grow in order to be able to move at all, also seems to suggest that locomotion depends on this other kind of non-sub-

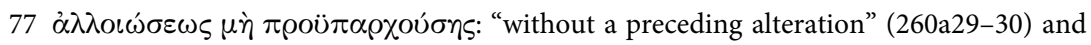

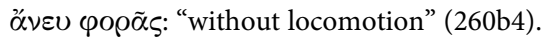

78 See Phys. VIII 7, 260b17-19. For my discussion of the third argument see chapter 5, for Aristotle's explanation of this way of priority in Phys. VIII 7 see section 5.4.1.

79 Also Simplicius expresses this view in In Phys. 8, 1265, 16-20, where he states that in

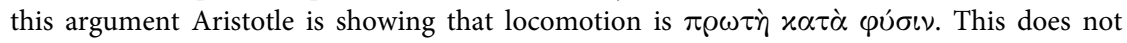
refer to the kind of priority for which the fifth argument (261a13-23) according to Aristotle explicitly argues, namely for priority in nature ( $\tau \tilde{\eta} \varphi v ́ \sigma \varepsilon \iota \tau \rho o ́ \tau \varepsilon \rho o \nu)$ and in essence ( $\varkappa \alpha \tau^{\prime}$

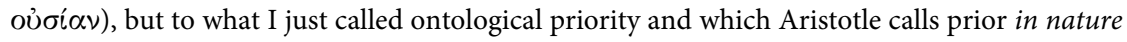
(and in essence) and assigns it to Plato in Met. V 11,1019a1-4, namely the one according to which $x$ is prior to $y$, if and only if $x$ can exist without $y$, but not vice versa. This is also the kind which is presented in Cat. 12,14a29-35, as the second kind of priority.

80 Simplicius, In Phys. 8, 1265, 17-19, clearly thinks that Aristotle shows in the argument that locomotion does not depend on the occurrence of other kinds of change, however, he does not explain how exactly this is supposed to follow from what is said by Aristotle. 
stantial change. ${ }^{81}$ In both cases indeed locomotion would not occur without a preceding change in quality and quantity. This, however, does not contradict the claim about locomotion's priority, nor does it show that a change in place always presupposes a preceding change in quality or quantity. For, if locomotion, as the argument has shown, must always precede alteration and growth, then of course such cases of alteration and growth that may be necessary in a certain context for locomotion to occur also presuppose another locomotion. And to say that in general every locomotion presupposes alteration or growth would clearly contradict the assumption that the latter two always imply a previous locomotion. Therefore, neither change in quantity nor in quality can be a necessary prerequisite for locomotion in general, or, to put it in other words, there are-and according to the argument there need to be-instances of locomotion that do not depend on either of the two other non-substantial kinds of change. Furthermore, it is impossible for there to be any instance of the other two non-substantial kinds of change without a locomotion being necessarily involved. But this amounts to saying that locomotion may exist without change in quantity or in quality, while the converse certainly does not hold. Thus, it is correct to claim that locomotion has ontological priority over the other two kinds of change.

\subsection{Conclusion}

What has this chapter shown? First of all we have seen that the growth or diminishment of an organism, i.e. its change in magnitude, presupposes a preceding alteration, and this alteration again presupposes a preceding locomotion. In consequence it became clear that the occurrence of both alteration and change in magnitude in living beings requires that locomotion take place beforehand. As we have seen, this does not necessarily mean that the subject of the respective change in quality or quantity changes in place, but that something which may or may not be identical with the subject of these changes needs to undergo locomotion in order for growth, diminution, or alteration to occur.

The fact that the argument shows primarily that locomotion has priority over the other two non-substantial kinds of change that occur in living beings turned out not to be a problem; rather it became clear that the argument, as the first of five arguments for locomotion's primacy, in fact focuses

81 For the fact that locomotion belongs only to those living beings who are about to reach or already have reached the end of their development see Phys. VIII 7, 260b32-33 and 261a14-19. 
on rejecting a possible objection against the priority claim, namely that growth, by being one of the basic processes living beings undergo as selfsustaining organisms, seems to precede locomotion or even might be necessary for this kind of change to occur in general. But by showing that the contrary is true and that change in place is necessary for alteration and growth to occur in living beings, I have also shown that locomotion, in virtue of being prior to the changes caused by living things, is also prior to all other changes caused by living beings that are self-movers, i.e. to all changes in the cosmos apart from those that are caused by superlunary phenomena.

In showing that locomotion must precede any change in quantity or quality that occurs in a living being, but also that the converse does not hold, Aristotle establishes that locomotion has what one might call ontological priority over the other two kinds of non-substantial change in living beings, and accordingly over all changes caused by living beings that are self-movers. In this way the argument presents an important reason for locomotion's primacy, which finds its expression in the fact that locomotion must precede the other kinds of change in the sense stated above. The argument, therefore, may be considered a successful one, though in a different sense than one may expect at first glance. The discussion, however, has also made clear that more arguments are necessary if the truth of the priority claim is to be established. 


\section{Locomotion necessarily accompanies each of the other kinds of change, but not vice versa}

\subsection{Overview}

Immediately following the presentation of the first argument, the second argument is introduced. It is stated in the following lines:

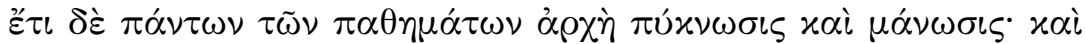

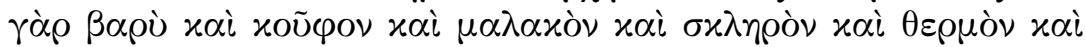

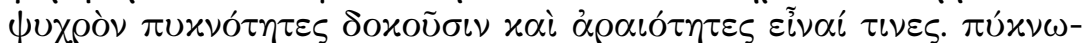

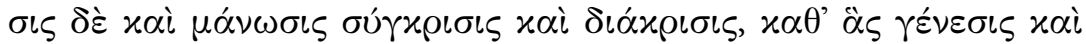

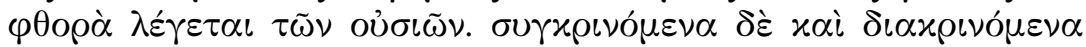

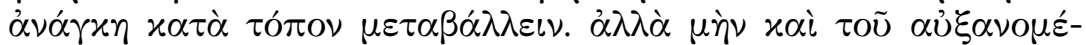

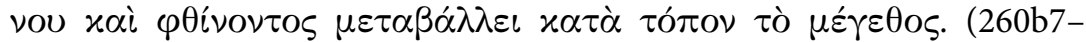
15)

But further, a source of all the affections is condensation and rarefaction. For also heavy and light and soft and hard and hot and cold seem to be some kinds of density and rarity. But condensation and rarefaction are aggregation and segregation, on the basis of which we speak of generation and corruption of substances. But what undergoes aggregation and segregation necessarily changes in place. Surely, also the magnitude of what is growing and diminishing changes in place.

This argument shows that any change in quality, substance, or quantity involves change in place in the sense that undergoing any of the three aforementioned kinds implies that a part or parts of the respective subject change in place. Although locomotion is a necessary concomitant of all of the other changes, the converse does not hold: locomotion is not necessarily accompanied by any of the other kinds. Or, to put it more simply, Aristotle shows that whatever undergoes a change in quality, quantity, or substance, also necessarily changes with respect to place in a sense, while there is no need for the subject of locomotion to change in any of the other respects. Since in this sense none of the other three kinds of change can occur without the involvement of locomotion, while locomotion, in turn, does not necessarily depend on any other type of change, this argument shows another way in which locomotion has ontological priority over the other 
kinds of change. ${ }^{1}$ Yet, it is important to emphasize that attributing to locomotion this kind of priority, contrary to what has been stated in the literature, in no way implies that any other kind of change can be reduced to locomotion.

In order to show all this, I will argue, Aristotle focuses on the processes that occur on (what one might call) the material level when each of the different types of change takes place. In this way Aristotle demonstrates that locomotion is the primary kind of change, as it is an ineliminable part of every other kind of change, but at the same time he does not argue that the remaining kinds of change are reducible to locomotion, since change in place is not the only explanatory factor needed to understand all of the different types. Accordingly, he rejects an assumption held by some of his pre-

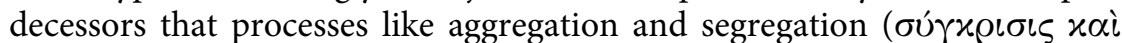
$\delta \iota \alpha ́ x \rho \iota \sigma \iota)$ are more important than and prior to locomotion in the sense that they are responsible for every change that occurs in the cosmos.

The passage at first glance seems to be problematic to the reader of Aristotle, as certain assumptions made here appear to clearly contradict basic premises of Aristotle's philosophy and a non-Aristotelian terminology seems to be employed. Because of this it was argued that in these lines Aristotle is not presenting his own theory, but rather is arguing from his predecessors' point of view. ${ }^{2}$ However, I will present reasons that strongly suggest that this argument needs to be read as Aristotle's own.

As I see it, the argument consists of three sub-arguments. ${ }^{3}$ The first shows that what undergoes a change in quality (alteration) needs to change in place. The second argues that the same is true for the subject of a substantial change (generation and corruption), and the third that the subject of change in quantity (growth and diminution) also necessarily changes with respect to place. I will now present a detailed examination of each of these three arguments. I will proceed in inverse order, starting with the last one on the relation between change in quantity and locomotion (4.2), fol-

1 As we have seen in my discussion in section 3.6, $x$ is ontologically prior to $y$, if and only if for there to be $y$ there also must be $x$, but not vice versa.

2 See for instance Philoponus, In Phys. 8, 896. Aquinas, In Phys., L. VIII, 1.XIV, 1089, thinks that most of this argument is based on the probable assumptions of earlier philosophers ("secundum quod erat probabile ex opinione aliorum philosophorum"). See also Wagner (1967), 688, and Graham (1999), 122-123. Zekl (1988), 289, n.114, at least takes 260b7-12 not to be stating an Aristotelian view. On the other hand, Themistius, In Phys. 8, 225, 26-226, 7, Simplicius, In Phys. 8, 1266, 10-1267, 28, as well as Ross (1936), 709, Cleary (1988), 81, and Morison (2002), 14-15, basically seem to take the argument to present Aristotle's own view.

3 Accordingly, I do not agree with Graham (1999), 187, who takes Aristotle to present one single argument for the claim that locomotion is prior to change in affections, as his reconstruction of the argument in the appendix shows. 
lowed by an analysis of the second (4.3) and the first argument (4.4). In a last step I will summarize the outcome of my discussion and evaluate to what extent the second argument taken as a whole shows the priority of locomotion over the other kinds of change (4.5). In the course of my inquiry it will be necessary to look at selected passages from other works by Aristotle, especially from his De Generatione et Corruptione, since without an acquaintance with these passages the second argument for the priority of locomotion cannot be properly understood.

4.2 What changes in quantity changes with respect to place

\subsubsection{Overview}

The third of the three sub-arguments aims at showing that whatever undergoes a change in quantity necessarily changes with respect to place in some sense. This means that growth and diminution must always be accompanied by locomotion, but not vice versa. From this it follows that locomotion has ontological priority over change in quantity, since in this sense any change in quantity depends on this concomitant change in place, while the occurrence of locomotion does not entail any quantitative change. In my view, the reason for this claim is that in growing or diminishing, the subject's parts change in place so that the whole may also be said to change in place in a certain sense, namely with respect to its parts, while, as my discussion will also make clear, the fact that something undergoes a change in place does not ipso facto entail any other change. I take this idea to be of utmost importance for making sense of the second argument as a whole, since, as I will show, the way in which the relation between change in place and change in quantity is characterised by Aristotle, may serve as a paradigm for relating locomotion to change in quantity and in substance.

In order to show this I will proceed as follows. By making use of passages from Phys. IV 4 and GC I 5 I will explain in what way it is basically correct to say that what grows or diminishes changes in respect of place (4.2.2). This will be followed by a further elaboration of this claim, which will lay the groundwork for a discussion of certain problems that this thesis seems to imply. This discussion, I will argue, leads to a substantial claim about locomotion, namely that what changes in place need not change the inner spatial order of its parts in any way (4.2.3 and 4.2.4). Finally, I will explain that although change in quantity is characterized as change with respect to place this does not, as one might think, lead to a reduction of change with respect to quantity to that with respect to place, which clearly would contra- 
dict assumptions fundamental to Aristotle's theory (4.2.5). I will conclude by summarizing the results of this section (4.2.6).

\subsubsection{What is growing moves to a larger place}

After having claimed that the subject of every change in quality or substance undergoes a change in place, Aristotle ends the passage with a statement about change in quantity and its relation to change in place. ${ }^{4}$ In this very brief remark-consisting of only one and a half lines-it is stated that "surely, also the magnitude of what is growing and diminishing changes in place." ${ }^{\prime 5}$ As with subjects that undergoe changes in quality or in substance, the subject of change in quantity also seems to undergo a change with respect to place. The reason for this claim is that $x$ 's magnitude ( $\mu \varepsilon \dot{\gamma} \varepsilon \theta 0 \varsigma$ ) in either growing or diminishing changes in such a way that the place which $x$ occupied before its change in quantity differs from the one it occupies afterwards. Even though Aristotle's explanation is rather short, this seems to be a reasonable assumption. The place of a full-grown oak tree, for instance, is different from the place it occupied at an earlier stage when still a shoot. The more the shoot grows, i.e. the larger it becomes, the more space it occupies. ${ }^{6}$ The same is true of any other thing that changes in size.

The passage from the Physics is not the only one in which Aristotle correlates change in quantity with change in place. In fact, Phys. IV 4 and GC I 5 seem to characterize growth and diminution in the same way. In order to understand the relation between change in quantity and in place it is useful to take a closer look at these two passages, which clearly suggest that this view is Aristotle's own, but which also tell us more about the relation between the two kinds of change.

4 As in the previous chapter, I take 'change in quantity' ( restricted to organic change in quantity, that is, to cases of growth ( $\alpha$ $\left.\xi_{\eta} \sigma \iota \varsigma\right)$ or diminution ( $\varphi \theta i \sigma \iota \varsigma)$ of things that have their own source of this kind of change within themselves, i.e. as these concepts are used in Phys. VIII 7, GC I 5 and de An. II 4. For more on this see section 3.4.

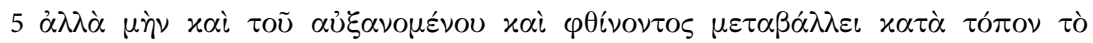

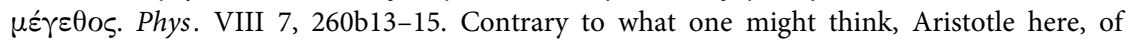
course, does not mean to say that it is primarily some magnitude which changes in place, but that the respective subject undergoes a change in place in virtue of having a magnitude.

6 This, of course, is not the most accurate description of the process of growth, which no doubt is more complicated than stated here, since such an increase in size, of course, does not necessarily have to go hand in hand with an increase in volume: suppose, for instance, that the shoot, although increasing in size with respect to its height, becomes thinner, so that its volume as a whole does not increase. Yet, for my purposes the description does what it is supposed to do, namely it shows that growth involves a change in place of the growing thing. 
Phys. IV 4 tells us first of all that growth and diminution, besides loco-

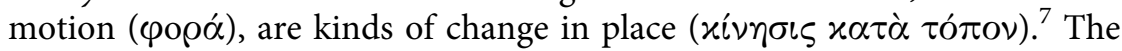
reason presented for this claim is that "also in growth and diminution something changes [in place] and what formerly was here, in turn has changed position into something smaller or larger."

There are two important points made in this passage from Phys. IV 4. (1) Change in quantity, besides locomotion ( $\varphi \circ \rho \alpha$ )́, is explicitly called change in place here by Aristotle. Hence, there obviously seems to be a way for him in which changes of a certain type may be considered as changes of another type in a certain respect. (2) The passage supports my understanding of the thought stated in the last sentence of the passage in Phys. VIII 7: by growing, the oak tree changes in place, since it now occupies more space. Or, to put it more generally, after growth or diminution has occurred, the place of the subject of this change is now different-its place has changed.

The passage in GC I 5 suggests something similar, but also tells us a little more about the sense in which growth and diminution need to be considered as changes with respect to place. ${ }^{9}$ It says that what undergoes a change in quantity, i.e. grows or diminishes, changes in place, yet with the provision that it does so "in another way than what is undergoing locomotion."10 Here, too, growth and diminution are considered as changes in place which, however, are different from locomotion. The reason for this, Aristotle tells us, is the following:

For what is undergoing locomotion changes place as a whole, but what is growing is like that which is beaten out; for while it remains its parts change in place $[\ldots]$, but the parts of what is growing always change to a larger place, but to a smaller one those of what is diminishing. ${ }^{11}$

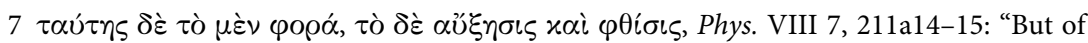
this [i.e. of change in place] there is locomotion on the one and growth and diminution on the other hand." For the full passage see 211a12-17. Unlike in Phys. VIII 7 and other passages, the term 'locomotion' ( $\varphi \circ \rho \alpha$ ) here is not applied in the usual sense, that is, as a synonym for change in place (

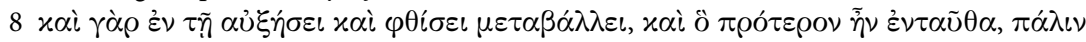

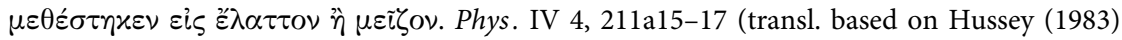
with mod.).

9 I shall only deal with GC I 5 insofar as it is of relevance for understanding the second argument for the priority of locomotion. For the discussion of the whole chapter see Code (2004).

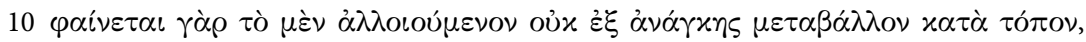

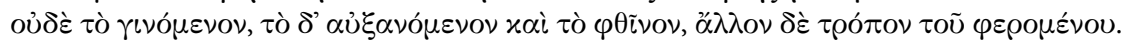
GC I 5, 320a17-19: "For it is clear that what is altering does not necessarily change in place, nor what is coming to be, but what is growing and what is diminishing [does so], yet in another way than what is undergoing locomotion."

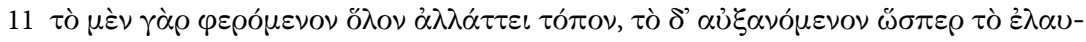


The difference between the two ways of changing in place is that what is undergoing locomotion changes with respect to place as a whole (ö $\lambda$ ov

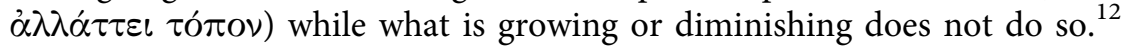
The change undergone by the latter, Aristotle tells us, is similar to some-

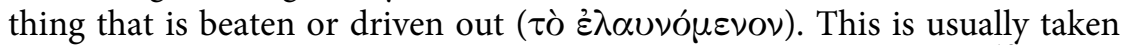
to refer to a piece of metal that is worked on while being fixed. ${ }^{13}$ As an example, one might think of traditional bowls or plates made of metal and ornamented by being "beaten out" with a hammer and chisel. The object on which the craftsman works remains in the same place because it is fixed, while parts of it are driven out during subsequent stages of the work so that its shape changes and the place occupied by the object so to speak expands in virtue of these parts' changing in place. ${ }^{14}$

For Aristotle something similar seems to happen in things that growe. g. in the case of the young oak tree. If the tree is not replanted it will basically remain in the same place, but its specific or primary place will change as the tree grows. 'Place' here is used in both a stricter and a looser sense it

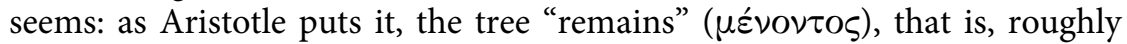
speaking the tree remains in the same place and does not leave its original position by moving away as would something undergoing a change in place as a whole. One could say that it still remains in its original place insofar as this place metaphorically speaking is incorporated by the tree's new place, or, as Code puts it, that which is growing "comes to occupy a larger place of

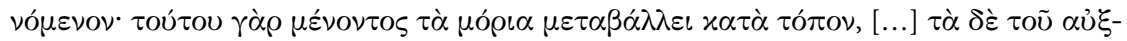

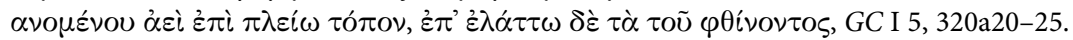

12 As in the passage from Phys. IV 4, locomotion here, too, does not stand for change in place in general as it usually does. But in GC $\varphi \circ \rho \alpha ́$ is not exclusively used in this specific sense, as is clear for instance from 1. $319 \mathrm{~b} 2$ in GC I 4, in which Aristotle tells us that a change

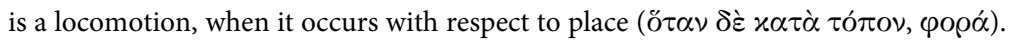

13 Neither Philoponus, Simplicius, nor Averroes in the Middle commentary on GC, expli-

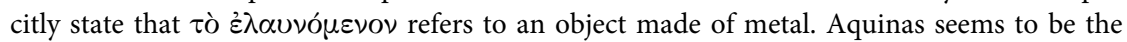

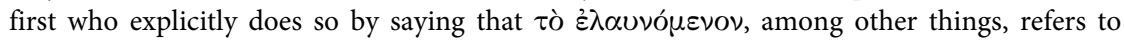
metal which by beating (metallum per malleationem) changes in the manner described (see In Gen., L.1, 1. XI, 85). Indeed $\varepsilon^{\lambda} \lambda \alpha u v \omega \omega$ was used in this sense (see LSJ, 529). There is a consensus among modern commentators on this question: Joachim (1922), 112-113, Williams (1982), 103, Code (2004), 173, Kupreeva (2005), 107, and Buchheim (2010), 337, agree on this reading, which also makes sense to me. Rashed (2005) does not seem to say anything about this.

14 Of course, as was noted by Philoponus (and Joachim (1922), 112-113, and Williams (1982), 103, following him), the case of the metal that is beaten out is analogous to that of an object undergoing growth only to a certain degree, and there are significant differences between the two processes (In Gen. 1, 71, 25-31). Yet, the analogy serves its purpose by showing in what way something may be said to change in place with respect to its parts, while the whole stays put. 
which its original place is a proper part."15 But strictly speaking, with respect to its primary place ${ }^{16}$ the tree changes in place, since the place it occupied before the process of growth differs from the place it occupies now. The reason for this change in place, Aristotle tells us, is that by growing, the parts of the oak tree change their place and each of them moves "to

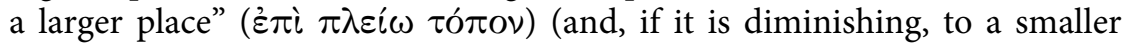

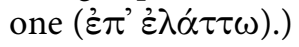

The GC-passage, like the one from Phys. IV 4, also supports this understanding of the relation that exists between change in quantity and change in place according to Aristotle. It confirms that (1) any subject of a change in quantity in a way undergoes a change in place, and that (2) the reason for this is that in undergoing a change in size the subject's magnitude becomes larger or smaller and therefore occupies a larger or a smaller place. Yet, GC I 5 also tells us that the subject does not undergo a change in place in the full sense, i.e. as a whole, but merely with respect to and in virtue of its parts.

In Phys. V 1 Aristotle expounds on what it means to say that something $x$ changes with respect to its parts and lists it as one of the ways in which something $x$ may be said to undergo a change, but clearly distinguishes it from change in the proper sense. According to Phys. V 1, I would be justified in saying that my body has changed from being sick to being healthy, because a part of it, for instance the eye or the chest, has been restored to health. ${ }^{17}$ In a similar way we often say that $x$ is changing although only one or several of its parts are doing so. According to the distinctions Aristotle draws in $\mathrm{V} 1$, he would say that properly speaking it is not the case that I (or my body) am becoming healthy, but since only a part of me is doing so, I am changing in this sense with respect to one or several of my parts ( $x \alpha \tau \grave{\alpha}$ $\mu \varepsilon^{\prime}(\eta)$. If something undergoes a change in this way, it is, properly speaking, not really changing, as it is not the subject of the respective change. For this reason Aristotle in Phys. V 1 states that in the subsequent examination he will leave out such cases and concentrate on those that count as instances of full change. ${ }^{18}$ These are changes in which what is said to be the subject of the change undergoes a change itself with regard to what it is. In this sense we say that in growing, a tree changes in place, because parts of it change their places. We speak like this in everyday language and, as we see in Phys. $\mathrm{V} 1$, Aristotle is well aware of this and makes use of it in the passage under discussion: in a sense what grows or diminishes changes in place, but only

15 Code (2004), 173.

16 The primary place of something $x$ according to Aristotle is the place which is "neither smaller nor greater" than $x$ ( $\left.\mu \eta^{\prime} \tau^{\prime} \varepsilon^{\prime} \lambda \alpha^{\prime} \tau \tau \omega \mu \eta^{\prime} \tau \varepsilon \mu \varepsilon i \zeta \omega\right)$ Phys. IV 4, $211 \mathrm{a} 2$.

17 See Phys. V 1, 224a23-26.

18 See Phys. V 1, 224b26-28. 
with respect to its parts, since in contradistinction to something that undergoes a locomotion it does not change in place as a whole. The growing thing's parts are changing in place ${ }^{19}$ and thus need to be taken as the true subject of the locomotion that occurs while the whole is growing. The subject of the growth in this sense is different from the subject of the locomotion that occurs at the same time. The actual subject of this locomotion is a part of the subject of the change in quantity.

If this is correct, then there basically seems to be a way in which Aristotle may rightly claim that whatever is increasing or decreasing in size in a certain sense is also undergoing a change in place. But, as I will now show, there is a problem with this solution. The problem is that there are cases of growth or diminution in which the subject seems to undergo change in place as a whole in virtue of its change in size. But this would clearly contradict Aristotle's claim that although a change in the size of a subject goes hand in hand with a change in place, this is only true in the sense that it does so with respect to its parts. In dealing with this problem we will get to know an important feature of locomotion, namely that the parts of what undergoes this kind of change strictly speaking do not need to change their spatial order in any way whatsoever. Or, to put it another way, it does not follow from the fact that something $x$ undergoes a locomotion that $x$ 's parts change, since change in place per se does not entail any other change.

\subsubsection{Change in place implies no change}

in the spatial order of the subject's parts

As we have seen, Aristotle thinks that what grows changes in place only with respect to its parts. However, it is also true that what changes in place as a whole does so with respect to all of its parts. Now, if something changes in quantity as a whole, then according to GC I 5 all of its parts also change in quantity. ${ }^{20}$

Suppose, for instance, an infant is growing as a whole. The change in place of that which grows, in this case of the infant, is the change in place of its parts. The change in place of the parts again occurs in virtue of their change in quantity. Now if the infant is growing as a whole, and therefore all parts of its body are growing, then it seems that all of these parts also need to change in place in virtue of their growing. Since the changes in place of the parts derive from the growth of the same, one might think that the change in place of all the parts comprises a change in place of the infant

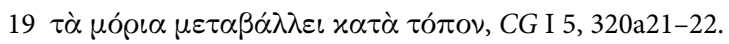

20 This is one of the criteria that according to GC I 5 need to be fulfilled for it to be said that growth or diminution has occurred. See GC I 5, 321a18-21. 
as a whole-after all, the parts of the infant's body grow in such a way that their growing taken together constitutes a change in quantity of the infant as a whole. Of course, it is not the case that if all parts of $x$ change, $x$ necessarily changes as a whole. But with respect to the stated example one needs to be able to explain why, contrary to what one might expect, the change in place of all the parts, which derives from their change in quantity, does not imply that the infant changes in place as a whole.

Therefore, let us suppose now that there is a case in which $x$ 's growing as a whole leads to a process in which all parts of $x$ change in place. Again, one may ask what the difference is between $x$ 's parts changing in size and the very same parts changing in place-for it is this difference that will explain why according to Aristotle $x$ in undergoing a quantitative change never undergoes a change in place as a whole, but merely with respect to its parts, even when all of $x$ 's parts are changing in place. Let us return to what Aristotle says about the difference between what he calls locomotion in $G C$ I 5 and the change in place that $x$ undergoes in virtue of growing. As we have seen, to say that $x$ is subject to the former means that it changes in place as a whole, while to say that it is subject to the latter implies a change only with respect to its parts. If I move my arm, i.e. change in place merely with respect to a part, it is clear that I do not change in place as a whole. But in the case in which all of $x$ 's parts change in place it is less obvious why this does not count as a change undergone by $x$ as a whole-especially as it derives from the change in quantity that $x$ undergoes as a whole.

Although he does not explicitly state this, Aristotle seems to be well aware of this difficulty and therefore says something more about the way in which the change in place of that which grows differs from the change in place that something undergoes as a whole. I have left out this additional explanation in the quotation thus far in order to focus in this preliminary investigation on the basic difference between the two ways in which something can change with respect to place. In the full passage from GC I 5 the case in which something changes in size and thereby undergoes a change in place with respect to its parts is contrasted with the case of the locomotion undergone by a perfect sphere revolving on its own axis. The sphere always occupies the same space and for this reason like the subject of growth seems

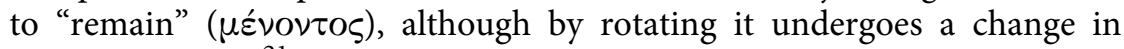
place as a whole. ${ }^{21}$ Now if the parts of the growing infant in our example were to change in place in the same way as the parts of the revolving sphere, then there would be no reason to say that the former is less a change in place as a whole than the latter.

21 For the explanation why the revolving sphere changes in place as a whole see Phys. VI 9, 240a29-b7. 
For Aristotle the crucial difference seems to be that the parts of the

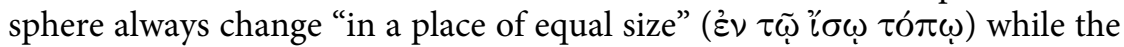
parts of what undergoes growth or diminution change to a larger or a smaller place, as by growing or diminishing they become larger or smaller. ${ }^{22}$ But in what way is this a reason for saying that the parts of the sphere form a whole with respect to their change in place, while the parts of the growing infant do not do so? In fact, one might argue that this confrontation of the two cases shows that growth and diminution are changes in place to a higher degree than the revolving sphere, for the place which the subject of the former occupies changes, while one might argue that the sphere's place does not change at all-indeed objections of this kind were uttered against Aristotle's claim that the revolving sphere undergoes a locomotion in the full sense. ${ }^{23}$

But let us return to our question. In what way is our argument supported by the fact that each part of the revolving sphere always changes to a place of equal size, while each part of that which changes in size changes to a smaller or greater place? It seems to me that an answer to this question will lead us to a criterion for distinguishing between a change in place as a whole and one with respect to its parts. Yet, in what way might this difference be responsible for saying that something $x$ undergoes one and not the other of the two ways of changing in place?

Contrary to what interpreters of this passage say, I would argue that the function of contrasting the two cases is to show that the inner spatial order between the parts of the sphere, and of what undergoes locomotion as a whole, does not change in any way, while the relation between the parts of that which grows necessarily changes, if the space that is occupied by the parts, and hence the whole, expands. ${ }^{24}$ Even if the proportions of that which is growing remain exactly the same throughout the whole change, the spatial relation of its parts changes. The distance between the infant's hands for instance increases when the infant grows as a whole, so that the spatial relation or order between the two hands changes. In growing, the parts of the body come to occupy another location in the whole to which they belong in

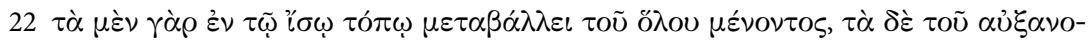

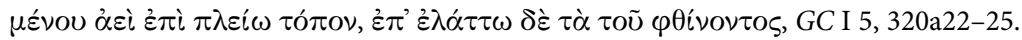

23 See Phys. VI 9.

24 Averroes and Joachim take this comparison to show that the change in place the growing thing undergoes is different from circular locomotion. According to their reading Aristotle operates in two steps: (1) he argues that the change in place of that which grows is different from rectilinear locomotion, then (2) that it also differs from circular locomotion (see Averroes, Middle Commentary, p.28), Joachim (1922), 112). Yet, this reading does not explain why for instance the problematic case I have presented does not count as a change in place as a whole, while, as I will show, my reading does. 
the sense that they no longer stand in the same relation to the other parts. The inner spatial order of the different parts changes in virtue of the whole undergoing a change in quantity-after all, this is exactly what growth and diminution are about. This, however, is the crucial difference between something that undergoes growth and diminution and something that undergoes a change in place as a whole, i.e. locomotion: all of the latter's parts change in place but nevertheless their inner spatial order and their relation to each other remain exactly the same.

In this sense, for $x$ to change in place as a whole means that all of its parts must change in place while remaining in the same inner spatial order, so to speak. In merely undergoing locomotion, a given part of the revolving sphere will always remain in the same relation to the other parts of the sphere. This is the reason why the sphere remains in a place of equal size, although all of its parts are changing in place, and why Aristotle contrasted this example with something that undergoes growth that does not change in place as a whole, but only with respect to its parts. The sphere retains its inner structure and the relation of its parts. This, however, is not only the case for the revolving sphere, but also for any other object that in undergoing one single motion changes from place A to B as a whole. Suppose I move a pen that I am holding in my hand from left to right in one perfect rectilinear motion: each part of it moves from its former to its new equalsized place without changing its relation to any of the other parts, i.e. the pen changes in place as a whole. Since with growth and diminution the situation is essentially different, Aristotle is correct to claim that both in a sense are kinds of change in place, though only insofar as the parts of their respective subjects move.

\subsubsection{A possible objection}

But is it really adequate to say that when $x$ undergoes locomotion, the relation of its parts always remains the same? There are many cases in which something undergoes a change in place as a whole, yet at the very same time its parts nonetheless change their relation to each other, and therefore seem to show that my interpretation must be wrong. The following case for instance appears to provide just such a counterexample. Suppose I walk from my office to the cafeteria to get a cup of tea. I do so by moving my legs. In the process of walking, however, the relation between my body's parts does of course change, although I certainly undergo a change in place as a whole and not only with respect to some of my parts!

I do not think that this is a problem for the interpretation of change in place as a whole that I have presented and the claims connected to it. Therefore, I will now discuss two strategies that might enable one to provide an 
answer to this objection. The first of these, namely the view that this objection would not arise if one were clear about the exact subject of the locomotion presented in the example, will not, however, solve the problem. Yet, as I will show, the problem can be solved by means of the second strategy, which is to show that this objection is based on mistaken assumptions about what change in place per se is responsible for.

The first way in which this objection might be faced would be to take a closer look at the change that is presented as one single change and that I undergo as a whole with respect to place in the example, i. e. my locomotion from the office to the cafeteria. For then it will become clear that this process of walking strictly speaking is not one single change, but may be analysed into a number of different changes of which the whole process of walking consists. The movement of my left leg, for instance, strictly speaking is not part of the locomotion that I undergo as a whole. This becomes clear if we ask what the subject of each of the two changes is. The subject of my left leg's movement is my left leg. We might say that my body undergoes a change when I move my left leg, yet only with respect to a part-just as in the previously cited example Aristotle provides in Phys. V 1, where the body is said to become healthy in virtue of the eye becoming so. ${ }^{25}$ The subject of my locomotion from the office to the cafeteria, however, is my body as a whole. According to the distinctions developed in Phys. V 1 one should say that my body undergoes at least two changes in place at the same time: one as a whole and another with respect to one of its parts, namely the left leg. But to say that two changes, each undergone by a different subject, are one and the same is absurd, even if they happen at exactly the same time and one of the subjects is a part of the other. Indeed, Aristotle shows in Phys. V 4 that one of the criteria for a change's unity is that the subject of the respective change be one and the same. ${ }^{26}$

Of course, it is true that there is a causal relation between my locomotion to the cafeteria and the contemporaneous movement of my leg, for without the latter I would not reach the cafeteria. But this fact does not make the moving of the leg a part of my body's locomotion as a whole. Leaving the causal relation aside, whether I move my left leg (or any other part of my body) plays no role in understanding what it means for my body to change in place as a whole. Therefore, it seems the objection is no objection.

Although what I've just said might appear to solve the problem at first glance, I will now show that it certainly cannot be considered as a way of successfully blocking the objection. The problem, as we have seen, was that with respect to the process of a man walking from place A to $B$ the inner spatial order of what seems to be the proper subject of the locomotion from

25 See my discussion of this example from Phys. V 1, 224a23-26, on p.77.

26 See Phys. V 4, esp.1. 227b31-228a1, 228a21-22. 
A to B changes, and hence the claim that locomotion basically does not entail any change of the inner spatial order of the subject's parts must be wrong. Yet, it seems that analysing what appears to be one locomotion into several locomotions might help us out of this impasse, for then, one might think, it will turn out that what was supposed to be a single locomotion from A to B actually consists of several locomotions, each of which taken by itself does not lead to a change in the inner spatial order of the subject's parts. But, as I will now show, the same case that was made with respect to my walking from A to B may be made with respect to the subjects of the changes into which my walking can be analysed, so that a more precise analysis of the change is no solution to the problem.

It is certainly correct that one needs to be clear in specifying the subject of each specific kind of change in place. As we have seen, this means for my locomotion from A to B that what seems to be one change in place must in fact be considered as (at least) three different changes in place, namely those of my two legs and that of my whole body. But this does not solve the problem, since the same argument that was made with respect to my locomotion from A to B, namely that it involves a change in the spatial order of my inner parts, may be made with respect to my right or left leg. For when I, as a human being that walks on two legs, change from place A to place B by walking, a change occurs not only in the relation between my legs and the other parts of the body, but also between the different parts of each leg: with respect to the left leg, for instance, the relation between the foot, the lower leg, and the thigh certainly changes. Granted, this might be solved by analysing the motion of the leg itself into different changes, say into the change in place of my thigh, of the lower left leg, as well as that of the foot; after all, the reason why we have joints is that in the process of walking the relation of the different parts of the leg should change. But this analysis also fails to solve the problem, since with respect to at least one of these three subjects of change, namely the foot, the same case may be made again: in stepping on the ground my foot deforms in such a way that its inner spatial order also changes; with respect to the other two parts of the leg one could add that even in this case muscles contract and sinews are stretched so that the order of their inner spatial parts does change in some respect. Again, one might be tempted to think that this problem may be solved simply by dividing the subject into the actual subjects of different changes until one finally arrives at a number of subjects, in our example the parts of a human body, with respect to which one might rightly say that the inner spatial order of each of these subjects does not change in any way. This, however, will never be the case, since it would presuppose that the continuous whole of the body (or of any other subject) could be divided into parts which are not further divisible into parts that can change their spatial relation to each other. This, however, as is well known, is impossible for Aristotle, as it pre- 
supposes that things would consist of atoms, an assumption that, as is pointed out for instance in GC I 2, leads to a number of serious problems, and is therefore untenable in Aristotle's view. ${ }^{27}$ Thus, what seemed at first sight to be an answer to the objection does not help us to deal with the objection after all.

What really solves the problem is clarifying the fact that the case of locomotion presented in the objection, i.e. my walking from A to B, is a special case of locomotion, namely that of a certain kind of animal, more specifically, a human being, and thus involves elements that do not belong to locomotion as such. A man performing locomotion usually does so by moving his limbs (thereby changing the relation in which its parts stand to each other). Yet, this in no way implies that this is the case for locomotion in general. If one merely thinks about my change in place from $A$ to $B$ and ignores the fact that I undergo locomotion as a human being-a living organism with arms and legs and with blood that circulates through the body-and in this sense abstracts from what is accidental and hence irrelevant to this change qua change in place, one can see that the change in the spatial order of the subject's part does not belong to locomotion per se; suppose I could move in space by hovering over the ground. Suppose, furthermore, in this way I could hover from place A to place B without moving in any other sense ${ }^{28}$ in one perfect rectilinear motion: as in the case of the pen, which we considered at the end of 4.2.3, in this case as well there is no reason to assume that any of my parts changes with respect to its inner-spatial order. The fact that this occurs when I walk from my office to the cafeteria is due to the specific way in which I as a human being move; but, again, locomotion per se does not entail any such change of the parts and it does not follow from the mere fact that something $x$ moves from A to B that $x$ 's inner parts change their spatial order. But another example suffices to show that the change of the inner spatial order of my parts when I walk has its reason in my specific way of performing locomotion and not in the nature of change in place as such. Suppose I would like to go out for a run, but since it is cold and raining outside I decide to exercise on the treadmill in my apartment. Thus, in moving my limbs on the treadmill in the fashion in which human beings usually do in order to run or walk from place A to B, I change the inner spatial order of my parts without ever leaving the place where I am performing this exercise.

It is clear therefore that locomotion per se does not entail a change in the inner spatial order of its subject's parts; the fact that in the aforementioned

27 For this discussion see GC I 2, 315b24-317a17.

28 Of course, in this example one also needs to ignore the fact while I am hovering over the ground, certain changes in the inner spatial order of my body's parts nonetheless occur, e.g. my blood circulates and so on. 
objection such a change occurs is due to the fact that a human being is performing locomotion and not that a change in place is occurring.

But our analysis of the objection has made it clear that the claim about locomotion not involving any change with respect to the inner spatial relation of its subject's part does not imply that in the course of locomotion the subject's parts do not change for whatever reason with respect to their inner spatial order; the claim is that change in place per se, as we have seen, does not necessarily entail that such a change of the inner spatial order of the subject's parts must occur, while this is the case for every occurrence of growth, and, as we will see later on, of each of the other kinds of change as well. Contrary to what one might have thought, therefore, the example of a man walking does not show that I am mistaken in my understanding of locomotion as a change in which strictly speaking the relation between the subject's inner parts change in no way, an understanding that I think underlies Aristotle's discussion of locomotion and growth in GC I 5 and Phys. VIII 7.

Confronting the change in place that occurs when something grows or diminishes with the locomotion of the revolving sphere thus helped us to spell out one of the features that make locomotion in the full sense so unique among the different kinds of change, namely that the inner structure of what undergoes locomotion as a whole is left completely untouched by locomotion. This insight is far from being trivial. For among other things it is because of this special character that locomotion is the only kind of change eternal things can undergo, which, as we will see later on, is another reason for its primacy, as the fifth argument for the priority of locomotion shows. ${ }^{29}$

\subsubsection{Compatibility with the irreducibility of the kinds of change}

As I have shown, Aristotle correctly claims that what changes in size in a sense also changes with respect to place. Yet, as pointed out at the beginning of this chapter, it is often assumed that the second argument does not present Aristotle's point of view, but rather that of his predecessors, especially of certain Presocratic thinkers. Those who make this claim, however, mostly base their hypothesis exclusively on what is said in the first and second sub-arguments and either ignore what is stated in the part on growth and diminution, or, at least in one case, assert that this is a more or less superfluous addition that does not really fit into the supposedly Presocratic context. ${ }^{30}$

29 For this see section 7.2.

30 For the latter see Zekl (1988), 289, n. 114, who claims that the part dealing with growth 
Yet, although this is not explicitly mentioned by any of the commentators of Phys. VIII, there nonetheless seems to be a way, one might think, in which Aristotle's claim that change in quantity in a sense necessarily involves change in place is problematic and might even contradict basic assumptions of Aristotle's theory of change, especially the one which I will call the principle of irreducibility of the kinds of change. But if the fact that change in quantity in a certain sense can be considered as change in place really might contradict this basic Aristotelian principle, then this problem surely needs to be addressed. The principle of irreducibility says that there are exactly four different kinds of change that are on a par and that cannot be reduced to each other. These four kinds of change, as we know, are change in quality, quantity, place and substance, and, as is stated for instance in Phys. III 1, derive their existence from "the categories of that which is" ${ }^{\prime 1}$, that is, are more than just arbitrary names for certain phenomena.

But if this is true one has to explain in what way it does not contradict the principle of irreducibility that growth and diminution are changes in place as Aristotle explicitly says in Phys. IV 4 and GC I 5. Part of the answer has already been given in my discussion above: change in quantity is not locomotion in the proper sense, as its subject changes in place only with respect to certain parts. However, the problem is not yet solved, but only shifted to another level. For the fact that what grows or diminishes merely changes in place with respect to its parts does not preclude the possibility that this change may be reduced-for instance by a Presocratic philosopher - to the movements of certain material parts, for example elements or atoms. ${ }^{32}$

First of all, Aristotle would-as he does in many places-reject the idea of the existence of indivisible constituents like atoms. But this argument would not suffice to reject this view in general. For the proponent of such a view, let us call him a reductionist, would agree to many of the things said so far. He of course would say that what changes in quantity changes in place. He would also agree with the Aristotelian assumption that if some-

and diminution obviously is a "Zusatznotiz" without giving any reason for his assumption. By contrast, Wagner (1967), 688, who at least admits that change in quantity is sometimes considered as change in place by Aristotle, does not state in what way the section on change in quantity does not fit into Aristotle's theory. Graham (1999) completely ignores the whole section on change in place and mentions it neither in his commentary (122-123) nor in his reconstruction of the argument presented in the appendix (187).

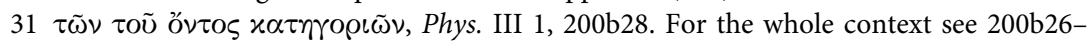
201a9. Something similar is said in Phys. V 2 in which the different kinds of xiv derived from the different categories.

32 I would like to thank Caleb Cohoe for pointing this out to me. 
thing grows, some additional material is added, while if something diminishes, something of what we call the change's subject is taken away. He would part ways with Aristotle, however, in claiming that this is all that happens: what we, for instance, call the growth process that an infant undergoes, is not a special kind of change, but merely the movement of the basic material parts of which the infant consists and those which are added in the process of growth. If this were the case, then the principle of irreducibility would clearly be violated, for then nothing besides change in place would occur.

The reductionist's understanding of growth indeed is compatible with the basic assumptions stated above. Yet, it does not necessarily follow from the fact that whatever changes in size also changes in place with respect to its parts. Because from what I have said here and in the previous chapter it has become clear that for Aristotle the process of growth in living beings is much more than the movement of the subject's material constituents. I can only give a rough outline of the reasons for this here, since a thorough treatment of this matter presupposes dealing with fundamental ontological assumptions that underlie both Aristotle's and the reductionist's views. For my purposes the following should suffice. The reductionist is not capable of explaining the core feature of change in quantity, namely that a substance increases or decreases in size by material either being added to or taken away from that which undergoes this change, while this subject nevertheless remains what it is. Let us return to the example of the growing infant. It is the infant's form, and not its matter, that is primarily responsible for its being an infant, i.e. a human being, although matter is necessary for the infant's being a human being as well. The reductionist basically reduces the infant, or any other substance, to its material constituents and neglects the form, which is an essential part of a hylomorphic composite. In other words, he is unaware of the fact that entities like human beings are more than-to put it boldly-mere heaps of matter, and are what they are only in virtue of their respective form. According to Aristotle, the problem with many of the earlier thinkers was that they took matter to be the only principle of nature and were not aware of the existence of another principle, namely form. ${ }^{33}$ Form, however, plays a crucial role in the processes of growth and diminution: what grows or diminishes does so with respect to its form, otherwise there is no reason for the subject to remain what it is and to fulfil its essence, i.e. the criteria that something needs to meet in order to belong to a certain class of beings. If an appendage like my hand grows and is to remain this same appendage with a specific function in the whole of the organism, it needs to increase in size in proportion to the rest

33 See for instance Phys. I 2, 194a18-21. 
of the body, and each part of it needs to grow according to the same proportion ( $\alpha \nu \alpha ́ \lambda o \gamma o \nu) .{ }^{34}$ In order to explain how this is possible, it surely does not suffice to say that some extra material is being added to my body and to my hand.

Therefore, the reductionist by reducing change in quantity to certain local changes of material that occur on the material level cannot account for change in quantity as it occurs in nature. As we have seen, Aristotle agrees that when something undergoes a change in quantity, then it necessarily also changes in place. Yet, he would add, this is not all and certainly not the most important thing to be said about change in quantity, if one is presenting a scientific explanation of this kind of change.

\subsubsection{Conclusion}

We have seen that Aristotle is correct in claiming that whatever undergoes growth or diminution, i.e. a change in quantity, changes with respect to place. Yet, this is not true in an unqualified sense, as what is changing in size does not change in place as a whole, but with respect to its parts. Change in place in this sense necessarily accompanies any change in quantity. It also became clear that if something changes in place in the strict sense, then all parts of it change in place without their inner spatial order being changed in any way, that is, without any other kind of change having to be involved. In comparison to growth and diminution locomotion is therefore prior and more fundamental in the sense that the occurrence of any such change in quantity necessarily involves locomotion, since that which changes in quantity must always change in place with respects to its parts, but not vice versa. Therefore, this argument has shown that locomotion more specifically has what one might call ontological priority over change in quantity insofar as no change in quantity can occur without change in place, while the converse does not hold.

All of this fits very well into Aristotle's theory of change and does not contradict his thesis that the kinds of change are irreducible. Hence, there is no reason to think that the part of the second argument that deals with the relation between change in quantity and change in place is not compatible with or does not represent Aristotle's own view.

34 See GC I 5, 321b28-29. 


\subsection{What undergoes generation or corruption changes with respect to place}

\subsubsection{Overview}

The second of the three sub-arguments is stated in the following lines:

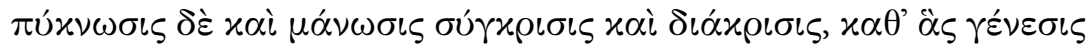

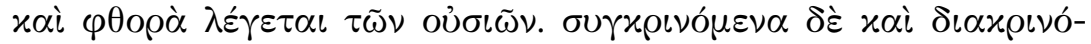

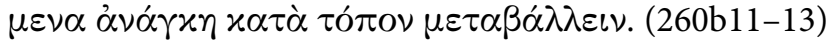

But condensation and rarefaction are [1] aggregation and segregation, on the basis of which we speak of generation and corruption of substances. ${ }^{35}$ [2] But what undergoes aggregation and segregation necessarily changes in place.

This argument is supposed to show that what undergoes a change in substance changes in place, which means that both generation and corruption are necessarily accompanied by locomotion, but not vice versa. This shows that locomotion has priority over substantial change in much the same way that it has over change in quantity, namely it is ontologically prior to change in substance. For, as with change in quantity, change in substance cannot occur without locomotion, while the converse does not hold. I take the following to be the basic structure of the argument:

(1) What undergoes generation or corruption undergoes aggregation, or segregation, or both.

(2) What undergoes aggregation, or segregation, or both also undergoes change in place.

(3) Therefore, what undergoes generation or corruption undergoes change in place. $(1,2)$

The core idea behind this argument, as I see it, is that the fundamental pro-

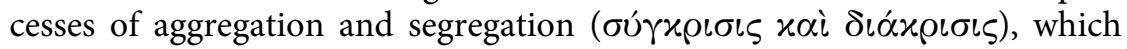
are an essential part of any process of coming to be or perishing, involve the locomotion of the basic material components of substances, i.e. of their elemental bodies.

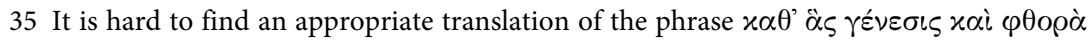

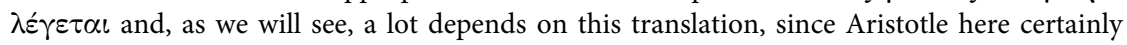
does not want to make the claim that generation and corruption are nothing more than this,

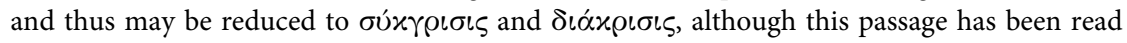
this way (see p.95, n. 62). See the discussion in Morison (2010), 93-94, for a similar usage of

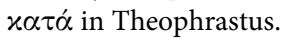


In order to show this I will now start with a detailed analysis of the passage, in the course of which I will proceed as follows. Against the background of certain passages from GC I 2 and the Meteorology I will first of all focus on showing that, contrary to what most interpreters of Phys. VIII say, it is Aristotle's own view that generation and corruption in a sense occur in virtue of aggregation and segregation. In examining his reasons for making this claim, I will argue that any change in substance for Aristotle necessarily involves an aggregation or segregation of the fundamental components of the respective substance (4.3.2). After that I will discuss the claim that any aggregation or segregation necessarily involves a change in place of that which undergoes it. I will argue that Aristotle is right to make this claim, since each of the two processes always goes hand in hand with a change in place of the basic material components of the substantial change's subjects, so that everything that is subject to generation or corruption also changes in place (4.3.3). I will conclude by summarizing the results (4.3.4).

\subsubsection{Generation and corruption in virtue of aggregation and segregation}

First of all, it appears striking that in this passage Aristotle uses the concepts

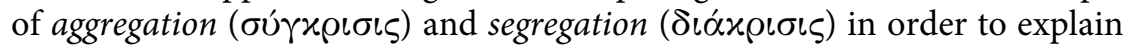
the phenomena of generation and corruption. The terms of aggregation and segregation have not played an important role in the Physics so far, and up to this point have mainly been used by Aristotle in order to describe the doctrines of some of the earlier philosophers, in which both concepts play an important role as fundamental principles in nature. ${ }^{36}$ In fact, two chapters later, at the end of Phys. VIII 9, where Aristotle argues for the claim that circular locomotion is the primary kind of locomotion, some of these opinions are restated in order to show that his predecessors-at least implicitly-also presupposed the priority of locomotion. ${ }^{37}$ Indeed, this passage in Phys. VIII 9 also presents the view that generation and corruption only occur in virtue of aggregation and segregation. ${ }^{38}$ Consequently, this and other assumptions stated in the second argument, and hence in the argument as a whole, are often taken not to present a genuine Aristotelian view. ${ }^{39}$ Rather, scholars have noted, Aristotle appears to be arguing from

36 See for instance Phys. I 4, 187a29-31, VIII 9, 265b19-21, GC II 1, 328b33-329a5, and Met. I 3, 984a13-16.

37 See Phys. VIII 9, 265b17-32.

38 See Phys. VIII 9, 265b30-32.

39 Already Philoponus, In Phys. 8, 896, and later on Aquinas, In Phys., L. VIII, 1.XIV, 1089 , took the view presented here to be non-Aristotelian, or in the case of Aquinas, to be at least based on the probable assumptions of earlier philosophers. Solmsen (1960), 178, with 
(some of) his predecessors' point of view here in this argument in VIII 7, perhaps in order to, as Graham thinks, "demonstrate that even advocates of alternative natural philosophies must grant this point" ${ }^{\text {, }}$, namely that change in place is the primary kind of change. According to this interpretation the passage shows that even if one starts from the mistaken assumptions of Aristotle's predecessors, one is forced to conclude that locomotion is primary. In this way, those who hold these mistaken views are shown that this indeed is what follows from their assumptions; the argument is successful because it is persuasive. However, the passage thus interpreted would not contribute anything to the fundamental argument of Phys. VIII 7, the goal of which is to show that locomotion really - not merely based on erroneous assumptions-is the only possible candidate for being the kind of change that has its primary and direct source in the first unmoved mover.

Thus, if there is a way in which this argument may be read as a serious argument for the priority claim, then this reading should be preferred over the orthodox one. I will argue that this is possible. In my understanding Aristotle adopts Presocratic terminology to a certain degree in order to show that the subject of a substantial change always undergoes change in place with respect to its basic material components and that locomotion is the primary kind of change.

The only way to see whether my interpretation is correct is to examine the relation that according to Aristotle exists between generation and corruption and the two phenomena called aggregation and segregation. The place where Aristotle discusses this relation in more detail is GC I 2. What Aristotle states here seems indeed at first glance to support the claim that the second argument does not present Aristotle's own view and also was taken that way. ${ }^{41}$ For, in this chapter it is argued that change in substance, i. e. unqualified generation and corruption ${ }^{42}$, for a number of reasons cannot be aggregation and segregation. Thus, substantial change cannot be

respect to the passage in question thinks that Aristotle here "merely performs a courtesy bow to the opinio communis [...] but does not accept this opinion." Also Wagner (1967), 688, Zekl (1988), 289, n. 114, and Graham (1999), 122-123, reject that this argument presents Aristotle's own assumptions and arguments. Simplicius, In Phys. 8, 1266, 10-1267, 28, as well as Ross, seem to take the passage as presenting a genuine Aristotelian view (or at least do not state any doubts about this) and Ross, 709, reads it as "an incidental reminder that $\sigma u ́ \gamma x \rho\llcorner\sigma \iota \varsigma$

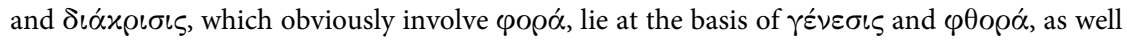

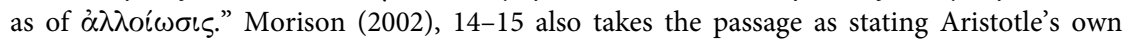
assumptions and argument.

40 Graham (1999), 123.

41 See Graham (1999), 123.

42 See GC I 3, 317b1-13. For Aristotle's understanding of unqualified generation and corruption see also Phys. V1, 225a12-20. 
defined in terms of these two processes. ${ }^{43}$ This seems to contradict what is stated in the passage from Phys. VIII 7-at least at first glance.

In GC I 2, however, Aristotle also explicitly states that he nevertheless thinks that "aggregation and segregation exist" and occur in nature. ${ }^{44}$ Yet, Aristotle is careful to emphasize that his understanding of the processes of aggregation and segregation differs significantly from that of his predecessors. Crucially, Aristotle thinks it is wrong to say that what aggregates or segregates are indivisible particles like atoms, as some of the Presocratic thinkers claimed. ${ }^{45}$ In fact GC I 2 presents among other things arguments aimed at refuting these and other mistaken assumptions about aggregation and segregation. Yet, Aristotle does not really present examples of actual

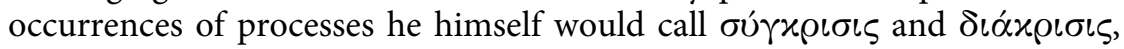
but he does so in other places, for instance in the Meteorology.

There he states that for example water vapour, of which clouds consist, is the segregation of water ( $\check{\delta} \alpha \tau 0 \varsigma \delta \iota \alpha x \rho \iota \sigma \iota \varsigma)$ and tells us that clouds are

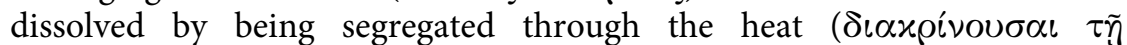
$\theta \varepsilon \rho \mu$ ó $\tau \tau \iota)$ originating from the sun. ${ }^{46}$ In another passage of the same work Aristotle explains that certain phenomena of light often appear in the night sky "when [air] becomes further aggregated" (ö $\tau \nu \nu \sigma \gamma \varkappa \rho \iota \theta \tilde{\eta} \mu \tilde{\alpha} \lambda$ $\lambda \circ \nu) .{ }^{47}$ These and many other passages clearly indicate that Aristotle uses

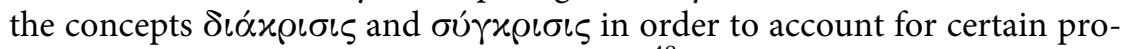
cesses that play an important role in nature. ${ }^{48}$

The passages quoted above also suggest that the two concepts are essential for explaining how the four elemental bodies, i.e. earth, water, air, and fire, undergo generation and corruption. Aristotle argues that each of the four elements can turn into any of the other elements. ${ }^{49}$ If, for example, water is heated, it undergoes segregation and at some point perishes, so that air comes to be. ${ }^{50}$ These passages show that for Aristotle generation and

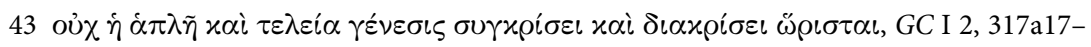
18.

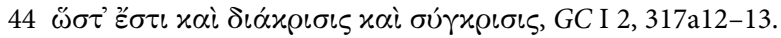

45 This becomes clear for instance in the full context of the passage I just quoted in n.44, i.e. GC I 2, 317a12-17. There Aristotle states that aggregation and segregation exist "but not

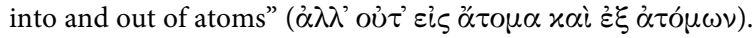

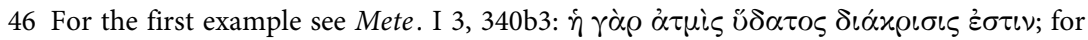
the second see Mete. I 3, 340a29-30.

47 See Mete. I 5, 342b16-17.

48 For more examples see for instance Mete I 3, 340a8-10, 341a4, a9-10, and Mete I 4, 344b20-24. In GA IV, 6, 775a11-13, for example, Aristotle describes what happens when an animal develops and comes to be in terms of $\delta \iota \alpha ́ x \rho \iota \sigma \iota$.

49 This claim is made for instance in GC I 3, 339a36-b2, GC II 2 329a35-b1, and 329b2224. In what way they are transformed into each other is discussed in GC II 4.

50 For the change from air to water for instance, i. e. the coming to be of water and the 
corruption of the four elements take place in virtue of aggregation and segregation. Although it is wrong to say that this is all that happens when one of the elemental bodies comes to be or perishes, and that this process may be reduced to nothing but aggregation or segregation, one has to have in mind that substantial change in GC I 2 is described as a change in the form

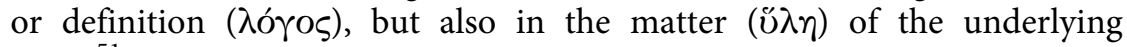

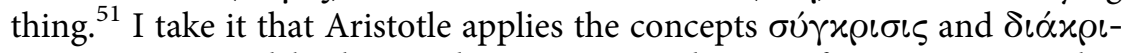
$\sigma \iota \varsigma$, terms coined by his predecessors, in order to refer to processes that occur on the material level and are an essential part of the elemental bodies' generation and corruption, but also, as I will show, of any other substance's generation and corruption. That Aristotle views these concepts as playing such a significant role in understanding substantial change is also supported by a statement made in GC I 2, where it is stated that something which undergoes aggregation or a segregation becomes more or less susceptible to corruption as a result. ${ }^{52}$ However, the occurrence of aggregation or segregation does not necessarily bring about a substantial change: heating a portion of water, for instance does not have to lead to the corruption of the portion of this element, although the heating, as we have seen in the examples from the Meteorology involves segregation of the water, which is manifested in an increase in the water's volume. But if water is heated long enough, then it will perish at some point due to the fact that it has undergone a segregation and no longer has the form of water, i.e. is no longer characterized by its specific combination of the basic qualities of cold and wet and by its motion towards its sphere. ${ }^{53}$ Therefore, undergoing either segregation or aggregation is not a sufficient condition for an element to undergo generation or corruption. Nevertheless, these two processes are obviously an essential part of what happens when elemental bodies come to be or perish. In this way, i.e. with respect to the elements, Aristotle in Phys. VIII 7 correctly says that we speak of generation and corruption in virtue of $\sigma u ́ \gamma x \rho \iota \sigma \iota \varsigma$ and $\delta \iota \alpha ́ x \rho \iota-$ $\sigma \iota \varsigma$, since the occurence of one of the two is a necessary condition for the occurence of either of the former two processes. But, this of course, does

perishing of air, which Aristotle describes as a process of aggregation see for example Mete. I 3, 341a4 and 341a9-10. For the reverse process and the change from air to fire, i.e. the coming to be of fire and the corruption of air, which occur by means of segregation, see Mete. I 3 , $340 \mathrm{a} 8-10$ and $340 \mathrm{~b} 3$.

51 See GC I 2, 317a23-24. I take it that the reason why Aristotle mentions the material aspect of a substantial change here in $G C$ while he usually neglects it in other characterisations of change in substance is that he focuses on what happens on what one might call the material level.

52 See GC I 2, 317a27-29.

53 For the characterisation of the elements by the pairs of qualities of hot-cold and drymoist see GC II 3, 330b3-7. 
not mean that this is all that happens in a substantial change, nor that a change in substance is reducible to aggregation and segregation.

This fact also has implications for the coming to be of all natural things in general. The four elements of earth, water, air, and fire, are the basic material constituents of all bodily things that exist in the sublunary sphere. This is why Aristotle thinks it necessary to inquire into what these elements are and what role they play, if one is to understand how generation and cor-

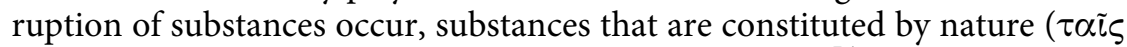

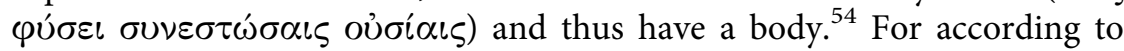
Aristotle-and here he basically agrees with his predecessors-it is a change in the elements, either an aggregation, or a segregation, or some other kind of change, that is at least partly responsible for the generation and corruption of things. ${ }^{55}$ In other words, any generation or corruption of things that have a body necessarily involves $\sigma u ́ \gamma \varkappa \rho \iota \sigma \iota \varsigma$ or $\delta \iota \alpha ́ x \rho \iota \sigma \iota \varsigma$ of its basic material components, i.e. the elements. That this is Aristotle's view becomes clear when he explicitly identifies the mixing of the elemental bodies, whereby these bodies perish in order to form homoeomeres like flesh and bone, with the process of aggregation. ${ }^{56}$ The dissolving of such a mixture accordingly needs to be understood as segregation. Thus, not only the changes of the elemental bodies, but also the substantial change which composite substances like plants and animals undergo always involves aggregation and segregation insofar as the basic material components of these substances do so. In this sense one may say that generation and corruption in general are processes of aggregation or segregation of the elements and occur in virtue of these processes.

But generation and corruption, of course, cannot be reduced to these processes, which take place on the material level. The crucial point about substantial change is that it is a change with respect to the form of that which undergoes it. This is the reason why Aristotle emphasizes that gen-

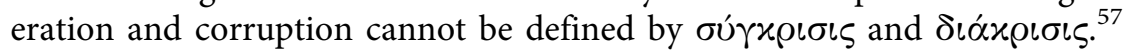
It is true that the occurrence of either of the latter two processes is a necessary condition for one of the former to take place, but the mere occurrence

54 See GC II 1, 328b31-33. For the fact that the four elemental bodies are the basic material constituents of substances with respect to their bodies see also, e.g. GC II 8, 334b31-32, and GA I 1, 715a8-11.

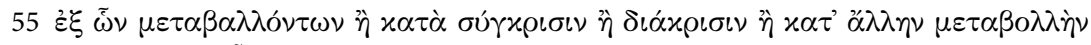

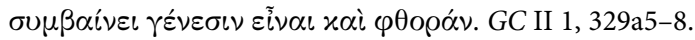

56 In GC I 6, 322b8, Aristotle says explicitly that हे $\sigma \tau \iota \delta^{\prime} \dot{\eta} \sigma u ́ \gamma \varkappa \rho \iota \sigma \iota \varsigma \mu i \xi \iota \varsigma$. This mixture of the elemental bodies, however, leads to the homoeomeres, which again serve as the matter of composite substances. For more on this see for instance Mete. IV 12, 389b24-29 and GA I $1,715 \mathrm{a} 8-11$.

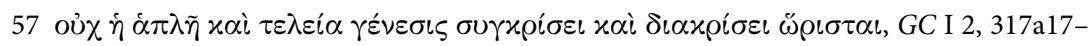
18. See p. 92 , n. 43 . 
of a segregation or aggregation of the underlying material does not explain the coming to be of an animal or a plant, i.e. a being with a specific formalthough this, at least according to Aristotle, is exactly the view held by some of the Presocratics, who reduced generation and corruption to changes of the material of the respective subject and were not aware of the fact that an appropriate explanation must also involve the principle of form. ${ }^{58}$ Thus, what Aristotle means by saying that "unqualified change in substance is not through segregation and aggregation" 59 and cannot be

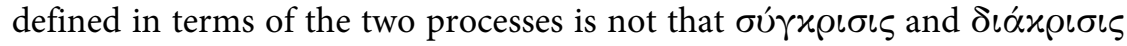
do not play any role in this kind of change, but that for a substantial change to occur it is not enough for the respective thing to undergo nothing but segregation or aggregation. ${ }^{60}$ In other words, it is a necessary, but not a sufficient condition for generation and corruption that aggregation or segregation occur.

But, as I said before, this is only true if one has a correct understanding of what it means for Aristotle that something undergoes aggregation or segregation, and if one does not take these processes to be of the sort (oi $\alpha \nu$ ) that Aristotle's predecessors thought they were, because then indeed generation cannot possibly involve aggregation (and corruption, not segregation, one might add) as is explicitly stated at the end of GC I 2. ${ }^{61}$ This, however, is the mistake interpreters of Aristotle make when they claim that it cannot be Aristotle's own view that we speak of generation and corruption of substances in terms of segregation and aggregation. ${ }^{62}$

But, contrary to what most interpreters say, Aristotle's claim about the connection between change in substance and aggregation or segregation that is made in the second argument may be read as stating his own view, although he makes use of his predecessor's terminology here. ${ }^{63}$ The pro-

58 Again see Phys. I 2, 194a18-21.

59 GC I 2, 317a20-21.

60 That this must be wrong, even if aggregation and segregation are understood in the Aristotelian sense, is clear from the fact that there are instances of the two phenomena that

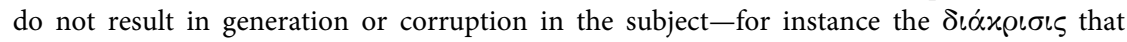
occurs when heated water expands.

61 GC I 2, 317a30-31.

62 Apart from those already mentioned, see also Carteron's translation, which mistakenly

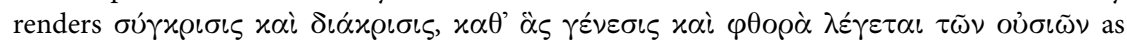
"[o]r condensation et raréfaction sont concrétion et séparation, et on y réduit la génération et la destruction des substances."

63 See GC I 2, 317a30-31. This situation is different for GC, as scholars seem to agree more or less that there is a connection between substantial change and $\sigma 0 \dot{\gamma} \varkappa \rho \iota \sigma \iota \varsigma$ and $\delta \iota \dot{\alpha}-$

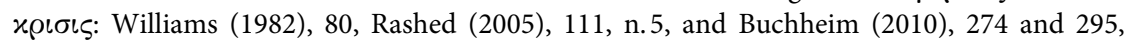
agree that Aristotle GC I 2 does not say that it is wrong in general that generation is aggregation, but that it cannot be aggregation "of the sort some people [i.e. some of the predecessors] say it is" (oí $\alpha \nu \delta \dot{n} \tau \iota \nu \varepsilon ́ \varsigma \varphi \alpha \sigma \iota \nu)$ (Transl. Williams). Yet, Williams at the same time does not 
cesses which, according to Aristotle, may be (but certainly do not have to be) called aggregation and segregation are an ineliminable part of changes that occur on the material level of things. Yet, it is important to emphasize that, in contradistinction to the view that one might be tempted to share with certain scholars, saying that aggregation and segregation are a necessary part of such changes is far from saying that these changes may be

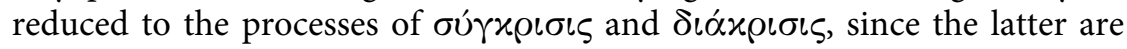
not the only explanatory factors needed in order to understand what happens when a change in substance occurs. ${ }^{64}$ This then is the way in which Aristotle in Phys. VIII 7 can rightly claim that it is "aggregation and segregation on the basis of which we speak of generation and corruption of substances." ${ }^{65}$ According to this view, what undergoes generation or corruption in a sense also undergoes aggregation or segregation, since the former involves segregation and aggregation with respect to the subject's basic material constituents, i.e. its elements.

\subsubsection{What aggregates or segregates must change with respect to place}

Now that this is clear one still needs to understand in what way the fact that aggregation and segregation stand in this relation to generation and corruption shows the priority of locomotion.

Aristotle seems to think that locomotion's priority over generation and corruption is shown by the fact that "what undergoes aggregation and segregation necessarily changes in place." ${ }^{66}$ The idea behind this claim seems to be this: segregation and aggregation are nothing more than, and can be reduced to, the locomotion of the respective subject's basic constituent parts. That this is what Aristotle has in mind in making this claim is supported by a passage from Phys. VII 2. Here Aristotle explicitly states thatalthough a special status needs to be assigned to the processes of aggregation and segregation involved in generation and corruption-all aggregation and segregation are basically forms of locomotion and should not be

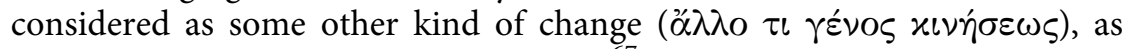
some of Aristotle's predecessors thought. ${ }^{67}$

\footnotetext{
leave this statement unqualified, while Rashed and Buchheim think that this is in perfect accordance with Aristotle's theory. (Joachim does not deal with this question.)

64 See for instance Carteron's translation of the respective passage in VIII 7 that I just cited in n. 62.

65 Phys. VIII 7, 260b11-12.

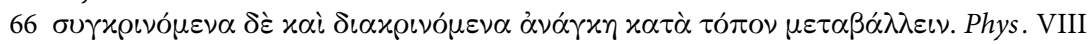
7, 260b12-13.

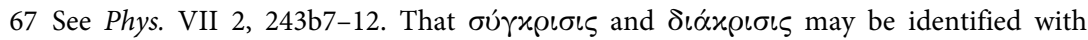


That undergoing aggregation and segregation imply that the respective subject changes with respect to place in a sense becomes even clearer when we think back to the examples of these two processes given above. As we have seen, an elemental body's undergoing either of the two processes goes hand in hand with its increasing and decreasing in size, as water for instance by being heated undergoes segregation and expands in volume before finally being transformed into air. From the discussion of the connection between change in place and change in quantity we have seen that something necessarily undergoes a change in place with respect to its parts when it changes in size. ${ }^{68}$ Therefore, the aggregation or segregation of a portion of a certain element implies an increase or decrease in size, and hence involves a change in place with respect to the element's parts.

This is even more obvious for cases of generation in which a new substance comes to be from different parts and for cases involving the corruption of such a substance. The process of aggregation or combination undergone by the material components from which a new whole is coming to be needs to involve a change in place of these components, since they have to move together in order to form one new continuous body. The same is true of corruption: if a body undergoes segregation and dissolves into its material components in the process of corruption, these parts need to change with respect to place.

\subsubsection{Conclusion}

Thus, in the way I have presented above, Aristotle is right to claim that what undergoes aggregation or segregation necessarily changes with respect to place, namely with respect to its parts. As in the case of change in quantity, that which is coming to be or is perishing does not change in place as a whole, but with respect to its parts, that is, its basic material components. As with respect to change in size, this argument has shown that generation and corruption is always accompanied by a change in place, while there is no reason to assume that the converse must hold. Therefore, in examining what happens on the material level when generation and corruption occur, it has turned out that both processes, as growth and diminution, presuppose and necessarily go hand in hand with change in place, and cannot take

change in place is also clear from what Aristotle states in the passage in Phys. VIII 9 in which he tries to show that his predecessor's assumptions-at least implicitly-also presupposed that change in place is primary. There he explicitly states that aggregation and segregation are

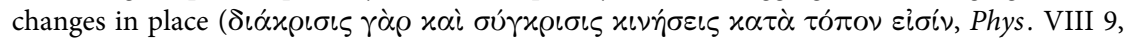
265b19-20).

68 For this see section 4.2.2. 
place without it. The situation for locomotion is different: as we have seen in the previous section, locomotion in the strict sense involves neither generation, nor corruption, nor any other type of change. Locomotion therefore is also prior and more fundamental to any substantial change, since the latter necessarily involves locomotion in the way previously described, but not vice versa. Thus, locomotion has ontological priority not only over change in quantity, but also over change in substance, since the latter cannot occur without change in place, while change in place in no way entails the occurrence of generation or corruption.

It has also become clear that there are compelling reasons for thinking that the assumptions underlying this argument clearly represent Aristotle's own view and that his argument should be read as telling us something significant about why Aristotle thinks that locomotion is the primary kind of change.

\subsection{What changes in quality changes with respect to place}

\subsubsection{Overview}

I will now discuss the passage in which the argument for the last of the three claims made in the second argument for the priority of locomotion is stated. It reads as follows:

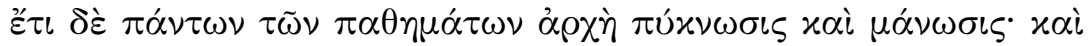

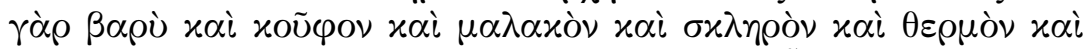

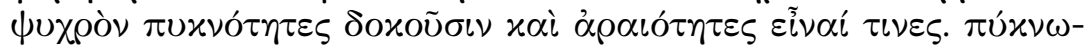

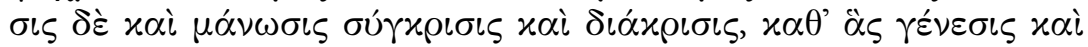

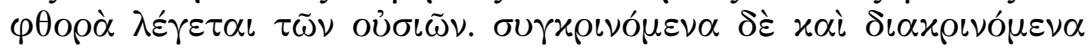

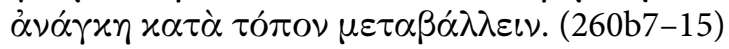

But further, a source of all the affections is condensation and rarefaction. For also heavy and light and soft and hard and hot and cold seem to be some kinds of density and rarity. But condensation and rarefaction are aggregation and segregation, on the basis of which we speak of generation and corruption of substances. But what undergoes aggregation and segregation necessarily changes in place.

According to this argument whatever changes in quality also has to change with respect to place. I take it that the argument is basically this: every change in quality necessarily involves either condensation or rarefaction. Condensation and rarefaction, however, are forms of aggregation and segregation. What undergoes aggregation and segregation changes with respect to place. 
I will argue that this argument aims at showing that locomotion is prior to change in quality, in the sense that whenever something undergoes a change in quality, i. e. an alteration, this change must always be accompanied by a change in place, but not vice versa. Accordingly, no alteration can occur without locomotion, while the converse does not hold. This argument therefore shows that change in place has ontological priority over change in quality. In this way the argument fits perfectly in the larger context of the second argument for the priority of locomotion as a whole, since in the two other sub-arguments it was shown that change in place is ontologically prior to the other two types of change, i.e. in quantity as well as in substance, since both are necessarily accompanied by change in place, too, while the occurrence of locomotion does not depend on any other type of change. Hence, if the last of the three sub-arguments presented here is correct, then locomotion is necessarily concomitant to all other changes, but not the other way round, and thus is ontologically prior to each of the other three kinds of change.

In my discussion I will proceed as follows. I will start by asking what exactly Aristotle means by claiming that condensation and rarefaction are a source of all qualities and change in qualities. Against the background of Phys. IV 9 I will argue that Aristotle thinks that for something to have any kind of quality it must have a certain state of density and that thus any change in quality must involve some change in density (4.4.2). After that I will present Aristotle's reason for making this claim: firstly, I will show that for Aristotle every alteration involves a change with respect to the four basic qualities of hot-cold and dry-moist (4.4.3). Next, I will explain that any change with respect to these four basic qualities goes hand in hand with a change in density, i.e. condensation or rarefaction, and that for this reason every alteration is accompanied by a corresponding change in density (4.4.4). After that, by making use of the way in which the terms condensation and rarefaction and of aggregation and segregation are employed by Aristotle, I will show that Aristotle is correct in holding the view that the former are instances of the latter (4.4.5). Since it is clear from the previous discussion that aggregation and segregation necessarily go hand in hand with locomotion, I will conclude by arguing that this is also the case for condensation and rarefaction, which shows the ontological priority of locomotion over alteration (4.4.6). I will end by summarizing the results of my examination (4.4.7).

As in the case of the argument discussed in the previous section, serious doubts have been uttered as to whether the claim made here about alteration represents Aristotle's own view. In the course of my inquiry I will therefore also discuss reasons for thinking that this is not a serious Aristotelian claim. I will argue that this part of the second argument-like the other parts-may be read as representing Aristotle's own theory. 


\subsubsection{What does it mean that condensation and rarefaction are principles of quality?}

I will now begin by presenting what I take to be the basic idea behind the claim that Aristotle establishes, i.e. that one "source of all affections is condensation and rarefaction." 69 Thereby, it will also become clear that, contrary to what some scholars think, this assumption is in perfect accordance with what is stated about the two phenomena of condensation ( $\pi \dot{u} x \nu \omega \sigma \iota \varsigma$ ) and rarefaction ( $\left.\mu \alpha \alpha^{\prime} \omega \sigma \iota \varsigma\right)$ in Phys. IV 9, the passage most important for Aristotle's conception of the two phenomena, and that the view expressed in this claim may thus be considered as Aristotle's own. I will continue my analysis by examining the different premises on which the argument is based, an argument that as a whole is supposed to show that locomotion has ontological priority over change in quality.

Aristotle's claim that condensation and rarefaction are a source of all affections, as I will show, means that for explaining how all kinds of qualities, and hence all kinds of change in quality, come about one needs to refer, among other things, to these two processes, as they are at least partly responsible for there being qualities. ${ }^{70}$ The reason for this claim is presented in the next line ( $\gamma \alpha \dot{\rho} \rho)$, which says that this is the case, because "heavy and light, soft and hard, and hot and cold seem to be some sort of densities and rarities." 71 According to this theory, if $x$ is qualified in one of these ways, there seems to be a state of density and rarity-of the whole of, or parts of $x$ 's body-that corresponds to having the respective quality. Furthermore, in this context Aristotle does not provide further explanation for what is stated here, which again makes it necessary to look elsewhere. But as in the

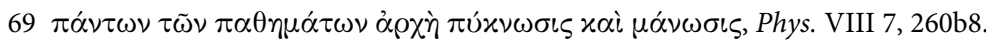

70 Note that Aristotle merely speaks of $\dot{\alpha} \rho \chi \dot{\eta}^{\prime}$ and not $\dot{\eta} \dot{\alpha} \rho \chi \dot{\eta}^{\prime}$ which could be read as saying that the two processes are the sole source and principle of these things. I take $\pi \dot{\alpha} \theta \eta \mu \alpha$ to stand for what Aristotle calls $\pi \alpha \theta$ ó $\varsigma$ in other places and what in the context of my discussion stands for all kinds of qualities in Aristotle. My reason for doing so is that in GC, which in my view needs to be understood as the theoretical background of this passage, especially I 4, where Aristotle discusses alteration, this kind of change is explicitly described as occurring with respect to $\pi \alpha \dot{\theta} \theta \circ \varsigma$ as the process in which something "changes in its own qualities" ( $\mu \varepsilon \tau-$

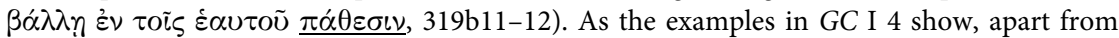
one exception, this covers the whole spectrum of alterations that against the background of the discussion of quality in Cat. 8 seem to be possible (for more see n. 83 on p. 103). Another even more important reason is that in order to show that locomotion is prior to change in substance, quantity, and quality in general, it is not enough to show that it has priority over certain cases of change in quality, namely of perceptible qualities.

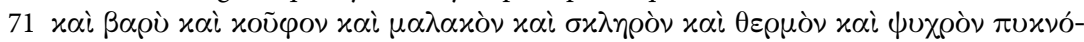

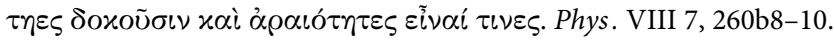


case of the two other sub-arguments, more information on this topic is to be found elsewhere in his work, especially in Phys. IV and De Generatione et Corruptione, which in my view lays out the theoretical background to this argument.

With respect to the terms $\pi \dot{x} x \nu \omega \sigma \iota \varsigma$ and $\mu \alpha \nu \omega \sigma \iota \varsigma$ we are in a situation

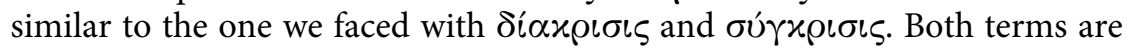
often used by Aristotle in order to refer to certain theories of his predecessors. ${ }^{72}$ Furthermore, with respect to Aristotle's usage of both terms this was taken as a reason for denying that the second argument presents Aristotle's own view. ${ }^{73}$ In fact, the two terms are also stated in the aforementioned passage of Phys. VIII 9 as part of one of his predecessors' doctrines. ${ }^{74}$ But the most important motivation for saying that Aristotle here is rather presenting an argument consisting partly of a predecessor's non-Aristotelian assumptions is that the way in which the terms $\pi \dot{u} x \nu \omega \sigma \iota \varsigma$ and $\mu \alpha \alpha^{\prime} \omega \sigma \iota \varsigma$ are used by Aristotle in the passage of Phys. VIII 7 appears to be incompatible with his own theory.

But unlike aggregation and segregation, the concepts of condensation and rarefaction are used by Aristotle in other places in the Physics not merely in order to refer to certain doctrines of the Presocratics, but as a part of his own theory. The passages that are of importance for us are found in Phys. IV in the context of Aristotle's discussion of the void. What is stated there is in line with what is said about the two processes in the second argument for the priority of locomotion, although some interpreters of Phys. VIII seem to doubt this. ${ }^{75}$

Of particular importance for my purposes is the use of the two terms in Phys. IV 9. ${ }^{76}$ In this chapter Aristotle states his own theory of condensation and rarefaction and in doing so explicitly draws a connection between the

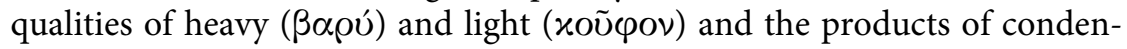

72 See for instance Phys. IV 9, 216b22-24, and Phys. VIII 9, 265b30-31.

73 See Wagner (1967), 688, Zekl (1988), 289, n. 114, and Graham (1999), 122-123. Additionaly, Philoponus, In Phys. 8, 896, 30-32, and also Wagner and Graham, argue that the use of $\delta 0 x o \tilde{\sigma} \sigma \nu$ (b10) and $\lambda \varepsilon ́ \gamma \varepsilon \tau \alpha \iota$ (b12) indicates that this is not Aristotle's own point of view.

$74266 \mathrm{~b} 30-31$. It is correct that $\pi \dot{x} x \nu \omega \sigma \iota \varsigma$ and $\mu \alpha \dot{\alpha} \nu \omega \sigma \iota \varsigma$ are mentioned in this passage, yet they are introduced as explaining generation and corruption, while the role they play in the constitution of qualities that is mentioned in VIII 7 is not stated. But the mere fact that both terms are mentioned in the discussion of the theories of Aristotle's predecessors alone does not show that they are always used in order to refer to those theories.

75 Again see the places in Wagner, Zekl, and Graham (see n.73). Wagner and Zekl merely state that the concepts of $\pi \dot{x} x \nu \omega \sigma \iota \varsigma$ and $\mu \alpha \dot{\nu} \omega \sigma \sigma \varsigma \varsigma$ as they are used in Phys. VIII 7 are incompatible with the theory developed about them in Phys. IV, however, neither Wagner nor Zekl says why this is supposed to be the case.

76 Besides Phys. IV 9 Aristotle also uses the two concepts as his own in Phys. IV 5, 212b23 and, as I will show later on, in various other places. 
sation and rarefaction. There he says that "the dense is the heavy, and the rare the light." 77 This, of course, does not mean that something merely by undergoing rarefaction or condensation changes with respect to its weight, although this passage has been read that way. ${ }^{78}$ This indeed would be absurd. Rather, what he obviously intends to say here is that there is a connection between a thing's density and its weight, because when comparing two things with respect to their weight their density matters. As Aristotle points out in Cael. III 1, of two things that have the same volume that which is of higher density is heavier than the other, since there is "more in the same material bulk." ${ }^{.79}$ In this sense a state of density or rarity may be assigned to heaviness or lightness.

In Phys. IV 9 Aristotle adds that basically the dense not only seems to be associated with the heavy, but also with the hard ( $\sigma x \lambda \eta$ oó $)$, while the rare (that is, the opposite of dense) he associates with the light, but also with the soft $\left(\mu \alpha \lambda \alpha \chi \alpha^{\prime} \nu\right){ }^{80}$ That this is plausible is clear from the following example. Suppose, I want to produce a statue from a lump of bronze. In order to do so I heat the bronze; it expands, i. e. becomes less dense, looses its hardness more and more until, at a certain point, it even turns liquid, which allows me to pour it into the statue's form. In cooling, the bronze contracts, becomes denser and hard again.

So far, this understanding of Aristotle's claim matches perfectly with what is said in the second argument for the priority of locomotion, since four of the qualities mentioned there-namely heavy, light, hard, and softare clearly assigned to states of density and rarity in Phys. IV 9, which paral-

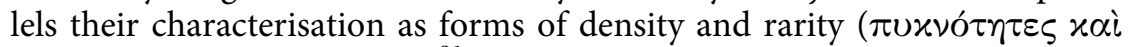

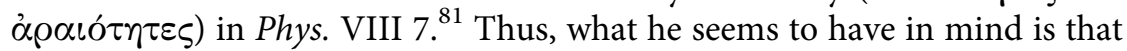
when something changes in respect of quality a change in density is somehow involved. Since having a certain density corresponds to having certain qualities, a change in the density of $x$, that is condensation or rarefaction, implies a change in $x$ 's qualities. In this sense an alteration would always go hand in hand with a change in density.

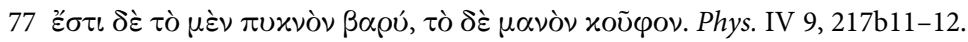

78 This seems to be the view held by Graham (1999),123, who takes the alleged falsity of this view as another reason for claiming that Aristotle does not present his own view anywhere in the argument.

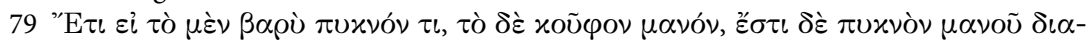

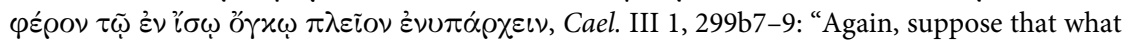
is heavy is a dense body, and what is light rare. Dense differs from rare in containing more matter in the same bulk." (Transl. Stocks).

80 See Phys. IV 9, 217b16-18.

81 Therefore Graham (1999) is wrong when he claims that "nowhere in his physical theory" does Aristotle account "for basic qualities in terms of condensation and rarefaction" (122). 
But so far it has only become clear that this is the basic idea behind the claim in question, and that there is no reason to doubt that this is Aristotle's own view. We have yet to examine whether he is right in claiming that condensation and rarefaction are sources of quality and change in quality. For, thus far I have only shown that this is true for two of the three examples presented in Phys. VIII 7, namely for the two opposite pairs of heavy-light and hard-soft. But although the qualities of hot $(\theta \varepsilon \rho \mu o ́ v)$ and cold ( $\psi \times \chi \rho o ́ v)$ are mentioned in the course of the discussion in Phys. IV 9, a connection between these qualities and states of rarity and density is not established there. Even if this were clear, however, how would it show that all change in quality, and not only with respect to the three mentioned pairs of qualitative opposites, is connected with a change in the respective thing's density? For, Aristotle claims in the second argument for the priority of locomotion that condensation and rarefaction are a source of all affections

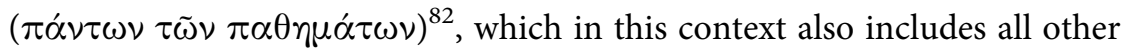
kinds of qualities as well, because for Aristotle not only changes in the aforementioned qualities, but also in colour, taste, or from health to sickness, from uneducated to educated, or from a round to an angular shape count as change in quality, i. e. as alteration. ${ }^{83}$ Apart from this, one needs to keep in mind that the goal of this argument is to show that locomotion is prior to alteration in general and not only with respect to certain kinds of change in quality.

As I will now argue, the solution is to understand that Aristotle here is focusing-as he did with the other two sub-arguments-on what happens on the material level when something undergoes alteration. Against this background it becomes clear that any occurrence of alteration on this level involves a change of the four fundamental qualities that are partly responsible for the constitution of substances in the sublunary sphere (4.4.3) and that this, again, goes hand in hand with a change in the relevant thing's density (4.4.4).

82 See Phys. VIII 7, $260 \mathrm{~b} 8$.

83 See p. 100, n. 70. If one understands alteration in the sense in which it is explained in $G C$ I $4,319 b 10-12$, namely as change with respect to $\pi \alpha \dot{\alpha} \theta 0 \varsigma$, and one takes into account which examples are presented in GC I 4 for this kind of change, then it is clear that alteration covers the whole spectrum of alterations one would expect against the background of Cat. 8, where the different kinds of qualities are listed, and is not restricted to change in affection in the sense of change in perceptible qualities. For according to the examples in GC I 4 alteration covers change in quality in the sense of a change with respect to state (e.g. becoming educated), condition (e.g. becoming sick), shape (e.g. angularity of bronze), and perceptible qualities, namely tangible qualities, colour, and taste. The only quality with respect to which according to Cat. 8 a change would be possible, but that is not explicitly mentioned in GC I 4 is the quality predicated of $x$ in virtue of $x$ haveing "a natural capacity or incapacity" (Cat. 8, 9a16, Transl. Ackrill). 
4.4.3 Every alteration involves a change in the four basic qualities

Aristotle states in GC II 4 that every alteration is a change in respect of tangible qualities. ${ }^{84}$ Such qualities include, for example the three pairs of opposites mentioned in the second argument, i.e. hot-cold, hard-soft, heavylight, but as we can see in the discussion of these kinds of qualities in GC II

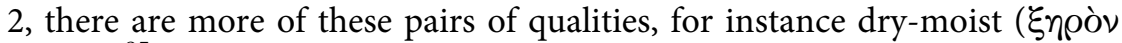
v̛(ó́v). ${ }^{85}$ This qualification of alteration, however, is striking and appears to be highly problematic, for this could be read as saying that all alteration is nothing more than, and hence may be reduced to, a change in tangible qualities. Then one could either say that this statement contradicts the claim about the irreducibility of the kinds of change, or, in order to avoid this, that the alteration Aristotle is talking about in GC II 4 does not include the other cases of change in quality that I just mentioned and that we, as well as Aristotle, also count as alterations. Both solutions, however, would be unsatisfactory.

Yet, the qualification of alteration stated in GC II 4 does not necessarily imply that this kind of a change is nothing but a change in, and thus only concerns, the qualities that are accessible through the sense of touch. ${ }^{86}$ Rather, there are reasons for thinking that what Aristotle means to say is that every alteration involves a change in the qualities of tangible things, a reading which some commentators favour. ${ }^{87}$ That this is what Aristotle has in mind seems to follow from the theory developed in De Generatione et Corruptione-especially in the first four chapters of the second book. One of the assumptions made in this context is that the principles ( $\alpha \rho \chi \alpha \hat{\imath})$ of perceptible bodies, or some of them, to be more precise, are the opposite pairs of certain qualities which correspond to touch ${ }^{88}$ However, not all of the qualities of touch that are presented in GC II 2 serve as principles, but only two pairs, namely hot-cold and dry-moist, as these are not reducible to any other qualities. ${ }^{89}$ Yet, this is the case for all other qualities of this kind which derive from the two fundamental pairs of opposites. ${ }^{90}$ In this sense

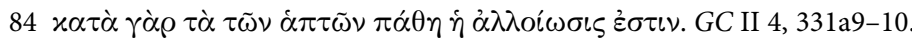

85 GC II 2, 329b18-20.

86 For a list of them see GC II 2.

87 See Philoponus In Gen. 2, 232, 9-12, Williams (1982), 162, Rashed (2005), LXXXVIII, and Buchheim (2010), 460-461.

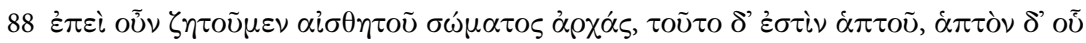

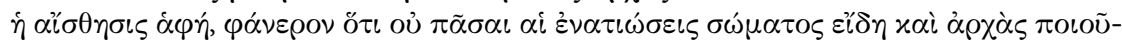

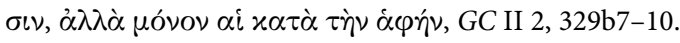

89 See GC II 2, 330a24-29.

90 GC II 2, 329b32-34. 
for instance the quality viscous ( $\gamma \lambda i \sigma \chi \rho o \nu)$ needs to be understood as a modified kind of wetness. ${ }^{91}$

The way in which the qualities hot-cold and dry-wet are combined is responsible for the form of each of the four elemental bodies of earth, water, air and fire. Air is hot and wet, but turns into water as its dryness is gradually overcome $(\kappa \rho \alpha \tau \eta \theta \tilde{\eta})$ by wetness, since water is characterised by the qualities of cold and wet. ${ }^{92}$ Similar processes explain the coming to be and the perishing of all elemental bodies, that is, their transition into each other. ${ }^{93}$ The simple bodies, however, are those out of which all compound substances in the sublunary sphere consist, as they are the basic material components of compound bodies. ${ }^{94}$

It is with respect to these bodies, again, that substances are qualified by the other perceptible qualities like for instance colour or taste, because it is a body that has colour, taste, and so forth. The same is true for the quality of having a certain shape, as for example the shape possessed by an object made of bronze. Since these bodies are essentially determined by their principles and elements, the perceptible qualities belonging to and predicated of them also are partially determined by those principles and elements, as their existence depends on that of the body in which they reside. In the same way that a change with respect to these basic components affects the body, the qualities belonging to it are likewise affected. Of course, it is absurd to say that for instance the colour of a body is affected as colour when the body is heated or becomes dry, since the colour itself does not become warmer or dryer. Yet, when the surface of the body is affected through these changes, or perhaps is even destroyed by them, then this of course affects the body's colour. But if such a connection exists, then, of course, a change with respect to a substance's body and of the qualities belonging to it necessarily implies a change on the level of the basic elements and principles.

If an apple, for instance, ripens and its colour changes from green to red in the process, it is clear that a change has taken place in the material of the apple or some of its material components, a change that corresponds to its becoming red. Accordingly, the apple's change in colour involves and is accompanied by a change with respect to the elements and principles. The same is true of a change in taste that the apple may undergo. Suppose I take a green, unripe apple from the tree and taste it. It will be sour, while the same apple left on the tree for two more weeks in order to fully ripen will taste sweet, or at least sweeter than the unripe one. Of course, for this change from sour to sweet there is also a corresponding change with respect

91 See GC II 2, 330a5-6. For other examples see 329b32-330a12.

92 See GC II 4, 331a29-32.

93 See GC II 4, 331a23-b11.

94 See for instance GC II 8, 334b31-32, and GA I 1, 715a8-11. 
to the basic material components of the apple, i.e. its principles and elements. This is even more obvious with a change in shape. In the example presented in GC I 4, where an object made of bronze changes from spherical to angular, it is clear that this change of the underlying bronze is a change with respect to the elements of the body; after all it is a change in the shape of the body. That the other case stated in GC I 4, of a body that alters from health to sickness, is one in which something in the body, i.e. a perceptible quality, changes is self-evident, as the subject of this change is explicitly said to be the body by Aristotle. ${ }^{95}$

We have seen that all changes in perceptible qualities as well as those in shape (spherical to angular) and condition (becoming sick) involve and are accompanied by changes that occur with respect to the principles and basic elements, although this is merely part of, and certainly not a full description of, what happens in the aforementioned cases of alteration. ${ }^{96}$ But this means that the simple bodies which are the elements of all compound substances also change. The only way in which they can change is with respect to the four basic qualities hot-cold and dry-moist, which determine the form and being of each element. ${ }^{97}$ And this, I would argue, is the sense in which each of the previously examined cases of alteration involves an alteration with respect to the qualities that are perceptible by touch.

But so far I have only presented cases of alterations with respect to perceptible qualities or to shape and conditions. As I said before there are still other cases of alteration, as for instance the change of a human being from uneducated to educated, which according to Cat. 8 counts as an alteration with respect to a state ( $\left.\varepsilon \xi_{\imath} \varsigma\right)$. I will call such alterations, another example of which would be becoming virtuous, a change with respect to psychological qualities. ${ }^{98}$ According to the claim made in GC II 4 alteration in generaland not only the types of alteration discussed above-can be characterized at least partly as change with respect to tangible qualities. But for this claim to be true one needs to show that for cases of alteration of psychological qualities, as well, a corresponding change must always occur in tangible qualities. This is certainly not the place to present a detailed argument for a connection between what one might call the psychological and the material levels, as this would presuppose an in-depth analysis of other writings of Aristotle's that is outside the scope of this book. For my purposes the following should suffice.

95 See GC I 4, 319b12-13.

96 For the different classifications of change in quality see p.103, n. 83.

97 This fits perfectly with the fact that in Phys. IV 3, 210b25-26, Aristotle states that health is connected to the quality of hotness, which accordingly might mean that a change from health to sickness involves a change in the basic qualities of hot and cold.

98 See Cat. 8, 8b26-9a10. 
There certainly are good reasons for thinking that according to Aristotle every alteration with respect to a psychological quality is accompanied by a corresponding alteration of a perceptible quality, and hence, as we have seen, one of touch. That Aristotle thinks that certain changes in the body correspond to certain changes in the soul is clear. For instance he seems to think that anger goes hand in hand with a heating of the blood in the area of the heart and that blushing is concomitant with feeling ashamed, while turning pale with being afraid. ${ }^{99}$ There are no grounds for saying that Aristotle denied that a similar relation exists in general between alteration of psychological and of perceptible qualities, an assumption which from our point of view seems very reasonable. ${ }^{100}$

But if I am right, and every alteration of psychological qualities indeed goes hand in hand with an alteration of the perceptible qualities of the respective body, then from what I stated above it follows that psychological alterations, too, involve alterations of tangible qualities and thus also with respect to the elements and principles of the substance's body to which they belong. That is to say, a change of state, for example becoming a virtuous person, also goes hand in hand with certain changes that the elemental bodies undergo with respect to the four basic qualities. Therefore, there are very good reasons for saying that the claim about change in quality from $G C$ II 4 is correct, i. e., that indeed every alteration is also an alteration in respect of tangible qualities, insofar as any such change involves a change with respect to the four basic qualities of hot-cold and dry-moist. As we have seen, however, this does not mean that alterations in general can be reduced to such changes. Now that it is clear that when something undergoes alteration it also undergoes a change with respect to the four basic qualities, it remains to show that a change in the basic qualities, again, always goes hand in hand with condensation or rarefaction in some way. For then it will become clear that in this way all alterations also involve condensation or rarefaction. This will be accomplished in what follows.

99 For the first example see de An. I 1, 403a31-b1, for the second EN V 9, 1128b13-14. In de An. I 1, 403a3-25, Aristotle states that affections of the soul in general most likely cannot occur without a corresponding affection of the body.

100 We would say for instance that a learning process, be it becoming educated or virtuous, goes hand in hand with the formation of new synapses in the brain and hence has a material correspondent. 
4.4.4 Every change in the four basic qualities involves condensation or rarefaction

So far it has become clear that Aristotle in saying that $\pi \dot{u} x \nu \omega \iota \sigma \varsigma$ and $\mu \alpha \dot{\nu} \omega \sigma \iota \varsigma$ are principles of all qualities and hence of all alteration, is claiming that any such changes involve some change in density that occurs with respect to the thing that alters. I have already presented the first part of the reason for this claim, namely that any change in quality necessarily involves a concomitant change with respect to the four basic qualities of the change's subject. Now I will argue that this change of the four basic qualities necessarily involves condensation and rarefaction, and in consequence, it will become clear that every alteration, in virtue of occurring by means of a change in the four elemental qualities, always goes hand in hand with condensation or rarefaction.

That a change from hot to cold, or vice versa, goes hand in hand with condensation and rarefaction is clear from examples stated at an earlier point in the discussion. As each of the elemental bodies becomes hotter or colder, a change in volume also occurs. As we have seen, as water is heated it expands and becomes more rarefied, but contracts when cooled. The same is true of the other elements. This already suffices, since these phenomena according to Aristotle can be explained by making use of the concepts of condensation and rarefaction.

But, as we have seen, for the argument to work, condensation and rarefaction also have to be "sources" of $d r y$ and moist, as well as of the change from one of the two contraries to the other. Although Aristotle does not explain in what sense this is the case, I think it follows from his theory insofar as it can be inferred from the role the basic qualities of dry and moist play for the simple bodies. To which of the four elements an elemental body belongs, i.e. which form it has, depends on the way in which the four basic kinds of qualities are combined. Fire is characterised by the qualities of hot and dry, air by hot and moist, water by cold and moist, and earth by cold and moist. ${ }^{101}$ If an element is affected in such a way that one of its defining qualities turns into its contrary, then the elemental body as this particular elemental body perishes, and a new one that belongs to the kind of simple bodies characterised by the new combination of the basic qualities comes to be. If, for example, water, which is essentially characterized by a combination of cold and moist, is affected in such a way that its being moist is overcome $(\varkappa \rho \alpha \tau \varepsilon i \nu)$ by dryness, as Aristotle puts it, then the water perishes in the process, and earth, which is cold and dry, comes to be instead. ${ }^{102}$ Con-

101 See GC II 3, 330b1-9.

102 See GC II 4, 331a32-36. 
comitant with this change, however, is the water's change in density, for a smaller portion of earth arises from a larger portion of water. As we have seen with respect to the change from water to air, this seems to be true in general for any process of transformation from one kind of element to another, since the difference in size between the portion of the perishing element and the portion of the element that has come to be occurs without any additional matter being added and thus is a process of either condensation or rarefaction as described in Phys. IV 9. ${ }^{103}$ Accordingly, any change from one element to another involves a change in density, as the change in size cannot be explained otherwise.

That this must be what happens becomes clear in another way. We saw in the previous section that any transformation of an element into another

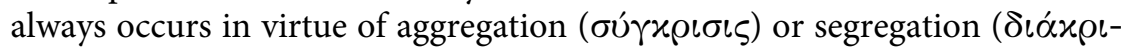
$\sigma \iota \varsigma)$. Therefore, when for example earth is turned into water, or fire into air - in each case a change from dry to wet taking place-aggregation or segregation of the elemental bodies are necessarily involved in both processes. ${ }^{104}$ As I will have to show later on ${ }^{105}$, the aggregations and segregations that occur when elements are being transformed are processes of condensation and rarefaction, i.e. changes in the respective thing's density. Thus, it is clear that of the two basic pairs of qualities, not only a change with respect to hot-cold, but also to dry-moist always corresponds to a change in the density of that which is affected.

As we have seen above, any alteration necessarily involves a change with respect to the four basic qualities of hot-cold and dry-moist. In addition it has just become clear that every change with respect to these four basic qualities, again, goes hand in hand with condensation or rarefaction, i.e. a change in density. Therefore, one is justified in inferring that any change in quality -in virtue of involving a change with respect to the four basic qualities-also requires the occurrence of either a $\pi \dot{u} \varkappa \nu \omega \sigma \iota \varsigma$ or a $\mu \alpha \dot{\alpha} \omega \sigma \iota \varsigma$, that is, a change in density.

This then is the sense in which the processes of condensation and rarefaction may be seen as sources of all other qualities: all kinds of qualities

103 In the example from Phys. IV 9 a larger portion of air comes to be from a smaller one of water. The water changes in size without any additional stuff being added (see 214b1-2). That $\pi \dot{x} \nu \omega \sigma \iota \varsigma$ and $\mu \alpha \dot{v} \nu \omega \sigma \iota \varsigma$ always go hand in hand with a change in quantity is also clear from the way they are characterised in the discussion of Phys. IV 9. If condensation and rarefaction for Aristotle did not imply a change in size of their respective subject, there would be no reason for Aristotle's opponent to claim that only the existence of the void can explain why the universe does not bulge, nor for Aristotle to discuss this problem in the way he does (See Phys. IV 9).

104 See for instance Mete. I 3, 340a8-10, where the change from air to fire is described as a process of segregation.

105 See section 4.4.5. 
have in common that each of them is connected with a certain state of density. When there is an alteration and the quality changes, there is always a concomitant change with respect to density, that is, condensation or rarefaction. By referring to these two processes one can explain part of what happens when something undergoes alteration, namely that its basic material components, or at least some of these, change with respect to density. And this is the sense in which $\pi \dot{u} x \nu \omega \sigma \iota \varsigma$ and $\mu \alpha \nu \omega \sigma \iota \varsigma$ may be called a principle or source ( $\left.\alpha \rho \chi \dot{\eta}^{\prime}\right)$ of all qualities. Of course this does not mean that the basic qualities, much less any quality, can be reduced to states of rarity and density or changes in these qualities to condensation or rarefaction, although this passage has been understood this way. ${ }^{106}$ To evaluate the argument, one needs to have its context in mind. Aristotle is referring to condensation and rarefaction as essential parts of alteration in order to show that alteration, too, necessarily involves change in place and that locomotion therefore is prior to alteration.

Therefore, there clearly is a certain sense in which one could correctly argue that alteration has its source in condensation or rarefaction, namely by focusing on special processes that occur on what one could call the material level. Yet, this alone of course does not show that locomotion is the primary kind of change. In order to reach this goal another step is taken by Aristotle in his argument. This next step is to identify condensation and rarefaction with aggregation and segregation, the latter of which, as I have already argued, necessarily involve a change in place. Therefore, I will now examine whether Aristotle's claim that "condensation and rarefaction are aggregation and segregation" 107 is correct.

\subsubsection{Condensation and rarefaction are forms of aggregation and segregation}

To my knowledge, there is no other place in which Aristotle explicitly says anything about the relation between condensation/rarefaction and aggregation/segregation. Therefore, I will attempt to characterize the relation between them by examining his use of the terms (rather than by examining what he explicitly says about them).

The way in which the terms are applied clearly suggests that the claim about the relation of the two pairs of phenomena as it is stated in Phys. VIII 7 is indeed what Aristotle has in mind, and not, as one might think, merely a reference to the theory of an earlier philosopher. For there are some passages in Aristotle in which processes in nature that are described in terms

106 Therefore, I do not agree with Graham (1999), 122, who thinks that in this argument

"Aristotle seems to reduce apparently simple qualities to condensation and rarefaction".

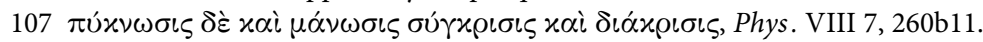


of aggregation and segregation on one occasion are characterised with reference to condensation and rarefaction on another. The evidence I will present is once again based primarily on passages from the Meteorology, although more relevant passages may be found in other places.

In some places, for instance the change from air to water is described as aggregation $(\sigma \dot{\gamma} \gamma x \rho \iota \sigma \iota \varsigma)$, while in others the very same process is termed condensation $(\pi \dot{\kappa} \times \nu \omega \sigma \iota \varsigma) .{ }^{108}$ Another example is the explanation of certain phenomena of light that occur in the sky: Aristotle accounts for these phenomena as being the result of an aggregation of air in the heavens. The more a portion of air is aggregated $(\sigma \cup \gamma x \rho t \theta \tilde{\eta})$, the easier it is to ignite. Conversely, things are described as being less likely to catch fire when they are in a state of rarity ( $\mu \alpha \nu$ ó$\left._{\tau}\right)$ ). ${ }^{109}$

But if for Aristotle condensation and rarefaction indeed are kinds of aggregation and segregation, why does he not simply say that the latter are sources of all qualities, rather than introducing what seems to be a superfluous premise that uses the terms $\pi \dot{u} x \nu \omega \sigma \iota \varsigma$ and $\mu \alpha \dot{\nu} \omega \sigma \iota \varsigma$ ? My assumption is that although it is right to say that every condensation is an aggregation and every rarefaction a segregation, the converse does not hold. Rather, condensation and rarefaction seem to be sub-classes of aggregation and segregation. The difference between $\pi \dot{u} x \nu \omega \sigma \iota \varsigma / \mu \alpha \dot{\alpha} \nu \omega \sigma \iota \varsigma$ and $\sigma u ́ \gamma x \rho \iota \sigma \iota / \delta \iota \dot{\alpha}-$ xpırıs is that the former two terms seem to be restricted to changes undergone by a subject that has some kind of unity. A certain portion of earth or water, for instance, can undergo condensation or rarefaction, since the respective portion can serve as one continuous thing due to its continuity and therefore can expand or contract by being either condensed or rarefied. Speaking of these two processes presupposes a subject that is characterised by some basic kind of unity, as it does not make sense to say that for example two drops of water undergo one process of condensation.

The situation is different for $\sigma \dot{\gamma} \gamma x \rho \iota \sigma \iota s$. As I think the examples show, the term aggregation basically encompasses all cases of condensation. But in addition it also covers cases in which one thing comes to be from a combination of other separate things. For example it is possible that two different things, e.g. two portions of water, undergo aggregation and combine

108 For the transformation from air to water as $\sigma u ́ \gamma x \rho \iota \sigma \iota \varsigma$ see for instance Mete. I 3, 341a4 and 341a9-10. For the characterisation as $\pi u ́ x \nu \omega \sigma \iota \varsigma$ see Mete. I 12, 348b10-12, III 2, 372b30-33, and III 2, 372b22-24. In the latter passage Aristotle talks about the process by which vapour, that is very moist air, is turned into water. The reverse process from water back to vapour accordingly is called a $\delta \iota \alpha \chi \rho \iota \sigma \iota \varsigma$ in Mete. I 3, $340 \mathrm{~b} 3$.

109 For the first see Mete. I 5, 342b16-17, where it is stated that these phenomena often appear in the night sky "when [air] becomes further aggregated" (ó $\tau \alpha \nu \sigma \nu \gamma \chi \rho \iota \theta \tilde{\eta} \mu \tilde{\alpha} \lambda \lambda o \nu$ ), for the second Mete. III 1, 371a27, where an object is said to be less ignitable by a fiery wind, because of its rarity (for the whole context of this see 1.15-27). 
into one larger drop of water. ${ }^{110}$ This is what happens when a mixture $\left(\mu i \xi_{\imath \iota}\right)$ is being formed; different portions of different elements are combined into a whole new product. The process of mixing, however, is explicitly identified by Aristotle as an aggregation. ${ }^{111}$ Yet, we would not say that from the condensation of a portion of earth and another one of fire flesh comes to be. ${ }^{112}$ This process is for Aristotle an aggregation, but nonetheless a portion of flesh that came to be by means of aggregation may very well undergo condensation once again.

The same is true of rarefaction. When Aristotle says that a portion of water becomes rarefied he is not referring to a process in which it is divided into other separate portions of water. Furthermore, the passages in which $\mu \alpha \dot{\nu} \omega \sigma \iota \varsigma$ is used suggest that he rather seems to be thinking of a change in which the underlying thing expands without loosing its basic sense of unity. This process of course may ultimately lead to the destruction of this whole. But if it were destroyed in the sense that it came to lack its sense of unity, this would no longer be a rarefaction, but could still be appropriately be called a segregation-for this is exactly what happens when composite substances perish and are dissolved into more basic components. Even though processes of rarefaction certainly are involved when a body is decomposed, it would be absurd to say that this decomposition is merely a rarefaction. This dissolution of the mixture is a segregation.

One reason why Aristotle uses the terms condensation and rarefaction to describe alteration could then be that describing it in terms of aggregation and segregation may suggest that a change in quality might involve the segregation, and potentially the corruption, of the change's subject-a conclusion Aristotle surely wants to avoid.

\subsubsection{What changes in quality changes with respect to place}

As I have already stated in the chapter on the relation between substantial change and locomotion, every case of aggregation and segregation is accompanied by a change in place of its fundamental material components. Since condensation and rarefaction are aggregations and segregations, it is clear that these phenomena are connected with change in place in the same way. Accordingly, alteration also necessarily involves change in place in the sense that whenever an alteration occurs a change in place with respect to the fundamental material components or parts must occur as well. That

110 See GC I 2, 317a27-29.

111 See GC I 6, 322b8.

112 See Met. VIII 17, 1041b13-14, where it is stated that fire and earth are the elements of flesh. 
locomotion, by contrast, does not presuppose, condensation, rarefaction, alteration, or any other kind of change is clear from my discussion of the relation between change in quantity and locomotion, for there it was shown that it is a unique feature of locomotion that-in the strict sense-it does not involve or depend on any other change. ${ }^{113}$ In this sense the argument has shown that locomotion is ontologically prior to alteration.

\subsubsection{Conclusion}

In this section I have shown that Aristotle in a sense is correct to claim that condensation and rarefaction are a source of all qualities and thus of all changes with respect to quality, as there is a corresponding change in density for any alteration that occurs. This is because any alteration necessarily involves a change with respect to the two pairs of elemental qualities of hotcold and dry-moist, which again goes hand in hand with a change in the relevant thing's density. By making use of the way in which Aristotle applies the terms condensation, rarefaction, aggregation and segregation it then became clear that change in density, i.e. $\pi \dot{x} x \nu \omega \sigma \iota \varsigma$ and $\mu \alpha \dot{\nu} \omega \sigma \iota \varsigma$, is a kind of aggregation and segregation and therefore, like the former, necessarily involves change in place.

Thus, locomotion is also prior to and more fundamental than alteration insofar as every change in quality is necessarily accompanied by locomotion, but not vice versa. For, that which alters due to condensation or rarefaction also changes in place at the same time, namely with respect to its basic material components, while locomotion does not necessarily involve any other change whatsoever.

The examination has therefore made clear that this argument, too, may be read as presenting Aristotle's own assumptions, as these not only are in accordance with Aristotle's theory, but also play an important role in showing another way in which locomotion is the primary kind of change.

\subsection{Conclusion}

Although Aristotle does not explicitly qualify the sense of priority the argument was supposed to demonstrate with respect to locomotion, the second argument taken as a whole makes clear that locomotion is primary insofar as change in quantity, quality, and substance is necessarily accompanied by a change in place, since their respective subject changes in place in the sense

113 See section 4.2 .3 . 
that its basic material parts or components do so. The converse, however, does not hold: there is no need for locomotion to be accompanied by any of the other changes. In fact, I have shown that it is a specific feature of locomotion that in the strict sense its subject does not change in any other respect than place and that its inner order is left completely untouched, so to speak. But since locomotion therefore does not entail the occurrence of any of the other kinds of change, while each of the other types cannot occur without locomotion, it again became clear that locomotion has ontological priority over the other three kinds of change, although in a different sense than that presented in the first argument for locomotion's priority.

My analysis has also shown that the argument as a whole, contrary to what many scholars say, not only can be read as a statement of Aristotle's own theory, but should be read as such, for several compelling reasons. There is no need to take the argument as one in which Aristotle merely argues from his predecessors' point of view in order to show that the priority of locomotion also would follow from their partly mistaken assumptions. In fact the argument presents important reasons for the assumption that locomotion is the primary kind of change.

Yet, it has also become clear that Aristotle makes use of terms that were coined by his predecessors and that he himself seems to use only in certain contexts. I hold that he has at least two reasons for doing so. These reasons also tell us something about the specific role the second argument plays in the larger project of showing the primacy of locomotion. Firstly, using these notions helps to focus on what one might call the material side of the different kinds of change. This special perspective on the phenomenon of change enables Aristotle to show that locomotion is ontologically prior to the other kinds of change from this specific point of view as well: with respect to the most basic level of explanation, namely that of the elements and principles of composite substances. Without locomotion none of the other kinds of change could occur, while the occurrence of change in place does not depend on any of the other kinds.

This leads us to the second point. This special perspective also made it possible for Aristotle to reject a view held by his predecessors, namely that there may be other processes that are more fundamental than locomotion and that accordingly should be called primary. If this were the case, it might threaten Aristotle's claim that locomotion as the primary, i.e. most fundamental, change is the only possible candidate for being directly caused by the first unmoved mover. He was successful in this respect as well. 


\section{All changes depend on the first locomotion, but not vice versa}

\subsection{Overview}

Apart from some remarks about the different kinds of priority that I will focus on later in this chapter, the third argument follows directly after the second one and is presented in the following passage:

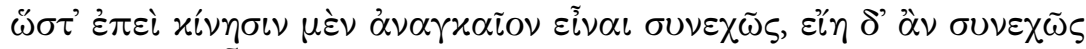

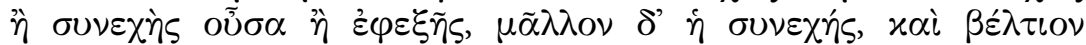

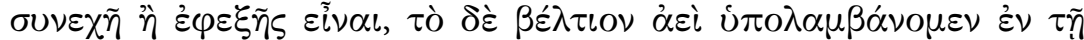

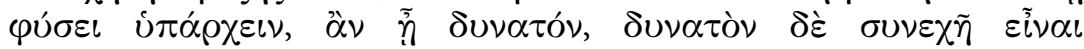

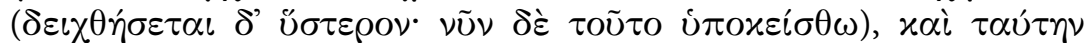

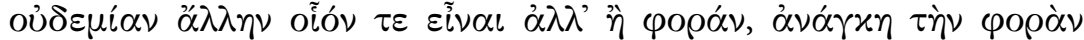

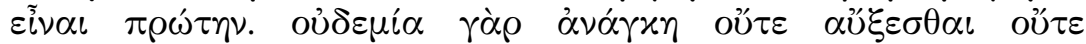

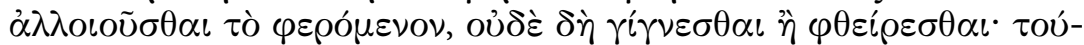

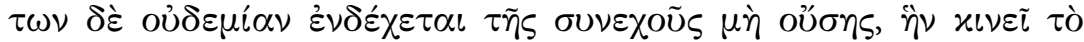

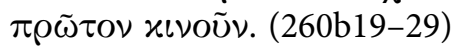

Therefore, as change must exist continuously, and it would exist continuously either by being continuous, or [by being] a succession of changes, but in a fuller way the continuous one, that is, it is better to be continuous than to be in succession, and we presuppose that the better is always the case in nature, if it is possible, and [since] it is possible that it is continuous-this will be shown later, but let us just suppose it for now, and that this can be no other [change] than locomotion-locomotion must be primary. For neither is there necessity for that which undergoes locomotion to undergo growth, nor alteration, nor generation or corruption. But of these [other changes], none may [be] if the continuous one is not, which the first mover is causing.

The third argument basically shows that locomotion has ontological priority over the other kinds of change, since only a change in place in principle may be one, continuous, and eternal and thus is the only possible candidate for being the one eternal change which is directly caused by the first unmoved mover. This means that change in place in virtue of being this only candidate is necessary for the occurrence of any of the other three 
types of change, but not vice versa $a^{1}$ : since every change in the cosmos depends on this first eternal change, while it itself does not presuppose the occurrence of any other change, there is an asymmetric relation of ontological dependency between this primary change of place and all other kinds. And this, in addition to what was presented in the first two arguments, is another sense in which locomotion has ontological priority. Accordingly, the argument implies that whenever there is any change, one needs to presuppose the occurrence of locomotion, while there being locomotion in no way entails the occurrence of some other change.

The way in which the argument is presented, however, is not straightforward and at first glance it is not easy to distinguish the different steps that Aristotle makes from one to another in his argumentation. The passage begins by stating one of the two main premises of the argument, namely that "change must exist continuously". What Aristotle certainly means by this is that change must exist without intermittence, that is, it must be eternal. ${ }^{2}$ This clearly is a reference to the claim for which Aristotle argued in the first two chapters of Book VIII of the Physics. There it was shown that if there is change in the cosmos in the way we observe it, then change has always existed and will always exist, i. e., is eternal. ${ }^{3}$ The first of the two main premises on which the third argument for the priority of locomotion relies then is that change exists eternally. As I will show, Aristotle rightly assumes that the everlasting change clearly needs to be one single change and cannot be a composite of more or less independent changes, since it is directly caused by the first unmoved mover, which is characterised as causing a change that is one in a special sense and eternal. This is where locomotion comes into play, for, as Aristotle claims in the second main premise of the argument, this eternal change "can be no other [change] than locomotion." ${ }^{.4}$ From these two premises Aristotle then draws the conclusion that locomotion must therefore be primary. ${ }^{5}$ Consequently, in this argument locomotion's primacy, contrary to what one might think at first glance, does not derive from the fact that locomotion alone can be the one eternal change that is caused directly by the first unmoved mover, but according to

1 A more general definition of ontological priority, as I shall show later on, will be that $x$ is prior to $y$ in this way, if and only if there is $y$ there also must be $x$, but not vice versa. See 5.4.1 for more on this.

2 This also seems to be what most of the commentators think. See Philoponus, In Phys. 8, 897, 17-18, Simplicius, In Phys. 8, 1269, 17-18, Aquinas, In Phys., L. VIII, 1.XIV, 1091, and Wagner (1967), 689.

3 See for instance Phys. VIII 1, 252b5-6.

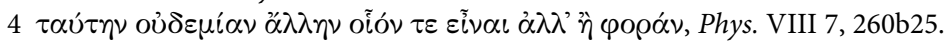

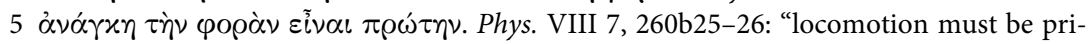
mary." 
Aristotle is due to the fact that it, in virtue of being the only possible candidate for this change, is responsible for the occurrence of any other change in the universe. It is this extra step which makes locomotion's ontological priority clear by establishing a connection between the change of things in the cosmos and the unmoved mover as first cause of all changes. Although of course different steps are being taken in the argument, the basic thought behind this passage accordingly seems to be this:

(1) There is one continuous and eternal change.

(2) Only locomotion can be this change, of which the first unmoved mover as the source of all change is the direct cause, since it alone can be one, continuous and eternal.

(3) Therefore, locomotion has ontological priority.

But before this inference can be made, a more thorough analysis of the argument is necessary. I will proceed as follows: first, I will focus on showing in what way the fact that change exists eternally must imply here that the eternal change needs to be one single change (5.2). In order to do so, the different ways in which change in principle may be eternal need first of all to be analysed (5.2.1). As I will argue it is clear from the context of Phys. VIII that the only way possible in the context of the argument is that the eternal change is one and continuous (5.2.2). Yet, since this also presupposes understanding which criteria need to be fulfilled for a change to be one and continuous and thus eternal in the required sense, I will examine what is responsible for a change's having oneness or being a unity in the appropriate way (5.2.3). Building on this work I will then be able to show that locomotion is the only one of the four types of change which in principle can be one, continuous and eternal and that for this reason the primary change that has its direct source in the first unmoved mover can only be locomotion (5.3). After that I will relate this fact to the general remarks Aristotle makes on the different kinds of priority and especially to what he says about the kind that is important in this argument, i. e. ontological priority (5.4.1). Against this background I will then show that locomotion indeed has ontological priority over the other kinds of change, since all changes in the cosmos in the end depend on the primary change that the unmoved mover causes, that is to say, on a change in place, while the occurrence of this change in place does not necessarily entail any other change (5.4.2). I will conclude by summarizing the results of this chapter (5.5). 


\subsection{The unity of the eternal change}

\subsubsection{Two ways in which change may be eternal}

As we have seen, the starting point of the argument is the assumption that change is eternal. Aristotle then presents the only two ways in which this in principle may be possible:

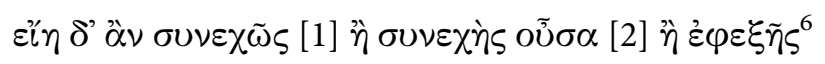

As I will show in this section, these two ways in which change may exist continuously, i.e. be eternal, are that either (1) there is one single change which is "continuous" ( $\sigma \cup \nu \varepsilon \chi n^{\prime} \varsigma$ ) as a whole, or (2) that change is eternal in virtue of there being a succession of changes that follow "one after another" ( $\varepsilon \varphi \varepsilon \xi \tilde{n} \varsigma)$ in some way and thereby so to speak would form an eternal change. The sentence quoted above could accordingly be translated like this: "it would exist continuously either [by being] continuous, or [by there being] one [change] after another." That these are the two basic options for an explanation of how change may be eternal is clear from what the term 'eternal' represents: something $x$ is eternal when there is no time at which $x$ is not. As we have just seen, this accordingly means for change that, given that it is eternal as is stated in Phys. VIII 1, this is the case either because there are a number of different changes that somehow are responsible for there being eternal change, or because there is one single change; either of the two options being the case implies that there is no time at which there is no change. ${ }^{7}$ This, however, makes clear that the term 'change' in this context is used in two different senses, namely as a count noun, in order to refer to one or more individual occurrences of change, but also as a mass term in the sense that Aristotle points out that in general some change is always occurring, without making clear how many different individual changes this involves, i.e. which of these two options is correct. ${ }^{8}$ Aristotle basically argues that change, in the sense of a mass term, exists continuously, in that

6 Phys. VIII 7, 260b20-21.

7 This, of course, does not exclude the possibility that there is one single eternal changeor several eternal changes-and at the same time a number of changes, which taken by itself would already make change eternal. As I said, Aristotle here first of all points out the two basic ways in which it is possible in principle to account for the eternal existence of change.

8 As we will see there is yet another ambiguity with respect to Aristotle's usage of the term change, namely insofar as 'change' as a count noun is applied in two significantly different ways that one needs to be aware of if one is to make sense not only of the argument presented here in Phys. VIII 7, but also of other arguments in Phys. VIII in general. 
there exists either one single individual change that is eternal, or a number of succeeding individual changes.

After presenting the two ways in which change (in the sense of the mass term) may be eternal, Aristotle quickly adds that the continuous change would be continuously "much more" or "in a fuller way" ( $\mu \tilde{\alpha} \lambda \lambda o \nu)$ than the composite change, i.e. that option (1) is to be preferred to option (2). ${ }^{9}$ However, he does not present any further reason for this strange claim, but merely adds another assertion, which also expresses that option (1) is to be preferred, since it is better ( $\beta \varepsilon \hat{\lambda} \tau \iota \mathrm{\nu})$ ) than option (2), again without explaining why this is supposed to be the case. ${ }^{10}$ The two assertions clearly both favour the first of the two principle options for eternal change, but no reasons are presented for either assertion.

A number of questions arise with respect to this passage. One concerns what seems to be the rather unusual way in which the term 'continuous' ( $\sigma \cup \nu \varepsilon \chi \varepsilon \dot{s}$ ) is applied here. According, to the definition of continuity in Phys. VI 1 and V 3 something $x$ is continuous with something $y$ if the limits at which $x$ and $y$ touch are one and the same, so that, one may infer, $x$ and $y$ in this sense form one whole. ${ }^{11}$ But apart from this two-place use of 'continuous' Aristotle also employs a one-place use of the term that is of special importance for understanding what goes on in Phys. VIII and in the third argument for locomotion's priority: for something $x$ to be continuous as a whole means that $x$ potentially is infinitely divisible. ${ }^{12}$

As Aristotle shows in Phys. VI, being continuous in this way is one of the core features of change in general. But if for Aristotle any change is continuous ${ }^{13}$, it is puzzling, and seemingly in tension with a fundamental prin-

$9 \mu \tilde{\alpha} \lambda \lambda$ ov $\delta$ ' $\dot{\eta} \sigma 0 \nu \varepsilon \chi \dot{\eta} \varsigma$, Phys. VIII 7, 260b21: "in a fuller way the continuous one".

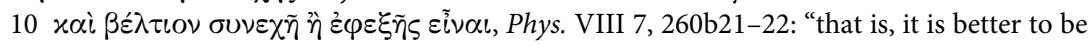
continuous than to be in succession". Thus, the $\chi \alpha i$ at the beginning of the phrase should be taken as exepegetical.

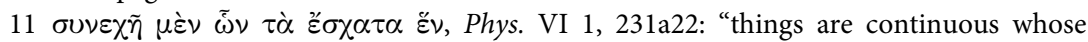
extremes are one". This is also what follows from the explanation stated in Phys. V 3, 227a11-

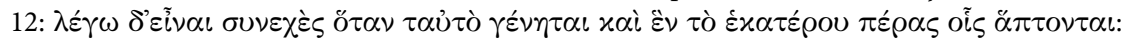
"I say that things are continuous when the limit of each by which they touch has become one and the same".

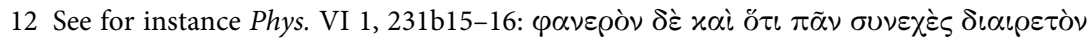

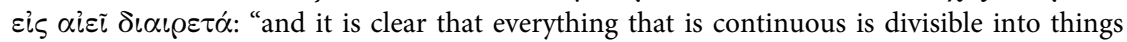
that are always divisible."

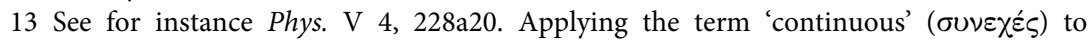
changes is somewhat curious: it is more or less clear what may be meant by saying that the limits of a (continuous) body's parts, for instance, are touching and one and the same. Yet, a change is essentially different from things like bodies, stretches of a road, etc., which makes it seem strange at first to say that a change is continuous because the touching limits of its parts are one and the same. For what exactly, one might wonder, are the limits of change and how 
ciple of Aristotle's theory of change, that a change that is explicitly characterised as continuous in our passage is contrasted with another that supposedly is not, while at the same time both changes by means of the adverbial form of $\sigma u \nu \varepsilon \chi \varepsilon \dot{\varsigma} \varsigma$ are said to exist continuously $(\sigma u \nu \varepsilon \chi \tilde{\omega} \varsigma) .{ }^{14}$ For a change that would be eternal in virtue of being composed of some other changes differs from the first one precisely in its not being continuous, and this seems to be the reason for preferring option (1) to option (2). In order to make sense of the argument as a whole one certainly needs to understand what exactly Aristotle means by these statements and in what way he is correct in making them.

Part of the difficulty lies in the fact that Aristotle here (but also in other places ${ }^{15}$ ) in addition to the two uses of the term 'change' already mentioned, i.e. as a mass term and a count noun, also implicitly presupposes two different notions of the word 'change' ( $x_{i}\left(\nu \eta \iota^{\prime}\right)$ ), namely a wider and a narrower notion, when it is used in the sense of a count noun. One needs to be aware of this difference in order to make sense of the third argument, because it is due to the fact that these two notions seem to be applied here that it is at all possible to confront the case of a continuous change with what seems to be a non-continuous one. The two notions of 'change' are these: on the one hand, the term 'change' may refer to a change that is continuous, i.e. whose (potential) parts form one whole change in virtue of their limits being one and the same. This kind of change is a change in the strict sense of the word, since usually for Aristotle every change must be continuous-in fact it is this very feature which allows Aristotle to reject Zeno's paradoxes in Phys. VI and thereby to make it possible to treat change as a phenomenon that is accessible to scientific inquiry.

On the other hand, there is a notion of change that is of a wider scope and which seems to encompass phenomena that we would also call 'change' in our everyday language, but that according to the strict understanding presented above would not count as one continuous change. The second way in which change (in the sense of the mass term) may be said to be eternal, i. e. by there being an eternal change that is composed of a number of individual succeeding changes so to speak, is an example of Aristotle's use of the wider notion of change. In contrast to the strict sense, such a change

are they supposed to touch? An explanation of this necessarily will need to refer to the different factors that determine a change, i.e. the subject, the realm (e.g. place or quality), and the time with respect to which the change occurs.

14 Therefore, Graham (1999), 125, is right when he notes that the use of $\sigma v \nu \varepsilon \chi \tilde{\omega} \varsigma$, at least at first glance, "as a modifier for cosmic motion is potentially misleading" because Aristotle "does not intend this qualification by itself to entail continuous motion" contrary to what one might think.

15 See for instance also Phys. V 4 (see p. 121, n. 17). 
consists of parts that for some reason do not form a continuous whole, but are merely in succession ( $\dot{\varphi} \varphi \xi \xi \tilde{\eta} \varsigma)$, because for two things $x$ and $y$ to be $\dot{\varepsilon} \varphi \varepsilon \xi \tilde{\eta} \varsigma$ means that $x$ is followed directly by $y$ without there being anything of the same kind between them. ${ }^{16}$ Nonetheless, these changes somehow seem to form some kind of unity, namely with respect to time, because the fact that one of these parts follows directly after the other is what allows us to speak of there being eternal change in the sense of the mass term, or even of there being an eternal change, although this is only true in a looser sense, since the parts as I will show later on cannot be continuous with one another. $^{17}$

To put it more generally the term 'change' in this sense stands for a change that consists of more or less independent changes that according to Aristotle are unable to form a whole in the same sense as a change that is continuous, but that nevertheless form a unity in some looser sense. This usage allows us to call the succession of two changes $c_{1}$ and $c_{2}$ one change, even if this would not count as a change in the stricter sense. The stricter usage, however, refers to a change whose parts are not independent, as they are continuous parts of this one change and not merely a loose succession of changes. This is what one has to have in mind when analysing Aristotle's comparison of the two ways in which change may be said to be eternal. On the one hand, there is a sequence of changes, of which, because one change follows the other, it is possible to say that there is, in a certain sense, an eternal change and that change in general therefore exists continuously, i.e. is everlasting. On the other hand, there is one single continuous, i.e. noncomposed, change which exists continuously and is eternal.

\subsubsection{Why the eternal change must be one and continuous}

But now that we have seen what Aristotle has in mind when he contrasts the two ways in which change basically may be eternal, it is still unclear why he prefers the first option, i. e. that of one eternal continuous change, to the second option. For both options, as Aristotle himself points out, in principle may serve to explain in what way there can be eternal change.

16 See Phys. V 3, 226b34-227a4, and VI 1, 231a23. Note, however, that this is not necessarily the case for things that are in succession' to each other, since two things that are continuous are also always $\dot{\varepsilon} \varphi \varepsilon \xi \tilde{\eta} \zeta$, while two things that are $\dot{\varepsilon} \varphi \varepsilon \xi \tilde{\eta} \varsigma$ do not necessarily have to be continuous (see Phys. V 3, 227a17-22).

17 For another example of a non-continuous change see for instance Phys. V 4, 229a5-6, where Aristotle speaks about "the [change] which is composed of alteration and locomotion"

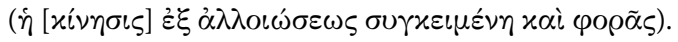


But here as well it is important to have the context of this passage in mind: the passage is not merely about explaining how change in principle may be eternal-since this has already been discussed at the beginning of Phys. VIII; although this argument as we will see stands on its own, it nonetheless is an argument for locomotion's primacy over the other kinds of change, i. e. for the claim that the change of which the first unmoved mover is the direct source must be locomotion. But as is stated in Phys. VIII 6, from the assumption that there needs to be one single unmoved mover it follows that this primary change must be one and continuous. ${ }^{18}$ Against this background it becomes clear why the first of the two ways in which change may exist continuously is favoured: basically, Aristotle tells us, it is correct that eternal change may be explained by the two aforementioned options; but when it comes to explaining the one eternal change which the unmoved mover causes directly, the second option does not work any longer and may be excluded, for a change that consists of a sequence of changes does not seem to Aristotle to be one and continuous. This, however, must be the case for the change of which the first unmoved mover is the direct source. Aristotle goes on to argue that the only kind of change which can be eternal, one and continuous is locomotion, from which it follows that locomotion is primary, because only it can be the kind of change that is directly caused by the first unmoved mover. ${ }^{19}$

Yet, as we have seen, Aristotle does not explain in this argument why it is that two or more different changes, one of which follows directly after the other, cannot be continuous and form one eternal change. Rather, since his reasons for doing so are far from obvious, he seems to presuppose that we are familiar with them. ${ }^{20}$

18 See Phys. VIII 6, 259a15-18.

19 The question why the first of the two options is more appropriate and better is hardly discussed by most commentators, although it is essential to make the connection to the rest of Phys. VIII that I have pointed out, for without this it is unclear why the first of the options should be preferred. Aquinas thinks that the reason for preferring option (1) lies in the fact that an eternal change that is consecutive has "more of the nature [ratio] of unity and eternity." (Transl. Blackwell et al. (1999)) ("plus habet de ratione unitatis et perpetuitatis", In Phys., L. VIII, 1. XIV, 1091). Yet, he does not explain in what way it belongs more to the account of eternity to be one and continuous. The only one who tries to explain why it is better for the eternal to be one single continuous change by relating the argument to the broader context is Philoponus, who points out In Phys. 8, 897, 19, that this option is to be preferred, since a continuous change is the one which appropriately may be said to have its cause in god

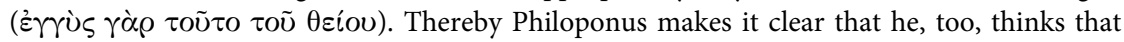
Aristotle here is talking about the eternal change whose direct source is the first unmoved mover.

20 In Phys. VIII 6 Aristotle of course makes the claim that only changes which are continuous may be one and that those which consist of one change following after another ( $\dot{\varepsilon} \varphi \varepsilon \xi \tilde{\eta} \varsigma)$ are not, but he does not present a reason for this claim there. See Phys. VIII 6, 259a16-18. 
Suppose, for instance, I were to set up lines of dominos standing on their ends, and after finishing such an arrangement, I were to push the first tile so that it knocks over the second, which topples the third, and so forth until all of the tiles have fallen. Each case of a toppling domino, of course, is a single change. But could one not also say that the process of one tile falling after another basically forms one single and continuous change in some way, if executed in a perfectly uniform manner? And if this really were the case, could we not go one step further and modify the thought experiment in such a way that an eternal change will be the outcome? For, suppose I were to make a line of tiles along a circular path, and that I were somehow able to stand each fallen tile on its end right after it falls (for example by using a robot or a special kind of machine). Once I start the process it could go on for ever, provided nothing is changed in the arrangement. In this way it seems that a change that may be thought of as one by being composed of a number of other changes would be eternal (at least in one direction).

As we will see, Aristotle would deny that the first example is one continuous change and hence that the same applies to the second example. The reasons for this are stated in Phys. V 4, where Aristotle discusses different ways in which a change may have oneness or unity. Since the third argument for locomotion's primacy is obviously based on the claim that a succession of changes that occur one after another cannot result in one continuous change, we should understand what the basic criteria are for saying that such changes taken as a whole cannot be one and continuous, and, therefore, why the second option for explaining that change is eternal may be ruled out. Aristotle obviously presupposes that the reader is acquainted with the account of unity and oneness of change that is presented in Phys. $\mathrm{V} 4$ and of which the current discussion clearly makes use to a certain extent. In what follows, I will therefore present parts of this account insofar as they are of importance for understanding the argument.

\subsubsection{The criteria for being one continuous change}

In Phys. V 4 Aristotle presents different ways in which a change may be said to be one. ${ }^{21}$ For the purposes of our discussion only one of these kinds, namely being one without qualification $(\dot{\alpha} \pi \lambda \tilde{\omega} \varsigma)$ is of importance, since as we will see this is the kind of unity that is specific to the change which is

21 In Phys. V 4 five ways in which a change may be called one ( $\mu i \alpha$ xi

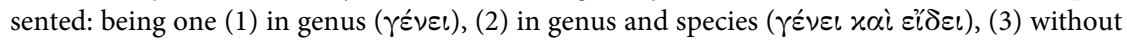
qualification ( $\dot{\alpha} \pi \lambda \tilde{\omega} \varsigma)$, (4) by being regular $(\delta \mu \alpha \lambda \tilde{\eta} \varsigma)$, and (5) by being complete ( $\tau \varepsilon \dot{\lambda} \varepsilon \varepsilon\llcorner\varsigma)$. All five of them are of importance in the discussion of Phys. VIII 7-9. 
primarily caused by the first unmoved mover and that according to Phys. VIII 6 must be one, eternal and continuous. ${ }^{22}$

Every change, Aristotle tells us in Phys. V 4, is basically determined by three factors: every change presupposes (1) a subject which is undergoing

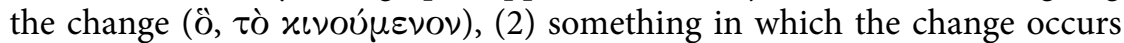

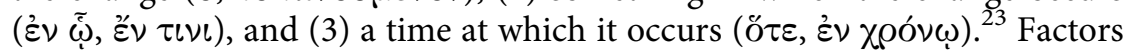
(1) and (3) are clear, but (2) needs further elucidation. Suppose, for instance, I am walking from my office to the cafeteria: the subject of the change is me, as I am the one undergoing a change in place. I may need five minutes to arrive at the cafeteria, so that the time in which the change occurs will be these five minutes. Factor (2), i.e. the that in which of the change, refers to the genus and species to which the change belongs. My walk from the office to the cafeteria is a change in respect of place and may be qualified even further with respect to the respective species of the change. ${ }^{24}$ For a change to be one without qualification, Aristotle tells us, each of these three factors has to be one. As the discussion in Phys. V 4 shows, Aristotle, by presenting these three criteria for being one change without qualification, spells out what it implies to be one continuous change with respect to these three factors. ${ }^{25}$ The three conditions that need to be fulfilled for a change to have this kind of unity are as follows:

1. The subject that undergoes the change must be one ${ }^{26}$

2. That in which the change occurs must be one and indivisible ${ }^{27}$

3. The time in which the change occurs must be one and without any gaps $^{28}$

This becomes clearer when we look at some of the examples which Aristotle presents in this context and which illustrate cases in which the unity of a change is not given. In one of these examples two men are recovering from the same disease at the same time. ${ }^{29}$ In this case conditions (2) and (3) are

22 See Phys. VIII 8, 261b36-262a5, where Aristotle points out that a change that is one in the necessary sense needs to fulfil the three criteria of being one $\delta \pi \lambda \tilde{\omega} \varsigma$ that I present in this section.

23 See Phys. V 4, 227b23-26.

24 Note that, unlike in Phys. V 1, the $\dot{\varepsilon} v \bar{\varphi}$ accordingly does not stand for the time in which the change occurs (see Phys. V 1, 224a35).

25 See Phys. V 4, 228a31-b10.

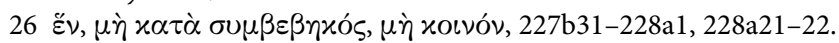

$27 \varepsilon \check{\nu}, \alpha \ddot{\alpha} \tau \mu o \nu, 227 \mathrm{~b} 29-30$.

$28 \varepsilon \dot{\varepsilon} \nu \alpha, \mu \grave{\eta} \delta \iota \alpha \lambda \varepsilon i \pi \varepsilon \iota \nu, 227 \mathrm{~b} 30-31$.

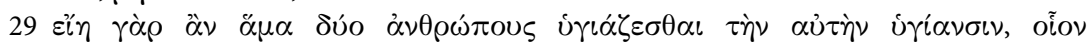
o่ $\varphi \theta \alpha \lambda \mu i \alpha \varsigma$, Phys. V 4, 228a1-2: "for there might be a case of two men at the same time restored to health in the same way, as for instance from a disease of the eyes" (Transl. Hardie \& Gaye with mod.). 
fulfilled: the two changes are one in genus and in species, both are alterations that lead from the same starting point, that is a certain disease of the eyes, to the same endpoint, the health of the eyes, and both changes occur at one and the same time. But since both processes take place in two different men and therefore in two different subjects, condition (1), the unity of the subject, is not fulfilled. This also makes clear why the domino example does not present the case of a change which is one without qualification: also in the two domino examples condition (1) clearly is not fulfilled, since each domino is the subject of a single change. Therefore, it is clear why this kind of change cannot be one, for what should one say is undergoing this change? There is no continuous whole which may serve as the subject of this change, a change that is composed of a number of succeeding changes.

This chapter also explains why changes that fulfil conditions (1) and (3), but not condition (2) cannot be one without qualification and continuous as a whole, and for this reason a fortiori cannot be eternal. Consider the following of Aristotle's examples. Suppose a man immediately after having changed his place by running a mile falls into a fever, i.e. is subject to an alteration. ${ }^{30}$ One might think that the subject is one since in both changes the man undergoes a change. The time is one as well, as the latter change immediately follows the former. Why should one not say that this is one continuous change?

The reason Aristotle presents is this. Any change that is a change in the strict sense is continuous. As we know from the explanation of 'continuous', something is continuous if the limit at which its parts touch are one and the same. ${ }^{31}$ Accordingly, the limit at which adjacent parts of one continuous change touch must be one and the same. The same is true for two changes, if we are to think of them as parts of a continuous change that may be formed by them: the extremes ('́ $\sigma \chi \alpha \tau \alpha)$, i. e. the limits ${ }^{32}$, at which the two changes touch need to be one and the same. But this is the reason why two changes that differ in genus can never form one continuous change. Think of Aristotle's example again: although it is possible that a man, immediately after having run a mile, falls into a fever, it is impossible that the extremes of the change in place and the change in quality become one. The extremes of the two changes differ in category, one being the end of the run that is connected to a certain place, the other the starting point of falling into a fever, a certain quality. The same, of course, is true of any two changes which differ with respect to the genus in which they occur. A succession of changes that differ in genus, therefore, can never form one

30 For this example see Phys. V 4, 228a27-28.

31 See p. 119, n. 11 and n. 12.

32 As Phys. V 4, 228a29-30, in combination with the explanation of $\sigma u v \varepsilon \chi \varepsilon \varepsilon \varsigma$ in V 3, show, Aristotle thinks of the extremes ( $\left.\varepsilon^{\prime} \sigma \alpha \tau \alpha\right)$ of changes as their limits $(\pi \varepsilon \rho \alpha \varsigma)$. 
continuous change, i. e. can never constitute one single change without qualification.

But it is important to note that, although such changes cannot be considered one without qualification, there nonetheless is a way in which a number of changes that at least stand in the relation of one coming right after the other $(\varepsilon \varphi \varepsilon \xi \tilde{\eta} \varsigma)$ may form a certain whole and be called continuous

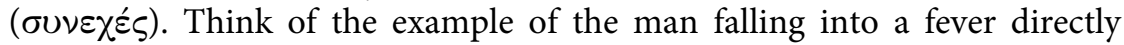
after his run: the locomotion and the alteration that immediately follows it occur in one uninterrupted stretch of time and in this way may be said to be continuous with respect to time. For this reason Aristotle is right when he states in the third argument for locomotion's priority in Phys. VIII 7 that the fact that there is a succession of changes in principle explains how there can be eternal change, namely with respect to the time in which the changes occur as a whole. Yet, this does not change the fact that changes which differ in genus can never form one continuous whole, since it is impossible for their extremes to be one and the same. Accordingly, it is clear why certain changes, although they occur one after another ( $\varepsilon \varphi \varepsilon \xi \bar{\eta} \delta)$, cannot form one single and continuous change and, therefore, a fortiori cannot form one continuous change that is eternal.

From what we have seen it is clear that a change in place and a succeeding change in quality for instance cannot form one continuous change and that accordingly there is no way in which a combination of generically different changes can comprise one continuous change that is eternal. But it is still unclear why Aristotle claims in Phys. VIII 7 that a combination of changes that differ from the example discussed above insofar as they are generically one but that also occur one after another ( $\dot{\varepsilon} \varphi \varepsilon \xi \tilde{\eta} \varsigma)$, are not able to form one continuous change that is eternal, i.e. a kind of change of which the first unmoved mover could be the direct cause. For in contrast to generically different changes, they do have extremes that in principle may become one. Why should it be impossible for instance that there is an eternal change in quality or quantity? Could one not think, for example, of something eternally changing from white to black and from black to white over and over again, or of some object undergoing an increase in size until a certain magnitude is reached, and then decreasing again until a certain size is reached, and so forth ad infinitum?

This question indeed is puzzling, since according to Aristotle, and as we just saw, even changes that are not one in genus may be said to form a continuous whole with respect to time, although they cannot form one change in the relevant sense, i.e. in being one without qualification. What is the reason then for saying that it is impossible that a chain of succeeding changes which are all of the same genus cannot form one eternal change? For, as I have shown, this is what Aristotle presupposes in the third argument by saying that the first of the two options for change being eternal is 
to be preferred to the second one, since only the eternal change that is one and continuous can be the change which is directly caused by the first unmoved mover. In fact, as we will see, Aristotle addresses this problem later on in Phys. VIII 7 and 8 and in doing so shows that the only change which in principle can be one, continuous and eternal is locomotion, or, to be more specific, circular locomotion, while this is impossible for any of the other kinds of change. But if the argument which Aristotle presents for this claim (and about which I will say more later on in section 5.3) proves successful, it will ultimately show not only that the first of the two ways in which there can be eternal change is to be preferred, but also that locomotion as the argument claims is primary. ${ }^{33}$

\subsubsection{What is better is the case in nature}

As I said before, Aristotle seems to take it for granted that it is clear why the first of the two ways in which change may be eternal is to be preferred over the second, and, as I have started to show and will continue to show after this section, against the background of Phys. VIII he has very good reasons for doing so: preferring option (2), i. e. that there is one single and eternal change, fits better with what was stated in the previous chapters of Phys.

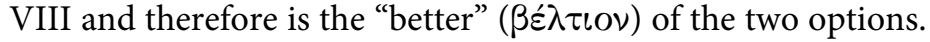

Aristotle's next step is to make use of an assumption he also applies in many other places, namely that "the better is always the case in nature, if it

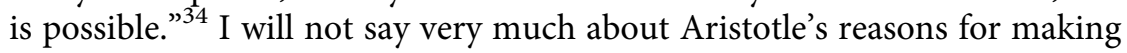
this assumption here; for my purposes it should suffice to say that this typical Aristotelian assumption is one of the general principles of his theory of nature in which the concept of teleology plays an essential role, and which, to give another example, also finds its expression in facts like the one that nature does nothing in vain. ${ }^{35}$ That the assumption that the better, if possible, is the case in nature, is a fundamental truth for Aristotle is also clear from many other passages in which the same thought is explicitly expressed. ${ }^{36}$ A scientific understanding of nature simply would not be possible without presupposing that there is some kind of rational order that is governed by and finds its expression in general principles like the one stat-

\footnotetext{
33 See Phys. VIII 7, 260b25-26.

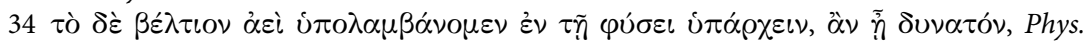
VIII 7, 260b22-24.

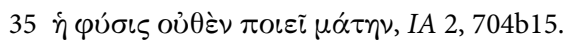

36 See for instance IA 2, 704b12-18, Phys. VIII 6, 259a10-12, GC II 10, 336b26-28, PA II 14, and 658a23-24, where Aristotle makes similar claims. For more passages related to this assumption see Bonitz's Index $836 \mathrm{~b} 28 \mathrm{ff}$.
} 
ing that of the different ways in which things may be, the best possible way will always be realized in nature.

Based on this assumption it accordingly follows that the first and better of the two ways in which change may exist continuously, namely by there being one single change that is eternal, must necessarily be the case. Since the only candidate for this change, as Aristotle will claim, is locomotion, Aristotle finally draws the conclusion that for this reason locomotion must be primary. ${ }^{37}$

All this of course has not been made clear thus far. First, of all the premise about nature of course states that the better is the case in nature, if it is

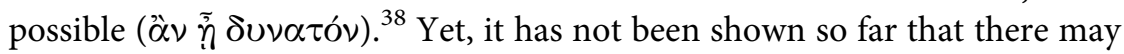
be a change that is one single change in the strict sense and that at the same time is eternal. Furthermore, the assumption that only locomotion can be this special sort of change has not been discussed yet. And even if these two assumptions were true, it still needs to be explained how exactly their truth is supposed to show locomotion's primacy.

As to the first point, we have seen that Aristotle at the beginning of Phys. VIII 7 raises the question whether there is one eternal change, and that it therefore is one of the tasks of chapters 7 and 8 to provide an answer to this question. The same, however, is also true for the second point, i.e. for the yet unproven claim that locomotion needs to be considered as the only change capable of being one and eternal in the necessary sense, because this may be seen as an answer to the second of the three questions that Aristotle raised at the beginning of VIII 7, namely which kind of change the single eternal change is, assuming that it can exist. ${ }^{39}$

Therefore, Aristotle at this point is obviously taking it for granted that such a change can exist, but also that this single eternal change "can be no other [change] than locomotion", and indeed he explicitly states that both facts will be shown later on and therefore may be presupposed as given for now. ${ }^{40}$ In fact, we will see that both points indeed will be shown to be true

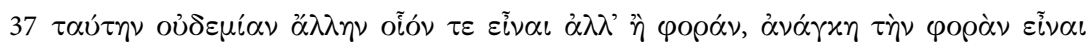
$\pi \rho \omega ́ \tau \eta \nu$. Phys. VIII 7, 260b25-26: since "this can be no other change than locomotion, locomotion must be primary."

38 Phys. VIII 7, $260 \mathrm{~b} 23$.

39 For the formulation of the two questions see 260a21-23. For more on the significance of these questions see section 2.4.3.

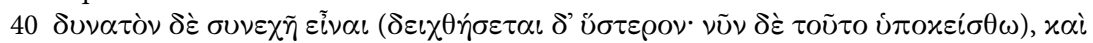

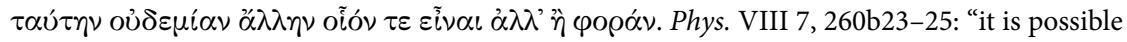
for [change] to be continuous-this will be shown later but let us just suppose it for now". That both assumptions are presupposed by Aristotle is clear from the fact that the truth of neither of them has been shown so far, but will be established in the discussion "later on". This is also suggested by the grammar, as the phrase starting after the brackets in $260 \mathrm{~b} 24$, and in which the second of the assumptions is stated, needs to belong to the $i \pi 0 x \varepsilon i \sigma \theta \omega$ in the 
in the course of the discussion that starts in the penultimate paragraph of Phys. VIII 7 and is continued throughout the whole of Phys. VIII 8 . $^{41}$ As I have already said, all this is part of the task that was set at the beginning of chapter 7 and discussing the two points will provide an answer to two of the three questions raised there; but as we are now beginning to see, in addition this will also contribute something to answering the third question, that is, which kind of change is the primary one-for after all the argument for locomotion's primacy that I am discussing at the moment obviously makes essential use of the answers to the first two questions. ${ }^{42}$ Thus the overall structure of this passage is as follows:

(1) Change exists continuously, i.e. is eternal. (Phys. VIII 1)

(2) Change is eternal, either by (a) there being one single eternal change, or (b) a number of changes in succession. (analytical truth)

(3) But in the case of alternative (a) - a single and eternal changechange exists more continuously, and this is better. (from Phys. VIII 6)

(4) What is better is the case in nature, if possible. (general principle)

(5) It is possible that there is one single change that is eternal. (Phys. VIII $7 \& 8)$

(6) Only locomotion can be this one single and eternal change. (Phys. VIII 7\&8)

(7) Therefore, locomotion is primary.

As we can see, the third argument for the priority of locomotion relies essentially on whether the arguments presented for premises (5) and (6) are successful. For this reason I will now have a look at parts of Phys. VIII 7 and 8 in order to gain a basic understanding of Aristotle's reasons for making the claim that indeed there is a single eternal change and that this change can only be a locomotion, insofar as this is of relevance to my inquiry. As I said before, this examination, will at the same time allow us to continue the discussion that was interrupted by this section, since its remaining part falls together with examining the arguments for premises (5) and (6) as they are stated in 7 and 8 of Physics Book VIII. Therefore, I will now present Aristotle's basic reasons for claiming that a single change that is one and eternal can exist and that this can only be locomotion, and

brackets. Simplicius, In Phys. 8, 1269, 34-35, also reads this passage in this way, as he states that the assumptions are taken as being established (i $\pi 0 x \varepsilon i ́ \mu \varepsilon \nu \underline{\alpha} \tau \varepsilon^{\prime} \omega \varsigma \varepsilon^{\prime}(\lambda \eta \pi \tau \alpha \iota)$.

41 See Phys. VIII 7, 261a27-VIII 8, $265 \mathrm{a} 12$.

42 That answering the first two questions obviously is necessary for answering the third question, i.e. the one regarding the primary kind of change, also shows that these three questions, as I argued in the second chapter, are closely connected to each other and must not be examined in isolation from each other (see section 2.4.3). 
thus why different changes that are generically one and that occur in succession may not form one eternal change. After all this is shown, I will examine in what way Aristotle is able to conclude in his last step that change in place must be primary. ${ }^{43}$ This last step is of special importance, since it is puzzling how Aristotle actually arrived at the conclusion that locomotion is primary, although the term primary, as my reconstruction of the argument clearly shows, is not used in any of the premises Aristotle presents in this argument.

\subsection{Locomotion alone can be one and eternal}

As we have just seen, and as is explicitly stated in the third argument, Aristotle does not present any reason for the assumption that there is any such change at all that is continuous and eternal, but merely presupposes it here and states his intention to show that this must be the case later on. ${ }^{44}$ Since the third argument as a whole relies on this claim it is crucial that Aristotle makes clear that he is right to make this assertion in order to show that locomotion has ontological primacy. But the argument, other parts of which may be found in Phys. VIII 7 and 8, is not only necessary for the thesis that locomotion is primary, but, as I pointed out in a prior chapter, for the whole theory that change is eternal and that there needs to be a first unmoved mover. ${ }^{45}$ All this is only possible if there is a change that is one, continuous and eternal. The argument for this claim is given later on, after the presentation of the five arguments for the priority claim is completed. Since it will establish that circular locomotion is this special kind of change, it in one sense already belongs to the task of showing that circular locomotion is the primary kind of locomotion; in another sense, as we have seen, it provides an argument for a claim that is essential for the third argument for the priority of locomotion, which makes it necessary, at least to a certain degree, to discuss the reasons Aristotle presents for this claim here. ${ }^{46}$ For, only if Aristotle shows that locomotion alone can be the kind of change that in principle may be one and eternal, can one say that locomotion is ontologically primary in the sense that it is the only candidate for being the change that is caused directly by the first unmoved mover.

In what follows I will therefore present what basically are Aristotle's reasons for making this claim. Although the arguments presented for this

43 See Phys. VIII 7, 260b25-26.

44 See Phys. VIII 7, 260b25-26

45 See section 2.4.3.

46 Aristotle himself points out this connection in Phys. VIII 7, 261a27-31. 
assumption are far from uncontroversial, I will not be able to discuss them here in depth, but only insofar as they are of relevance to my inquiry. Aristotle proceeds in three steps to show that if there is one continuous and eternal change, this can only be locomotion, or, to be more precise, circular locomotion. First of all he makes clear that none of the other three kinds of change is an appropriate candidate for the change that is one and eternal (261a31-b15), secondly he explains in what way the same is true with respect to most kinds of locomotion (261b28-264b9), and finally he argues that circular locomotion can be one, continuous and eternal (264b9-28).

\subsubsection{None of the other three kinds of change can be one and eternal}

The argument is not merely about showing that there can be locomotion that is one, continuous and eternal, but also about making clear that of the four different kinds of change locomotion is the only type for which this is possible. Therefore, Aristotle first of all explains that it is impossible that any of the other kinds of change could form one continuous and eternal change, and then he shows that this is possible for a certain kind of change in place only. As I will show, the basic argument for the first assumption is that every change that belongs to one of the three other kinds of change, but also every change that is composed of such changes, needs to come to a stop at some point in time, so that it cannot form one single eternal change. I will now show in more detail in what way this assumption is correct.

As we know from previous discussions, every change is a change from something ( $\dot{\varepsilon} x \tau \iota \nu O \varsigma)$ to something ( $(i \varsigma \tau \iota) .{ }^{47}$ As Aristotle points out elsewhere, it is because of the fact that every change occurs between limits or extremes that it is unclear in what way one single change that is eternal could exist at all. ${ }^{48}$ One way in which these changes nevertheless may be eternal, one might think, could be if the subject were to cycle back and forth from the starting point to the endpoint of the change over and over again. In this way, it appears, the subject would be undergoing a change continuously, that is, there would be one continuous eternal change of one single subject. As I pointed out before, this seems to be reasonable, since the subject in these cases would undergo a succession of changes so to speak that are all of the same genus, which makes it possible for their extremes to become one and the same, thus enabling them to form one continuous whole with respect to that in which they occur. Accordingly, if we think of

47 See for instance Phys. V 1, 224b1, VI 10, 241a27, and VIII 2, $252 \mathrm{~b} 10$.

48 See Phys. VI 10, 241a26-28, and VIII 2, 252b9-12. As I stated before, it is part of the task of Phys. VIII 8-9 to show that there nonetheless is one continuous and eternal change (see section 2.4.3). 
something $x$ 's change in temperature, this would mean that after becoming hot it cools down again, after which it changes its temperature to hot again and so forth ad infinitum. Similar examples can be made for alteration, generation and corruption. Aristotle, however, argues that such a succession of changes cannot be one and continuous, since-and this is the crucial point-the time in which any of these changes would occur is necessarily intermitted at some point, so that the succession of these changes cannot be considered as a continuous whole. The reason for this claim is the following.

The starting point and the endpoint of each of the other three kinds of change, Aristotle tells us in this chapter, are opposites to one another, so that each of these changes occurs between opposites. ${ }^{49}$ In the case of alteration, these opposites are the contrary qualities, for change in quantity, i. e. growth and diminution, smallness and magnitude, and for generation and corruption, the contradictory opposites of being and non-being. ${ }^{50}$ It is this fact which rules out that a single change in quality, quantity, or substance may be eternal merely in virtue of the subject's going back and forth between starting point and endpoint an infinite number of times. For according to Aristotle, this would entail that something $x$ at one and the same time undergoes contrary changes, which is impossible. ${ }^{51}$ The consequence of this is that $x$ needs to come to a standstill before undergoing a change that is contrary to the one $x$ underwent before, so that, as Aristotle puts it, a certain amount of time will elapse between the two changes; but if there is a time of rest between two changes, then these two changes cannot form one continuous whole, since the criterion of unity in time is not fulfilled: "So that if it is impossible that something changes in opposite ways at the same time, the change will not be continuous, but there will be some time between them", i.e. between the opposite changes. ${ }^{52}$

The following example should illustrate the idea that seems to inform Aristotle's argument: it would be contradictory to say that something $x$, in undergoing a change in temperature, at the same time is changing from hot to cold, but in another sense it would not, as it is also changing from cold to hot. Or, to put it the way Aristotle does in the cited passage, $x$ at the same time would be undergoing opposite changes, namely from hot to cold and

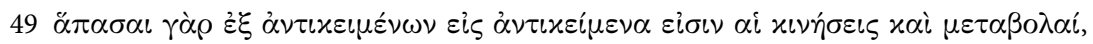
Phys. VIII 7, 261a32-33: "For all non-substantial changes and changes are from opposite to opposite".

50 See Phys. VIII 7, 261a34-36.

51 See Phys. VIII 7, 261b15, and especially Phys. VIII 8, 264a28-29 where this principle is

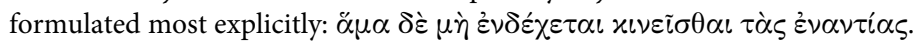

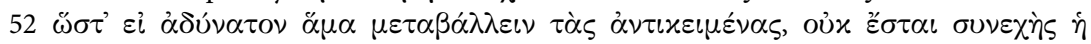

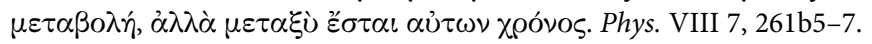


from cold to hot, which is impossible. Therefore, Aristotle thinks that the subject of the change needs to stop undergoing a change for some time, and that the first change must end before the subject can undergo a change back to the starting point. Accordingly, after having changed from cold to hot the subject needs to come to a standstill before it can change from hot back to cold again. But then the time in which the change occurs is intermitted, i. e. is no longer one, and thus one of the criteria for being one single and continuous change is not fulfilled. The same of course is also true for cases of generation and corruption: it is impossible to say that something $x$, at the same time and in the same respect, is coming to be and perishing, i.e. not coming to be ${ }^{53}$ Hence, there can be no such change that belongs to any of the other three kinds of change that exist apart from locomotion.

The following example should make this clearer: suppose something $x$, say a portion of water, is heated from $1{ }^{\circ} \mathrm{C}$ to $100{ }^{\circ} \mathrm{C}$. This according to Aristotle would count as one continuous change, since each of the three necessary criteria is fulfilled. What exactly, one might wonder now, distinguishes this case from the one in which the same portion of water, after being heated to $100^{\circ} \mathrm{C}$, is cooled down to $1{ }^{\circ} \mathrm{C}$ again? For could we not also say that the heating of the water to $100{ }^{\circ} \mathrm{C}$ for instance also consists of at least two different changes, namely one from $1{ }^{\circ} \mathrm{C}$ to $50{ }^{\circ} \mathrm{C}$ and another from $50{ }^{\circ} \mathrm{C}$ to $100^{\circ} \mathrm{C}$ and that it therefore is unclear in what way these two changes form a unity in this case, but not in the other one? The crucial difference, however, is that both processes of heating, i.e. from $1{ }^{\circ} \mathrm{C}$ to $50{ }^{\circ} \mathrm{C}$ and from $50{ }^{\circ} \mathrm{C}$ to $100{ }^{\circ} \mathrm{C}$, are changes in which the subject is becoming warmer and in which the starting and the endpoint are not opposed to each other. In the second case, however, the changes clearly are opposed to each other, since the starting point of the one change is the end point of the other, and vice versa, which according to Phys. V 5 is the criterion for saying that two changes are opposites. ${ }^{54}$ Again, in the latter case the change from cold to hot and from hot to cold cannot form one single change, since there has to be a certain time interval in which the subject is not changing. But since the same is true of any other succession of opposed changes, none

53 Aristotle, of course, is very aware of the fact that this is not a change between contraries, but between contradictories. Yet, as he makes clear, the important point is that generation and corruption in virtue of being opposite to each other cannot be present in the same underlying thing at the same time and in the same respect, and hence there needs to be an intermittence in time. See Phys. VIII 7, 261b3-15.

54 In Phys. V 5 Aristotle systematically discusses in what way non-substantial changes are contrary to one another. According to this chapter a change $c_{1}$ is contrary to another change $c_{2}$, if $c_{1}$ is a change from $p$ to its contrary $q$, while $c_{2}$ on the other hand is a change from $q$ to $p$. In this sense, for example a change from health to disease is contrary to the change from disease to health (see Phys. V 5, esp. 229a30-229b10). 
of the four kinds of change apart from change in place can form one continuous change that is eternal.

\subsubsection{Only circular locomotion can be one and eternal}

After this Aristotle goes on to show why most of the different kinds of locomotion also cannot form a change that is one and eternal in the necessary sense. The only kind of change in place that can be eternal in the appropriate way, he claims, is circular locomotion. The basic reason Aristotle presents for the stated claims is that as in the case of the other types of change most kinds of change with respect to place necessarily involve an intermittence in time, and therefore cannot be one and eternal without qualification. This, however, as we will see, is not the case with circular locomotion, since an eternal motion that consists of one and the same locomotion along a circular path in no way involves contrary motions and in contrast to all changes does not have to stop at some point. I will now present the reasons for each of these claims, which are presented in Phys. VIII 8 in more detail. Once again, I will focus on presenting the basic assumptions that must be made if one is to understand Aristotle's claims, insofar as these are important for my inquiry; thus, I will not examine the whole passage here in detail.

There are three types of local motion, namely circular locomotion, rectilinear locomotion and locomotions which consist of a mixture of both types. ${ }^{55}$ If straight or circular locomotion cannot be one and eternal in the appropriate way, then, of course, the same must be true of the mixed motion which is composed of both types. ${ }^{56}$ First of all, it again seems to be clear that straight locomotion cannot exist continuously, because this kind also has a certain limit $(\pi \varepsilon \pi \varepsilon \rho \alpha \sigma \mu \varepsilon \dot{\nu \eta}){ }^{57}$ Accordingly there cannot be a rectilinear locomotion along an infinite path. This seems reasonable if one bears in mind that Aristotle thinks that the extension of the cosmos is finite and that a rectilinear locomotion for this reason cannot go on forever, since its subject will reach the limits of the universe at some point. But as in the case of the other kinds of change one might think that a change in place along a straight line could be one and eternal if the subject were to go back and forth between the place from which its starts and the place which is the endpoint of this (part of the) change. Yet, according to Aristotle such a change, too, would involve an intermittence of time, i.e. a state of rest in

55 See Phys. VIII 8, 261b28-29.

56 See Phys. VIII 8, 261b29-30.

57 See Phys. VIII 8, 261b32. In fact it is stated for instance in Phys. III 6, 206a16, that no magnitude ( $\mu \varepsilon \hat{\varepsilon} \varepsilon \theta 0 \varsigma)$ can be infinite in extension. 
the change's subject, as such changes would involve contrary locomotions. This is because rectilinear locomotion in one direction and in the opposite direction according to Phys. VIII 8 are contraries, which is also in accordance with what is said in the discussion of contrary changes in Phys. V 5. ${ }^{58}$ Hence, in this case as well, a pause between the two different changes is necessary. This implies that rectilinear locomotion from A to B and from B to A cannot occur in one continuous stretch of time, but has to be intermitted at some point. ${ }^{59}$

This, however, is very different in the case of circular motion ( $\chi \cup \varkappa \lambda \tilde{\omega}$

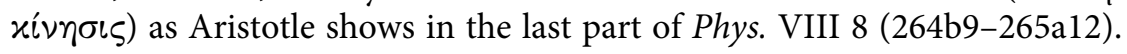
According to Aristotle, in contrast to the other kinds of change, it is no problem to consider circular locomotion that is repeated over and over again as one, continuous and eternal change. As we have seen, construing an eternal change from any of the other kinds of change always entails the impossible consequence that something $x$ undergoes a change and in the same time and respect also undergoes the contrary change.

According to Aristotle, the reason why it is possible for circular locomotion to be eternal lies in the fact that it differs significantly from all other types of change. Of course, locomotion on a circular path, too, needs to have a starting point as well as an endpoint; yet, in contrast to all other changes the starting point and the endpoint in this case are one and the same and thus cannot be contrary to each other. ${ }^{60}$ This is made clearer by the following diagram:

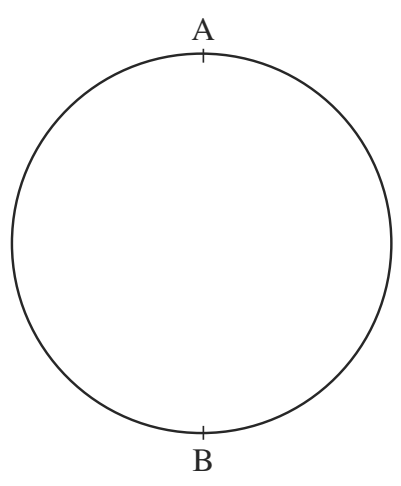

A

Fig. 1

58 See Phys. VIII 7, 261b34-36, and V 5, 229b6-10.

59 Another reason that according to Aristotle shows that the change from A to B and the one from B to A need to be contrary changes is that they annihilate each other (see Phys. VIII $8,262 \mathrm{a} 6-8)$.

60 See Phys. VIII 8, 264b10-11. 
The subject, by starting to move from some arbitrary point A on a circular path, is already moving towards one and the same point A again which, according to Aristotle, shows that this cannot be a locomotion to its contrary, for this would presuppose that the starting point and the endpoint are contrary to one another. ${ }^{61}$ The subject of a rectilinear motion, however, moves to another place-in our example from A to B. The movement from $A$ to $B$ and from $B$ to $A$ that occurs along a straight line, therefore, is composed of two local changes with different starting and end points, namely the extreme points of the rectilinear path of the motion; these points are therefore contrary to each other. ${ }^{62}$ Therefore the locomotion from A to B is contrary to that from B to A. This, as we have seen, presupposes that the subject of this change comes to a halt after having ended either of the changes and before moving back to the starting point again.

But could a similar case not be made for circular locomotion as well? Suppose, for instance, there is some other arbitrary point B on the circle (see Fig. 1). Could one not say that moving from A to B is one change, and moving from $\mathrm{B}$ to $\mathrm{A}$ is another, each of which has a different starting point? The difference between this case and locomotion along a straight line, Aristotle seems to think, is that the subject of circular locomotion merely passes through B, but does not have to turn around ( $\alpha \nu \alpha x \alpha ́ \alpha \pi \tau \varepsilon \iota)$ in order to return to its original starting point, and thus would not move with a motion contrary to the first one. According to this argument, the subject of the circular movement therefore never needs to stop moving towards A and, thus, never starts a new change before reaching $\mathrm{A}$. It is one local change the subject undergoes in moving from $\mathrm{A}$ to $\mathrm{A}$ in which it passes $\mathrm{B}$, among other points. ${ }^{63}$

It is because of the fact that any (complete) local movement along a circular path ends where it begins-in our case at A-that its subject can continue to undergo this motion again and again and in this way changes continuously without an intermittence of time being necessarily involved. Therefore, Aristotle concludes that there is no reason for an eternal change that consists of an infinite number of repetitions of the very same circular locomotion, so to speak, not to go on continuously without any interruption. ${ }^{64}$ For this reason, and because he has shown that the same is impossi-

61 See Phys. VIII 8, 264b10-17.

62 See Phys. VIII 8, 264b14-17.

63 Aristotle obviously thinks that $x$ in moving in a circle never undergoes changes or parts of a change that are contrary to each other. This, among other things, is far from clear and needs further argument, for although $x$ is always moving towards $\mathrm{A}$, one might come to think for instance that in moving downwards and upwards at different times of the circular locomotion $x$ in fact does undergo contrary motions.

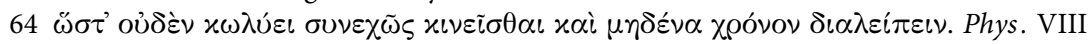
$8,264 \mathrm{~b} 17-18$. 
ble for change in quality, quantity and substance as well as for all other types of change in place, Aristotle at the end of Phys. VIII 8 is able to claim to have shown that no other change besides locomotion can be infinite and continuous, i.e. one without qualification. ${ }^{65}$ But in showing this he has not only presented a reason for saying that the primary kind of change in place is circular locomotion, but has also provided an argument for a claim already stated at Phys. VIII 2 and on which the whole theory developed in chapter 1-6 of this book depends, namely that a change that is one and eternal in the strict sense is possible and can exist at all. ${ }^{66}$ There certainly is much more that needs to be said with respect to the arguments presented for the claim that a special kind of locomotion alone, namely circular locomotion, can be one and eternal; yet, for the purpose of getting a basic idea of what may be Aristotle's reason for making this claim, this certainly is enough. ${ }^{67}$ Now that this has been shown, I will return to the discussion of the third argument. But before explaining how all of the arguments given above combine to show that locomotion has ontological priority over the other kinds of change, I will discuss the remarks that Aristotle makes about this kind of priority in connection with the passage in question, as they might tell us more about Aristotle's view of ontological priority.

\subsection{Locomotion has ontological priority}

\subsubsection{Ontological priority}

As we have seen in the discussion of the first two arguments, Aristotle does not explicitly qualify the way in which he thinks they show that locomotion is primary, but rather presupposes that the reader is acquainted with the

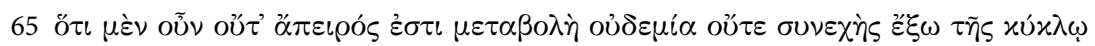

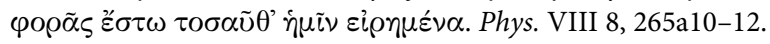

66 See Phys. VIII 2, 252b9-13. For more on this see section 2.4.3.

67 A thorough analysis of these arguments, which after all are presented on more than three Bekker-pages of text, among other things for instance should also deal with Aristotle discussion of Zeno presented in Phys. VIII 8. For, Zeno's paradoxes also might make one think that, contrary to what Aristotle claims, there may be an eternal change along a straight line: since the runner, although moving by traversing half the distance of the previous distance by each step, will never reach the endpoint and thus keep on moving forever. A possible answer Aristotle might give to this could be that-if this indeed were an eternal change-it would presuppose that the runner at some earlier point traversed a distance that is larger than the finite cosmos. For, as the distance the runner needs to traverse by every additional step decreases into smaller and yet smaller parts, the distance increases ad infinitum as one goes back in time. 
notions of priority and primacy. Yet, Aristotle, of course, is well aware of the fact that there are different ways in which something $x$ can be said to be prior to something $y$. This may be seen for instance in his discussion of the different senses of priority in Cat. 12 or Met. V 11, but also in Physics VIII 7. For, after giving the first two arguments for the priority of locomotion and before introducing the third argument, Aristotle surprisingly starts to present three different ways in which a change $x$ may be said to be prior to a change $y$. For each of these three senses he then presents an argument that is supposed to show that locomotion is prior to the other kinds of change in the respective way. ${ }^{68}$ Here are the three senses of priority as they are presented in the passage:

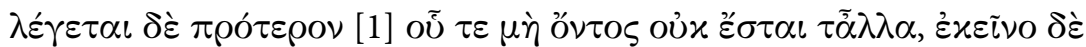

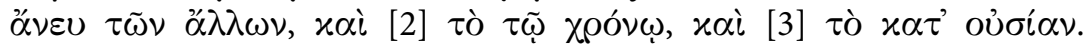
(260b17-19)

Something is called prior [1] when, if it is not also the other things will not be, while it [is] without the other things, and [2] [prior] with respect to time, and [3] with respect to essence.

I will call these three ways (1) ontological priority, (2) temporal priority, and (3) priority in essence. In this chapter I focused on the argument which shows that locomotion is prior in the first sense, i.e. that of ontological priority. ${ }^{69}$ Although it has already become clear in the discussion of the previous two arguments what it means to be ontologically prior to something else, I will examine Aristotle's explicit remarks on this kind of priority here, since Aristotle certainly had good reasons for making these remarks at this point of the discussion, and it may be that they shed additional light on the notion of ontological priority.

As I have already mentioned in the discussion of the first two arguments, something $x$ has ontological priority over something $y$ if the prerequisite for there to be $y$ is that there be $x$, but the converse does not hold. In other words, $y$ cannot be without there being $x$, while $x$ can be without there being $y$. The relation between $x$ and $y$ is an asymmetric relation of ontologi-

68 It is striking that Aristotle only presents three senses of priority here, although there are more then these three senses, as for instance the discussion in Met. V 11 and Cat. 12 show. Simplicius, In Phys. 8, 1269, 6-10, argues that the reason why Aristotle only deals with these three kinds of priority here is that these are the only senses ( $\eta \mu \alpha \iota \nu o ́ \mu \varepsilon \nu \alpha)$ of being prior or posterior which are of importance when comparing changes with respect to their priority. This seems reasonable, although one could add that these are the senses of priority that for Aristotle are of special importance for showing that locomotion is prior to the other kinds of change insofar as they are related to the fact that locomotion is the primary kind of change, i. e. the change which is directly caused by the first unmoved mover.

69 For temporal priority see chapter 6 and for priority in essence see chapter 7. 
cal dependency. ${ }^{70}$ From what we have seen it is clear that there being $x$ is a necessary condition for there to be $y$, while there being $y$ is a sufficient condition for there to be $x$. Accordingly, we can say that whenever there is $y$, there also needs to be $x$. To give an example, one might say that the rain clouds over Berlin are prior in this way to it raining in Berlin: if it rains in Berlin, this necessarily implies that there are rain clouds over Berlin, yet, the mere fact of rain clouds over Berlin does not imply that it is raining in Berlin. A definition of ontological priority then may be the following:

OnTOLOGICAL PRIORITY: $x$ is ontologically prior to $y$, iff if there is $y$ there also must be $x$, but not vice versa. ${ }^{71}$

The third argument that Aristotle presents for the priority claim aims at showing that locomotion is ontologically prior to any of the other kinds of change. According to our definition this means that if there is change in quality, quantity, or substance, then there must also be change in place, while it is not true that if there is change in place, there must also be some occurrence of any of the other kinds of change. Accordingly, the argument needs to show that if there is no locomotion, then there also cannot be any other kind of change, but not vice versa. Yet, if this is really what needs to be shown, one may wonder if this task has not been fulfilled already, since this is exactly what the first two arguments showed. One of the tasks of the remainder of this chapter will therefore be to find out in what special way this argument shows that locomotion has ontological priority over each of the other kinds of change and in what sense this is of importance for the larger project of showing that the change which is directly caused by the first unmoved mover can only be circular locomotion.

\subsubsection{A third sense in which locomotion is ontologically prior}

While it has been made clear in the previous discussion that indeed only locomotion can be one, continuous and eternal, it still remains to explain in what way this implies that "locomotion must be primary."72 For this is the conclusion that Aristotle obviously draws from what was said before, although it is really puzzling how one could actually arrive at this conclu-

70 See section 3.6 , esp. p. 68, n. 79 . There I also pointed out that what I call ontological dependency corresponds to the second kind of priority presented in Cat. 12 and to what Aristotle would call priority in nature and in being in Met. V 11, 1019a1-4.

71 Or, if one would like to give a more formal definition of this relation: $P_{\mathrm{o}}(x, y) \equiv \mathrm{j}(y) \rightarrow \mathrm{j}(x) \wedge \neg(\mathrm{j}(x) \rightarrow \mathrm{j}(y))$

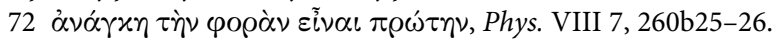


sion, since, as I have already stated ${ }^{73}$, the term 'primary' is only mentioned once in the whole argument, namely in the conclusion. But how can Aristotle infer that locomotion has primacy when at the same time no reference seems to be made to this fact in any of the premises? The answer to this will be given in what follows.

According to the remarks that I just examined more closely, the argument is supposed to show that change in place has ontological priority over the other kinds, that is, change in place is necessary for each of the other types of change to occur, but not vice versa. ${ }^{74}$ Therefore, one needs to find a way in which the fact that only locomotion can be one and eternal shows locomotion's ontological priority. In my view, the solution lies in the fact that change in place by having this special quality is the only possible candidate for the kind of change of which the unmoved mover is the direct source. Since none of the other kinds of change can exist without this first primary motion, which, as we have seen, can only be a locomotion, it is clear that they would not occur and in this sense not exist if there were no locomotion. For, as Aristotle points out in Phys. VIII 6 none of the other changes in the cosmos would happen without the primary change that is caused by the first unmoved mover. ${ }^{75}$ Therefore, it is this extra step of making use of the connection between changes undergone by things in the cosmos and the unmoved mover as first cause of all changes which establishes locomotion's ontological priority.

But this also makes clear then how Aristotle in this argument arrives at the conclusion that locomotion must be primary, although the term 'primary' $(\pi \rho \omega \tau \eta)$ does not appear in any of the premises, but is stated for the first time in the conclusion: 'primary' as we have just seen needs to stand for 'ontologically primary' here. Aristotle, therefore, in showing that without locomotion (in virtue of its being the only possible candidate for the eternal change that is caused by the first unmoved mover) none of the other kinds can occur, while the converse does not hold, also makes it clear that indeed "locomotion must be primary", namely ontologically primary.

That this must be the sense in which locomotion has ontological priority, however, is made clear by what is stated in the last four lines of the passage that I have examined in this chapter. First of all Aristotle claims that "there neither is necessity for that which undergoes locomotion to undergo

73 See p. 130 and my reconstruction of the argument on p. 129.

74 Simplicius, In Phys. 8, 1269, 15-16, again says that this argument shows priority in nature ( $\varkappa \alpha \tau \dot{\alpha} \varphi v ́ \sigma \iota \nu)$ which, as I already pointed out elsewhere, for him means the same kind of priority that I call ontological priority. For more on this see p. 68, n. 79, in section 3.6.

75 See Phys. VIII 6, 259b32-260a10. 
growth, nor alteration, nor generation or corruption." ${ }^{76}$ For if locomotion indeed is the change that is primarily caused by the first unmoved mover and on which all other changes in the cosmos depend-and as we have seen it is the only possible candidate-then it cannot presuppose any of the other types of change. ${ }^{77}$ And this is in perfect accordance with what was shown in the previous two arguments, especially in the second, which made clear that change in place is the only change that per se does not entail the occurrence of any other change. This is different for all other kinds of change since they would not exist "without there being the continuous [change], which the first mover is causing." 78

This however makes clear that the argument not only shows that locomotion has ontological priority, but also presents one more way in which locomotion is ontologically primary than the two previous arguments did. ${ }^{79}$ In the first argument it was shown that locomotion must be ontologically prior, since any change in quality and quantity that has its source either directly or indirectly in a living being entails the occurrence of a preceding locomotion. It was also shown that the converse does not hold. The second argument proved that no change in quality, quantity and substance can occur without locomotion, in the sense that with respect to what happens on the material level when things change, every occurrence of the other

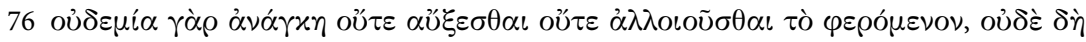

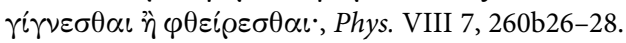

77 Philoponus, In Phys. 8, 899, 18, exemplifies this thought by pointing out that the locomotion of the heavens does not involve any of the other changes, which is correct since according to Aristotle eternal things may not change in any other respect than place.

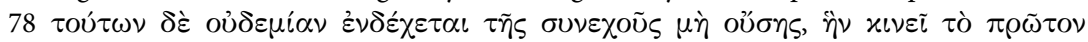

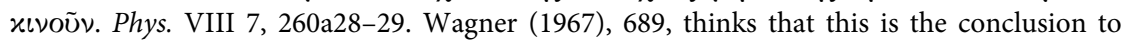
which the argument really leads and not what is presented as the conclusion by Aristotle in 260b25-26. I think this is wrong, since I have shown how what is said in b25-26 follows from the argument and because I hold that Aristotle in 260b28-29 spells out in more detail what was shown before and thereby makes clear that locomotion is ontologically prior: since the continuous and eternal change that is caused directly by the first unmoved mover is locomotion, all other changes in virtue of their depending on the change which the first unmoved mover causes also depend on locomotion. Accordingly, Graham (1999), 126, is also wrong when he says that the latter part of the argument starting at $260 \mathrm{~b} 26$ does not seem to be "relevant for the former"; as I said, Aristotle here spells out the implications of what it means to say that locomotion is the primary change in the sense stated in the argument, and at the same time makes use of what was shown in the two first arguments: the change that is caused directly by the first unmoved mover as such cannot presuppose any other change; it does not do so because locomotion per se does not entail the occurrence of any of the other kinds of change.

79 Therefore, it is unclear to me why Graham (1999), 124, claims that this argument "does not seem to exploit the present sense [of priority ] to full advantage." 
three kinds of change is necessarily accompanied by a change in place, but not vice versa. The third argument makes use of the fact that all changes in the cosmos depend on the eternal change that is directly caused by the first unmoved mover, and thereby establishes that the other kinds of change depend on locomotion insofar as they depend on the first eternal motion. That is to say, the third argument has presented another reason for saying that an asymmetric relation of ontological dependence holds between locomotion and the other kinds of change, and hence for saying that locomotion must be the primary kind of change. This argument in particular made it possible to see that it is the special characteristics of change in place, namely the fact that it can be one, continuous and eternal, that is essentially connected with the fact that the change that has its primary source in the first unmoved mover must be locomotion.

\subsection{Conclusion}

What has this chapter shown? First of all we have seen that as Aristotle states explicitly the third argument, too, is supposed to make clear that locomotion has ontological priority over the other kinds of change, in other words that there can be locomotion without any of the other kinds of change, while the converse does not hold.

The argument starts from the assumption of the eternal existence of change. Against the background of the discussion of Phys. VIII, it has become clear that change needs to be eternal in virtue of their being one continuous and eternal change and not, as one might have thought, by there being a succession of different changes: Aristotle, in referring to the eternal change, clearly means the one and continuous change of which the first unmoved mover is the primary cause and which rules out the second way in which the existence of eternal change can be explained. In order for this to be clear, it was necessary to understand in what way a change may be said to be one, continuous and thus eternal in the necessary sense. The outcome was that only changes that are one with respect to their time, their subject, and also to the genus and species of the change are one without qualification and continuous. In the penultimate step I showed why neither change in quality, nor in quantity, nor in substance can form one continuous and eternal change, and that this is only possible for locomotion, or more precisely, circular locomotion.

The final conclusion then is that change in place is ontologically prior to all of the other kinds of change insofar as the primary change of which the first unmoved mover is the direct source and on which all other occurrences of any change ultimately depend can only be a locomotion. Since this 
special locomotion does not presuppose the occurrence of any of the three other types of change, Aristotle can conclude that locomotion indeed has ontological priority over all of the other kinds of change. It also turned out that Aristotle by means of the third argument presents yet another sense in which change in place has ontological priority. This argument made it clear in particular that locomotion alone can be the change that is directly caused by the first unmoved mover. 


\section{Locomotion has temporal priority}

\subsection{Overview}

The presentation of the fourth argument for locomotion's priority follows directly after that of the third one and is stated in this passage:

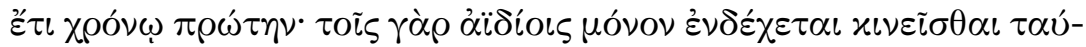

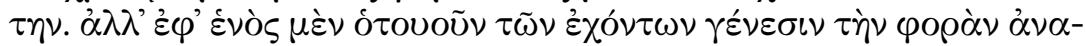

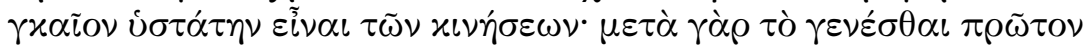

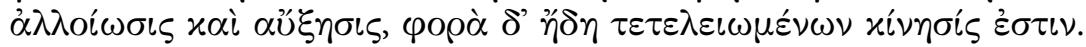

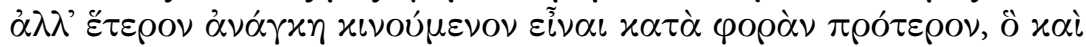

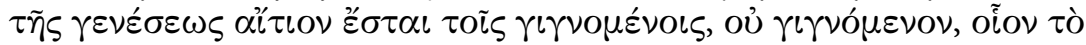

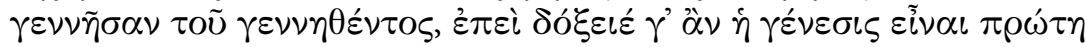

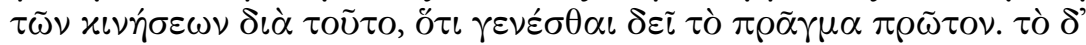

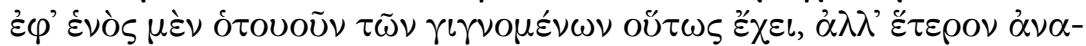

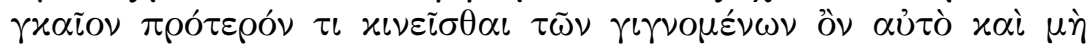

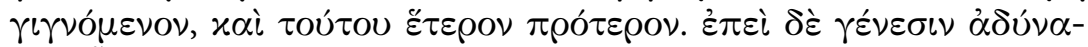

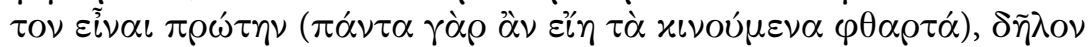

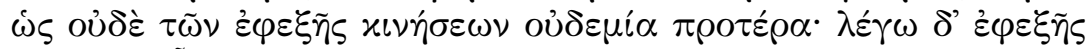

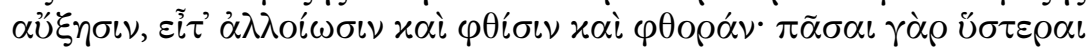

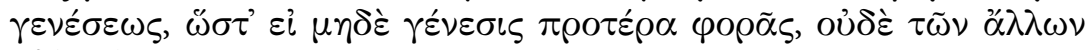

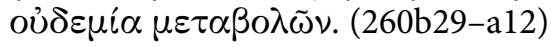

Furthermore, it [i.e. locomotion] is primary in time, because for eternal things it is only possible to undergo this change. But in any single thing of those which have coming to be locomotion must be the last of the changes. For after coming to be first alteration and growth [come to the thing], while locomotion is a change of things that already have achieved completion. Yet, it is necessary that there is something else which is undergoing locomotion before and that will be responsible for the coming to be of the things that are coming to be, but which [itself] is not coming to be, as for instance that which begets for what is begotten, since otherwise coming to be might seem to be primary among the changes for the reason that the thing [which undergoes a change] needs to come to be first. And in any single thing of those which are coming to be it is this way, but it is necessary that some other thing is changing prior to the things that are coming to be that itself is and is not coming to be, and another thing prior to this. But as it is impossible that generation is pri- 
mary (because then everything that is changing would be perishable) it is clear that also none of the succeeding changes are prior, and by succeeding I mean growth, and then alteration, diminution, and corruption. For all are later then coming to be, so that if not even coming to be is prior to locomotion, also none of the other changes.

The argument presented in these lines aims at showing that locomotion in general is prior in time to the other kinds of change. Aristotle thinks this follows directly from the fact that locomotion is the only change which can be eternal and which eternal things can undergo: in virtue of being the only possible candidate for the eternal change that is directly caused by the first unmoved mover, locomotion is temporally prior to any occurrence of each of the other three kinds of change insofar as this eternal locomotion will always be going on before any of these other changes occurs.

In the majority of this passage Aristotle is discussing a possible objection that might contradict his thesis about temporal priority, namely that there seem to be cases which rather suggest that locomotion with respect to time is the last of the different kinds of change, since in the development that living beings are subject to, the relevant thing alone is able to undergo its specific locomotion after it has already undergone alteration and growth, and first of all has come into being, i.e. undergone generation. This objection, however, will be rebutted by making reference to the eternal movements of the heavens that are the cause of every other kind of change and which also temporally precede the changes that occur in the sublunary sphere. In order to make this clear a more detailed analysis of the passage is necessary. Therefore, I will now present my examination of this passage, in which I will proceed as follows.

I will begin by examining how the fact that the only kind of change eternal things can undergo is change in place shows that locomotion has temporal priority over the other kinds of change (6.2). After that I will discuss an objection that may be raised against this claim, namely that locomotion, with respect to individual perishable things like living beings, appears not to be the primary, but rather the last kind of change, which might make one think that not locomotion, but rather generation, is the primary kind of change (6.3). I will argue that the appropriate reply to this objection is that every generation of such an individual being is temporally preceded by an eternal locomotion and that the objection therefore poses no threat to Aristotle's thesis about locomotion having priority in time (6.5). Finally, I will end by summarizing the results of this chapter (6.6). 


\subsection{Locomotion has priority in time,} since it is the only change eternals can undergo

The passage begins with Aristotle stating what this argument is supposed to show, namely that change in place must also be prior in time to each of the other kinds, that is, it must precede change in quality, quantity, and substance. ${ }^{1}$ Right after this claim about locomotion's temporal priority is made,

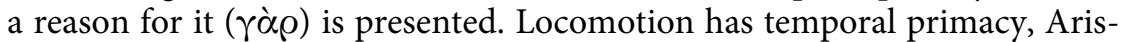
totle tells us, because eternal things cannot undergo any other kind of change apart from locomotion. ${ }^{2}$ The latter claim is in accordance with other passages in Aristotle, yet, it does not say much more about why this implies locomotion's temporal priority. ${ }^{3}$ For something $x$ to be eternal, according to Aristotle, means that it has always existed and always will exist, so that $x$ cannot possibly have come to be at some point and also cannot perish later on. ${ }^{4}$ For this reason eternal things, apart from being unable to undergo generation and corruption, also cannot and do not undergo any of the two other kinds of change, e.g. in quantity or quality, since both types, in contrast to locomotion-as it is put in the fifth argument later on-always

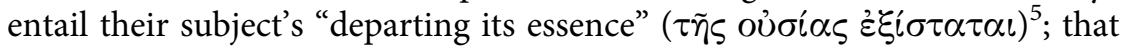
is to say, in principle, if they carried on without limit, they would entail their subject's corruption. Aristotle will argue later on that this is significantly different with respect to change in place, as this type of change, even if it went on forever would not lead to its subject's corruption, and in this sense leaves its subject completely untouched. Of the four kinds of change, locomotion, therefore in fact preserves its essence best, which is another reason for its priority, namely its priority in essence. ${ }^{6}$

The argument also clearly makes use of the assumptions that were shown to be true in the previous chapter: of all the different changes that exist, only change in place can belong to eternal things, since it is the only change capable of being one, continuous and eternal, which, as we have seen, is

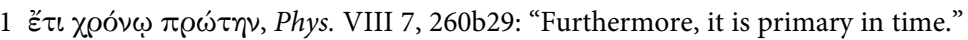

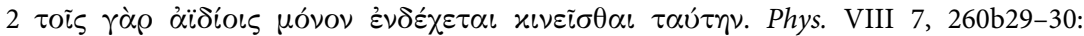
"Because for eternal things it is only possible to undergo this change."

3 See for instance Met. XII 2, 1069b25-26, which suggests that the only change eternals can undergo is change in place, but also Cael. I 3, 270a12-35, where Aristotle shows that the primary body only undergoes circular locomotion and thus is exempt from all other types of change that exist.

4 See for instance Cael. I 12, 281b25-282a1.

5 Phys. VIII 7, 261a20.

6 See Phys. VIII 7, 261a20-23. I shall I explain this in detail in section 7.2. 
necessary for a number of reasons for changes undergone by eternal things, like for instance the primum mobile, which is directly caused to change by the first unmoved mover. As we have also seen, each of the other kinds of change, that is, change in quality, quantity, and substance can only be finite. Against this background then it is clear why the mere fact that eternal entities only change with respect to their place shows, in Aristotle's view, that locomotion in general must have priority in time. In the discussion in Phys. VIII 1-6 it was established that there must be at least one eternal change. ${ }^{7}$ In addition, the previous chapter of my discussion showed that this eternal change can only be locomotion. This eternal locomotion then will always be temporally prior to, i.e. earlier than, any other non-eternal type of change, because such a finite change needs to start at some point, and will always be preceded in time by the eternal locomotion of the heavenly spheres and bodies, which in virtue of being eternal may therefore be said to occur earlier than it.

Given that this is the correct understanding of the first two lines ${ }^{8}$, it also follows that priority in time here is used in the sense in which it is introduced in Cat. 12 and Met. V 11. ${ }^{9}$ For $x$ to be prior in time to $y$ then merely means that $x$ is earlier than $y$. In this way, for instance, the father of $x$ is prior in time to $x$, since he existed earlier than $x .^{10}$

The definition of temporal priority that underlies the fourth argument for locomotion's priority accordingly would be the following:

TEMPORAL PRIORITY: Of two changes $x$ and $y, x$ is temporally prior to $y$, iff there is a time prior to $y$ at which $x$ is occurring.

7 See for instance Phys. VIII 6, 259a13-20.

8 There is consensus among Themistius, Philoponus, Simplicius, Aquinas, Ross (1936), Wagner (1967), and Graham (1999) that this is the way in which the first two lines of the passage and therefore the basic argument stated here need to be understood.

9 See Cat. 12, 4a26-29, and Met. V 11, 1018b14-19. In Met. V 11 as well, $x$ being prior in time to $y$ means that $x$ is earlier than $y$, although Aristotle's definition of temporal priority in terms of being closer or farther away from the now is of course not unproblematic. For more on the problematic definition see Kirwan (1993), 153.

10 Note that, as we will see later on, the fact that the eternal locomotion is prior to any occurrence of the three other kinds of change does not contradict the fact that this locomotion also succeeds each of these changes. 


\subsection{Objection: Locomotion is the last of all changes in perishable things}

If this were all there is to say about locomotion's temporal priority, then Aristotle could have stopped after the first two lines of the passage, yet, his discussion of this fact will continue for fifteen more lines. ${ }^{11}$ Clearly, then, Aristotle thinks that there are more things that need to be said with respect to the claim that locomotion is prior in time to the other kinds. The motivation for continuing this discussion, as we will see now, is an objection that may be raised against the assumption of the general temporal priority of locomotion. According to my reading the passage therefore is not primarily about explaining in what way locomotion is prior with respect to time; for as we have just seen, this follows more or less directly from what was stated in the previous argument, which is also the reason why Aristotle discusses this claim only in the first two lines of the passage and does also not really give a detailed presentation of the argument for it there as well. The whole passage accordingly should be read as being primarily about dealing with a possible objection against the claim of locomotion's temporal priority and how that claim may be reconciled with Aristotle's theory of there being a first unmoved mover that is responsible for all other changes that occur. ${ }^{12}$

For, right after the remarks on locomotion being the only type of change eternal things can undergo, a fact is presented that might contradict the claim of locomotion's temporal primacy or that is at least difficult to fit into Aristotle's theory. This fact is that in things which in contrast to eternal

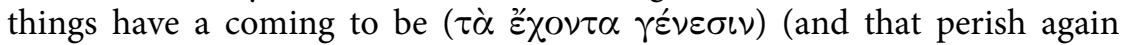
later on) locomotion is not primary at all, but quite the contrary even seems

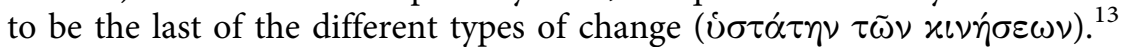
For with respect to each such thing, Aristotle tells us, the sequence of changes is this: after the process of its coming to be is set in motion, the first changes to occur are alteration and change in quantity, namely growth, while locomotion comes to the thing at a rather late stage in its development, but-and this is crucial here-certainly at a later point than the other three kinds of change. ${ }^{14}$

11 In fact, this passage is the longest of the five passages in which the five arguments for locomotion's priority are presented.

12 This is the reason why I take it that Aristotle's long discussion of locomotion's temporal priority is a necessary part of the discussion of the primacy of locomotion and not, as Graham (1999), 127, asserts a superfluous addition which indicates Aristotle's "propensity for philosophical overkill." Yet, as I said, Aristotle here most of all focuses on showing that a serious objection to his thesis is not a problem, but fits quite well into his larger theory.

13 See Phys. VIII 7, 260b30-32.

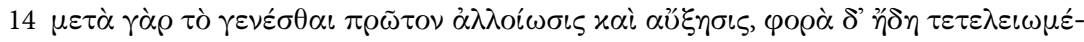


This claim about the temporal posteriority of locomotion will also play an important role later on in the fifth argument for the claim that of the four kinds of change, locomotion is primary in essence. Aristotle will say a little more about this claim there, and since understanding the details of this assumption is of much more importance for making sense of the fifth argument, I will present a thorough discussion of it in this context later on. ${ }^{15}$ To understand the current passage it is sufficient to know that what Aristotle is claiming here is this: in the process of a living thing's coming to be, locomotion is the last of the four kinds of change to come to these things, in the sense that any such being is actually able to perform its specific locomotion as a whole only after it, in the course of its development, has already undergone alteration, and growth as a whole, insofar as these changes have their source at least partially in the living thing's soul and are not completely caused by some external source. ${ }^{16}$ Accordingly, the term 'locomotion' ( $\varphi \circ \rho \alpha$ ) is used in a special sense here and does not stand for just any kind of change in place something $x$ may be subject to in general, but only for such cases of locomotion for which the respective thing as a self-mover may be responsible itself. ${ }^{17}$ If the claim is correct-and as I shall show in the next chapter Aristotle himself presents very good reasons why this is the case-then locomotion indeed seems to be the last of all changes in the sense in question.

But how then, one might wonder, does that fit with Aristotle's claim that locomotion is prior in time to all other kinds of change, if it clearly is last in this way? For this fact rather speaks for the assumption that coming to be,

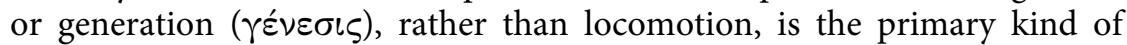
change. As Aristotle points out later on, against this background one indeed

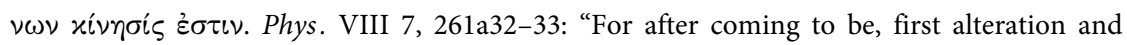
growth [come to the thing], while locomotion is a change of things that already have achieved completion."

15 See section 7.1.

16 I do not mean to say that for instance an animal's soul is responsible for all these changes in the very same respect, nor that it is fully responsible for its own generation, yet its soul certainly plays $a$ role for the occurrence of these changes. The point is that Aristotle here clearly excludes such changes that the respective being does not undergo as a whole and in virtue of being a living organism. For more on this see section 7.1.3.

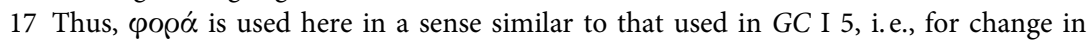
place that the subject undergoes as a whole (see 4.2.2, esp. p.76f.). Therefore, the claim about the posteriority of locomotion does not contradict what was shown in the first argument, for there Aristotle did not argue that alteration and growth have to be preceded by a change in place the respective thing undergoes as a whole, but by some change in place that occurs in the respective thing. It is clear that the scope of this posteriority claim cannot encompasses all things that have a coming to be, but only those which in potential have the capacity to move themselves as a whole, i.e. self-moving animals. For more on the special use of the term $\varphi \circ \rho \alpha$ see the next chapter, especially section 7.1.3. 
might come to think that generation is prior to locomotion, as well as to any other kind of change; for it certainly is correct that the prerequisite for something $x$ undergoing a change in quality, quantity, or place, $x$ needs to exist in the first place. ${ }^{18}$ Accordingly, if $x$ changes in any of these respects at $t_{2}$, but did not exist at an earlier point $t_{1}, x$ must have come to be at some point of time between $t_{1}$ and $t_{2}$. One might therefore come to the conclusion that generation not only in this case but also in all other cases of such changes must be primary in time. And while it is true that the subject of any of the aforementioned changes that occur in the sublunary sphere needs to have come into being before undergoing the respective change, yet, according to Aristotle this neither implies that this is true of all changes in the cosmos, nor that generation must be primary in time in general.

The problem with this assumption is that the objector obviously treats changes as phenomena that seem to occur in isolation from the framework of the different causal relations in which they are embedded as parts of the cosmos. Because of this, Aristotle's strategy will be to show that any process of coming to be as such a part presupposes other changes that occur temporally prior to it in nature or the cosmos and that locomotion is prior in time in general, not in spite of the fact that changes in perishables presuppose their generation, but because they do so. Contrary to what the stated objection may suggest at first glance it then not only not contradicts the claim about locomotion's temporal priority, but in fact may be read as an affirmation of it. In order to show this I will now focus on Aristotle's answer to the objection that is stated in the central part of this passage, i.e. in 261a1-12. ${ }^{19}$

\subsection{Coming to be presupposes an earlier locomotion}

Aristotle, however, does not appear to see any problem in the fact of locomotion's temporal posteriority in living beings, and in fact this assumption, as I will show in the next chapter, is in accordance with and even implied by his theory of the soul as it is stated in the De Anima. ${ }^{20}$ Nonetheless,

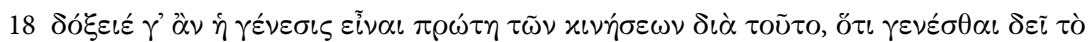
$\pi \rho \tilde{\alpha} \gamma \mu \alpha \pi \rho \tilde{\omega} \tau o \nu$. Phys. VIII 7, 261a3-5: "coming to be might seem to be primary among the changes for the reason that the thing needs to come to be first." I take it that this second objection about generation being the primary kind of change follows necessarily from the first one.

19 Since all commentators basically agree on the basic structure of the argument, all also think that 260b30-33 presents a possible rejection that is addressed in 261a1-12; see Themistius, In Phys. 8, 226, 6-13, Philoponus, In Phys. 8, 899, 24-25, Simplicius, In Phys. 8, 1270, 17, Aquinas, In Phys., L.VIII, 1. XIV, 1093, Ross (1936), 709, Wagner (1967), 689, and Graham (1999), 127.

20 See section 7.1.4. 
Aristotle thinks this is no reason to deny locomotion's general temporal priority.

Having raised the problem, Aristotle then states what he thinks is an appropriate answer to it. In order to do so he makes the following four points: (1) any process of coming to be presupposes that there is some other

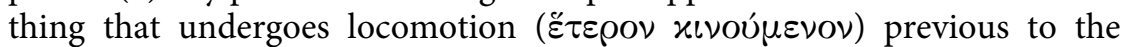
occurrence of this process. ${ }^{21}$ This assumption is further specified by pointing out that (2) this previously moving thing needs to be the cause ( $\alpha i \tau i \alpha)$ of that which is coming to be $\mathrm{e}^{22}$, and (3) that this thing (which one may call the generator) "itself is and is not coming to be". ${ }^{23}$ (4) The relation between the generator and that which it causes to come into being is further qualified by being compared to that of the begetter ( $\gamma \varepsilon \nu \nu \tilde{\eta} \sigma \alpha \nu)$ and the begotten $(\gamma \varepsilon \nu \vee \eta \theta \varepsilon v)^{24}$, for the former is what is causally responsible for the coming to be of the begotten.

The cases Aristotle probably has in mind here are those of, for instance, a father that, serving as the generator, causes the coming to be of his child. For the father in contrast to his child already is a human being in the fullest sense possible, i.e. in actuality, and is no longer undergoing a process of coming to be (see claim (3)). But the relation between the father as the generator and that which is generated, i.e. the child, lies not only in the fact that the former is the cause of the latter's coming into being and that this is the case because of the father's maturity, but according to what is stated in claim (1) also that the father for some reason needs to perform a change in place prior to the generation of the child. This is plausible insofar as the father in order to become a generator and to beget a child needs to come in contact with a female, that is, the potential mother of the child. Because they are not always in this state of contact, in principle either the father, or the mother, or both need to move towards each other, i. e. change in place. Yet, as Aristotle holds the view that the father as the bearer of the form of the human being, in contrast to the mother, who provides the matter, is the

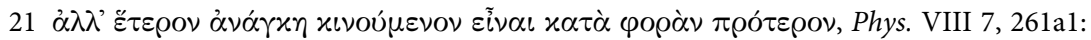
"Yet, it is necessary that there is something else which is undergoing locomotion before". The

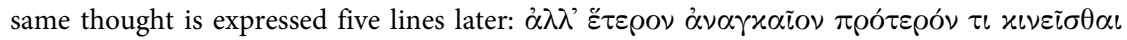

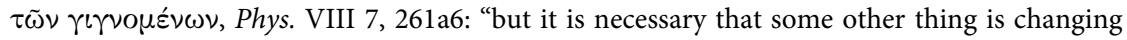
prior to the things that are coming to be"

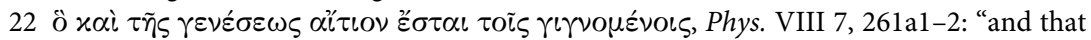
will be responsible for the coming to be of the things that are coming to be".

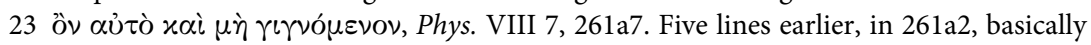
the same claim was made, yet there it was only stated that the generator is oủ rervó $u \varepsilon v o \nu$ and not that it "itself is", which however, follows from the fact that it causes a change and is not in a process of becoming.

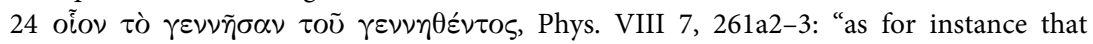
which begets for what is begotten". 
generator of the child, the father must clearly undergo a change in place if the two are to come into contact. ${ }^{25}$ This obviously is the sense in which Aristotle thinks that any coming to be is temporally preceded by some other thing's locomotion, namely that which serves as its moving cause. Accordingly, the locomotion that is responsible for the coming to be of something in this way is prior to, or, as one could also say, earlier than, the generation that is caused, because in order for the latter to occur the causer must first of all undergo a change in place. In this sense, however, it is clear that locomotion, in virtue of being prior in time to generation, is also prior to alteration and growth, which according to the objection were also supposed to precede locomotion.

If this is the solution to the problem, then the whole picture would be this: in living things at first glance it seems that locomotion is posterior in time, insofar as it is the last of the different kinds of change which this thing may undergo as a whole in the sense in question. Yet, as we have seen, this is not the case, since in order for the thing to come to be it is necessary that what serves as the moving cause of the thing's generation change in place beforehand.

This also fits very well with Aristotle's assumption that a species in virtue of consisting of an infinite number of members is eternal. ${ }^{26}$ For it is not only the case that for instance one human being is caused by another human being, but of course the man who is the father of the next link in this eternal chain of beings himself was caused to come into being by his father, who again was brought into being in the same way. For this reason one might think that this is what Aristotle is referring to when he states that there not only needs to be a generator that changes in place before that which it generates can come to be, but also another thing which again is prior to the former in this sense. ${ }^{27}$

25 By this I therefore do not mean to say that generation can only occur by the male moving towards the female, while the female does not or even must not be active at all; the point Aristotle wants to make here is that the begetter, and this can only be the father in the proper sense, needs to change in place-no matter whether the mother also does so.

26 For the claim about the eternity of a species in virtue of the infinite series of male members, each of which is "causally responsible for the subsequent members in the series" see Bodnàr (2010), section 4, who in this context also points to Phys. III 6, 206a25-27, where it is stated that there is infinity "with respect to man", which probably means with respect to the generations of man as the translation of Hardie \& Gaye suggests.

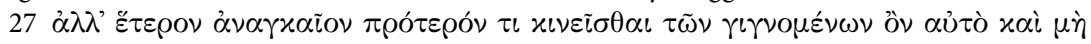

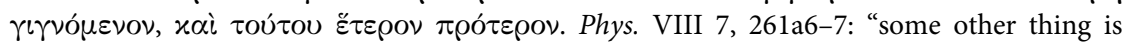
changing prior to the things that are coming to be that itself is and is not coming to be, and another thing prior to this." Note that the point about another mover that is previous again to the mover of that which is coming to be is left out in the first statement of claim (1). As I will show later on, this sentence has a different meaning than the one it seems to have in the current context. 
But does this explanation really make clear that locomotion is prior in time in general in spite of the fact that it is posterior in the sense stated by the objection? Although everything said so far seems to fit together very well with what is stated in the passage as a whole, and it is certainly correct that there must be some generator that performs locomotion in order to cause the coming to be of its offspring, one could say that this temporally prior locomotion again presupposes the coming to be of the generator in the first place. In other words, the fact that $x$ 's father moves from place A to place B before, and in order to, make $x$ come into being does not show that this kind of locomotion is prior in time to coming to be in general. Such an occurrence certainly is earlier than the respective coming to be in the same way as my father, my grandfather, and my great grandfather are prior to me; but this does not make clear that there is a way in which locomotion may be said to have temporal priority in general over the other kinds of change, especially with respect to coming to be, because in a species' eternal chain of beings there will always be such a process of coming to be that is prior in time to the locomotion and which some member of this species performs.

In order to solve this problem it is helpful again to consider the context of this passage: the passage presents one of the five arguments for the priority of locomotion. This claim is essentially connected to the discussion in Phys. VIII 1-6 in which Aristotle shows that change must be eternal and that therefore a first unmoved mover has to exist. In fact, Aristotle is interested in showing that locomotion is the primary kind of change for the sake of showing that only this kind of change can be directly caused by the first unmoved mover. But how is the fact that locomotion seems to have temporal posteriority connected to this greater context? That there certainly is such a connection is indicated by what Aristotle presents as the basic reason for the general temporal priority of change in place, namely the fact that eternal things can only undergo this kind of change. But in what way does this help to show that locomotion indeed is prior in time in general despite the fact that in a certain sense locomotion may be said to be the last of changes in this respect as well? Aristotle clearly does not think that claiming that eternal things, like for instance the heavenly bodies, can only change in this way is enough to explain how the objection may be reconciled with the claim about locomotion's primacy in time, for otherwise he would have stopped after writing the first two lines of this passage.

In order to solve this problem one has to have in mind that the things that are undergoing eternal locomotion are not just arbitrary things in the cosmos, but rather things that without exception play a fundamental role in the processes that occur in it. The first principle of eternal locomotion is the first unmoved mover. The eternal circular locomotion of which it is the direct source, i.e. that of the outermost sphere, again is the cause of all other 
changes in the cosmos. ${ }^{28}$ The fact that locomotion in this sense is responsible for all changes in the universe, as we have seen, is one of the reasons for its ontological priority. ${ }^{29}$ Neither coming to be nor perishing, nor any of the other kinds of change may be without this primary change in place. ${ }^{30}$ Accordingly, the generation of perishable things, too, depends on this primary change, that is to say, there exists some causal connection between the primary eternal change that is locomotion and the generation of living beings that necessarily precedes the performance of any of their specific locomotions in time. As I shall show now, this connection of the generation of things to the eternal movements that occur in the heavens will help us to see in which way change in place indeed is prior in time in general, although in some individual living things locomotion in the stated sense needs to be considered as the last of changes.

\subsection{The locomotion of the sun as a cause of generation}

Yet, apart from the fact that the eternal change that is caused directly by the first unmoved mover, i.e. the locomotion of the outermost sphere, is the cause of generation and corruption as well as of every other change in the cosmos, it is unclear what precise role this primary change plays for these changes, that is, in what exact causal relation it stands to the occurrences of the coming to be of individual perishables. For in what way does it make sense to say that, for instance the uniform and unchanging movement of the sphere of the fixed stars is responsible for the coming be of specific living beings, for example my neighbour or his cat?

Again, at the end of Phys. VIII 6 it is pointed out that every change in the universe has its source in the first unmoved mover, since without the primary change that it causes no other change could exist. ${ }^{31}$ However, Aristotle makes clear that this change cannot be directly responsible for generation, corruption or any of the other kinds of change that occur, since it persistently causes one and the same change, a change that is eternal and characterised by absolute uniformity. ${ }^{32}$ Yet, it is due to its causing the movement of this primum mobile, which may be identified with the outermost sphere, that all of the other changes in the end occur, for the primum

28 See Phys. VIII 6, 260a1-3. For more on this see the next section.

29 See my discussion in chapter 5; for the claim that all changes depend on the change which is directly caused by the first unmoved mover, see Phys. VIII 6, 260a1-3.

30 See Phys. VIII 6, 260a1-3.

31 See Phys. VIII 6, 260a1-3.

32 See Phys. VIII 6, 260a3-5. 
mobile again serves as the cause of all other changes. But in contrast to the relation that exists between the first unmoved mover and the outermost heavenly sphere, the relation in which the latter stands to the things it causes to move changes. This accounts for the movements of the other heavenly bodies, e.g. the moon, the sun, and the other planets, and hence ultimately explains why there exists such a diversity of changes in the cosmos. ${ }^{33}$

All this is stated in rather abstract terms in Phys. VIII 6, yet is presented in a more tangible form elsewhere in Aristotle. The fact that the eternal locomotion of the heavenly bodies and thus also that of the outermost sphere is responsible for changes is made clearer, for instance by what is stated in GC II 10. There Aristotle states that the eternal locomotion leads to the generation of things in the sublunary sphere by making the generator

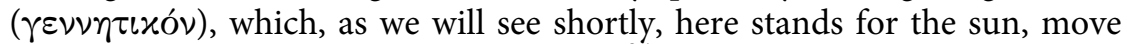
nearer to or farther away from the earth. ${ }^{34}$ That this is the background to the argument for locomotion's priority is not only indicated by GC II 10 , but also by two further passages. One of these can be found in Phys. II 2, the other one in Met. XII 5. For, in these two texts examples for the causal connection between the coming to be of a living being and the eternal locomotion of the heavens, or more precisely one of the heavenly bodies, is presented.

In Phys. II 2 Aristotle explains the generation of a human being in which, it seems, one of the heavenly bodies is necessarily involved. There it is pointed out that when a human being comes to be, not only another man, i.e. the father, is responsible for this, but also the sun, "for man is begotten by man and by the sun as well." ${ }^{35}$ The very same thought is presented in the passage from Met. XII 5, yet here some additional information is given. In this context a man, or to be more precise the father and the sun, are said to be responsible for the generation of another member of the species of human beings. They are also characterised as external causes, while the sun and its motion along the ecliptic, more specifically, are also described as a moving cause of a man's coming to be. ${ }^{36}$

33 See Phys. VIII 6, 260a5-10. For this see Ross (1936), 92.

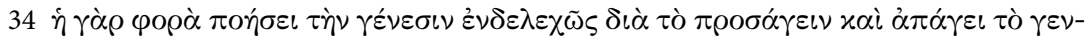

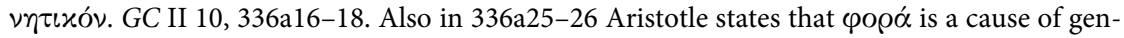

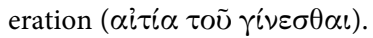

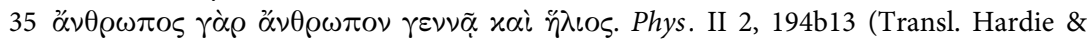
Gaye). Philoponus, In Phys. 8, 899, 26-28, Simplicius, In Phys. 8, 1270, 37, as well as Ross (1936), 710, point to this passage from Phys. II 2; Graham (1999), 127, also refers to the motion of the sun and the corresponding discussion in GC II 10.

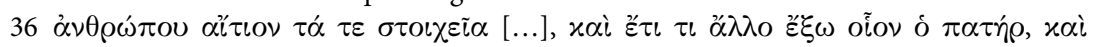

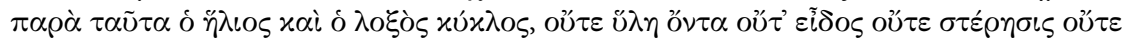

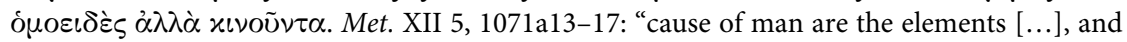
further some other external thing, e.g. the father, and besides these the sun and its oblique 
In what way the sun may be involved in the coming to be of living things like human beings was indicated in the passage from GC II 10 to which I have already referred: the generator, i.e. the sun, by undergoing locomotion moves closer to or farther away from the object that is affected by it, and this movement is what is (at least partly) responsible for the occurrence of generation. This thesis is confirmed by observation, as we "see that when the sun comes closer there is coming to be, and when it retreats, perishing." ${ }^{37}$ And indeed it makes sense to say that the sun as the heavenly body which is the main source of heat and light is necessary for there being life on earth at all and by its movement therefore plays an essential role in the coming to be and perishing of living things. ${ }^{38}$ By undergoing its eternal motion along the ecliptic the sun causes not only night and day, but also the cyclic recurrence of the seasons, a cycle which in turn accounts for the cycle of life and death on earth. ${ }^{39}$ Yet, the eternal locomotion of the sun, as well as all the other eternal motions that occur persistently in the superlunary sphere must all, "in spite of their plurality, be in some way subordinated to a single principle", namely the one unmoved mover. ${ }^{40}$

This then explains more precisely in what way there is a causal connection between the coming to be of perishable things like living beings and the change which the eternal things undergo. For, it is the movement of the

course, which are neither matter nor form nor privation nor of the same species with man,

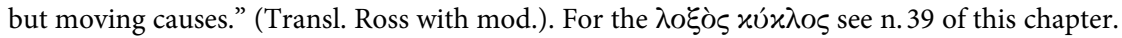

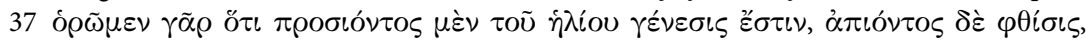

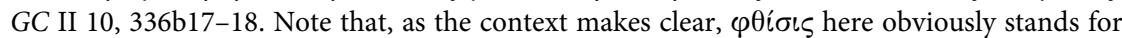
a change in substance, namely perishing; although this is certainly a meaning to which the

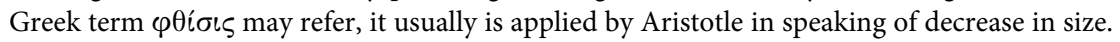

38 Also in Mete. I 9, 346b20-23, the locomotion of the sun is presented as being responsi-

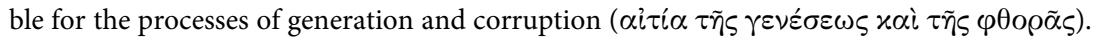

39 See GC II 11, 338a17-b5. Also Wieland (1992), 237-238, points to the passages from Phys. II 2 and Met. XII 5 and emphasizes the essential role that the sun as a necessary condition of generation plays for Aristotle in virtue of being responsible for certain natural phenomena, such as the seasons or the winds (see p.238, n.7). Yet, it is important to note that generation and corruption as well as the seasons do not occur alone in virtue of the sun's continuous circular locomotion, but are only possible because the sun's movement is also one of

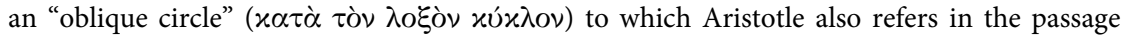
from Met. XII 5 that I quoted above (see p. 155, n. 36). Only this can account for the change in distance between the sun and the earth that occurs in the course of a year (for this see GC II 10, 336a31-b9). For more on this see Buchheim (2010), 535-537.

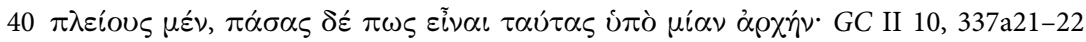
(Transl. Joachim). That the principle ( $\dot{\alpha} \rho \chi \hat{\eta})$ about which Aristotle talks here must be the first unmoved mover of Phys. VIII is clear from what is stated in 337a17-20. Aristotle argues for what seems to be a different position in Met. XII 8 where he states that there must be a plurality of unmoved movers by means of which the different motions of every single sphere may be explained (see 1073a22-b1). I will not discuss this here any further. 
sun that is to a certain degree responsible for the coming to be of a man as well as of all other living beings. The eternal locomotion of the sun however is caused (at least indirectly) by the first unmoved mover. ${ }^{41}$ Just as all the other eternal things in the cosmos that are subject to change, so, too, the sun has always undergone its locomotion. By contrast, the coming to be of a perishable individual thing is a finite change and has to start at some point in time. Therefore, the locomotion of the sun will always be prior in time to such a coming to be, since in virtue of undergoing an eternal locomotion it will always be in motion before the respective case of coming to be is caused. In this sense then, it is clear in what way there will always be a locomotion that is prior in time to every case of generation, without there being a generation that is prior to this preceding locomotion. The only sense in which one may say then that locomotion is the last of changes in things that have a coming to be is by ignoring that its coming to be is connected to certain processes in the cosmos. This would make sense if one is only interested, for instance in the developmental stages through which an animal as the member of a certain species passes in its coming to be; but this certainly must not be done when one tries to work out a causal explanation of the different changes that occur in the cosmos, which to a certain degree is what Aristotle is doing when he claims locomotion's priority in the context of Phys. VIII.

Against the background of what has been stated so far it also becomes clear that claim (3) which says that the thing which causes the generation

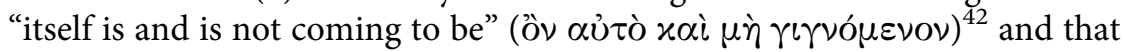
I examined above must have a different meaning than the one I stated further above. ${ }^{43}$ As I have shown, it is plausible to basically take claim (3) as referring to the male member of a species which as the father of that which is generated no longer undergoes its coming to be, but is completely what it is, for instance a full man. ${ }^{44}$ But now that we have seen that the sun also plays the role of a cause in this process of generation, one might think that claim (3) therefore refers to both the father and the sun, for also the sun "itself is not coming to be", in fact, never came to be, but is eternal.

While claim (3) as it is stated above may be referring to both father and sun, the more specific qualification that is added in 261a7 makes clear that

41 By the sun being indirectly caused to move by the first unmoved mover I mean that there is a finite chain of movers and moved things that has its starting point in the first unmoved mover and that necessarily leads to the sun's change in place. Thus, I do not mean to refer to a case of what one might call deviant causation of a change.

42 See Phys. VIII 7, 261a7. As I pointed out on p.151, n.23, the same claim in principle is made five lines earlier in 261a2.

43 See p. 151-152.

44 See p. 151. 
the phrase cannot refer to an eternal thing like the sun, but only to something that (like the father) itself has a coming to be: for also with respect to that which "itself is and is not coming to be", Aristotle tells us, there must

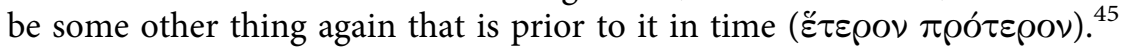
This, however, is impossible with respect to the sun, as there is nothing which is prior in time to something that is eternal or to the eternal locomotion of an eternal thing. The "other thing" whose locomotion and existence according to Aristotle must temporally precede the father, one would think, may either stand for (1) another perishable thing that is responsible for the father's coming to be, e.g. the father's father, or (2) the sun, which again is responsible for the father's coming to be as well. In my earlier discussion of claim (3) I stated that Aristotle here seems to have option (1) in mind. ${ }^{46}$ Yet, against the background of what we have seen since then, it has become clear that only the second option can be the correct one, i.e. that the "other thing" that necessarily precedes the father must refer to the sun (or some other eternal thing) that operates as a cause of the coming to be of the respective thing.

For if option (1) were correct and the phrase in question referred to some other perishable thing, then the causal relation that exists between the thing that is coming to be and the eternal cause that is responsible for its generation would not be established. This, however, as we have seen, is essential in order to make clear that the eternal locomotion is prior in time with respect to any generation. For if the "other thing" stood for some other perishable being that is responsible for the father's generation, e.g. the father's father, then, as we have seen before ${ }^{47}$, asking for the father's cause would ultimately lead to an infinite chain of male members of a certain species in which each member is responsible for the next member's coming into being. Only if by the "other thing" an eternal being like the sun is meant, i. e. option (2) is chosen, can we circumvent the argument that ultimately leads to an infinite regress and establish the connection between that which is coming to be and its eternal cause. And this, as we have seen, ultimately shows locomotion's general priority in time. ${ }^{48}$

45 See Phys. VIII 7, 261a6-7, note that this more specific qualification is only made in connection with the second formulation of claim (3) and not with its first appearance in the context of 261a1-3.

46 See section 6.4, p. 150-153.

47 For this see p. 152.

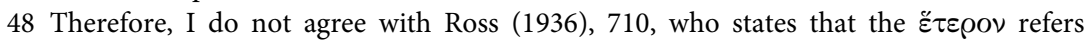
"either to grandparents, \&c., or to the sun, or indeed the whole celestial system". My understanding is in line with what Philoponus says in In Phys. 8, 900, 6-8, for also he states the two mentioned options but, but makes clear that the latter one is to be preferred. Accordingly, I also do not agree with Zekl (1988) who, as the translation and n. 120 on p.289, clearly show, 
The following diagram may help us to summarize what was stated in this section, i.e. to reformulate in what way it is correct in general to say that locomotion is prior in time to any occurrence of generation, although locomotion seems to be posterior in time in things that undergo this process:

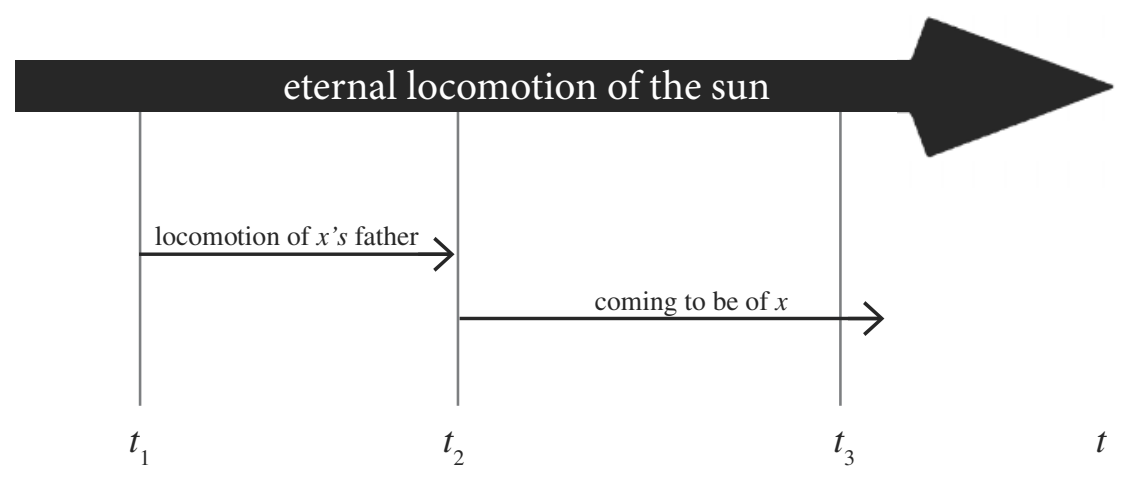

Fig. 2

This diagram shows three changes: (1) the eternal locomotion of the sun which has neither beginning nor end, (2) the coming to be of something $x$, and (3) the locomotion of $x$ 's father, which precedes $x$ 's coming to be.

The coming to be of a new living being $x$, of a man for instance, begins at $t_{2}$. At $t_{3}$, that is at a rather late point of its coming into being, $x$ has developed to such a high degree that it is able to move itself as a whole from one place to another, i.e. it has the capacity to perform its specific locomotion from then on. Since $x$ has already undergone both alteration and growth as a whole before $t_{3}$, locomotion with respect to this process of coming to be is the last of the four kinds of change. Yet, Aristotle points out that for $x$ to come to be there must be some cause that undergoes locomotion prior to $x$ 's coming to be. As we have seen, it is $x$ 's father as well as the sun that are responsible for $x$ 's coming to be, and both of these undergo locomotion that is prior to the process of generation started at $t_{2}$. Yet, the sun's locomotion temporally precedes not only the coming to be of $x$, but also the locomotion (as well as the coming to be) of $x$ 's father. In this way, every process of coming to be depends on an eternal change in place that is always temporally prior to the respective case of coming to be. Thus, one can conclude that with respect to any process of coming to be there is a locomotion that is prior to it in time, that is not preceded by any other change, and without

obviously takes Aristotle to be referring to an infinite chain of perishable beings here, i. e. that

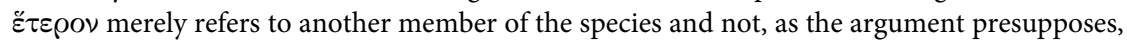
to some eternal thing that undergoes locomotion. 
which it would not occur. It is therefore correct to say that locomotion is posterior not in an unqualified sense, but solely with respect to the coming to be of any single thing. This, however, in no way contradicts the assumption of locomotion's general priority, because for each generation there is something which undergoes locomotion prior to it, namely the heavenly body of the sun that is causally related to and thus responsible for the coming to be of the respective thing.

In making use of this causal connection that exists between eternal and perishable things in the sublunary sphere Aristotle therefore can successfully reject the objection that locomotion rather seems to be posterior to generation, or to put it differently, is able to harmonise the fact of locomotion's posteriority in perishable things with his claim about locomotion's general temporal priority. The objector makes the mistake of focusing on what happens in the sublunary sphere and thereby ignores the fact that anything that has a coming to be, as a part of the cosmos, is embedded into a larger framework of causal relations. Emphasizing that such causal connections exist is of utmost importance for dealing with the objection at issue, since merely pointing to the fact that the eternal locomotions that eternal things in the superlunary sphere undergo always precede any other finite change in time does not really address the apparent problem of locomotion's posteriority in perishable things. This is because the objector who looks at things from the restricted perspective stated above does not see how this fact is supposed to relate to his assumption that generation with respect to sublunary things obviously seems to precede locomotion, rather than the other way around. Hence, the reason why Aristotle makes use of the causal relations that exist between the super- and sublunary spheres is to make the objector see that the changes he takes to be independent of the heavens' eternal motions in fact necessarily need to precede the generation of things and any change succeeding to it in order for the latter to occur at all.

Of course the objector would be right to point out that against this background locomotion indeed in general precedes any generation in the sense in question, but that this fact does not seem to be of any significance, since at the same time it is also true that the eternal locomotion of the sun and of all other moving eternal things is succeeded by the generation of perishable things, as well as any other finite change in the sublunary sphere, and in this sense again appears to be posterior. But this point makes clear again what Aristotle's reason is for bringing causality into play in this argument, when it should basically suffice to point to the eternal locomotion of the heavenly spheres and bodies in order to show locomotion's general temporal priority: the sun's movements that are previous to something's generation are responsible for this change and therefore of importance for harmonising the stated objection with Aristotle's priority claim and thus with his larger 
theory about the existence of change in the cosmos. The movements of the sun that occur after a certain change has taken place of course do not play any role in this change and thus are irrelevant for the question whether there is a locomotion that in general precedes any generation without itself being preceded by some other change. Aristotle therefore successfully shows that locomotion is not posterior in an unqualified sense, but only with respect to the generation of perishable things in the sublunary sphere. As we have seen, this fits very well with the assumption that locomotion has general priority, since for each generation there is something which undergoes locomotion prior to it, namely the sun. Accordingly, it also cannot be the case that, contrary to what the objection seems to suggest at first glance, generation is prior to the other three kinds of change. ${ }^{49}$

This, however, establishes locomotion's temporal priority not only over generation, but also over the other kinds of change with respect to which locomotion is the last to occur in individual perishable things. For, as is pointed out at the end of the passage, if not even generation is prior to locomotion in the way just stated, how could this be the case for the other kinds, which depend on the respective thing's coming to be and therefore can only occur after it? For alteration, growth, and diminution, as well as corruption, all presuppose an existing substance with respect to which the change may occur and in this sense are changes that succeed $(\dot{\varepsilon} \varphi \varepsilon \xi \tilde{\eta} \varsigma)$ and thus are posterior to generation. But if generation is posterior to locomotion, then $a$ fortiori all succeeding changes are also posterior to it. ${ }^{50}$ With respect to these changes it is correct that the respective subject needs to come to be first of all before any of them can occur, but as we have seen in this chapter the case is significantly different for locomotion, as there are eternal things which change in place and since these changes are responsible for any generation that occurs. Thus, one may conclude that Aristotle in the passage discussed in this chapter successfully shows that locomotion has priority in time over each of the other kinds of change. ${ }^{51}$ In doing so he once again presented reasons for the claim that locomotion is the primary kind he

49 Aristotle also presents yet another argument for this claim in a parenthetical remark in 261a8 which, however, is not necessary for the whole argument to work. According to this argument it is impossible that generation could be the primary kind of change that is directly caused by the first unmoved mover and which is the cause of all other kinds of change in the cosmos, "because then everything that is changing would be perishable", i. e. eternal things as well, which for Aristotle is impossible.

50 See Phys. VIII 7, 261a7-12.

51 Therefore, I cannot agree with Graham (1999), 127-128, that Aristotle does not show that locomotion is prior in time but "just prior in some general sense". Graham however is right in saying that in this argument not every step is spelled out in detail. But as I have shown in my discussion of the passage it nonetheless becomes quite clear in what way Aristotle shows that locomotion is primary in time in general. 
claims it needs to be, a change that has its primary source in the first unmoved mover, and which for this reason also temporally precedes all of the finite changes that occur in the cosmos.

\subsection{Conclusion}

What are the results of the analysis of the fourth argument for locomotion's primacy? First of all I have shown in what way the fact that locomotion is the only kind of change eternal things may be subject to implies locomotion's temporal priority over the other kinds of change: as was shown in the previous chapter, locomotion alone can be eternal and therefore is the only possible candidate for the change eternal things undergo, which also makes it the only candidate for the primary change that is directly caused by the first unmoved mover. In virtue of being eternal and having no beginning or end, the changes which eternal things undergo necessarily precede any instance of the other three kinds of change in time, as each of them is always finite. Accordingly, locomotion in virtue of being the only possible candidate for the eternal change that is directly caused by the first unmoved mover has temporal priority over any occurrence of each of the other three kinds of change, insofar as this eternal locomotion will always be going on before the occurrence of any of these other changes.

Yet, in contrast to this it seemed that there are cases which rather suggest that locomotion with respect to time is the last of the changes. For, in the development that living beings are subject to, these things are only able to undergo their specific locomotion after they have already undergone alteration and growth. The discussion of this objection has also made clear that against this background one might even come to think that generation in general, and not locomotion, is the primary kind of change. For the three kinds of non-substantial change, and corruption as well, presuppose the existence of an object with respect to which they may occur, and that, as it appears, needs to be brought into being before it may be subject to a change.

Since the fact of locomotion's posteriority in this sense seems to contradict the claim about locomotion having temporal priority over the other kinds of change, Aristotle devotes the majority of the passage to rebutting this objection. And as we have seen, the case at issue is actually compatible with Aristotle's claim about locomotion's temporal priority. For, each generation of some thing is partly caused by the sun and its eternal change in place, and hence the generation that, with respect to perishable things, precedes locomotion is itself preceded by a locomotion that is not preceded by any change. By making use of this causal connection between the changes 
in the superlunary and sublunary spheres, Aristotle makes clear that any change in the sublunary sphere, i.e. any process of generation as well, is embedded into a larger framework of causal relations in the cosmos and thus cannot be examined in isolation from its different causes.

In this way then it has become clear that locomotion in virtue of the fact that all changes that eternal things undergo are locomotions indeed has temporal priority over the other kinds of change in virtue of their being responsible at least partly for the changes that occur in the sublunary sphere. This again has shown that, of the different kinds of change, locomotion is the only appropriate candidate for the change that is directly caused by the first unmoved mover. 


\section{Locomotion is prior in essence}

7.1 Locomotion is prior in essence, since it is last in coming to be

\subsubsection{Overview}

The fifth way in which locomotion should be considered as the primary

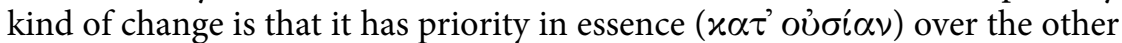
kinds of change. Aristotle presents two arguments which taken as a whole are supposed to establish the truth of this premise. The first one shows that locomotion has priority in essence in perishable things (7.1) and the second argues that the same is true with respect to eternal things (7.2). I will start with an analysis of the first argument, and after this I will turn to the second one. The first argument is presented in the following lines:

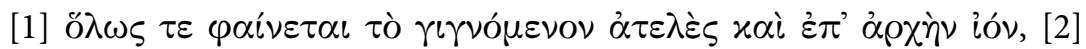

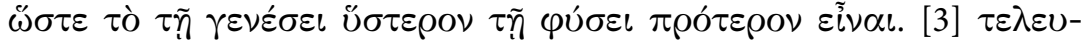

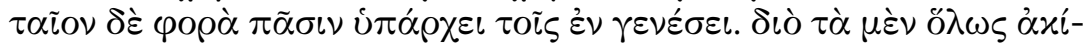

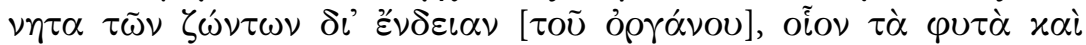

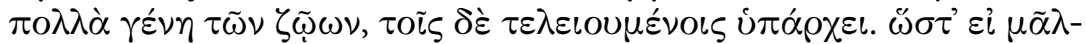

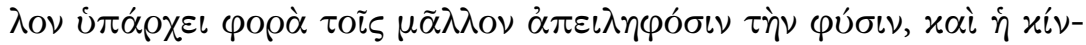

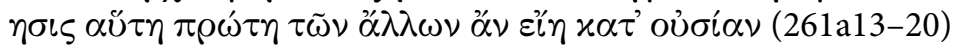

[1] In general what is coming to be clearly is incomplete and proceeding towards a principle, [2] so that what is posterior in coming to be is prior in nature. [3] But locomotion belongs lastly to all things that are coming to be. Because of this some of the living beings are entirely incapable of moving due to a lack [of an organ], just as the plants and many genera of animals, but it belongs to those which are about to attain completion. Therefore, if locomotion rather belongs to those which have received their nature to a higher degree, this [kind of] change would also have primacy over the other [kinds] in essence

This argument aims at showing that locomotion is primary in essence, because it is later in the development of living things than alteration, growth, and diminution. This means, I will argue, that in living beings the capacity to cause locomotion is prior in essence to the capacities for the other two changes. This also finds its expression in the fact that having locomotion is more specific for certain kinds of things and more important 
for fulfilling the essence and the form that something has by belonging to a certain kind. I take the following to be a basic reconstruction of the argument that is supposed to show that this claim is correct:

(1) If $x$ is posterior to $y$ in the coming to be of living things, then $x$ is prior in essence to $y$ with respect to living things.

(2) In the coming to be of living things locomotion is posterior to alteration, growth and diminution.

(3) Therefore, locomotion is prior in essence to alteration, growth and diminution with respect to living things.

The reason why Aristotle presents this argument is that he needs to deal with a problem that had already been raised in the discussion of the fourth argument. As we have seen, the fourth argument was supposed to show that locomotion has priority in time ( $\varepsilon \vee \chi \rho o ́ v \omega)$ over any other kind of change. ${ }^{1}$ Yet, in the discussion of the argument it was also stated that-on a smaller scale, namely with respect to each living thing that has a coming to belocomotion is not primary at all, but on the contrary even is the last of the

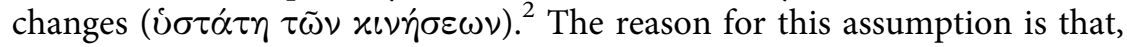
of the different kinds of change, locomotion in the process of the development of a living thing comes last and in fact only belongs to those things which are about to reach the end of their coming to be, or already have completed it. ${ }^{3}$ In answer to this objection Aristotle rightly claims that the coming to be of any living thing is temporally preceded by an eternal locomotion that is causally responsible for the generation of this living thing and for this reason also precedes the changes that supposedly were prior to locomotion. Nonetheless, Aristotle still seems to think he needs to say more about the fact that locomotion is last in the development of certain living things and how this fits into his theory that change in place is primary. For this reason he picks up the fact about the posteriority of locomotion at the beginning of the fifth argument again and shows that locomotion is prior in a more important sense-namely prior in essence - not only in spite of, but because of its posteriority in the development of living things. ${ }^{4}$ This

1 For the following see chapter 6.

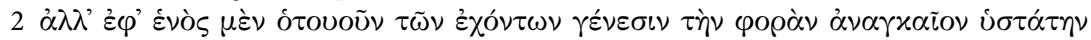

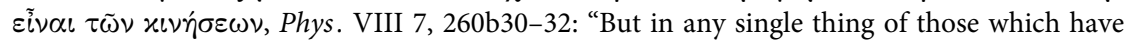
coming to be locomotion must be the last of the changes."

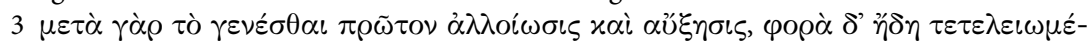

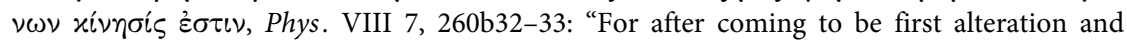
growth [come to the thing], while locomotion is a change of things that already have achieved completion."

4 This again makes clear that Aristotle has very good reasons for showing that locomotion is primary in different respects and not, as Graham (1999), 127, suggests in the part of his 
assumption fits very well into the wider context of Aristotle's general theory, in which teleology plays a crucial role. Changes occur for the sake of certain goals or ends. The development of an animal for example aims at the animal's becoming a full member of a certain kind. In order to fully understand why a change occurs and what its nature is, one has to know what its end is. For Aristotle therefore the end of changes have explanatory priority, and it is in this sense that locomotion's posteriority should rather be seen as an expression of its importance and priority in essence than the contrary.

In order to understand how exactly Aristotle's argument works and whether it is successful in showing what it needs to show I will present a detailed analysis of it. I will proceed as follows: To begin with, I will show that Aristotle's first premise, namely that what is posterior in coming to be is prior in essence, is correct. In order to do so, I will examine what it means to be prior in essence and argue that for $x$ to be prior in this way it must fulfil its essence to a higher degree than the thing it is compared to (7.1.2). Since the term 'locomotion' seems to be used in this argument in a special sense, my second step will be to analyse what it stands for in this context and show that it refers to the subject's capacity to be the source of its change in place (7.1.3). I will then show that the argument's second premise, i.e. the claim that locomotion is last in the generation of living things, is correct. In order to do so it will be necessary to deal with certain aspects of Aristotle's theory of the soul (7.1.4). Against this background I will argue that to say that attributes or features of something $x$ are prior in essence means that they are more specific to what $x$ is (7.1.5) I will conclude by evaluating to what extent the argument shows that locomotion is prior in essence. I will argue that it shows locomotion's priority in essence in living things, but that it is only in connection with the second sub-argument that locomotion's general priority in essence is established (7.1.6).

\subsubsection{The reversed priority claim}

In my view, sentence (1) in the quote above means the following: the process of coming to be of living things is goal-directed and aims at reaching a certain endpoint, completion, at which this living thing has fully become such and such a thing. An infant, for instance, right after its birth can neither walk, nor nourish itself, but it will be able to do so after having reached maturity. That this is what Aristotle has in mind becomes clear when he states in sentence (1) that a being that is in the process of coming

commentary on the argument for locomotion's temporal priority, that he has a "propensity for philosophical overkill”. 
to be is incomplete $\left(\dot{\alpha} \tau \varepsilon \lambda \varepsilon^{\prime} \zeta\right)$ and proceeding towards its principle ( $\dot{\varepsilon} \pi^{\prime}$

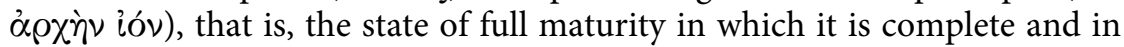
which it begins its life as a full member of the genus to which it belongs. Having attained its principle, the former infant is now no longer undergoing the process of coming to be a human being, but has completely received its nature and is now a member of this species in the full sense. In this sense the principle $\left(\alpha \rho \chi \eta^{\prime}\right)$ is the endpoint of the development of this living thing, but also the starting point at which the full being of the man as a full grown human being begins. ${ }^{5}$

That this is the picture that Aristotle has in mind in sentence (1) is also suggested by a parallel passage in Metaphysics IX 8 which is part of Aristo-

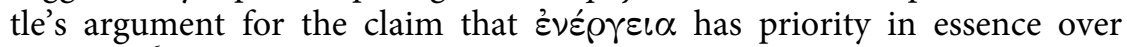
$\delta \dot{v} \alpha \mu \iota \zeta{ }^{6}$ In this passage it is also stated that what is undergoing the process of coming to be "proceeds towards a principle", but in addition the

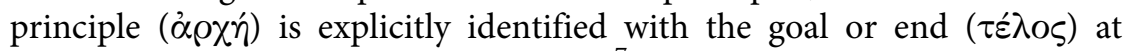
which the process of coming to be aims. ${ }^{7}$ The end at which the coming to be of a living being aims is maturity, i. e. being what it is not only potentially but in the full sense.

As in our passage from the Physics, this passage from the Metaphysics also seems to connect the assumption about the goal directedness of the development of living things with another claim, namely the one stated in sentence (2) that "what is posterior in coming to be is prior in nature" as it is put in Met. IX 8, is prior in form and essence:

5 See also Beere (2009), 300, who characterises the form as it is used in a similar example in Met. IX 8 in the same way and explains what this means in more detail.

6 See Met. IX 8, 1050a4-9. This passage and the kind of priority discussed there and in its context has been subject to intense scholarly debate (see for instance Witt (1994), Panayides (1999), Makin (2003), and Beere (2009), 293-324.). I shall only deal with it insofar as it is of relevance for developing an understanding of priority in essence that fits both arguments for locomotion's priority in essence in Phys. VIII 7, which, as I will argue, have to be read in conjunction. Although most of the interpreters of Met. IX 8 at least refer to the first argument, none mentions or discusses the second one. For a minute analysis of the passage from Met. IX 8 that has proved essential to my understanding of the cited passage and its notion of priority in essence see Beere (2009), esp. 293-304. My understanding of this kind of priority is especially indebted to the connection Beere draws between $x$ having priority $\varkappa \alpha \tau^{\prime}$ oủoí $\alpha \nu$ over $y$ and $x$ 's fulfilling more of the norms that are relevant for the form that $x$ and $y$ have in common than $y$ (for this see p.315). Note that, in contrast to Beere and most other interpreters, I translate $x \alpha \tau$ ' oủ $\delta$ i $\alpha \nu$ with 'in essence' for reasons that will become clear later on in this chapter.

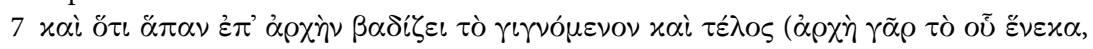

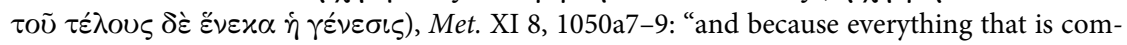
ing to be proceeds towards a principle, i.e. an end (for, that for the sake of which a thing is, is its principle, and the becoming is for the sake of the end)" (Transl. Ross, with mod.).

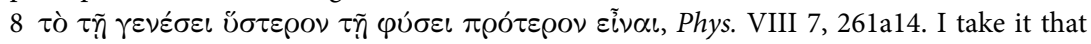


the things that are posterior in coming to be are prior in form and in essence (e.g. man to boy and human being to seed; for the one already has its form, and the other does not $)^{9}$ (Met. IX 8, 1050a4-7)

I will call this assertion that what is posterior in coming to be is prior in essence, the reversed priority claim. That this assumption for Aristotle in both passages derives from the fact that everything that is coming to be moves towards a principle, i.e. its form, is clear from the way in which the two assumptions are connected with one another in both of the texts: in the Physics-passage the reversed priority claim is presented as a conclusion

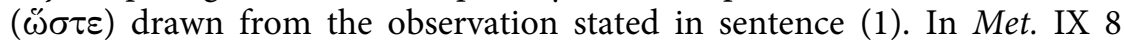
Aristotle justifies the reversed priority claim (ö $\tau$ ) by referring to the incomplete's proceeding towards its end. At least in the passage from the Physics nothing further is said about how this assumption follows from sentence (1). It also does not present a full account of what it means for $x$ to be prior in essence to $y$. Aristotle here is merely stating the first premise of the argument for locomotion's priority in essence and seems to presuppose that the reader is acquainted with both the reasons for this assumption and the notion of priority in essence.

This is not the case in the passage from the Metaphysics in which two examples are presented to make the two points clearer. In the first example Aristotle compares a boy and a man, in the second a seed and a human

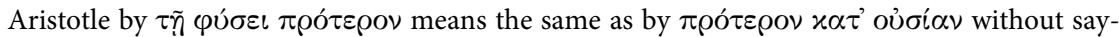
ing this explicitly. This is clear firstly from the fact that in this passage from the Physics he uses both names for the same kind of priority (see 261a14 and 19-20), and secondly, because this argument is introduced as one for the priority in essence of locomotion (see 260b15-19).

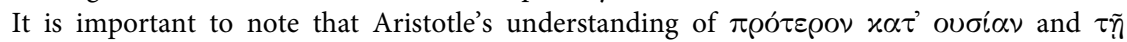

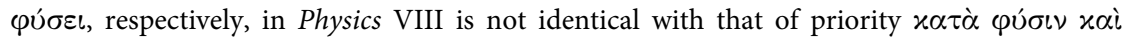

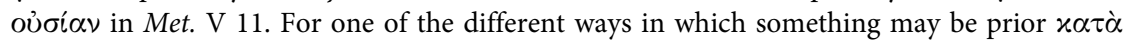

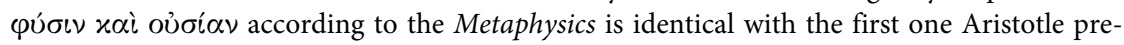
sented in Phys. VIII 7, namely the one I called ontological priority (see sections 3.6 and 5.4.1). Nevertheless, it is significant that Aristotle in Met. V 11, 1019a1-4, seems to think that prior-

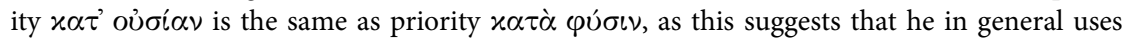
both terms in order to refer to one and the same kind of priority. This, too, supports the

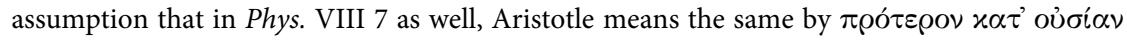

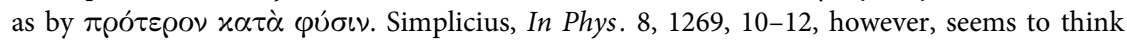
that Aristotle here in Phys. VIII 7 in contrast to Met. V divides ( $\delta\llcorner\varepsilon \tilde{\imath} \lambda \varepsilon v)$ priority in essence and in nature and treats them as independent of each other. This is clearly wrong for as I just stated Aristotle in one and the same argument states that locomotion is shown to be prior in

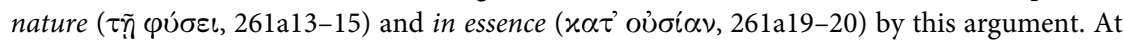
the same time, confusingly, Simplicius, as his statements on the 5th argument show (1271, 23-28), seems to be very aware of this fact.

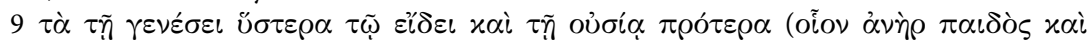

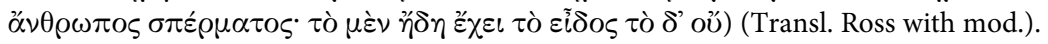


being. According to this example the man is prior in essence and form to the boy and in the same way the human being to the seed. The reason for this lies in the fact that the man and the human being, in contrast to the boy

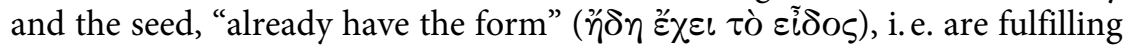
their respective form and in this way have reached the principle and end at which the process of their coming to be was directed. This is not true for a boy, who is not a man, but who in the process of becoming a man is proceeding towards fulfilling the form of manhood. For example, he is not able to father a child at this stage of his development. In the same way the seed is on its way to become what its coming to be aims at, namely a human being, but it is still far from having reached its form, that is from being a complete human being. The man has more of the characteristics that are specific and essential to being a man, i.e. that represent its essence (oủ $\sigma i \alpha$ ) and nature $(\varphi \dot{v} \sigma \iota \varsigma)$, than the boy. For this reason the man may be called prior to the boy in essence and in nature. The examples from Met. IX 8 tell us something about the notion of priority in essence which the Physics passage also seems to presuppose. According to this understanding $x$ has priority in essence over $y$, if $x$ fulfils the essence of that which $x$ and $y$ are both becoming to a higher degree than $y$. But this also makes clear that priority in essence is a relation between things that belong to one and the same kind and therefore have the same essence or form, relative to which one may say that $x$ fulfils this essence better than $y{ }^{10}$

The man is prior in essence to the boy, because he fulfils the criteria for being a man, and accordingly its essence as well, to a higher degree than the boy. The example, of course, may be extended by adding further individuals. For instance, we may include the seed out of which a man will develop and put it in relation to the boy and the man. The seed fulfils the essence of a man even less than the boy, for it lacks many of the features which the boy in his coming to be a man already acquired, so that the seed has less priority than both boy and man.

These examples not only help clarify what Aristotle has in mind when he says that $x$ is prior in essence to $y$, but also show another assumption that Aristotle presupposes in formulating the reversed priority claim and that one needs to be aware of: in its coming to be, every living thing passes through a certain succession of developmental stages. This order of developmental stages is unvarying and specific to the kind to which the thing that is coming to be belongs, and this is why Aristotle is able to connect this order of coming to be with the notion of priority in essence. The principle $\left(\dot{\alpha} \rho \chi \eta^{\prime}\right)$ towards which something is developing not only determines the goal of the coming to be, but also the stages through which something has

10 See Beere (2009), 314-315. 
to pass in order to reach its specific endpoint and in which order this takes place. ${ }^{11}$ Every male human being roughly speaking originates from a seed, develops into an embryo, then into a boy before finally becoming a fullgrown man, and there is a set of attributes that is specific to each of these stages. This means that $x$ and $y$ (both coming to be members of a kind $k$ ) in their development towards being full members of $k$ acquire the attributes essential for being $k$ in exactly the same order. Thus, if $x$ and $y$ are of the same priority in essence, then both are at the same stage of development and therefore have identical sets of essential attributes. If $x$ is prior in essence to $y$, it has completed more of the steps necessary to become $k$ than $y$, and thus fulfils $k$ 's essence to a higher degree than $y$. The more developmental stages something passes through, the more essential attributes it acquires, attributes that are characteristic for its belonging to a certain kind. What this basically means is that $x$ is essentially prior to $y$, if $x$ fulfils their common essence to a higher degree than $y$. On this understanding, a definition of priority in essence would read as follows:

PRIORITY IN ESSENCE: Of two things $x$ and $y$, both individuals of one and the same kind $k, x$ is prior in essence to $y$ relative to $k$, iff $x$ fulfils the essence of $k$ to a higher degree than $y$.

Applying this to the cases discussed so far, namely for things that have a coming to be, this means that of two living things $x$ and $y$, both belonging to kind $k, x$ is prior in essence to $y$ relative to $k$, if and only if $x$ has more of the essential attributes of $k$ that are acquired in a $k$-specific order than $y$. One might think that the reference to fulfilment of essence in the definition implies that essential priority applies only to things that have a coming to be, i. e. a process in which the essential features are acquired step by step. In fact, the reversed priority claim explicitly limits its scope to things that have a coming to be, i. e. perishables. This, however, is not a sufficient reason to assume that the relation of priority in essence has the same scope. In my view, priority in essence is not restricted to things that have a coming to be, but, as I will argue later on also applies-at least in principle-to eternal things. The reversed priority claim follows from the account of priority in essence and the fact that there is an unvarying order of coming to be that must be followed by the living things that undergo such a process. It is not a definition of essential priority in terms of coming to be, but rather a corollary. Yet, in the two texts I have examined this claim is central to understanding what priority in essence is, as the texts do not say anything more explicit about essential priority than what is stated in the quoted passages.

11 That Aristotle assumes there to be a specific order of development that is determined by what the thing is becomes clear in PA I 1, 640b1-4 as well, where this is pointed out explicitly. 
According to my definition of priority in essence, only individual substances can be substituted for $x$ and $y$. Essential priority, therefore, seems to be a relation between substances. This is also what is suggested by the examples mentioned in Met. IX 8, where such individuals are compared with respect to the fulfilment of their respective form: the man is prior to the boy, as the human being is to the seed; since man and human being are fulfilling their form, they are complete with respect to their essence. But, as the application of the reversed priority claim in the passages from Met. IX 8 and from Phys. VIII 7 also show, not only individual things can be called prior in essence, but also states and features of those individuals-after all, the one passage argues for the claim that locomotion is prior in essence to the other kinds of change, while the other that $\varepsilon v \varepsilon \varepsilon^{\rho} \rho \varepsilon \iota \alpha$ has priority in

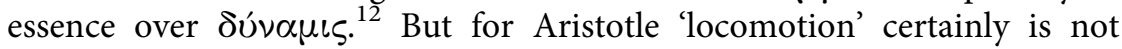
something one could call a substance or an individual and which accordingly could be substituted for one of the variables in the definition of priority in essence. This, however, is not a problem.

Something $x$ is called prior in essence to $y$ when it fulfils the form that is common to $x$ and $y$ to a higher degree and has more of the respective essential features than $y$. That is to say that $x$ is prior to $y$ in having at least one additional essential feature that $y$ does not have. In the coming to be of living things, each of the features, however, corresponds to a specific stage of development at which it is acquired by the living thing as a member of a natural kind. Because of this fact the feature may be compared to other such features. According to Aristotle, for instance, a living being acquires the feature of locomotion later than, say, alteration, namely at a stage at which it is about to reach its completion. ${ }^{13}$ Thus, in this respect locomotion-qua specifically belonging to a nearly complete being-is prior in essence to alteration, which individuals of the same kind that are less developed already posses.

Accordingly, I hold that the relation of essential priority applies primarily to individual substances and in a derivative sense to essential features or attributes, even though whether $x$ is prior in essence to $y$ depends on which of those features $x$ has. Hence, there is no problem in saying that certain features have priority in essence over other ones, and therefore Aristotle is justified in calling locomotion prior in essence to the other kinds of change.

As we have seen, Aristotle presupposes that there is an unvarying order of developmental stages through which every member of a certain kind $k$ has to pass step by step in order to reach the endpoint of its development and become a full member of $k$. As Aristotle points out, the more something proceeds towards the principle of development, i.e. its endpoint, the

12 See Met. IX 8, 1049b4-5.

13 See Phys. VIII 7, 261a15-17. 
more posterior it is in its coming to be. Accordingly, the farther away something is from the end of this process, that is, the fewer the stages of development through which it has passed, the more prior it is in its coming to be. A definition of priority in coming to be then reads as follows:

Priority IN COMING to Be: Of two things $x$ and $y$, both individuals of kind $k, x$ is prior to $y$ in coming to be $k$, iff $x$ is at a stage of the $k$-specific sequence of developmental stages through which $y$ already passed.

This means for example that in the process of becoming a man the stage of being a boy precedes the final stage of being a man and accordingly every man will have passed the stage of boyhood in his development before reaching full manhood. Therefore, the boy is prior in coming to be to the man, as the seed is to the human being.

In looking at the definition of priority in essence in connection with priority in coming to be, it now becomes clear why Aristotle comes to assert the reversed priority claim. As we have seen above, $x$ is prior to $y$ if $x$ fulfils their common essence to a higher degree than $y$. Being prior in essence for things that are coming to be means being more complete. Thus, if $x$ is prior in essence to $y, x$ is at a stage of the $k$-specific order of development which $y$ has not yet reached. In the opposite case, $y$ is at a developmental stage which $x$ has already passed. According to the definition just stated, $y$ then is prior in coming to be to $x$ and $x$ is posterior to $y$ while $x$ is prior in essence to $y$ and $y$ posterior to $x$ in this way. Thus, the relation of $x$ being prior to $y$ in essence is the converse of the relation of $y$ being prior to $x$ in coming to be $k .{ }^{14}$ Accordingly, there is no $x$ for which it is true to say that it is prior to $y$ in coming to be and also prior to $y$ in essence at the same time and in the same respect. Hence, Aristotle is right to assert the truth of the reversed priority claim, i. e. the assumption that what is posterior in coming to be is prior in essence.

\subsubsection{A different use of the term 'locomotion'}

The first of the two premises on which the argument for locomotion's priority in essence is based, i.e. the reversed priority claim, has been established. The second premise is stated in sentence (3) of the passage quoted above and says that "locomotion belongs lastly to all things that are coming to be". ${ }^{15}$ (1) If what is posterior in coming to be is prior in essence, and (2) if locomotion is, in the coming to be of living things, posterior to alteration

14 Or, if one would like to put it more formally: $P_{\text {being }}(x, y) \leftrightarrow P_{\text {coming-to-be }}(y, x)$.

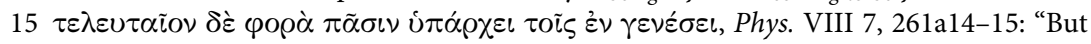
locomotion belongs lastly to all things that are coming to be." 
and change in quantity, then (3) locomotion is prior in essence-at least with respect to living things.

But from the way in which the term 'locomotion' ( $\varphi \circ \rho \alpha$ ) is used in the passage it is obvious that Aristotle here means something different than in other places. Certainly it does not merely stand for 'change in place' in general as it does in the other arguments presented so far. For otherwise there would be no reason for claiming that locomotion "belongs" only to certain things from a certain time onwards while others do not have it at all. Everything that has a place can undergo a change with respect to its place. Hence, it is absurd to think that what is undergoing the process of coming to be something, e.g. to be a man, cannot undergo a change with respect to its place until certain other things belong to it, things that are usually acquired before locomotion is. A human embryo, for instance, is far from being complete and needs to pass through many different stages before it becomes a full-grown man. Yet, surely it is subject to change in place in its mother's womb. Thus 'locomotion' certainly has a more specific meaning here.

That 'locomotion' is employed in a special sense in this passage is made clear by Aristotle himself when he argues that locomotion does not belong to all living things, but only to those which are about to attain completion. ${ }^{16}$ When he argues that, due to ( $\delta \iota 0$ ) the posteriority of locomotion in the coming to be of living things, there are some that may not move at all, while the ones that are nearly complete, i.e. that are reaching the end of their coming to be a certain kind of animal, have locomotion and can move. The former are "immovable" ( $\alpha x i \nu \eta \tau o \nu)$, Aristotle tells us, "just as the plants and many genera of animals." ${ }^{\prime 7}$ Again, there is nothing which in general prevents any kind of living thing that has a place from undergoing a change in place. For instance I may repot a plant in my garden from a shadowy to a sunny place; a sponge in the sea might drift from its original place to a new one-the same is even true of inanimate things like stones. Therefore, being immovable does not mean being incapable of undergoing any change in place at all. Aristotle's point in the example rather is that living things like plants and certain animals, sponges for instance ${ }^{18}$, do not have locomotion in the sense that they merely undergo it passively, but rather that they lack the capacity to perform their own, i.e. self-caused, changes in place. The

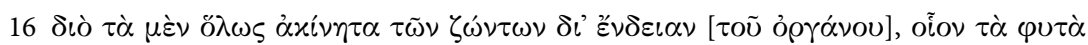

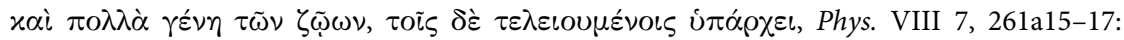
"Because of this some of the living beings are entirely incapable of moving due to a lack [of an organ], just as the plants and many genera of animals, but it belongs to those which are about to attain completion."

17 Phys. VIII 7, 261a16-17.

18 As Simplicius, In Phys. 8, 1271, 30-32, points out, Aristotle in this passage apart from plants has beings like zoophytes in mind, to which for instance sponges belong. 
principle and cause of the kind of locomotion Aristotle is talking about here, I will argue, lies within the animal itself, namely in its soul, as I will argue, so that an animal which has this capacity may be called responsible for this change in a way that is quite different from passively undergoing a change in place that is caused primarily by some external mover. In fact, I will show that Aristotle has something like the following in mind when he talks about priority of locomotion here: there is a specific capacity in the soul for each of the three non-substantial kinds of change that an animal qua having a soul may be a source of. It is with respect to these three capacities that this locomotion can be called primary. ${ }^{19}$

Because of the posteriority of locomotion in the development of living things, some living beings, namely those that are at an earlier stage of development, are incapable of performing such self-caused changes in place in just the same way as things that are members of a certain kind will always lack the capacity to self-locomote. These immature beings-at least at this stage of their development-also completely lack the capacity to move themselves. ${ }^{20}$ Therefore, what Aristotle clearly means by saying that 'locomotion belongs to $x^{21}$ is that ' $x$ has the capacity to cause its own change in place,' and not merely that in general it may undergo a change in place in some way. That 'locomotion' is used in this special sense here, of course,

19 For this see section 7.1.4.1.

20 Note that my reading differs from the traditional reading of this passage in an important respect. Ross and Zekl, for instance, hold that the sub-clause introduced by oiov presents examples of the things that are immovable $\left(\alpha x^{i} i \eta \eta \tau\right)$ and, accordingly, understand oíov in the sense of 'i.e.' (see Ross, 445, Zekl (1988), 203.) My view is that the oiov stands for something like 'just as' and that Aristotle is merely comparing things that basically are capable of performing locomotion, but may not do so at an early stage of their development, to such beings as plants, as both lack this capacity. This fits better into the line of argument presented here: it does not follow from the fact that locomotion is last in the development of living things that plants and certain animals lack the capacity to locomote, while this fact is a explanation for why certain beings may not locomote at the beginning, but can do so at a later point of their development. In addition, as Zekl's notes on this passage indicate, the traditional understanding might lead one to assume that Aristotle in this passage is referring to a "Stufenbau der Natur" according to which things like plants would be less perfect, i. e. considered incomplete due to some lack, even if they are fully developed (see Zekl (1988), 203, and n. 121, 289). Of course, Aristotle also seems to use 'incomplete' ( $\left.\alpha \tau \varepsilon \lambda \varepsilon^{\prime} \varsigma\right)$ in order to refer to lower genera of animals, for instance at the beginning of de An. III 11 (see 433b31-434a2) but, as our passage is about the typical development of members of a certain species, 'incom-

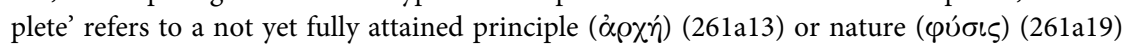
of that which is coming to be.

21 I take this to be the translation of the expression ' $\varphi \rho \rho \alpha$ $\delta \pi \alpha ́ \alpha \chi \varepsilon \iota ~ x$ ' which Aristotle employs in all the cases in our passage in which the capacity to perform locomotion in the manner described belongs to something $x$ (see Phys. VIII 7, 261a15, 17, and 18). 
has consequences for the understanding of this argument, which raises at least two difficulties that one has to address.

First of all, it is puzzling how the fact that the capacity of locomotion is posterior in the coming to be, i.e. prior in essence, is supposed to lead to the conclusion that locomotion has primacy over the other kinds of nonsubstantial change, as Aristotle infers a few lines later. ${ }^{22}$

Secondly, even if this is the case, the argument, as we have seen, is not about locomotion in general, but about a special kind of change in place, namely self-caused locomotion. But if the premises of the argument are only about this special way of locomotion and not about locomotion in general, then the argument cannot lead to a conclusion about locomotion in general. Aristotle is surely aware of this fact and does not intend to equivocate 'locomotion' in the special sense with its broader meaning. Most likely, he has good reasons to think that the priority of this capacity contributes something to showing the priority of locomotion in general.

Apart from these two points that follow from the special use of the term 'locomotion' and that are about the structure of the argument, one may also have doubts about the second premise of the argument, namely that locomotion is last in the process of coming to be of all beings undergoing this process. Aristotle seems to presuppose its truth and does not present any reasons for this assumption here. I will start by showing that Aristotle's assumption is right, while an answer to the two remaining questions will be given later on.

\subsubsection{Does locomotion come to things last?}

One reason why Aristotle presupposes the truth of the assumption that the capacity of locomotion comes last in the process of coming to be might be that he thinks this to be obvious from observation. An infant, for instance, is unable to walk around right after birth and it takes a while until it is able to perform its own locomotion. The same is true for other animals, like for instance dogs or cats. Other animals, however, precocial ones such as horses, are able to walk almost right after they are born. And certain kinds of fish-for instance the guppies ${ }^{23}$ in my fish tank-can swim around right after leaving their mother's body. While this may not contradict the assumption that locomotion is rather late in the coming to be of animals, it nevertheless shows that the development of animals may differ from case to

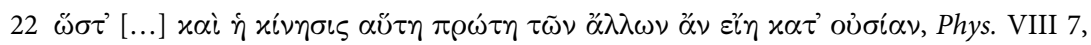
261a13-20: "Therefore [...] this [kind of] change would also have primacy over the other [kinds] in essence".

23 Poecilia reticulata. 
case, which then raises the question whether there are kinds of living beings in whose development locomotion is not last. For this reason, I do not think that Aristotle's assumption was based on mere observation-at least not primarily. As I will now show, this assumption is in accordance with and follows from his theory of the soul as it is stated in the De Anima. In fact, the first of the two arguments for locomotion's priority in essence presupposes this theory without mentioning it explicitly. Accordingly, I will now deal with the aspects of this theory that are of importance to my understanding of this argument.

\subsubsection{Capacities of the soul}

According to Aristotle, the soul as the principle of life of living things has different capacities. ${ }^{24}$ Which capacity the soul of a certain living being has depends on what kind of living thing it is. A plant's soul, for instance, only has the capacity of nutrition that is responsible for a living thing's nourishment, growth and reproduction. ${ }^{25}$ But the soul of every other living being also has this capacity. More highly developed forms of life, however, have additional capacities which plants lack. All animals, in contrast to plants, for example are able to make perceptions and therefore have a certain capacity that is responsible for this kind of sensory activity. As we have seen, some, but not all, of the animals have the capacity to move from place A to place B. According to Aristotle's theory, such animals, in contrast to sponges or other animals of that kind, therefore have a soul which may be the source of their self-motion, or to put it in other words, they have a soul which has the locomotive capacity. ${ }^{26}$

As we have seen, the argument under discussion clearly refers to such capacities, as the term 'locomotion' does not mean 'change in place' in general, but rather stands for the capacity to cause one's own change in place. ${ }^{27}$ In this sense $x$ has locomotion, if it can cause its own change in place. As I said, the argument presented may show that the capacity to self-locomote is prior in essence to the capacity to perform any of the other changes, rather

24 The difference between things that have a soul and those that do not lies in the fact that the former have life while the latter do not (see de An. II 2, 413a20-22). The soul is the principle $(\dot{\alpha} \rho \chi \dot{\eta})$ of the kind of activities that are specific to things that live (see for instance de An. II 2, 413a22-25 and 413b11-13).

25 See for instance de An. II 2, 413a31-b1.

26 See for instance de An. II 4, 415b21-23.

27 See p. 173. This also seems to be in accordance with comparable passages in the $D e$ Anima where Aristotle for instance says that ' $x$ has perception' and obviously means that $x$ has the capacity to perceive (see for instance de An. II 3, 414b4, III 3, 427b11-12, and III 11, 433b31-434a2). 
than that locomotion has priority over the other kinds of change. But it is the latter which Aristotle intends to show in Physics VIII 7.

The thought behind Aristotle's argument seems to be the following: in living things each of the non-substantial kinds of change corresponds to and is caused by a certain capacity or part of the animal's soul. If the capacity to change in place is prior in essence to the animal's capacity to change in quality and in quantity, then (in some way) locomotion itself is prior in essence to the two remaining non-substantial kinds of change. Because of this, Aristotle does not compare all of the different kinds of change that a living thing may undergo in general, but only those of which the source $(\dot{\alpha} \rho \chi \dot{\eta})$ in some way lies in the living being itself and that thus is responsible for it in some sense. ${ }^{28}$ This is also the reason why Aristotle only has the non-substantial kinds of change in mind here: my inner principle of change and rest certainly was not responsible for my coming to be.

From what Aristotle says in the De Anima it is clear that change in quantity is caused by the nutritive part of the soul $(\theta \rho \varepsilon \pi \tau \iota x o ́ v)^{29}$ and change in

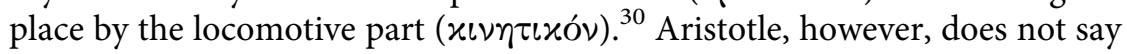
in the De Anima which of the different capacities or parts of the soul is responsible for causing a change in quality that occurs in the animal. One might think that the sensory part ( $\alpha i \sigma \theta \eta \tau \iota x o ́ \nu)$ does so, as it is responsible for perception insofar as the soul is a cause ( $\alpha \rho \chi \eta \hat{\eta})$ of this sensory activity. But there are no doubt other occurrences of alteration in a living thing besides perception that originate from its soul and that are not merely changes undergone passively, for instance the case in which my skin becomes darker after I take a sunbath. Thus, saying that the sensory part is

28 I do not want to claim here that a living being is responsible in the same way for all the different changes that its soul is a cause of and which it undergoes not merely passively. Yet, one may say that these changes are on a par insofar as the living thing's soul is their source or

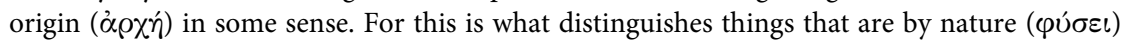
from such that are not: as Phys. II 1, 192b13-15, claims, the former have the source of their changes within themselves, be it a change in quality, quantity, or place. These are the kinds of change which are of relevance to the argument in question. The fact that an animal's locomotion has an exceptional status, since in some sense it is the only kind of change in the animal that may be called self-motion in the appropriate sense, is of no importance here (see section 3.5, esp. p.62, where I refer to the relevant passage in Phys. VIII 2 and 6). On a discussion of the latter see Morison (2004).

29 The nutritive capacity is responsible, among other things, for taking in and transforming nourishment and assimilating it to the body so that the living being grows. See de An. II 4, 415a22-26 and 415b26-27, and also de An. III 9, 432b8-11.

30 In de An. II 2, 413b11-13, Aristotle states that the soul is the origin ( $\alpha \rho \chi \eta ்)$ of and defined by various activities, one of them being locomotion ( $\chi \iota \nu \eta \dot{\sigma} \varsigma \varsigma$ ). Later in II 3, 414a3132 , when he enumerates the soul's capacities he explicitly speaks of this capacity as $\chi \iota \nu \eta \tau \iota x o ́ \nu$ $\alpha \tau \grave{\alpha} \tau o ́ \tau o \nu$. 
responsible for all of the relevant alteration, because it is responsible for perception, is not sufficient. In addition, perception is not the process one typically thinks about when speaking about alterations that occur in living things, and indeed it is not characterized as a full-blooded alteration, but merely as a sort of $\left(\dot{\alpha} \lambda \lambda \operatorname{oi}^{\prime} \omega \sigma \iota \varsigma \tau \iota \varsigma\right) .{ }^{31}$ The relation between the cause of the change, i.e. the sensory part, and that which undergoes the change differs significantly from the relation between the cause of an animal's change in place and quantity. For the argument to work, however, there must be a part of the soul that is responsible for certain alterations that occur in the animal in the same way that such a part exists for the other two kinds of change.

That this is what Aristotle has in mind becomes clear in a passage in De Partibus Animalium I 1, in which he points out which of the parts is responsible for alteration. ${ }^{32}$ In this text Aristotle says explicitly that the three kinds of non-substantial change (of which the living thing itself is the source) are caused not by the whole of the soul, but rather by one specific part. ${ }^{33}$ In accordance with the De Anima this passage also presents "the part which is present even in plants", i. e. the nutritive part, as the origin ( $\left.\dot{\alpha} \rho \chi \hat{\eta}^{\prime}\right)$ of growth (and diminution). ${ }^{34}$ It has the capacity to change nourishment into (blood and) flesh and in this way makes it possible for the nourishment to be assimilated into the body in the process of growth. ${ }^{35}$

According to PA I 1, the perceptive part of the soul ( $\alpha i \sigma \theta \eta \tau \iota x \delta$ ) is the origin $(\dot{\alpha} \rho \chi \hat{\eta})$ of alteration in a living being. ${ }^{36}$ This is far from self-evident. It seems that, for Aristotle, an alteration, for instance the case in which I get a tan, is caused by this part of the soul in the following way. ${ }^{37}$ The sensory part receives some input and reacts by initiating the respective change: in the example, the sun's shining on my skin alone does not make the colour of my skin change; this only happens if the sensory part of my soul, having

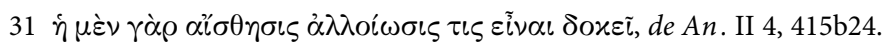

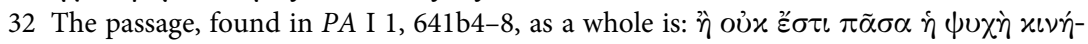

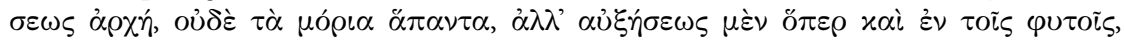

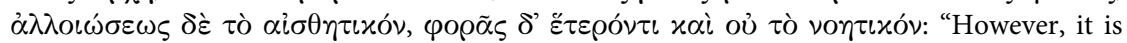
not the case that all soul is an origin of change, nor all its parts; rather of growth the origin is the part which is present even in plants, of alteration the perceptive part, and of locomotion some other part, and not the rational" (Transl. Lennox (2001)).

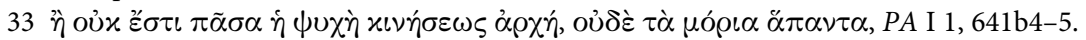

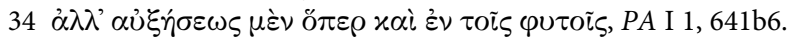

35 For the process of growth see GC I 5 and $d e$ An. II 4 . For my understanding of the process of growth see section 3.2.1 in my discussion of the first argument for the priority of locomotion, where the relevant passages in Aristotle are discussed.

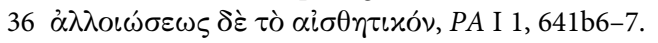

37 For this see Balme (1992), 91-92, on whose interpretation of this passage from PA I 1 my understanding of it is based. 
received this sensory input, initiates the bodily reaction. ${ }^{38}$ However, this does not imply that the alteration is caused by the sensory part of the soul alone; as there must be nourishment that the nutritive soul can transform into a part of the body in order for the body to grow, there also needs to be some sensory input for the alteration to take place; nevertheless it is the nutritive soul that is responsible for the occurrence of the growth in the first place, as is the sensory part for the respective alteration. ${ }^{39}$ The fact that such alterations are caused by the sensory capacity, of course, does not mean that this capacity of the soul is the primary source of all changes in quality a living being undergoes. Only those alterations for which the animal itself is responsible in the aforementioned way are caused by the soul's sensory capacity. My soul is not responsible for the warming of my skin that occurs when I take a sunbath, but it is for the darkening of my skin.

The passage from PA I 1 does not name the part that is the origin of locomotion and that, according to the De Anima, one may call the locomotive part $\left(\varkappa \iota \nu \eta \tau \iota \delta^{\prime} \nu\right)$. But it says that this part is different from the nutritive, the sensory, and the rational part of the soul ${ }^{40}$, which makes clear, again, that for locomotion, too, there is a specific part or capacity in the soul that is responsible for this kind of change. For my purposes, that is for understanding Aristotle's argument for the claim that locomotion has priority in essence, this is sufficient.

\subsubsection{Priority in essence of the locomotive capacity}

To sum up what I just said: for each of the three kinds of non-substantial change that a living being undergoes and for which it is responsible in the sense that they originate in the animal's soul, there is a specific capacity or part of the soul that is responsible for it. In this group of capacities, as Aristotle claims, the one for locomotion is primary.

According to what Aristotle says in the De Anima and elsewhere, these different capacities or parts of the soul stand in a relation of dependency.

38 This is a modified version of an example Balme (1992), 92, uses.

39 Another, more complex example would be the case in which I feel I have been treated unjustly and in reaction become angry so that, among other things, my face turns hot and red. That such cases count as alterations may be seen in Aristotle's discussion of shame in $E N$ IV 9. Shame, Aristotle tells us, is "more like a passion than a state" ( $\pi \dot{\alpha} \theta \varepsilon \iota \gamma \grave{\alpha} \rho \mu \tilde{\alpha} \lambda \lambda o \nu)$, since "people who feel disgraced blush, and those who fear death turn pale", which shows that

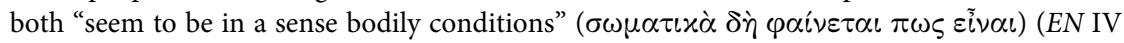
9, 1128b10-15, Transl. Ross). Thus when I blush, Balme (1992), 92, argues, my "memory or expectation of certain pains or pleasures" cause the sensory part of my soul to make my cheeks become hot and red.

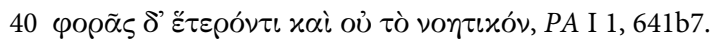


An animal cannot have the sensory capacity without having the nutritive one, while there are living beings that have the latter without the former. ${ }^{41}$ The locomotive capacity and the sensory capacity stand in a similar relation: having the former presupposes also having the latter, but not vice versa. ${ }^{42}$ The relation between these capacities therefore is one of ontological priority. As we have seen in the discussion of the third argument for the priority of locomotion, $x$ is ontologically prior to $y$, if and only if $x$ can exist without $y$, but not vice versa. In terms of the three capacities of the soul this means that (1) the locomotive capacity cannot exist without the sensory one, but not vice versa, and (2) the sensory capacity cannot exist without the nutritive one, but not vice versa. Therefore, (3) the locomotive capacity also cannot exist without the nutritive one, but not vice versa.

For this reason, all living beings have the nutritive part in common, no matter whether they also have the capacity for sensation or locomotion. However, it is impossible for there to be a living being which has the sensory capacity, but does not have the nutritive one. In the same way, it is not possible for there to be a living thing that has locomotion, but lacks perception or nutrition. Accordingly, the different capacities may be ordered in the following way according to their ontological priority:

1. Nutritive capacity

2. Sensory capacity

3. Locomotive capacity

As with respect to priority in coming to be, with respect to ontological priority it is also not the capacity for locomotion that is prior to the rest, but the one that is responsible for growth and diminution, i.e. for nutrition. In fact, the capacity to cause one's own change in place is posterior to the two other relevant capacities in this way. But, as we have seen, the argument is not about showing that the capacity for locomotion has ontological, but that it has essential priority. Aristotle has already shown in the first three arguments that locomotion in general is ontologically prior to the other kinds of change. A result of the third of these arguments (which I discussed in chapter 5 of my work) was that, from a broader perspective, every change in quantity and quality, even if it is self-caused by a living thing's nutritive

41 See de An. II 3, 415a1-3.

42 See de An. III 10, 433b27-30, where Aristotle argues that an animal is only capable of

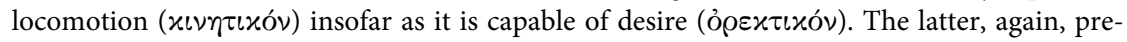

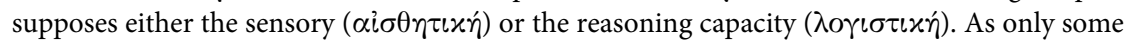
of the animals have reason, but all of them have desire (see de An. III 11, 434a5-7), and since some of them may move themselves without having reason, it is clear that the locomotive capacity presupposes the sensory one. However, there are animals, for instance sponges, which are capable of sensory activity but not of locomotion. 
or sensory capacity, ontologically depends on a preceding locomotion. ${ }^{43} \mathrm{At}$ this point I can only say that it will become clear later on that the ontological posteriority of the soul's capacity for locomotion, as well as the fact that it is posterior in coming to be, does not contradict its essential priority, but even needs to be understood as the expression of its priority in essence.

The relation of ontological dependency that exists between certain capacities finds its expression in the process of development of any living thing, even though Aristotle does not point this out explicitly. If (1) the capacity to move oneself cannot exist without the capacity for sensory activity, and if, as Aristotle presupposes, (2) capacities to perform certain things are developed at different stages and times in the process of coming to be, then it follows that (3) a capacity $x$ that has ontological priority over a capacity $y$ also will be prior in the process of coming to be. Accordingly, the nutritive capacity, for instance, will always be prior to the capacity to locomote in the coming to be of every living thing. In this way the order of ontological priority of the soul's capacities corresponds to the order of their development and hence their priority in the process of coming to be. Since the relation of being prior in coming to be is the converse of the relation of being prior in being, it follows that the higher the ontological priority of a soul's capacity, the lower its priority in essence. The relation between the three kinds of priority may be made clearer by means of the following diagram:

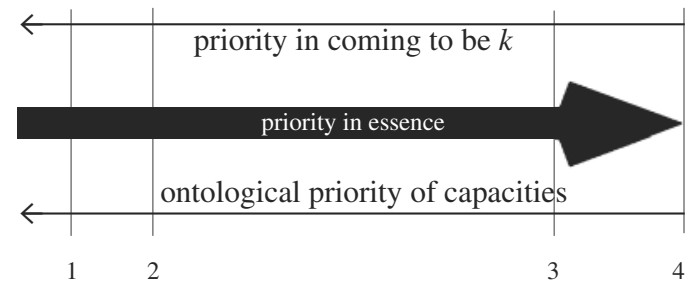

Fig. 3

In Fig. 3 something $x$ is in the process of becoming a full member of kind $k$. The vertical lines represent different moments in $x$ 's existence. At $t_{4} x$ is

43 It is important to emphasize, therefore, that the fact of the locomotive capacity's ontological posteriority is absolutely compatible with what is stated in all three arguments for locomotion's ontological priority, although one might think differently at first. I have just explained in what way this is true with respect to the third argument. Also according to the first argument a change that has its source in a living thing's nutritive or sensory capacity, i.e. in a capacity that is ontological prior to the locomotive capacity, nonetheless is ontologically dependent on the locomotion that necessarily has to occur in order for the alteration or growth to take place (see chapter 3). As the second argument shows, it is true in the same way that any such change in quality or quantity will be accompanied by a change in place, while the converse does not hold (see chapter 4). 
fully $k$, the end of its coming to be $k$ has been reached. The closer $x$ is to the full being of $k$ the more priority in essence it has. Conversely, the more prior $x$ is in the process of coming to be $k$, the less prior it is in essence. Suppose that $x$ at $t_{1}$ has the nutritive capacity, at $t_{2}$ the sensory one, and at $t_{3}$ the locomotive one. Accordingly, of the three moments $t_{1}-t_{3}, x$ at $t_{1}$ has the least priority in being, but the highest in coming to be $k$. In addition, at this moment it only has the capacity that is of the highest priority ontologically, namely that for nutrition, as it is capable of existing on its own. It is the other way round at $t_{3}: x$ at this point is of the highest priority in essence, but of the lowest in the coming to be $k$, and has the capacity of the least ontological priority, namely the locomotive capacity, which presupposes that it also has the nutritive and the sensory one. But, as stated by the reversed priority claim, the capacity to locomote is of the highest priority in essence.

Following Aristotle's theory, it is clear that of the soul's three different capacities to cause any of the three non-substantial changes, the one responsible for locomotion comes to things last. That is, Aristotle is right to claim the second of the two premises of the first argument for locomotion's priority in essence. But before returning to the discussion of the argument as a whole I would like to point out that the discussion of the development of capacities also adds something to our understanding of the concept of priority in essence. As I will argue now, it shows that there is another criterion for saying that $x$ has priority in essence over $y$.

\subsubsection{Another sense of priority in essence}

As we have seen, $x$ is prior in essence to $y$, if and only if $x$ fulfils their common essence to a higher degree, i. e., has more of the essential features specific to $k$ than $y{ }^{44}$ I have also argued that the essential features may also be called prior to other such features (derivatively). As one can see in Fig. 3, $x$ is closer to what it takes to be $k$ when it has locomotion, rather than merely nutrition, which all living beings have in common. This means that $x$ is of higher priority in essence when it has locomotion, because it is an essential part of its nature to have this capacity, and it accordingly fulfils more criteria of being $k$ than when it merely has nutrition. For instance, it is more specific for a human being to have locomotion than to have nutrition. Or to put it differently: of the three possible answers to the question what a man is, (a) a living being that has the nutritive capacity, or (b) the sensory one, or (c) the locomotive one, the last is the most precise and presents more of

44 See p. 170. 
a man's essence and nature than (a) and (b)-especially since, due to the dependency of capacities discussed previously, (a) and (b) are also implied by (c). It is more specific for a man to have the capacity for locomotion than for growth and alteration, since animals like sponges also have the latter two, though not the first. Having the capacity to self-locomote makes a human being more what it is than alteration or growth and diminution.

Thus, at least with respect to the three aforementioned capacities, one may say that the capacity which is prior in essence also is more specific to that to which it belongs. This tells us something more about what it might mean for an essential feature $x$ of $k$ to be prior in essence to another such feature $y$ : if $x$ is prior in essence to $y$, then $x$ is more specific to $k$ than $y$ and not vice versa. That is to say, having feature $x$ is responsible to a higher degree for and contributes more to fulfilling the form and essence of $k$ than having feature $y$.

This opens up a way to determine whether something is prior in essence to something else, without making reference to the coming to be of something. It provides a measure by means of which one can tell whether something fulfils its essence to a higher degree than something else of the same kind, or whether an essential feature is more responsible for its bearer's fulfilment of essence than another feature.

Here is another example: Aristotle would certainly agree that thinking is more specific to man than locomotion, for this is what differentiates him from all-or at least most-of the other animals which possess locomotion. Based on what I have said, 'thinking' is therefore prior in essence to 'locomotion'. That this is the case follows from the reversed priority claim: in the development of human beings, the fully developed capacity for thought is posterior to that for locomotion. Hence, according to this assumption the former also has essential priority over the latter. ${ }^{45}$ The assertion that if an essential feature is prior in essence to another one, then the feature is more specific to what its bearer is, i.e. its essence, is a substantial claim. I cannot argue for its general truth here, even though it is not unlikely that Aristotle would agree with it. Yet, I have shown that it is the case for priority in essence with respect to the three kinds of non-substantial change, and we should keep in mind that the concept of priority used to compare different kinds of change, according to Aristotle, may differ in some way from other uses of this concept.

45 This implies a substantial claim about the connection between the order in which essential features are acquired in the coming to be and their specificity: since what is later in the coming to be is prior in essence and what is more specific is prior in essence, the coming to be of a living thing proceeds from the less to the more specific. I will not argue for this claim here. 
The understanding of priority in essence presented above is of utmost importance to the later discussion of the second argument for locomotion's priority in essence. Without it, as I will show later, the first and second argument for locomotion's essential priority cannot argue for the same kind of priority, but for two different kinds of priority. Thus, only with the additional criterion of specificity at hand does it become clear that Aristotle has not made the mistake of equivocation. After these remarks I will now summarize the results of the discussion of the first argument for locomotion's priority in essence.

\subsubsection{Conclusion}

As we have seen, Aristotle is right to presuppose the truth of the first premise, i.e. of the claim about reversed priority, on which his argument for locomotion's priority in essence is based. The concept of priority in essence that underlies this claim is that for $x$ to be prior in this way it must fulfil its essence and form to a higher degree than the thing to which it is compared. I have also showed that the term 'locomotion' is used in a special way in this argument. Accordingly, saying that locomotion is prior to the other kinds of change in our context means that the capacity to locomote is prior to the capacities of a living thing's soul to be a source of the other two kinds of non-substantial change, and also that this is more specific to being that which something is according to its form and nature. My discussion has also showed the truth of the second premise on which this argument for locomotion's priority in essence is based, namely that it is last in the coming to be of living things insofar as its capacity comes to things later than the capacity for the other two kinds of change.

If one takes into account that 'locomotion' stands for 'capacity to cause one's own locomotion', then the reconstruction of the argument presented is as follows:

(1) If $x$ is posterior to $y$ in the coming to be of living things, then $x$ is prior in essence to $y$ with respect to living things.

(2) In the coming to be of living things the capacity to cause locomotion is posterior to the capacity to cause alteration, growth and diminution.

(3) Therefore, in living things, the capacity to cause locomotion is prior in essence to the capacity to cause alteration, growth and diminution. 
The argument itself is sound. Yet, one has to keep in mind in what context it is stated. It is one of the two arguments by means of which Aristotle intends to show that locomotion, not the capacity to self-cause locomotion, is prior in essence. But it is also Aristotle's answer to a possible objection against the priority claim. For, as we have seen in the discussion of the fourth argument, locomotion is the last of the different kinds of change ( $\delta \sigma \tau \alpha \dot{\tau} \tau \tau \tilde{\omega} \nu \chi \iota \nu \eta \dot{\sigma} \sigma \varepsilon \omega \nu$ ), as it comes last to individual living things in their development. ${ }^{46}$ But this fact of the posteriority of locomotion seems to contradict the thesis that it is the primary kind of change, a thesis which is supposed to show that only locomotion can be the kind of change that has its primary source in and is directly caused by the first unmoved mover.

Aristotle's answer to this objection, as we have seen, is that locomotion is prior in another, more important sense of priority, not in spite of the fact that it is posterior in coming to be, but rather because it is posterior, which shows its primacy. As I have stated at the beginning of this chapter, it is important to keep in mind that in the greater context of Aristotle's theory teleology plays an essential role. Changes occur for the sake of reaching certain goals or ends; in the case of the coming to be of animals the goal is for them to reach their maturity, that is, to completely fulfil their form and essence. Explaining, and therefore knowing, why a change occurs and what its nature is, is only possible by making reference to its goal, which is why the ends of changes have explanatory priority. But for those perishable living things that at least potentially are able to move themselves it is more essential and specific to them that they be able to serve as the source of their own locomotion, than the source of other changes, especially since being the source of one's locomotion implies that one also has the capacities, i.e. parts of the soul that are responsible for the other partly self-caused changes to occur. That is to say, having the capacity for locomotion contributes more to fulfilling a living thing's form and nature, and to reaching the goal for the sake of which this whole process of coming to be takes place. This is the sense in which locomotion-in virtue of the locomotive capacity's priority-is prior in essence and in nature, which, as I have shown, is not only claimed, but also shown by Aristotle in the first half of the fifth argument.

But Aristotle does more than merely deal once again with the stated objection against his claim of the primacy of locomotion and show the essential role that locomotion plays for perishable living things. For, in doing so he also presents very good reasons for assuming that this must be the kind of change which is directly caused by the first unmoved mover, which in Met. XII is identified with god. Showing that locomotion is pri-

46 See Phys. VIII 7, 260b30-33. 
mary involves comparing it to other kinds of change, and this is exactly what Aristotle does here in examining what role it plays in beings in comparison to the other kinds of change.

But this project is not yet completed, because so far only perishable living things have been considered. In the second part of the fifth argument, Aristotle therefore will present reasons for the claim that locomotion is primary in eternal things as well. If the second sub-argument is also successful in showing what it is supposed to show, then the fifth argument taken as a whole shows that having locomotion in the sense at issue has priority in essence over the other kinds of change in all kinds of beings. This means that the second argument is not merely an additional reason for the primacy of locomotion, but needs to be considered in connection with the first one, and vice versa. Without the second argument the general priority in essence of locomotion would not be shown. As I will state in the course of the following discussion, this last step, however, presupposes understanding locomotion's priority in essence in terms of its being more specific to that to which it belongs, and this, as I have shown, implicitly underlies Aristotle's discussion of the first sub-argument. This also supports my view that there indeed is a close relation between the first and second arguments.

Therefore, one may conclude that Aristotle at the end of the passage I discussed is right in claiming that he has shown that locomotion has "primacy over the other kinds of change" ${ }^{37}$-but only in the sense that he has proved this to be true in the sense in question, i. e. with respect to living things. In order to prove that the claim about locomotion's priority in essence is true in general it still needs to be shown that locomotion is prior in this sense for eternal things as well.

\subsection{Locomotion alone preserves its subject's essence}

\subsubsection{Overview}

The second argument follows right after the first one:

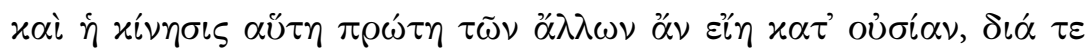

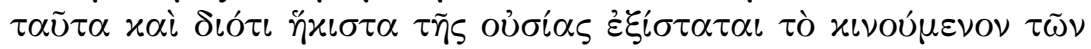

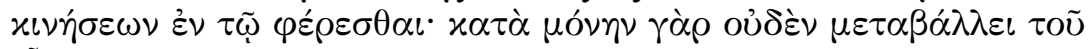

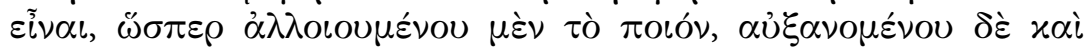

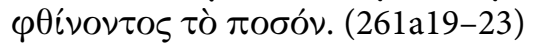

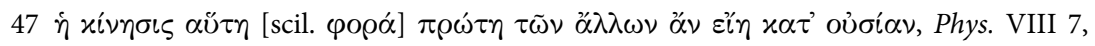
261a19-20. 
this [kind of] change would also have primacy over the other [kinds] in essence, because of this and [1] for the reason that what is undergoing a change of the [different] changes departs from its essence least in undergoing locomotion; [2] for it [i.e. locomotion] alone does not change anything of the being [of that which undergoes the change], as of what alters the quality [changes], and of what grows and diminishes the quantity.

The second argument presents another reason for locomotion's primacy in essence. The claim is that locomotion is prior in this sense, since of the four kinds of change it is the only one which completely preserves the essence of its subject. I will argue that Aristotle uses this claim to show in this second sub-argument that locomotion is also prior in essence with respect to eternal things, after having argued that locomotion is prior in this way in perishable things. If successful, he will have made clear that locomotion in this sense is primary in essence in all things that have locomotion.

According to this argument, locomotion has primacy over the other kinds of change, since, as sentence (1) states, if something $x$ is undergoing a change in place, $x$ somehow departs less from its essence (oủoí $\alpha$ ) than if it is undergoing any of the other kinds change. The reason $(\gamma \alpha \dot{\alpha} \rho)$ for this claim is presented in sentence (2). It does not appear to add very much to the claim already stated: $x$ 's being ( $\varepsilon i v \alpha \iota)$ does not change at all when $x$ undergoes a locomotion, while its being changes when $x$ is subject to alteration, growth or diminution, for $x$ then changes in quality or quantity. Aristotle does not present any further explanation for these claims, although they are far from self-evident and, as I will show, seem to contradict a basic Aristotelian assumption of his theory of change: change in quality and in quantity-along with locomotion-are labelled as non-substantial changes by Aristotle, i. e. as changes that by definition do not change their subject's essence. ${ }^{48}$ This seems to be in conflict with what is stated in sentence (1); for in what way can the non-substantial kinds of change be the cause for their subject's 'departing' from or 'stepping out' of its essence ( $\tau \tilde{\eta} \varsigma$ oủ $\sigma i \alpha \varsigma$ $\varepsilon \xi(\sigma \tau \alpha \tau \alpha \iota)$, i. e. its change in essence at all? And, more importantly, if they do not cause a change in essence in general, how could they be responsible for different degrees of change in essence-as suggested in sentence (1)? And assuming that these points turn out to be unproblematic, in what way would this argument fit into the greater context of the inquiry for the primary kind of change?

In order to solve these problems and to explain how the argument shows what it is supposed to show, it is necessary to look at it in more detail. I will proceed as follows: I will start by examining the claim stated in sentence (2), namely, that, if $x$ undergoes locomotion, $x$ 's being does not change at

48 See for instance Phys. V 1, 225a34-b5. 
all (see 7.2.2). Next, I will examine the claim from sentence (1) that of all kinds of change, locomotion, if undergone by $x$, changes $x$ in essence the least. I will argue that making sense of the argument presupposes distinguishing between ' $x$ undergoing a change in being' and ' $x$ undergoing a change in essence' - a distinction that is essential for this argument (see 7.2.3). After this I will suggest that alteration and change in quantity, in contrast to locomotion, seem to involve their subject's departing from its essence, as both may serve as necessary parts of certain substantial changes (7.2.4). As this proposal will turn out to be problematic, I will argue that the true reason for the asserted difference between locomotion and the other kinds of non-substantial change is that the latter in principle may, but do not have to, result in a change in essence of their subject, and that locomotion in this sense is indeed special (7.2.5). My last step will be to argue that it is because of this special feature that locomotion is the only change eternal things can undergo, and that this is the reason for its priority in essence with respect to such beings. Thereby, I will explain in what way the fifth argument as a whole supports Aristotle's claim that only locomotion can be the change which is directly caused by the first unmoved mover (see 7.3).

\subsubsection{Locomotion does not change its subject's being}

What does Aristotle mean by the claim that locomotion, in contrast to the other two kinds of non-substantial change, does not change anything of its

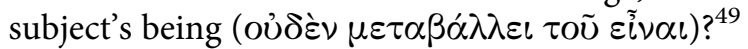

From what Aristotle says in sentence (2) it is clear that he certainly does not intend to say that change in quality and in quantity change their subject's being in the sense that they change what the subject is, i.e. its essence, while locomotion does not. According to what is stated here, a change in

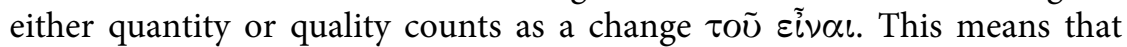
Eiv $\alpha$ l here does not stand for what is usually referred to by terms like 'essence' or 'substance' (oủ $\sigma i \alpha$ ). A mere change in quality or quantity is not a change in essence. Change in quality and in quantity are explicitly defined by Aristotle as non-substantial changes; saying that every change in quality and quantity is a change in essence of the respective subject, as sentence (2) would if Eiv $\alpha$ stood for oủ $\sigma i \alpha$, would contradict this basic assumption of the Aristotelian theory of change. In fact, the distinction drawn between substantial and non-substantial changes would be made obsolete. Thus, the

49 In what follows I will call the kind of change in which the subject is changed in being ( $\tau$ ũ giv $\alpha$ ) and about which Aristotle talks in 1. 261a22 'change in being'. As I will show, this

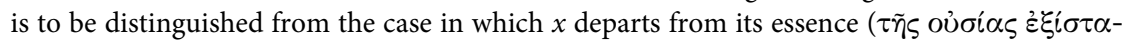
$\tau \alpha \iota)$. 
change in being ( $\tau$ õ $\varepsilon \tilde{i} \nu \alpha \iota$ ) that is discussed here is not a change in essence or substance, rather 'being' appears to be used in a broader sense here.

There is a way in which one may speak of a change in being in such a broader sense without saying that it is a change in the subject's essence: the four respects in which something $x$ may change were derived from the different "categories of being". 50 Three of these 'kinds of being' are quality, quantity, and place. Accordingly, a change in quality, quantity, or place by definition is a change of its subject's being, as what undergoes a change does so with respect to one of these four categories of being. ${ }^{51}$ But this is certainly not the respect that is of importance to Aristotle's explanation in sentence (2), because there it appears that only a change in respect of quality or of quantity counts as a change in its subject's being, while locomotion, i. e. the subject's change in place, does not. ${ }^{52}$ But why should one say this?

Let us consider some instances of the different kinds of change in order to get an idea how this might be possible. Suppose I change with respect to some quality and my face turns hot and red because I become angry, which -at least in this passage-seems to count as a change in my being. The same is true if I gain weight and increase in size because I have not done any exercise for a couple of months; in the passage at issue, this change in my quantity also counts as a change in my being. Not so, in the case of locomotion: if I go from my office to the kitchen to prepare a cup of tea, noth-

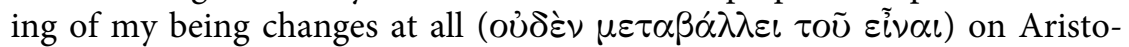
tle's view. This is an reasonable assumption and we would agree to this, for my mere movement from place A to place B, one could argue, does not change anything in me, while in the previous two cases obviously something in me does change.

Therefore, in my view the point that Aristotle wants to make here is that none of what one may call $x$ 's intrinsic attributes changes, when something $x$ changes in place, while at least one such attribute changes when $x$ undergoes any other kind of change. ${ }^{53}$ Accordingly, if $x$, from time $t_{1}$ to $t_{2}$, is

50 See Phys. III 1, 200b25-201a9, where in 1.200b28 Aristotle speaks of "categories of

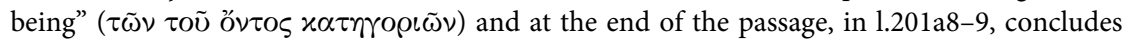
that "of change and non-substantial change there are so many kinds as of being" ( $\chi \iota \nu \eta \dot{\sigma \varepsilon \omega \varsigma}$

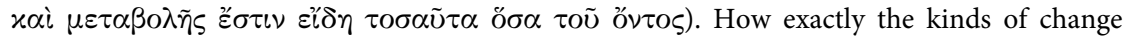
derive from the different categories is discussed in more detail in Phys. V 2.

51 Therefore, Wagner (1967), 690, argues that Aristotle is wrong to say that change in place does not change anything of its subject's being, since place ( $\pi 00$ ) undeniably is one of the kinds of being. The latter part of Wagner's claim is correct, as place indeed is one of the 'categories of being', but as I will show this is not the respect in which Aristotle thinks that locomotion does not change its subject's being.

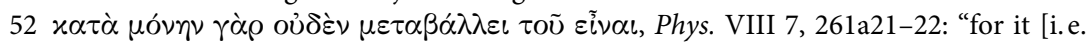
locomotion] alone does not change anything of the being."

53 Graham (1999), 128, therefore, points out that "[i]n modern terms we could say that 
undergoing a change only with respect to its place, $x$ itself at $t_{1}$ would be indistinguishable from $x$ at $t_{2}$. Apart from the negligible fact of $x$ at $t_{2}$ being older than $x$ at $t_{1}$, nothing in $x$ itself has changed. This is not the case when $x$ undergoes a change in quality or in quantity: to return to the previous examples, one could tell the difference between me at $t_{1}$ and me at $t_{2}$, for my face is red when I am angry at $t_{2}$ while it is pale at $t_{1}$; something in me or, as Aristotle puts it here, of my being, has changed. In the same way, there is a difference between me at $t_{1}$ and at $t_{2}$ in the second example, because I am larger at $t_{2}$ than at $t_{1}$, and also heavier, as growth for Aristotle always involves the addition of some extra material. ${ }^{54}$

This must be what Aristotle has in mind when he claims that locomotion

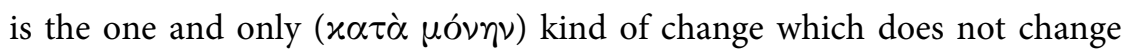

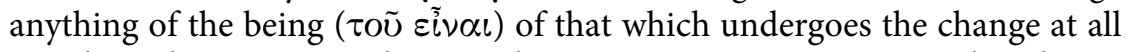
-a claim that is in accordance with common sense assumptions, but that at first glance is irritating in its wording to the reader of Aristotle, as it seems to contradict basic assumptions of his theory of change.

But now that this is clear, in what way is the fact that locomotion does not change its subject's being in the described sense a reason for the claim stated in sentence (1), namely that, of all kinds of change, the subject of change in place departs from its essence least and thus has priority in essence?

\subsubsection{Locomotion preserves its subject's essence best}

In other words, what sentence (1) says is that if something $x$ undergoes one of the remaining kinds of change, $x$ departs from or steps out of its essence

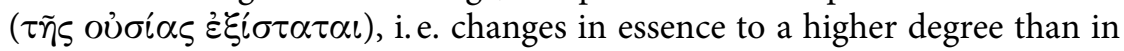
the case in which $x$ merely undergoes a change in place.

This claim makes sense with respect to coming to be and corruption. Both are defined as changing their subject with respect to its substance or essence $\left(\varkappa \alpha \tau^{\prime}\right.$ oủ $\left.\sigma^{\prime} \alpha \nu\right) .{ }^{55}$ For this reason sentence (2) does not say anything about coming to be and corruption, as there is no need for an argument showing the truth of this assumption: it is clear per definitionem that both change their subject's essence more than locomotion, since they are substantial changes, while the latter is a non-substantial one which does not

since location is a relational property, change of place involves a change only of relations, not of non-relational properties."

54 See my discussion of the first argument for priority in locomotion, where I show in what way Aristotle thinks that every process of growth involves the addition of something.

55 See for instance Phys. III 1, 200b33-34, Phys. V 1, 225a17-18. 
change its subject's essence at all. But if, of two changes $x$ and $y, x$ does not change its subject at all while $y$ does in some way, it is true to say that $x$ changes its subject less than $y$-even if $x$ does not change its subject in any way whatsoever.

A substantial change, however, is defined as a change either from what is to what is not, or from what is not to what is. ${ }^{56}$ Hence, a substantial change, in contrast to a non-substantial one, is not a change between contraries, but between contradictories, which means that there are no intermediates between the starting point and endpoint of the change. ${ }^{57}$ Accordingly, a change in essence cannot be a matter of degree: a (complete) change in essence, by definition, cannot change its subject's essence more or less than any other (complete) change in essence. Sentence (1), however, suggests that there are degrees to which a change's subject may depart from its essence, i. e. undergo a change with respect to its essence. As I have shown, there is no problem in saying that any substantial change changes $x$ 's essence more or to a higher degree than any of the non-substantial ones. But there is a problem in saying that, of the four kinds of change, locomotion changes its subject's essence least. For this requires that locomotion not only change its subject's essence less than coming to be and corruption, but also less than change in quality and in quantity. For this to be true it would suffice to show either that (1) locomotion does not change its subject's essence at all, while change in quality and quantity do in some way, or that (2) locomotion also does so, though to a lower degree than change in quantity and quality. This presupposes two problematic assumptions. First, it would imply that there are different degrees to which something may change in essence, which, as I just stated, contradicts what Aristotle says elsewhere about change in essence, i.e. in substance. Second, this implies that, at the very least, change in quantity or quality-and possibly even in locomotion-may change its subject's essence.

Let us start with the second of the two assumptions. As I said before, it would clearly collide with basic theorems of Aristotle's theory of change. If my face turns hot and red, or if I become larger due to laziness, does this imply a departure from-that is a change in-my essence, while no such change occurs when I walk from my office to the kitchen? In all three cases, accidental properties, at best, are changed, and thus none of them affects the essence of its respective subject-which is in accordance with the fact that Aristotle explicitly distinguishes change in quality, quantity and place, understood as non-substantial changes, from coming to be and corruption: the former are defined as changing something of a substance, but not the

56 Phys. V 1, 224b8-10 and 225a12-20.

57 See for instance Phys. V 1, 225a34-b5. 
substance, i. e. essence itself. ${ }^{58}$ Because of this it is puzzling that here, nevertheless, $x$ in undergoing locomotion is supposed to change in essence less than when undergoing any of the remaining non-substantial kinds. This problem might make one think that in our passage Aristotle by ' $x$ departing from its essence' does not mean ' $x$ undergoing a change in essence' and that oủ $\sigma i \alpha$ therefore does not stand for 'essence' or 'substance', but is employed in a different sense here. Indeed, it was suggested by Wagner that oủ $\sigma i \alpha$ has a broader meaning here and cannot be reduced to 'essence' in this context: whenever $x$ undergoes any change it "departs from its oủoí $\alpha$ " ( $\tau \tilde{\eta} s$

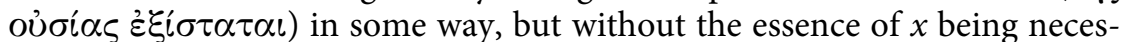
sarily affected. ${ }^{59}$ According to Wagner, Aristotle is saying exactly the same thing when he says that ' $x$ departs from its essence' ( $\xi \xi i \sigma \tau \alpha \tau \alpha l$ iñs

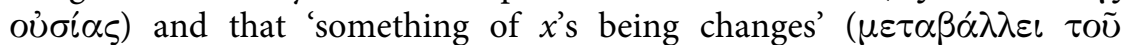
हiv ${ }^{2}(\iota)$, the expression used in the justification presented for sentence (1). This seems attractive since it would solve all the problems that I have pointed out.

For reasons I will state later, I nevertheless take it that Aristotle intends to make a distinction between the two cases and that this distinction is crucial for the argument made here. On my understanding, a change in being

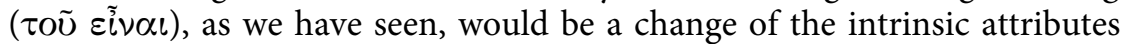
of $x$. It may concern accidental, but also essential attributes-a case I have not discussed so far. Thus, a change in being may, but does not have to, affect its subject's essence. A change in essence, by contrast, always does so. It is more than the mere change of some, perhaps accidental attributes of the change's subject and changes the very substance that underlies this change at its beginning; the subject of generation or corruption does not outlast such a change, and no longer exists when the change is over. Accordingly, a change in essence is also a change in being, but not vice versa.

But if, as suggested by Wagner, oủ $\sigma i \alpha$ does not stand for 'essence' here, and is used in a broader sense, this would raise the following difficulty: Aristotle claims that locomotion has priority in essence and presents two arguments for this claim. As my examination of the first argument has shown, this argument clearly presupposes the concept of essence: of two things $x$ and $y$, both being of one and the same kind $k, x$ is prior to $y$, if and only if $x$ fulfils the essence of $k$ to a higher degree than $y$. A consequence that results from Wagner's reading of the second argument is that the con-

58 For instance, the distinction between $x^{i} \nu \eta \sigma \iota \varsigma$ and $\mu \varepsilon \tau \alpha \beta \circ \lambda \eta \dot{\eta}$ introduced in Physics V is based on this essential difference.

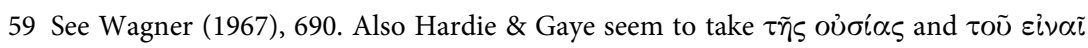
to refer to the same, and hence take them to stand for 'its being', and 'of being' respectively, although it is unclear what 'being' stands for in this context. 
cept of essence does not play any role in the second argument: locomotion is prior not because it changes its subject in essence (in the strict sense) least, but because it does not change its being (in the Wagnerian sense) at all. For a change in being to occur, however, it does not matter whether the change's subject undergoes a change in essence or not. According to this understanding, the concept of essence would play no role at all in deciding whether $x$ has priority in essence over $y$. Thus the definition of priority in essence underlying the second argument would be different from the one presupposed by the first argument for locomotion's priority in essence. If this were the case and Wagner's reading correct, then Aristotle is not presenting two arguments for one and the same way in which locomotion has priority, namely with respect to essence ( $\varkappa \alpha \tau^{\prime}$ oủ $\left.\sigma i \alpha \nu\right)$, but is rather arguing for two different ways in which it does, and is falsely using the same name for both, thus making the mistake of equivocation.

But if, as I see it, Aristotle thinks that both arguments show that locomotion is prior in the same way, then the definition of priority in essence that underlies the first argument also needs to be presupposed for the second one. Another reason that speaks for taking the phrase 'to depart from its essence' as referring to a substantial change, is that when Aristotle employs this term elsewhere, it stands for a change in the essence of the change's subject, which suggests that this is also the case here. ${ }^{60}$

But if my assumption is correct and the process of $x$ undergoing a change in being really differs from $x$ departing from its essence, one still has to face the problem which I mentioned above. If the fact that a change in quality or quantity, in contrast to locomotion, changes its subject $x$ 's being (sentence 2) accounts for its changing $x$ 's essence more than locomotion, but less than generation and corruption (sentence 1), then it seems that these non-substantial kinds of change must be taken to somehow lead to or involve a change in $x$ 's essence, that is, a substantial change, whereas locomotion does not. One might think that a way to deal with this problem is to read the argument as an a fortiori argument which could be reconstructed as follows:

(1) Of the non-substantial changes, only change in quantity and change in quality change the being of their subjects.

(2) Neither change in quantity, nor change in quality changes the essence of its subject.

60 This phrase does not seem to be used very often in Aristotle. Apart from the passage in Physics VIII, there is one in de An. I 3 (see 406b11-15). Also in Top. VI 6 (see 145a3-12) a

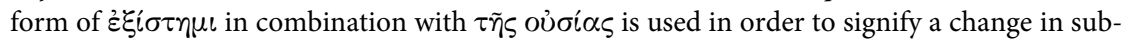
stance. 
(3) Therefore, a fortiori locomotion does not change the essence of its subject. $(1,2)$

Premise (1) takes up what is said in sentence (2) of our passage, namely that changes in quality and quantity change their respective subject in being while locomotion does not. Premise (2) refers to the fact that both of the kinds that can change their subject's being, because they are non-substantial changes, cannot change its essence. The conclusion then seems correct. But this argument involves an implicit premise that needs to be made explicit: only a change that can change its subject in being can change its subject's essence. This is due to the fact that, as I stated above, every change in essence is a change in being, while not every change in being is necessarily also a change in essence. If change in quantity and quality, which are changes in being, are incapable of making their subject depart from its essence, how then could locomotion be capable of doing so? In other words, if locomotion does not have the power to change $x$ in being, this is even more true of its power to change $x$ in essence.

The argument then is correct. However, it does not explain why locomotion should be less responsible, or even the least responsible, for its subject's

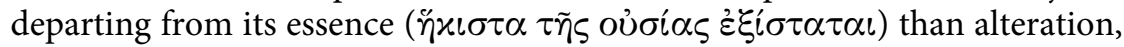
growth and diminution. Again, these are all non-substantial changes, and thus all of them are incapable of changing their subject's essence the same way; none of them does so more or less than any of the others. But it is this very attribute of changing its subject's essence the least which is supposed to make locomotion prior in essence to the other kinds of change.

Therefore, one should try to find a way in which it is appropriate to speak of such a difference in degree. In what follows I will argue that, in a certain respect, it is possible that the other two kinds of change are more responsible for their subject's change in essence than locomotion. By relating what I have said so far to a significant passage from Aristotle's discussion of alteration in Phys. VII 3, my first step will be to suggest that alteration and change in quantity, in contrast to locomotion, seem to involve their subject's departing from its essence, as both may serve as necessary parts of certain substantial changes (7.2.4). But since this proposal, as we will see, turns out to be problematic in many respects, my second step will be to argue that the true reason for the claimed difference between locomotion and the other kinds of non-substantial change is that the latter in principle may, but do not have to, result in a change in essence of their subject, and that locomotion in this sense is indeed special (7.2.5). 
7.2.4 Making $\mathrm{x}$ depart from its essence by being part of a change in essence?

\subsubsection{Alteration as part of a change in essence}

In chapter 3 of Physics VII Aristotle presents different arguments for the claim that alteration in the full sense occurs only in sensible things and the sensory part of the soul, and is not a change in the shape $(\sigma \chi \tilde{\eta} \mu \alpha)$, form $\left(\mu о \rho \varphi \eta^{\prime}\right)$, or state $\left({ }^{\varepsilon} \xi \iota \varsigma\right)$ of that which undergoes the change. ${ }^{61}$

Aristotle's first step is therefore to argue that the process through which the form or shape of a subject is changed is not, as one might think, an alteration. Rather, Aristotle claims here, this process by which the underlying matter takes on a certain form needs to be considered as a substantial change, namely coming to be ( $\gamma \varepsilon ́ v \varepsilon \sigma \iota \varsigma)$, which differs significantly from alteration. ${ }^{62}$ This is not what one would expect Aristotle to say, for, as I stated in the discussion of the second argument, alteration usually also covers the cases that are explicitly excluded here. ${ }^{63}$ Yet, for my purpose another, surprising remark that is made here is of importance: the coming to be of things, Aristotle tells us, by necessity seems to involve alteration. As the passage in which this is stated is of special importance for my argument, I will present it here in full:

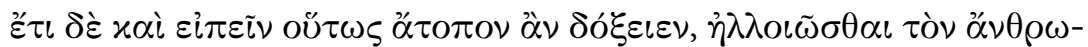

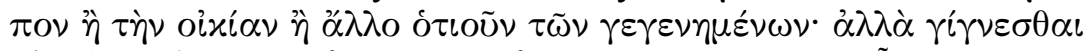

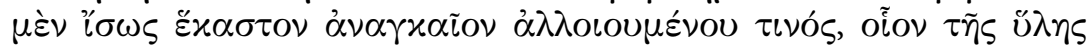

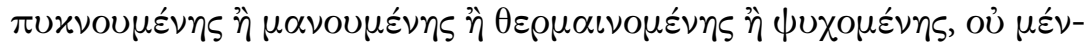

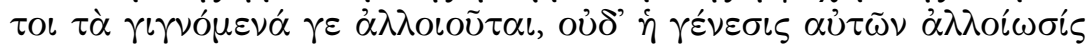

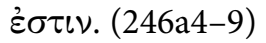

Besides, it would seem absurd to speak in this way: that the man, or the house, or anything else that has come to be underwent alteration. But probably it is necessary that each thing comes to be by something being altered, as for instance by the matter being condensed, or rarefied, or heated, or cooled; the things which are coming to be, however, surely do not undergo an alteration, nor is their coming to be an alteration.

If what Aristotle says here is correct, then coming to be necessarily involves alteration. Even though Aristotle is cautious in making this claim-he says that this is probably ( $i \sigma \omega \varsigma$ ) the case-there is no need to think that he has serious doubts that it is true at least for some cases of coming to be, even if it is not a universal principle. For my purpose it is enough to show that

61 See Phys. VII 3, 245b3-8 and 248a6-9.

62 For the full argument see Phys. VII 3, 245b9-246a9.

63 See section 4.4.2, esp. p. 100, n. 70, and p.103, n. 83, and their context. 
coming to be sometimes entails alteration of the matter and that it, in this way, may be a constitutive part of the process of coming to be without which the process would not take place. I will not examine whether this is true for all cases of coming to be.

The reason presented for this assertion is that something, for instance the matter $\left(\delta^{\prime} \lambda \eta\right)$, of that which is coming to be undergoes an alteration. Suppose a statue is being cast of a lump of bronze. In the process, the bronze is heated so that it can be poured into the mould. That is, the bronze is subject to an alteration, as it changes from being cold to being hot. At the same time the bronze, by becoming warmer, expands or, as Aristotle puts it in this context, is rarefied. Thus, the making of a statue from a lump of bronze necessarily involves alteration, for without melting the bronze, the statue could not be cast.

But is this also true of living beings? After all a bronze statue is a product of art, an artefact, and the coming to be of such things might differ significantly from that of living things. The science of nature, to which the treatment of change in Physics VIII belongs, deals, however, with things that are significantly different from artefacts, namely with things that have a nature, i. e. their own source of change-and hence of their own development and growth-within themselves. ${ }^{64}$ Yet, Aristotle obviously thinks that the coming to be of artefacts, e. g. of a house or a statue, is analogous to that of living things like human beings, at least insofar as in both cases the matter of which they are composed undergoes an alteration in their coming to be. ${ }^{65}$

But in what way might one say that an alteration occurs in the coming to be of, say, a man? Aristotle does not explain this, probably thinking it to be obvious. An explanation may be found in his understanding of the development of living things and of the processes that according to his biological works are involved in this development. One of these processes, and the one on which I will focus here, is concoction $(\pi \varepsilon \dot{\psi} \psi(\varsigma)$. Concoction plays an essential role in living things in general and in their coming to be in particular. For instance, it is necessary for the digestion of food, the production of blood and semen, and for the process in which the ovum, after its fecundation, develops into a full-grown living thing. ${ }^{66}$

Concoction in general is described as a process that operates by heat. ${ }^{67}$ According to Aristotle, through the heat of concoction, the matter of that

64 See Phys. II 1, 192b13-15.

65 See for instance Phys. VII 3, 246a4-9, in which, besides the coming to be of a human being, also that of a house is mentioned.

66 For digestion of food involving concoction, see for instance $P A$ II 3, 650a2-7; for the claim that blood is developed through concoction e.g. HA III 19, 521a17-18, and for the one that semen comes to be by concoction e.g. GA I 12, 719b2, or IV 1, 765b10-11. For the last point see what follows and n. 68 of this section.

67 See, for instance, Mete. IV 2, 379b12, and GA IV 1, 765b15-16. 
which is coming to be is also altered. Such an alteration of the matter by means of heat stands, for instance, at the beginning of the development of a human being. Right after what we would call the fecundation of the ovum, the semen causes a heating of the matter that underlies this process, i.e. the menstrual blood, and thereby initiates a development that, in the end and via many different stages, leads to a full human being. ${ }^{68}$ The heating of the menstrual blood clearly is an alteration of that out of which the man is coming to be, i.e. of his matter. Thus, Aristotle is correct to assert that in the coming to be of a man, the matter of which he is composed necessarily undergoes an alteration.

Yet, one needs to be careful not to confuse this alteration of the material with the coming to be of the human being. The alteration of the matter is a necessary part of the coming to be of the man, just as it is of the statue. But the heating of a lump of bronze alone does not automatically lead to a statue no more than the heating of that out of which a man comes to be necessarily leads to a man. Nevertheless, the coming to be of the man and the statue presuppose the alteration of the respective matter; it actually occurs by means of this alteration. Thus, there being such an alteration is a necessary, but not a sufficient condition for the coming to be of the respective thing. ${ }^{69}$

Even though Aristotle does not spell this out explicitly, it is clear that an alteration may be a necessary part of corruption ( $\varphi \theta 0 \rho \alpha$ ), that is, of the other kind of substantial change, as well. Suppose, for instance, a statue melts, and in losing its form is destroyed. In this case, too, the matter of the change's subject-namely the bronze-must undergo an alteration. If the bronze were not heated, the statue would not be destroyed (at least not in the manner described). ${ }^{70}$ Thus, alteration plays an essential role in this case of corruption too.

But, again, one should ask whether the corruption of living organisms also entails, or at least may entail, an alteration of the matter of that which is perishing. Does alteration in the corruption of a human being for instance play a similar crucial role? An example would be a deadly disease in the course of which the body is subject to a fever that makes the body temperature rise higher than $42,6^{\circ} \mathrm{C}$, so that the person affected by it dies; the proteins in the body undergo denaturation and the cells no longer work

68 As rennet makes milk become cheese by means of the vital heat $\left.(\theta \varepsilon \rho \mu o ́ \tau \eta \varsigma \zeta \omega \eta \tau \iota x)^{\prime}\right)$ it contains, the male's semen acts in a similar way on the menstrual fluid. For this see GA I 20, 729a10-14, and especially GA II 4, 739b20-26.

69 For this reason also Wieland (1992), 124, n. 13, states that "alles Entstehen vielleicht notwendigerweise dadurch bedingt ist, daß sich etwas ändert."

70 I do not mean to say that this is the only way in which the corruption of the statue may occur, nor that all possible ways involve an alteration. Yet, the destruction of the statue by melting it certainly does involve a change in quality of the matter. 
as they should. In this case as well, an alteration of the matter is a necessary part of this process of this kind of corruption.

It is important to keep in mind that what happens in the processes of corruption stated in the examples is more than the mere alteration of the respective matter, even though the alteration of the matter seems to operate as a cause of the corruption. In a change with respect to essence or substance the form of the subject is changed. Such a change may involve a change that occurs on what one might call the material level, but the corruption as a whole must not be reduced to what happens there, since this is not an appropriate explanation of a change in essence. The alteration involved is a necessary part of, but not identical with, the corruption. Aristotle considers things as compounds of matter and form, in which the form or essence of a given thing determines what it is. A human being, as such a compound, is more than its body or the mere aggregation of some atoms and molecules, and cannot be reduced to its material constituents. But this is exactly what happens when I mistakenly explain Socrates' dying from a fever as nothing but an alteration of Socrates' body.

From what we have seen, however, it became clear that an alterationalthough belonging to the kinds of non-substantial change-may be partly responsible for a change in essence in a certain way. This then, however, one might think, might serve as a reason for Aristotle's assumption that what undergoes an alteration departs from its essence to a higher degree than what undergoes locomotion.

Yet, even if this is the way in which this passage needs to be read, one still has to deal with the following problem. In the case of a statue undergoing

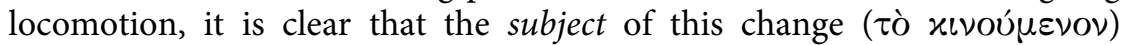
indeed does not change in essence in undergoing a change in place $(\varepsilon \nu \tau \tilde{\omega}$

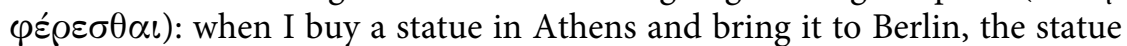
that is subject to locomotion does not change merely in virtue of undergoing a change in place.

But this is different in the case of alteration that is involved in a change in essence. Let us return to the example of the corruption of a bronze statue. In this process the statue completely departs from its essence. The subject of this change in essence of course is the statue. Of the alteration that the corruption entails, however, not the statue, but its matter is the primary subject. The matter is altered by being heated. However, the matter, which is the subject of the alteration, clearly does not step out of its essence by becoming warmer. Therefore, strictly speaking it is not correct to say that the subject of alteration departs from its essence to a higher degree than the subject of locomotion. Accordingly, one might think that, although alteration may be a necessary part of a change in essence, Aristotle's assertion that the subject of an alteration ( essence to a higher degree than that of a locomotion is wrong. 
Yet, Aristotle states elsewhere that in a looser sense we may say that it is the statue that undergoes a change in quality, i. e. is the subject of the alteration: as we have already seen in my discussion of the second argument, at the beginning of Phys. V 1 Aristotle points out that two of the ways in which something $x$ may be said to change is that $x$ changes accidentally $(\varkappa \alpha \tau \dot{\alpha} \sigma v \mu \beta \varepsilon \beta \dot{\eta} \varkappa O \varsigma)$ or with respect to its parts $(\varkappa \alpha \tau \dot{\alpha} \mu \varepsilon \rho \hat{\eta}) .{ }^{71}$ Of course, Aristotle also contrasts this looser everyday notion of change with a stricter, more scientific one, according to which something is said to change in the proper and primary sense, only if the subject of the change undergoes this change per se ( $\left.\varkappa \alpha \theta^{\prime} \alpha \dot{0} \tau o ́\right){ }^{72}$

As in the discussion of the second argument for the priority of locomotion, Aristotle appears to apply the looser notion of change here in this context as well. It is in this wider sense that one may say that the statue is subject to an alteration, since its matter is being altered. This point of view emphasizes that the alteration affects the statue as a hylomorophic compound and that this change may lead to or be involved in this compound's change in essence.

To sum up, it seems to be the case that what is subject to an alteration in this wider sense may depart from its essence to a higher degree than what is subject to locomotion-provided that, as I will argue, what undergoes locomotion does not change in essence in any way. I have shown that the reason may be found in the fact that change in quality sometimes serves as an indispensable part of change in essence.

Now it remains to examine whether it is also the case that what undergoes growth or diminution, i.e. changes in quantity, departs from its essence. Only then would it possible that, of the four changes, locomotion

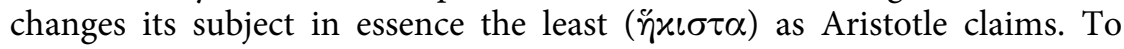
show that this is true, however, one would also have to analyse the role locomotion plays in substantial changes. I will now continue by focusing on the first of the two points and will deal with the second afterwards.

\subsubsection{Growth and diminution as part of change in essence}

In contradistinction to the passage from Phys. VII 3 that we discussed previously, as far as I can see, there is no text in which Aristotle explicitly points to a connection between change in essence and change in quantity, i. e. growth and diminution. Nevertheless, I think that there may be a rela-

71 See Phys. V 1, 224a21-24.

72 See Phys. V 1, 224a26-28. For this see also section 4.2.2, p. 77 f., in my discussion of the second argument for the priority of locomotion. 
tion here that is quite similar to the one between alteration and change in essence.

This is made clear by an obvious example, namely growth in the coming to be of living beings. In coming to be, that which is coming to be needs to grow in order to complete its development and become a full member of its respective kind. Growth, too, for Aristotle is an essential part of such cases of coming to be, that is, of a change in essence. This is clear, for instance, with respect to human beings: what is now an embryo needs to acquire a certain size in order to become a full-grown man, viz. it must grow and reach the magnitude specific to it as a human being. ${ }^{73}$ As in the case of the alteration of the matter, the mere growth of that which grows does not automatically lead to a full-fledged human being, yet without the occurrence of this change in quantity as a natural part of the development, the coming to be would not reach its goal.

That the other kind of change in quantity, namely diminution ( $\varphi$ i $\left.\sigma_{\iota \iota \varsigma}\right)$, is also connected to change in essence in a similar sense is indicated by the way Aristotle characterizes this kind of change. While growth is described as a change "towards the complete magnitude" that is specific to the respective living thing's nature, diminution is a change away from this natural magnitude. ${ }^{74}$ According to this characterization, a living thing has a magnitude that is specific to its nature and, one could add, to its form. Growth as part of the coming to be of a living being aims at reaching this specific goal. Diminution, however, is a departing from the magnitude that is proper to the respective living being according to its form and essence.

That this makes sense becomes clear when we think of certain cases in which a full-grown living being diminishes and becomes smaller: the process of dying or the progression of a severe illness, may go hand in hand with such a change in quantity: the organism becomes weak and emaciated, and loses the magnitude it usually has when it is in a healthy state.

As for the case of alteration, here as well I will refrain from making the claim that for Aristotle every diminution is part of such a change in essence. Nevertheless, there are instances of corruption of which becoming smaller is an essential part. By contributing to and being a necessary part of the process of corruption, diminution as alteration in a sense may be said to make its subject depart from its essence.

73 Aristotle for instance explicitly points out that natural growth always aims at reaching the complete magnitude that is specific to the nature of the respective thing (see VI 10, 241a33-b2, and V 2, 226a31-32).

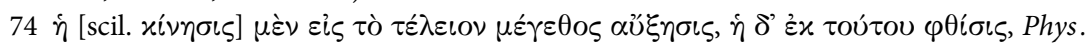

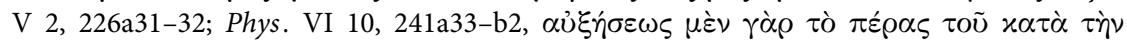
oix 
As we have seen, change in quality and quantity both are able to play a crucial role in substantial changes, although they are non-substantial kinds of change. For the discussion of the second argument for locomotion's priority in essence it seems to be of special importance that change in quality and quantity can serve as essential contributors to their subject's corruption. For it appears that in this way, i. e. in virtue of being such an indispensable part of the corruption process, both kinds of change may be said to make their subject depart from its essence. This, however, does not suffice for establishing what Aristotle claimed, namely that locomotion has essential priority, because what is undergoing locomotion departs from its essence the least. One still needs to show that locomotion does not make its subject step out of its essence, or at least does so less than the other two non-substantial kinds of change.

\subsubsection{Locomotion as a part of a change in essence?}

The reason presented for locomotion's being less involved in change in essence was that of the different kinds of change locomotion alone does not change the being of its subject in any way. ${ }^{75}$ None of what I called 'intrinsic attributes' of the subject $x$ of a locomotion changes merely because $x$ changes its place. But this is what happens in every change in quality or quantity, which is the reason why these kinds of change, in a way, can at least contribute to their subject's change in essence by being a part of this substantial change. A change in essence is a change that always occurs in that which is undergoing this change. Corruption, therefore, is a change in that which is ceasing to be. Since locomotion does not affect its subject's inner attributes, one accordingly may say that it cannot be a part of a change in essence in the way alteration and change in quantity can. This is in perfect accordance with parts of the results of my discussion of the second argument for locomotion's priority. For in this discussion I showed that locomotion per se does not entail a change of the inner spatial order of its subject $x$ 's parts, and hence, that $x$, apart from the change in place it undergoes as whole, is not changed in any way whatsoever, or, to put it in other words, $x$ is left completely untouched with respect to its being. ${ }^{76}$ This fact, as I showed, follows from locomotion's ontological priority, because, as I made clear in my discussion of the second argument as well, change in place is an inelimnable part of any other kind of change insofar as any change undergone by $x$ in quality, quantity, or substance necessarily

75 See Phys. VIII 7, 261a21-23; on this see 7.2.2.

76 See chapter 4, esp. section 4.2.3. 
involves a change in place of $x$ with respect to its parts, whereas change in place itself can occur without any other kind of change being involved. ${ }^{77}$

But if against this background one considers again what I have just presented as an answer to the question in what way one can say that changes in quality and in quantity change their subject $x$ 's essence to a higher degree than change in place, it becomes obvious that what seemed to be a good explanation does not really help us make sense of Aristotle's claim at all. For again: I have just shown that there are changes in substance of which change in quality or quantity are a necessary part and have presented this as the reason why alteration, growth and diminution may lead to their subject $x$ 's change in essence. But if the fact that change in quality and in quantity may be necessary parts of at least some cases of change in substance is a reason for saying that they may be responsible for their subject $x$ 's change in essence, then the same is even more true with respect to change in place, which, as I have shown in my discussion of the second argument, is a necessary concomitant of every case of change in substance. Thus, it clearly seems wrong to argue that because change in quality and in quantity can be essential parts of substantial changes, they therefore change their subject's essence to a higher degree than change in place; the same is even more true for locomotion. Therefore, at least in this sense it is wrong to say that locomotion makes its subject depart to a lesser extent from its essence than the other kinds of change, and thus another explanation for how Aristotle might be right in making this claim needs to be found. ${ }^{78}$

\subsubsection{Change in quality or quantity in principle may result in a change in essence}

To summarize what I have just stated: as we have seen, locomotion, on the one hand, seems to be what one might call the weakest kind of change, in that it does not change the being of its subject in any way and leaves its inner attributes completely untouched, which is in perfect accordance with what Aristotle says about locomotion in the second argument for locomotion's priority in essence. On the other hand, however, every change in substance necessarily requires that its subject change with respect to place in a

77 See the relevant sections in chapter 4.

78 Another reason why this explanation is problematic lies in the fact that it is essentially based on Phys. VII 3, which certainly is far from being a very reliable source of information about Aristotle's theory of change, since there, as I already pointed out, he espouses unorthodox doctrines without presenting any further support for them-for example the one that change in shape, contrary to what is stated for instance in GC I 4 and in many other places, does not count as an alteration. 
certain sense and, as we have seen, may only occur in virtue of this change in place. This, however, seems to be in conflict with Aristotle's claim that locomotion has essential priority, since its subject then, as we have seen, in no way seems to depart to a lesser extent from its essence than the subject of alteration, growth or diminution.

The solution to this problem is that both of the cases of locomotion that are contrasted here with each other differ with respect to what the actual subject of the respective change in place is. In the first case that which is said to change in place undergoes locomotion as a whole and therefore in the strict sense indeed is not changed in any other way than with respect to its place. In the second case, however, that which is said to change in place does so with respect to its parts, which is a completely different situation. ${ }^{79}$

In the argument that I am discussing at the moment, Aristotle, thus, seems to be claiming that any subject $x$, in undergoing a change in quality or quantity as a whole, is departing from its essence, while this is not the case for that which undergoes change in place as a whole. Otherwise, the claim that locomotion does not change the being of its subject would not make any sense at all, because something changing in place with respect to its parts, as we have seen, may very well lead to its corruption. Therefore, in order to find an appropriate solution one needs to compare change in quality, quantity, and place insofar as they are undergone by a subject as a whole.

Against this background my suggestion is that what Aristotle has in mind when he claims that $x$ undergoing a change in quality or quantity as a whole implies $x$ 's departing from its essence is that these kinds of change in principle may result in a change of essence, while this is impossible for locomotion. In what follows I will state the reasons for this claim in more detail.

Let us start by examining in what way this is true with respect to alteration. My claim is that certain alterations something $x$ may undergo as a whole can result in $x$ undergoing a change in essence in the sense that if the alteration goes on for too long and in consequence the respective quality becomes too extreme this ultimately results in a change in substance. Suppose, again, I have a fever, that is, my temperature rises and my body becomes hot. This alone does not yet lead to my corruption. But if this change in quality, i. e. the heating of my body, were to continue, it would result in my corruption at some point. That this is what Aristotle has in mind is supported by a passage in the Topics. There it is stated that, if an affection is intensified and increased, this changes the substance and-to

79 For the difference between $x$ changing in place as a whole as opposed to its changing in place merely with respect to its parts, and in what way the first does not involve a change of $x$ in the manner described, while the latter does, see my discussion of the second argument, esp. sections 4.2.2 and 4.2.3. 
use a more metaphorical rendering-drives the respective thing out of its essence $\left(\dot{\xi} \xi i \sigma \tau \eta \sigma \iota \tau \tilde{\eta} \varsigma\right.$ oủ $\left.\sigma^{i} \alpha \varsigma\right) .{ }^{80}$ This, of course, does not mean that every alteration leads to a change in substance, but only such as involve an affection's becoming too extreme. This fits perfectly with the example of the fever. My temperature usually does not increase beyond a certain limit, and after a while it drops again. But if the alteration were to continue and exceeded this limit, this would lead to my death. The same case can be made for becoming too cold. The mere fact that I become colder usually does not lead to my corruption; this only happens if the change continues and my body temperature falls below its natural limit.

To put what I just stated more generally, one may say that in undergoing an alteration $x$ is departing from its essence in the sense that $x$ is engaging in a kind of change that, were it to continue, would lead to $x$ 's change in essence. Alteration may be said to be responsible for its subject departing from its essence, as it in principle may, but does not have to, result in a change in essence.

Something similar may be said about change in quantity. Usually, undergoing growth or diminution does not result in the respective subject departing from its essence, but as for alteration one may think of cases in which it would. If such a change in size continues for too long and exceeds its natural limits it may also result in the subject's corruption. I have already mentioned that for Aristotle natural growth aims at reaching the full magnitude that is specific to the growing thing's nature and essence. ${ }^{81}$ Thus, if something keeps on growing and exceeds this natural limit, it no longer fulfils its essence and in this sense is no longer the substance it was before, in other words, it has changed in essence.

Although Aristotle is not that explicit about diminution, it is clear that this kind of change in quantity, if it continues and exceeds a specific natural limit, may result in its subject's change in essence. As I already mentioned, growth is characterized as a change "towards the complete magnitude" 82 that is specific to a living thing's essence and nature, while diminution should be considered as a change away ( $\left.\varepsilon^{\prime} x \sigma \tau \alpha \sigma \iota \varsigma\right)$ from this natural magnitude. ${ }^{83}$ Therefore, diminution can also lead to a complete loss of the magnitude that is specific to the thing according to its essence. Such a case, however, clearly would be a change in substance, since the essence would no longer be fulfilled.

Phrasing this in a more general way, we may say that in undergoing growth or diminution $x$ is departing from its essence in the sense that $x$ is

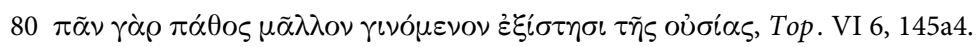

81 For this and also for diminution see section 7.2.4.2.

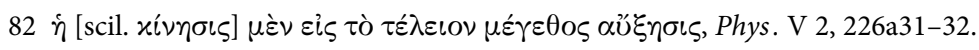

83 Again see Phys. V 2, 226a31-32, and Phys. VI 10, 241a33-b2. 
engaging in a kind of change that, were it to continue, would lead to $x$ 's change in essence. Growth and diminution may be said to be responsible for their subject departing from its essence, as it in principle may, but does not have to, result in a change in essence.

As we have seen, to say that something $x$ is departing from its essence does not imply that it at some point actually completely changes in essence. Metaphorically speaking one might say that when $x$ begins to undergo a change in quality or quantity the first step towards a change in substance is taken; whether this ultimately leads to a corruption of $x$ is another question. That this is correct appears more likely if one understands $\dot{\varepsilon} \xi i \sigma \tau \alpha \tau \alpha \iota \tau \tilde{\eta} \varsigma$ oüras in the sense of 'embarking on the process of departing from the essence', that is, by emphasizing the ingressive aspect of this form.

This can be made clearer by considering the following analogy. Suppose I leave the university building in Berlin and start walking north. If I keep on going long enough I will leave Berlin at some point. But it is not until I have crossed the city's border that I will actually have left Berlin. Yet, in a sense one may say that, although I am still in Berlin when I walk out of the building, I am nonetheless already in the process of departing Berlin at this moment in the sense that I am engaging in a kind of change that, were it to continue, would finally result in my crossing the city's border. In the same sense, I take it, one may speak of something $x$ departing from its essence in undergoing change in quality or quantity as a whole. For, as I showed, these changes may, but do not have to, lead to $x$ 's change with respect to essence.

The situation however is completely different when $x$ as a whole undergoes a change in place, since this cannot lead to $x$ 's change in essence. This has already been made clear in previous discussions. If $x$ undergoes locomotion as a whole, none of what I called the intrinsic qualities change, nor would this be the case with respect to the inner spatial order of its parts, as I put it in the discussion of the second argument. Both, however, seem to be necessary for $x$ to change in essence. In addition, one could also say that the reason for the fact that locomotion does make its subject depart from its essence is that the mere change in place of $x$ as change in place can never result in a change of $x$ 's essence.

But there are examples which seem to suggest that undergoing a change in place does result in a substantial change. Suppose, for instance, I have a fish tank with one goldfish inside. One day the gold fish jumps out of his fish tank and lands on the table, where it suffocates. Another example would be me for some reason walking into a burning house and perishing in the flames.

Both examples are cases of corruption, that is, of a substantial change. For both examples, one may say that the subject's undergoing locomotion as a whole leads to the destruction of the subject, since corruption would not have occurred without the preceding locomotion. Yet, it is important to 
emphasize that these changes do not happen solely in virtue of the subject's suddenly being at some other place, but because of what is at the respective place. The fact that the place where the goldfish landed is full of air instead of water, or that the place I went into is full of fire, is an accidental feature of the change in place. Suppose I know that goldfishes tend to jump out of their fish tanks and for that reason put a second one next to the one in which my goldfish lives so that it would not land on the table, but in the other fish tank instead. That is to say, by jumping out of the water it would not move to a place full of air, but to one full of water, and therefore would survive, although the place to which it moves and the locomotion that takes it there in both cases are more or less identical. The same is true for the house in which I burned to death in the other example: if I had entered the house and walked to exactly the same place at a time when it was not burning, I would not have died.

Thus, in undergoing locomotion $x$ is not departing from its essence merely in virtue of changing with respect to its place, and for this reason locomotion cannot result in $x$ 's corruption merely in virtue of changing $x$ with respect to its place. This understanding in a sense seems once again to be supported by a passage from Top. VI 6. There it is stated that substances do not differ merely by being at different places. ${ }^{84}$ Accordingly, one cannot say that the change of place makes a substance change with respect to its essence; $x$ 's place is irrelevant to what kind of being it is. Or, as Aristotle puts it, a land animal will still be a land animal even if it is in the water. ${ }^{85} \mathrm{In}$ the same way, I remain a human being, no matter where I go.

Therefore, what undergoes locomotion as a whole in no way departs from its essence, while that which changes in quality or quantity does so. Hence, Aristotle is right to claim in sentence (1) of the relevant passage from Physics VIII 7 that the subject of locomotion departs from its essence the least, although the reasons for this assertion are not explicitly stated in the text. That coming to be and corruption involve a change in essence is obvious from their definition as substantial changes. Yet, contrary to what one might have expected, it has become clear that change in quality or in quantity, in contrast to change in place, in a certain sense may make its respective subject step out of its essence. This is another reason why locomotion has a special status among the four kinds of change and, as I will now show, is correctly called primary in essence.

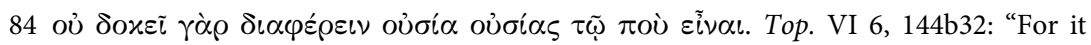
seems that locality cannot differentiate between one substance and another." (Transl. Pickard-Cambridge).

85 See Top. VI 6, 144b37-145a1. 


\subsection{Conclusion: Locomotion's priority in essence}

Now that we have seen that Aristotle is correct in claiming that locomotion has this special status, since locomotion alone cannot make its subject's essence change in the manner in question, but rather preserves it completely, it remains to explain in what way this is a reason for locomotion's priority in essence ( $\chi \alpha \tau^{\prime}$ oủ $\left.\sigma i \alpha \nu\right)$.

The first of the two arguments for essential priority showed that locomotion is prior in essence for perishable living things. The second argument, as I will make clear now, presents reasons why locomotion is also prior in essence with respect to eternal things that at least in principle can undergo some kind of change. The two arguments taken together then show that locomotion is prior in essence for perishable living things as well as for eternal things, that is, with respect to all things (apart from the unmoved mover) that are responsible for the changes that occur in the universe. ${ }^{86}$ That locomotion is prior in essence for living things was shown by Aristotle by making use of the reversed priority claim and the fact that locomotion comes last to perishable things in their development. As I have shown, this means that it is more specific to $x$ for it to have locomotion than alteration or growth and diminution. Having the capacity to self-locomote makes an animal more what it is than alteration or growth and diminution. It is more specific to $x$ as a member of a certain species to have locomotion.

But how does this connect to the second argument for priority in essence? This argument rather appears to be about change in place in general than about locomotion being more specific to something $x$ than any of the other kinds of change. The reason why locomotion has priority in essence seems to be that of the four kinds of change it makes its subject "depart from its essence the least" ( preserves the essence best. On this understanding, the better a change preserves its subject's essence, the more priority it has in essence. This may be a possible reading of our passage. But this understanding becomes problematic when we remember that the argument I just discussed is only one of two arguments that are supposed to demonstrate that locomotion has primacy in the same way, namely in essence ( $\chi \alpha \tau^{\prime}$ oủ $\left.\sigma \alpha \alpha\right)$. Therefore, in order to avoid assuming that Aristotle makes the mistake of equivocating two in fact different ways in which a change can have priority in essence, one should presuppose that the understanding of priority in essence under-

86 As I pointed out in section 3.4, p. $57 \mathrm{f}$. (n.51), Aristotle in $M A$ 6, 700b11-12, clearly states that all changes are either caused by living beings or by sources of change from the superlunary sphere, i.e. by things that are eternal. 
lying the first argument is the same as the one used in the second argument. ${ }^{87}$

But how does the reason why locomotion is said to be prior in essence in the second argument relate to the understanding of priority in essence presupposed by the first argument? One of the results of the discussion of the first argument was that the relation of essential priority applies primarily to individual substances, but in a derivative sense also to essential features of individuals. In this way, locomotion as such a feature of certain living beings may be prior to another essential feature, e. g. alteration. Of two features, the one which is more specific to what its bearer is, i.e. its essence, is prior in essence to the other one.

Aristotle does not tell us how the fact that locomotion does not change its subject's essence relates to this understanding of priority in essence. But

87 Philoponus, In Phys. 8, 900, 18-901, 3, thinks that locomotion is prior in essence (and nature) as it is supposed to be more complete and belongs to things that are more complete

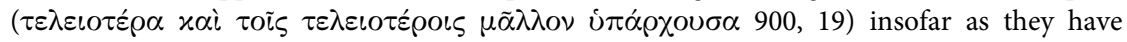
received their nature to a higher degree, yet, he does not say much more than what is stated in Aristotle's text. Simplicius seems to have something similar in mind and thinks that both arguments show that locomotion is prior in nature and essence as it belongs to more complete things. Like Philoponus, he does not explain why this is relevant, or how exactly the second of the two arguments for priority in essence shows that (see In Phys. 8 1271, 35-37, and 1272, $23-$ 25). Aquinas, In Phys., L. VIII. 1. XIV, 1094, follows either one or both of them in a sense when he claims that locomotion in this argument is shown to be primary in perfection ("primus perfectione"). All three say that locomotion's priority in essence (and nature) may be seen in the fact that it belongs to more complete things and at the same time does not change things that are complete. They do not say in what way there is one notion of priority in essence that underlies both arguments. The only way in which this could be done would be to say that to claim $x$ is prior to $y$ in this sense means that $x$ is more responsible for the completeness of the thing to which it belongs than $y$. As we will see, this sounds similar to what I think is the reason for locomotion's essential priority, yet, I hold that locomotion has this kind of priority in virtue of being a necessary part of a thing's essence, while they would be bound to say that it is prior because it just in some loose way is connected to the state of completeness of a thing; but this certainly is not in the spirit of the first argument. Also, most modern interpreters seem to think that Aristotle equivocates two different concepts of priority in essence, since they present the arguments in a way in which they cannot show locomotion's primacy in essence according to the same notion of priority in essence. Solmsen (1960), 237, n. 50, for instance, states that 'prior' with respect to essence stands for "a qualitative sense in which what is last in the order of becoming is first in that of being", but does not explain how this is supposed to fit to the second argument that, as the first one, is supposed to show that locomotion is prior in essence. Similar things may be said about what Wagner (1967), 690, and Graham (1999), 128129,187 , state in their commentaries. Peramatzis (2011), 205, n. 5, briefly refers to the discussion of priority $x \alpha \tau^{\prime}$ oủ $\sigma i \alpha \nu$ in Phys. VIII 7, claiming that $A$ is prior in essence to $B$ "if and only if $A$ can be what it is independently of $B$ being what it is, while the converse is not the case" (204). As my discussion of the second argument has made clear, this notion of priority clearly cannot underlie both arguments for locomotion's priority in essence. 
here as well it helps to have in mind the context in which the argument is stated: Aristotle is trying to demonstrate that locomotion is prior in different respects to the other kind of change in order to show that only locomotion can be the kind of change that is directly caused by the first unmoved mover. But in what way does what we have learned about locomotion in the second argument contribute anything to this project?

The solution may be found if we think about what is directly caused to change by the first unmoved mover, that is, the outermost heavenly sphere. According to Aristotle the spheres and the stars as part of the superlunary realm are not subject to substantial change, but are eternal. This, I take it, is what connects the fact that locomotion does not change its subject's essence to the greater project of showing that the kind of change that is directly and primarily caused by the first unmoved mover and undergone by the outermost sphere can only be locomotion. The way in which locomotion is prior in essence to the other kinds of change is with respect to the primum mobile and to eternal things: the outermost sphere can only undergo a change that leaves its essence completely untouched and which is of such a nature that it can be engaged in eternally without thereby posing any threat to its essence. As I have shown in my discussion of the second sub-argument for priority in essence, the only change which does this in the full sense is change in place. For, in contrast to change in quality and quantity, it does not affect its subject's being in any way and therefore not even in principle can it entail any substantial change; and that coming to be and corruption are not appropriate candidates has been clear from the beginning and did not need an extra argument.

The following then is the way in which locomotion is prior in essence with respect to the outermost sphere and to eternal things, respectively: locomotion belongs more to what the outermost sphere is, i.e. to its essence, in the sense that locomotion so to speak is more specific to it than any of the other kinds of change that one might have thought to belong to this or any other eternal entity. For, again, locomotion does not change its subject's being and essence in any way and this is the reason why the only change the eternal sphere of the stars (as well as all other heavenly bodies) ever has undergone and always will undergo is locomotion.

Aristotle does not present this explanation anywhere in the argument for locomotion's priority in essence explicitly. As is so often the case, the argument is rather compressed and presupposes a number of assumptions that are left unsaid. But at the beginning of the fourth argument, as we have seen, Aristotle at least states that "for eternal things it is only possible to change with respect to this change", i.e. locomotion. ${ }^{88}$ One-but, as has

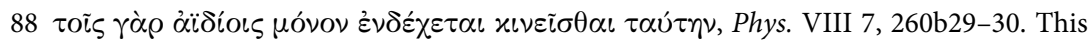
is clear also from the fact that the heavenly element, aether, according to Cael. I 3, 270a12-35, 
become clear, not the only-reason for this is the fact that locomotion in a certain sense may be characterised as the weakest kind of change, since what is undergoing a change in place does not change in being or in essence. This then is the reason why locomotion is prior in essence, and why it is the only possible candidate for the kind of change which the outermost sphere of the stars undergoes and which therefore has its direct and primary source in the first unmoved mover.

To conclude, the fifth argument taken as a whole shows that of the four kinds of change locomotion is primary in essence with respect to all things -apart from the first unmoved mover-that are sources of change in the cosmos, namely locomotive living beings and eternal things that are persistently performing locomotion. In doing so Aristotle has shown yet another sense in which locomotion is the primary kind of change and that for this reason the only appropriate candidate for the one and eternal change that is caused directly by the first unmoved mover is the kind that, among other types of priority, has essential priority over the other kinds of change.

may only change by undergoing locomotion. On this see also what I stated at the beginning of chapter 6.2, p. 146. 


\section{Conclusion}

In the following chapter I will summarize the results of my study. My first step was to examine the context in which Aristotle presented the arguments for the claim that of the four different kinds of change locomotion is the primary one. It became clear that this discussion is part of Aristotle's larger project of developing a general theory about the phenomenon of change which is worked out in Physics V-VIII. Physics VIII, to which the discussion of the priority claim more specifically belongs, needs to be considered as the part of the inquiry which brings the project to its completion: first of all Aristotle analyses the different concepts that are necessary for this enterprise and shows that change, contrary to what Zenon's paradoxes might suggest, is a phenomenon graspable by scientific inquiry and of which a consistent theory is possible. Building on the work done in Phys. V and VI, Aristotle in Phys. VIII ultimately develops a theory that accounts for the existence of change in the cosmos by showing that change always existed and always will exist, and that for this reason a first unmoved mover as an ultimate source of all change must be presupposed. As I have explained, discussion of the different arguments for the priority claim is crucial if this theory is to hold; for only if Aristotle is successful in showing that locomotion indeed is primary in all important respects will he be able to make clear at a later stage that the eternal motion of which according to him the first unmoved mover is the primary source can exist at all. Contrary to what the literature suggests, the discussion of the question which kind of change is primary, thus, is essential for what goes on in Physics VIII as well as for Aristotle's larger project of developing a general theory of change. Accordingly, it must not be considered as a superfluous addition that does not play any important role in the discussion into which it is embedded; rather, the contrary is the case, since without this discussion Aristotle would not be able to show that the theory developed in Books V and VI can be applied successfully to the whole of the cosmos in order to give a final causal explanation of the occurrence of change as we observe it day by day and thereby to account in an appropriate way for the empirical fact that change exists.

Therefore, in Phys. VIII 7 five arguments are presented that make clear that locomotion is prior to the other kinds of change in different respects. As we have seen, each of the first three of these five arguments shows that change in place has ontological priority over the other kinds of change in a specific sense. In the first argument, as became clear, Aristotle points out 
that of the three different kinds of non-substantial change locomotion must have ontological priority over the other two kinds, when they occur in living beings and the living being in question (by having a nature) is responsible for these changes to a certain degree. For, cases in which some living thing undergoes alteration, or growth and diminution always presuppose the occurrence of a preceding locomotion, while the converse does not hold. Yet, in this way the argument also made clear that locomotion by being prior to the changes living things are responsible for is also ontologically prior to all other changes that are caused by living beings, i.e, to all changes in the sublunary sphere apart from those that are caused by sources of change that lie outside this realm.

Next, my study showed that Aristotle in the second argument focuses on what happens on the material level when something undergoes one of the four different kinds of change and in this way makes clear that locomotion has ontological priority in another way: any change in quality, quantity, or substance entails the occurrence of a locomotion in the sense that whenever $x$ changes in one of these respects, then necessarily a part or parts, namely basic material components of $x$ change in place, so that one may say that each of these changes is always necessarily accompanied by change in place. But as my discussion also pointed out, $x$ undergoing locomotion in the strict sense does not entail that $x$ changes in any other respect apart from that of place, so that locomotion was shown to have ontological priority in this respect as well. As my discussion showed, this finds its expression in the fact that change in place is special insofar as the inner order of that which undergoes such a change in the strict sense-in contrast to any of the other three kinds of change-is left completely untouched. In discussing this second argument, which therefore needs to be considered successful, I also made clear that, contrary to how this argument is usually taken, it and the premises on which it is based are clearly Aristotle's own.

After that I turned to the third argument. As we have seen, Aristotle there shows a third way in which change in place is ontologically prior to the other three kinds of change. It first of all became clear that the only kind of change that in principle can constitute one single and eternal change is change in place. Therefore, locomotion-at least in this respect-is the only appropriate candidate for the change that is directly caused by the first unmoved mover and which is responsible for the occurrence of any other change in the cosmos. In virtue of the fact that this very first change needs to be a change in place, it again became clear that locomotion has ontological priority over the other changes, since they cannot occur without this locomotion, while the eternal change in place of the primum mobile, in having its direct source in the first unmoved mover, does not presuppose any other change. Accordingly, Aristotle also here comes to the conclusion that without change in place, none of the other three kinds of change are possi- 
ble, while the converse does not hold, i.e. that locomotion has ontological priority in this respect as well.

As I then pointed out in my discussion, Aristotle in the fourth argument, by building on what was shown in the previous argument, makes clear that this locomotion also has priority in time, although there are facts that seem to contradict this assumption. Since eternal things can only change with respect to place, it is clear that the change which the first unmoved mover causes directly and which the primum mobile undergoes-at least in this respect-can only be locomotion. For this reason, i.e. in virtue of this first eternal change being locomotion, it is clear that change in place is prior to any instance of one of the other three types of change, since an eternal change is always prior in time to any non-eternal one. As we have seen, however, Aristotle devotes most of this discussion to dealing with a possible objection to this claim: contrary to what one might think, the fact that an animal's ability to self-locomote comes to it at a rather late point of its development fits very well into Aristotle's theory. I have also shown that this fact in the same way does not imply that the generation of something $x$ always needs to precede $x$ 's change in place, and that generation therefore does not have to be considered the primary kind of change. For, since the locomotion of the heavenly spheres and bodies, especially that of the sun, is responsible to a certain degree for any occurrence of generation, it is clear that for each generation (as well as for any other change which the generated thing undergoes afterwards) there is a locomotion that occurs earlier than, i.e. is prior in time to, this generation (and the other changes). The fact that change in place has temporal priority in this way again made clear that of the different kinds of change locomotion alone can be considered an appropriate candidate for the change that is directly caused by the first unmoved mover.

The discussion of the last of the five arguments showed that locomotion also has priority in essence over the other kinds of change. As we have seen, Aristotle shows this by means of two sub-arguments, the first presenting reasons for the claim that locomotion has this kind of priority with respect to perishable self-movers, and the second proving the same with respect to eternal things that function as causes of change for other things. In examining the first sub-argument it became clear that locomotion has priority in essence in such living things, since their being able to move themselves as a whole is more specific to their being what they are in the full sense as members of a certain species than their having alteration or growth and diminution. That locomotion is last in the process of such beings' generation therefore turned out to be an expression of this kind of priority. As we have seen, the second sub-argument then made use of the fact that locomotion in contrast to the other three kinds of change in no way entails its subject's departing from what it is, i. e. it preserves its subject's essence best. Because 
it was shown that eternal things can only change with respect to place for precisely the reason that they must not undergo a change with respect to their being, it became clear that locomotion is prior in essence with respect to eternal things as well. This is of special importance since it again shows that locomotion alone can be the change that is caused directly by the first unmoved mover, since the eternal primum mobile can only change with respect to this weakest kind of change, which at the same time is of such a nature that it can be undergone eternally without thereby posing any threat to its subject's essence. The conclusion, therefore, was that Aristotle, by making these arguments, accordingly shows that locomotion is prior in essence to all of the other types of change with respect to both perishable and eternal things and insofar as it is prior in this way in all things that (apart from the unmoved mover) may serve as causes of change in the cosmos.

As my discussion of the five arguments has shown, Aristotle is therefore finally able to conclude that these arguments have made clear that of the four kinds of change, i.e. that with respect to quality, quantity, substance, and place, the last, that is, locomotion must be the primary one. ${ }^{1}$ But from a broader perspective, these five arguments thereby presented reasons for the claim that the only appropriate candidate for the eternal change which is caused by the first unmoved mover and on which all other changes in this sense depend must be locomotion. For, as I have shown, and as indeed also became clear especially with respect to the last three arguments, Aristotle, in determining which is the primary kind of change and in showing that this is change in place, is interested primarily in making clear that the type of change that can be eternal is also primary in the respects necessary for being the change which has its direct source in the first unmoved mover. ${ }^{2}$

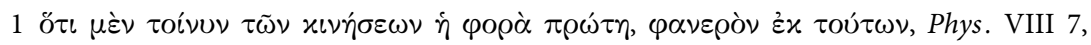
261a27-28: "That therefore of the changes locomotion is primary is clear from these [presented arguments]."

2 That this is what Aristotle has in mind here is also clear from the remark that follows right after the presentation of the fifth argument in 261a23-26. What these lines say, in my view, is that because of the fact that locomotion is primary in the different ways, it is also clear that-due to its primacy-it is the kind of change which self-movers like animals cause, which is in perfect accordance with VIII 6, 259b1-16, where the latter claim was made and shown to be true. Although, as I am well aware, this passage may be and in fact usually is taken to be yet another argument for locomotion's priority, I do not think that this is the case. Firstly, in contrast to most of the other arguments, no reference to the priority claim is made in these four lines. But most of all this 'argument' neither fits into the line of thought that connects the last three arguments, namely the reference to the first eternal change, nor to their arrangement as it is outlined in 260b16-18, since it cannot be read as an argument for locomotion's priority in essence. 
But one may wonder whether each of the five arguments is actually necessary for Aristotle to reach his goal of showing that locomotion must be the kind of change that is directly caused by the first unmoved mover. Some of these arguments, for instance the first and the fourth, clearly deal with possible objections that may be raised against the priority claim and, thus, certainly fulfil an important function: for, as I pointed out in the beginning, Aristotle needs to be able to provide an appropriate answer to these objections in order for the theory developed in the first six chapters of Phys. VIII, namely the one about the eternity of change and the necessary existence of a first unmoved mover that is source of all change in the cosmos, to hold. The arguments, which are not to be read as answers to possible objections, for instance the third and the last argument, are nonetheless necessary in order for Aristotle to present a full and consistent theory that as a whole makes it plausible that locomotion alone can be the change which the first unmoved mover imparts.

The first three arguments taken as a whole, as we have seen, show that locomotion is ontologically prior in several different respects. This conclusion made it clear not only that the other kinds of change ontologically depend on locomotion in various ways-and most importantly that, as the third argument pointed out, all changes can be traced back to the first locomotion that is caused directly by the first unmoved mover-but also that locomotion per se does not presuppose any of the other kinds of change in any of the three senses discussed in the first three arguments. All this must be shown to be true of the first change that has its direct source in the first unmoved mover; for, if this change depended on or presupposed any other kind of change, it could not possibly be the first change. But by means of these arguments Aristotle at the same time ruled out that any of the other three kinds of change is a possible candidate for the primary kind of change that the first unmoved mover causes directly, for all three, unlike locomotion, presuppose the occurrence of another change. Thus, these three arguments showed that locomotion as the primary change is the most fundamental or important, a conclusion which also finds its expression in the fact that, as Aristotle puts it in Phys. IV, change in place is also the "most common sort of change, and that which most properly so called". ${ }^{3}$ This is of utmost importance, too, since if one of the four kinds of change is fundamental to the other kinds of change, then the change that has its origin in the first principle of all change in the cosmos to which Aristotle's discussion of Phys. VIII leads must be of this kind. But showing that locomotion is necessary for any other type of change to occur, and in this sense is indeed

3 Phys. IV 1, 208a31-32 (Transl. Morison (2002), 11). As I pointed out before, something similar is said in Phys. VIII 9, 266a1-2. For more on the connection between the fact that

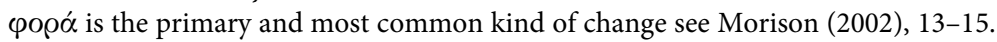


the most fundamental change, does not suffice to fully explain how it is that the primary change is locomotion-especially if one bears in mind that, as we have seen, there are further possible objections against this claim, but also that one needs to spell out in what way this claim fits with other Aristotelian assumptions about the cosmos as for instance the one that eternal things like the heavenly bodies may only change in a special way.

As I have pointed out, one of the aforementioned objections is discussed in the fourth argument, which showed that the fact that locomotion with respect to the development of certain living beings is temporally posterior to the other three kinds of change fits very well with the priority claim. Yet, apart from that, the fourth argument first of all made clear that locomotion is prior to the other kinds of change in the sense which, as Aristotle points out in Cat. 12, is the most fundamental sense of priority, namely temporal priority. ${ }^{4}$ This must be shown to be true, for one is right to expect that the first unmoved mover and the motion he causes directly is prior to the other types of change in the temporal sense as well. Or to put it the other way around, if locomotion did not have temporal priority over the other kinds of change in the stated sense, then it could not possibly be the change that is caused by the first unmoved mover, because this change must precede all other changes in time, which is also why it is essential for Aristotle to find a satisfying answer to the aforementioned objection.

With respect to the goal of presenting a full and consistent theory that as a whole makes it plausible that locomotion alone can be the change which the first unmoved mover imparts, the most important and powerful of the five arguments certainly is the fifth one; it not only makes clear that locomotion in general has essential priority in all things that (apart from the unmoved mover) are responsible for the causation of change in the universe, and that locomotion thus plays an extraordinary role in this context, but at the same time shows that change in place, due to its special nature, is the perfect (and indeed only) candidate for being the one eternal change that the outermost heavenly sphere undergoes, and that is directly caused to move by the first unmoved mover. For, again, of the four different kinds of change, locomotion alone leaves its subject's essence completely untouched. This makes it possible that the outermost sphere and the other heavenly bodies, which in virtue of being eternal cannot change with respect to their being or essence in any way whatsoever, nonetheless may change in the manner necessary for there to be change in the cosmos in the way we experience it day by day and even to do so eternally, namely by undergoing the type of change that, although being the most fundamental

4 In Cat. 12, 14a26-27, Aristotle states that of the different senses of priority, something $x$

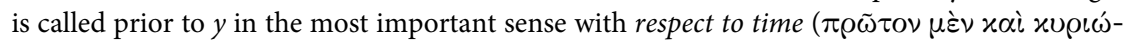

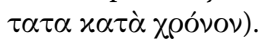


one, is at the same time the weakest kind of change in another respect, i. e. change in place. For only locomotion leaves its subject's essence completely untouched and is of such a nature that it can be engaged in eternally without thereby posing any threat to its subject's essence. In contrast to change in quality and quantity, which would entail their subject's corruption, if they carried on without limit-not to speak of generation and corruptionlocomotion does not affect its subject's being in any way and therefore not even in principle does it entail any substantial change. Thus, if there were no such change as locomotion, then Aristotle's causal explanation of change in the cosmos would collapse. In the sense at issue, change in place is both the only, and at the same time the ideal, candidate for the change that has its direct source in the first principle of all change, the first unmoved mover, and that the outermost sphere and the other eternal heavenly bodies always have been and always will be undergoing.

But one needs to be clear about the fact that Aristotle in the discussion stated in Phys. VIII 7 certainly is not aiming at presenting a deductive proof for the claim that the kind of change which has its direct source in the first unmoved mover can only be locomotion. Rather, Aristotle here is giving reasons that help us understand why this is the case and how this fits with empirical facts and our assumptions about the cosmos. This, however, is absolutely appropriate for a dialectical inquiry, which is what the discussion in Phys. VIII 7 should be considered. For, as I stated in the introductory part of my investigation, Book VIII, as a part of the Physics lays out the fundamental principles of the science of nature that do not admit of proof. This is exactly what Aristotle is doing in Phys. VIII when he spells out the implications of there being change in the cosmos, and in so doing shows that, first of all, change must exist eternally, that all changes in the cosmos may be traced back to a first principle of change, i.e. the first unmoved mover, and that the change primarily caused by this first source is a special kind of locomotion.

Although showing that locomotion is the primary kind of change is an essential part of providing the needed justification for the claim on which the theory developed in Phys. VIII 1-6 is based, this task as a whole is not completed after the presentation of the five arguments. For, in order to complete it, two more steps are necessary. First, Aristotle still needs to show that an eternal change is at all possible, and which kind of change this could be. I have presented parts of this discussion, which is stated in Phys. VIII 78 (261a28-265a12), since the last of the three arguments for locomotion's ontological priority, as we have seen, presupposes that there is a kind of change that may form one single non-composed change that is eternal. Aristotle shows that this change can only be a special kind of locomotion, namely circular locomotion. Therefore, in order to make sure that the one single change which is eternal is also the one which is primary, i.e. fulfils 
the other necessary criteria for being the change that is directly caused by the first unmoved mover, Aristotle also needs to show that circular locomotion is primary among the different kinds of change in place in the required respects. Indeed, Aristotle presents arguments for this claim in Phys. VIII 9. ${ }^{5}$ The upshot of the discussion is that there in fact is a change that as one single change can be eternal and that in all important respects has primacy over the other kinds of change. This change, which is the only possible candidate for the change that is directly caused by the first unmoved mover, is circular locomotion, the change which according to Aristotle the outermost heavenly sphere undergoes. Therefore, the existence of this special motion is correctly presupposed in the discussion of Phys. VIII 1-6. Against this background, Aristotle, thus, may be said to be successful in establishing a theory that accounts for the existence of change by making it possible to trace each single change back to its ultimate source, the first unmoved mover, and to the change that is caused by this source. In this way Aristotle shows that all change is in fact embedded in the larger framework of causal relations of the cosmos. But by successfully establishing this account he also makes clear that the theory he developed about change in the previous books of the Physics and which, as we have seen, is made use of extensively in Phys. VIII, may be applied successfully to the whole of the cosmos in order to give a final causal explanation of the occurrence of change as we observe it day by day, and in this sense is compatible with a consistent explanation of the empirical fact that there is change. My investigation, thus, in general has shed much light on the nature of change, in particular by spelling out the consequences that follow from the existence of change in the cosmos, which again strongly indicates that Physics VIII (together with Books V and VI) can only have belonged to the formerly independent treatise On Change, as was claimed in the introduction of my investigation.

Apart from that, however, the discussion of the arguments for the primacy of locomotion also showed a number of other important things. As I also mentioned in the introduction, the claim about the priority of locomotion is made in other works of Aristotle's as well and for instance plays an important role in the discussion in GC II 10, yet without the reasons for this claim being presented there. The systematic and successful argumentation for the priority claim provided in Phys. VIII 7 therefore provides the necessary grounds on which this claim may be made in other contexts and without which the assumption in all the stated contexts would not be justified.

5 The reasons that are presented in Phys. VIII 9 for the claim that circular locomotion is the primary kind of locomotion are that it is the only change in place that may be eternal and at the same time complete in itself ( $\tau \varepsilon \dot{\varepsilon} \lambda \varepsilon\llcorner O \varsigma)$ and simple $(\dot{\alpha} \pi \lambda \tilde{\eta})$, and (2) in its occurrence is absolutely regular ( $\left.\delta \mu \alpha \lambda \eta^{\prime}\right)$. Aristotle here again is clearly making use of further criteria for the unity of change that are presented in Phys. V 4. 
But my study also helps provide a deeper understanding of Aristotle's general theory of change. The discussion of the different arguments for instance helped spell out specific characteristics of the four kinds of change that to my knowledge have not been made explicit so far, but that, as we have seen, play a crucial role in Aristotle's general theory of change and may be of importance for understanding other still unclear passages in Aristotle. For instance, it became clear that Aristotle, contrary to what one might think, holds the view that even the non-substantial changes of alteration, growth, and diminution, in a certain sense may entail a change in their subject's substance, while locomotion is the only type of change for which this is not the case, since locomotion per se, as I pointed out, does not change the inner structure of its subject in any way whatsoever.

In addition, more light was also shed on the relation in which the different changes may stand to each other. Change in place as the primary kind of change, for example, does not entail the involvement of any of the other kinds, while the other kinds always involve an accompanying locomotion in some sense. One might also conclude from my discussion that processes of alteration are necessary constituents of growth, while the latter again may be considered as an essential part of the coming to be of things. This might imply that Aristotle thinks that changes that according to his own account would form a unity in the strict sense, in a certain respect nonetheless need to be considered as consisting of other changes as well, though without being reducible to these constituents.

Aristotle, in discussing the priority of locomotion, therefore, not only establishes that his theory about the eternity of change and the first unmoved mover as the ultimate source of all change is indeed justified, but obviously also continues to further develop and refine the general theory of change on which the whole of Physics V-VIII works. An essential part of this theory, as my investigation has made clear, is that change in place, i. e. locomotion, as the most fundamental and important type of change, has a special place among the different kinds of change and that this is what makes it the only appropriate candidate for the change that the first unmoved mover imparts, and that is responsible for all change in the cosmos. 


\section{Bibliography}

\section{Editions, Translations, Commentaries}

Ackrill, J.L. (1963). Aristotle. Categories and De Interpretatione, Oxford.

Balme, D.M. (1992). Aristotle. De Partibus Animalium I and De Generatione Animalium I (with passages from II. 1-3), Oxford.

Barnes, J. (ed.) (1984). The Complete Works of Aristotle, Princeton.

Blackwell, R. J. / Spath, R. J. / Thirlkel, W.E. (1999). Aquinas. Commentary on Aristotle's Physics, Notre Dame/Indiana.

Buchheim, T. (2010). Aristoteles. Über Werden und Vergehen, Berlin.

Bywater, I. (1894). Aristotelis Ethica Nicomachea, Oxford.

Carteron, H. (1952). Physique. I-IV, Paris.

-.(1956). Physique. V-VIII, Paris.

Conway, P. / Larcher, F. R. (1965). Aquinas. On Generation and Corruption. Unpublished but circulated in photocopied form, http://www.josephkenny.joyeurs.com/CDtexts/ GenCorrup.htm (09/01/2011).

Diels, H. (1882). Simplicii in Aristotelis Physicorum Libros Quatuor Priores Commentaria (Commentaria in Aristotelem Graeca. Vol.IX), Berlin.

Diels, H. (1885). Simplicii in Aristotelis Physicorum Libros Quattuor Posteriores Commentaria (Commentaria in Aristotelem Graeca. Vol.X), Berlin.

Drossaart Lulofs, H.J. (1965). Aristotelis De Generatione Animalium, Oxford.

Fobes, F.H. (1910). Aristotelis Meteorologicorum Libri Quattuor, Cambridge/Mass.

-. (1956). Averrois Cordubensis. Commentarium Medium in Aristotelis De Generatione et Corruptione Libros, Cambridge/Mass.

Graham, D. W. (1999). Aristotle. Physics Book VIII, Oxford.

Hagen, C. (1994). Simplicius. On Aristotle Physics 7, London.

Hardie, R. P. / Gaye, R. K. (1984). Physics. In: Barnes (1984). Vol. 1, 313-446.

Heiberg, I. L. (1894). Simplicii in Aristotelis De Caelo Commentaria (Commentaria in Aristotelem Graeca. Vol. VII), Berlin.

Hussey, E. (1983). Aristotle. Physics Books III and IV, Oxford.

Joachim, H.H. (1922). Aristotle. On Coming-to-be \& Passing-away, Oxford.

Kirwan, C. (1993). Aristotle. Metaphysics Books $\Gamma, \Delta$ and E. 2nd ed., Oxford.

Konstan, D. (1989). Simplicius. On Aristotle Physics 6, London.

Kurland, S. (1958). Averroes on Aristotle's De Generatione et Corruptione. Middle Commentary and Epitome, Cambridge/Mass.

Lennox, J. G. (2001). Aristotle. On the parts of animals, Oxford.

Lettinck, P. / Urmson, J. O. (1994). Philoponus. On Aristotle Physics 5-8 with Simplicius, on Aristotle on the void, London.

Louis, P. (1956). Aristote. Les parties des animaux, Paris.

McKirahan, R. (2001). Simplicius. On Aristotle Physics 8.6-10, London.

Minio-Paluello, L. (1949). Aristotelis Categoriae et Liber De Interpretatione, Oxford.

Moraux, P. (1965). Aristote. Du Ciel, Paris. 
Nussbaum, M.C. (1985). Aristotle's De Motu Animalium: Text With Translation, Commentary, and Interpretive Essays, Princeton.

Peck, A. L. (1963). Aristotle. Generation of Animals, Cambridge/Mass.

Pickard-Cambridge, W. A. (1984). Topics. In: Barnes (1984). Vol. 1, 167-277.

Rashed, M. (2005). Aristote. De la génération et la corruption, Paris.

Ross, W.D. (1924). Aristotle's Metaphysics. A Revised Text with Introduction and Commentary. 2 Vols., Oxford.

-. (1936). Aristotle's Physics. A Revised Text with Introduction and Commentary, Oxford.

S. Thomae Aquinatis. (1958). In Aristotelis Libros De Caelo et Mundo. De Generatione et Corruptione. Meteologircorum Expositio, Romae.

-. (1965). In Octo Libros Physicorum Aristotelis, Romae.

Sachs, J. (1995). Aristotle's Physics. A Guided Study, New Brunswick.

Schenkl, H. (1900). Themistii in Aristotelis Physica Paraphrasis (Commentaria in Aristotelem Graeca. Vol.V.2), Berlin.

Stocks, J.L. (1984): On the Heavens. In: Barnes (1984). Vol. 1, 447-511.

Strohm, H. (1970). Aristoteles. Meteorologie, Berlin.

Theiler, W. (1959). Aristoteles. Über die Seele, Berlin.

Todd, R. B. (2008). Themistius. On Aristotle Physics 5-8, London.

Vitelli, H. (1887). Philoponi in Aristotelis Physicorum Libros Tres Priores Commentaria (Commentaria in Aristotelem Graeca. Vol.XVI), Berlin.

-. (1888). Philoponi in Aristotelis Physicorum Libros Quinque Posteriores Commentaria (Commentaria in Aristotelem Graeca. Vol.XVII), Berlin.

-. (1897). Philoponi in Aristotelis Libros De Generatione et Corruptione Commentaria (Commentaria in Aristotelem Graeca. Vol.XIV), Berlin.

Wagner, H. (1967). Aristoteles. Physikvorlesung, Berlin.

Williams, C. J.F. (1982). Aristotle's De Generatione et Corruptione, Oxford.

-.(1999). Philoponus. On Aristotle's On Coming-to-Be and Perishing 1.1-5, Ithaca.

Zekl, H.G. (1987). Aristoteles' Physik. Bücher I (A)-IV( $\Delta$ ), Hamburg.

-.(1988). Aristoteles' Physik. Bücher V (E)-VIII( $(\Theta)$, Hamburg.

\section{Other Literature}

von Arnim, H. (1931). Die Entstehung der Gotteslehre des Aristoteles, Wien.

Barnes, J. / Griffin, M.T. (eds.) (1997). Philosophia Togata. II. Plato and Aristotle at Rome, Oxford.

Beere, J. (2003). Counting the Unmoved Movers: Astronomy and Explanation in Aristotle's Metaphysics XII. 8. Archiv für Geschichte der Philosophie 85, 1-20.

-. (2009). Doing and Being: An Interpretation of Aristotle's Metaphysics Theta, Oxford.

Bodnàr, I. (2010). Aristotle's Natural Philosophy. In: Zalta, E. N. (ed.): The Stanford Encyclopedia of Philosophy (Spring 2010 Edition), http://plato.stanford.edu/archives/spr2010/ entries/aristotle-natphil/ (09/01/2011).

Bonitz, H. (1870). Index Aristotelicus, Berlin.

Brunschwig, J. (1991). Qu'est-ce que "La Physique" d'Aristote? In: De Gandt, F. / Souffrin, P. (eds.): La Physique d'Aristote et les conditions d'une science de la nature, Paris, 11-40.

Cleary, J. (1988). Aristotle on the many senses of priority, Carbondale.

Code, A. (2004). On Generation and Corruption I.5. In: Mansfeld, J. / Haas, F. A. J. de (eds.): Aristotle's On Generation and Corruption I, Oxford, 171-193.

Drossaart Lulofs, H. J. (1969). Nicolaus Damascenus on the Philosophy of Aristotle, Leiden. 
Denniston, J.D. (1954). The Greek Particles. 2nd ed., Oxford.

Düring, I. (1957). Aristotle in the Ancient Biographical Tradition, Göteborg.

Flashar, H. (2004). Die Philosophie der Antike. Vol.3: Ältere Akademie, Aristoteles, Peripatos, Basel.

De Haas, F. A. J. / Mansfeld, J. (eds.) (2004). Aristotle's On Generation and Corruption I, Oxford.

Hankinson, R. J. (1995). Science. In: Barnes, J. (ed.): The Cambridge Companion to Aristotle, Cambridge.

Henry, P. / Schwyzer, H.-R. (eds.) (1951). Plotini opera. Vol. 1., Leiden.

Jaeger, W. (1955). Aristoteles. Grundlegung einer Geschichte seiner Entwicklung. 2nd ed., Berlin.

Kupreeva, I. (2005). Aristotle on Growth: A Study of the Argument of On Generation and Corruption I 5. Apeiron 38, 103-160.

Lang, H.S. (1981). Aristotle's Immaterial Mover and the Problem of Location in "Physics" VIII. The Review of Metaphysics 35, 321-335.

Liddell, H.G. / Scott, R. / Jones, H.S. (1996). A Greek-English Lexicon. With a Revised Supplement, Oxford.

Makin, S. (2003). What does Aristotle mean by Priority in Substance? Oxford Studies in Ancient Philosophy 24, 209-238.

Mansion, A. (1946). Introduction à la Physique Aristotélicienne. 2nd ed., Paris.

Moraux, P. (1973). Der Aristotelismus bei den Griechen. Von Andronikos bis Alexander von Aphrodisias, Berlin.

Morison, B. (2002). On Location. Aristotle's Concept of Place, Oxford.

-. (2004). Self-motion in Physics VIII. In: Laks, A. / Rashed, M. (eds.): Aristote et le mouvement des animaux: dix études sur le "De motu animalium", Villeneuve-d'Ascq, 67-79.

-. (2010). Did Theophrastus Reject Aristotle's Account of Place? Phronesis 55, 68-103.

Panayides, C. Y. (1999). Aristotle on the Priority of Actuality in Substance. Ancient Philosophy 19, 327-344.

Peramatzis, M. (2011). Priority in Aristotle's Metaphysics, Oxford.

Rapp, C. (2007). Aristoteles zur Einführung. 3rd ed., Hamburg.

Smyth, H.W. (1959). Greek Grammar, Cambridge/Mass.

Solmsen, F. (1960). Aristotle's System of the Physical World. A Comparison with his Predecessors, Ithaca.

-. (1961). Misplaced Passages at the End of Aristotle's Physics. The American Journal of Philology 82, 270-282.

Wardy, R. (1990). The Chain of Change, Cambridge.

Waterlow, S. (1982). Nature, Change, and Agency in Aristotle's Physics. A Philosophical Study, Oxford.

Wehrli, F. (ed.) (1955). Die Schule des Aristoteles. Texte und Kommentar. Heft VIII. Eudemos von Rhodos, Basel.

Wieland, W. (1992). Die aristotelische Physik. Untersuchungen über die Grundlegung der Naturwissenschaft und die sprachliche Bedingungen der Prinzipienforschung bei Aristoteles. 3rd ed., Göttingen.

Witt, C. (1994). The Priority of Actuality in Aristotle. In: Charles, D. / Gill, M. L. / Scaltsas, T. (eds.): Unity, Identity, and Explanation in Aristotle's Metaphysics, Oxford, 215-228. 


\section{List of Abbreviations}

$\begin{array}{ll}\text { Cael. } & \text { De Caelo } \\ \text { Cat. } & \text { Categoriae } \\ \text { De An. } & \text { De Anima } \\ \text { EN } & \text { Ethica Nicomachea } \\ \text { GA } & \text { De Generatione Animalium } \\ \text { GC } & \text { De Generatione et Corruptione } \\ \text { HA } & \text { Historia Animalium } \\ \text { IA } & \text { De Incessu Animalium } \\ \text { In Cael. } & \text { In Aristotelis de Caelo Commentaria } \\ \text { In Gen. } & \text { In Aristotelis Libros De Generatione et Corruptione Commentaria } \\ \text { In Phys. } & \text { In Aristotelis Physicorum Libros / In Aristotelis Physica Paraphrasis } \\ \text { LSJ } & \text { Liddell / Scott / Jones (see Bibliography p.222) } \\ \text { MA } & \text { De Motu Animalium } \\ \text { Met. } & \text { Metaphysica } \\ \text { Mete. } & \text { Meteorologica } \\ \text { PA } & \text { De Partibus Animalium } \\ \text { Phys. } & \text { Physica } \\ \text { Top. } & \text { Topica }\end{array}$




\section{Index Locorum}

Thomas Aquinas

\section{In Gen.}

L.I, 1.XI, 85: 76 n. 13

In Phys.

L.VIII. l.VIV, 1086: 39 n. 88

L.VIII. 1.XIV, 1089: 72 n. 2, 90 n. 39

L.VIII. 1.XIX, 1091: 116 n. 2, 122 n. 19

L.VIII. 1.XIX, 1093: 150 n. 19

L.VIII. 1.XIX, 1094: 208 n. 87

\section{Aristotle}

Cael.

270a12-35: 146 n. 3, 209 n. 88

272a28-31: 21

275b21-3: 21

281b25-282a1: 146

299b7-9: 102

Cat.

8b26-9a10: 106

9a16: 103 n. 83

14a26-27: 216 n. 4

14a26-29: 147 n. 9

14a29-35: 68 n. 79

De An.

403a3-25: 107 n. 99

403a31-b1: 107

406b11-15: 193 n. 60

413a20-21: 176 n. 24

413a20-28: 56 n. 47

413a22-25: 176 n. 24

413a25-b1: 60

413a31-b1: 176

413b11-13: 56 n. 47,176 n. 24, 177

414a31-32: 177 n. 30

414b4: 176 n. 27

415a1-3: 180

415a22-26: 177

415b21-23: 176

415b24: 178

415b26-27: 177 416a15-18: 56 n. 43

416a19-b31: 46

416b6-7: 47, 54 n. 39

427b11-12: 176 n. 27

432b8-11: 177

433b27-30: 180

433b31-434a2: 174 n. 20, 176 n. 27

434a5-7: 180 n. 42

EN

1128b10-15: 179 n. 38

1128b13-14: 107

GA

715a8-11: 94 n. 54, n. 56, 105

719b2: 196 n. 66

729a10-14: 197 n. 68

739b20-26: 197 n. 68

765b10-11: 196 n. 66

765b15-16: 196

775a11-13: 92 n. 48

GC

315b24-317a17: 84

317a12-13: 92

317a12-17: 92 n. 45

317a17-18: 92, 94

317a20-21: 95

317a23-24: 93

317a27-29: 93, 112

317a30-31: 95

317b1-13: 91

319b2: 76 n. 12

319b8-12: 47

319b10-12: 103 n. 83

319b11-12: 49 n. 23,100 n. 70

319b12-13: 106

320a8: 45 n. 4

320a8-10: 48

320a13-14: 54 n. 39

320a17-19: 75

320a20-25: 76

320a20-27: 64 
320a21-22: 78

320a22-25: 80

320a25-26: 64

321a3-5: 48

321a18-21: 78

321a18-22: 46

321a27: 63

321b12-13: 48

321b22-24: 46

321b28-29: 88

321b35-322a3: 46

322a1-3: 46, 47 n. 16

322a $4-5: 46$

322a5-6: 46, 47

322a24-26: 64

322b8: 94, 112

328b31-33: 94

328b33-329a5: 90

329a5-8: 94

329a35-b1: 92 n. 49

329b7-10: 104

329b18-20: 104

329b22-24: 92 n. 49

329b32-34: 104

329b32-330a12: 105 n. 91

330a5-6: 105

330a24-29: 104

330b1-9: 108

330b3-7: 93

331a9-10: 50 n. 29, 104

331a23-b11: 105

331a29-32: 105

331a32-36: 108

334b31-32: 94 n. 54, 105

336a16-18: 155

336a18-20: 11 n. 5

336a25-26: 155 n. 34

336a31-b9: 156 n. 39

336b17-18: 156

336b26-28: 127 n. 36

337a17-20: 156 n. 40

337a21-22: 156

338a17-b5: 156

339a36-b2: 92 n. 49

HA

521a17-18: 196 n. 66

$I A$

704b12-18: 127 n. 36

704b15: 127
$M A$

700a6-12: 57

700a16-17: 57

700b6: 57

700b11-12: 57, 207 n. 86

Met.

984a13-16: 90

1018b14-19: 147

1019a1-4: 68 n. 79, 139 n. 70

1020a7-11: 54

1041b13-14: 112

1049b4-5: 171

1050a4-7: 168

1050a4-9: 167

1050a7-9: 167 n. 7

1069b25-26: 146 n. 3

1071a13-17: 155

1072b8-9: 11 n. 5

1073a12: 11 n. 5

1073a22-b1: 156 n. 40

Mete.

340a8-10: 92 n. 48, n. 50, 109 n. 104

340a29-30: 92

340b3: 92, 92 n. 50, 111 n. 108

341a4: 92 n. 48, n. 50, 111 n. 108

341a9-10: 92 n. 48, n. 50, 111 n. 108

342b16-17: 92, 111

344b20-24: 92 n. 48

346b20-23: 156 n. 38

348b10-12: 111 n. 108

371a27: 111

372b22-24: 111 n. 108

372b30-33: 111 n. 108

379b12: 196

389b24-29: 94 n. 56

$P A$

640b1-4: 170 n. 11

641b4-8: 57 n. 48,178

641b7: 179

650a2-6: 47

650a2-7: 196 n. 66

658a23-24: 127 n. 36

Phys.

187a29-31: 90

192b8-15: 58 n. 53 
192b9-13: 25

192b13-15: 56, 177 n. 28, 196

192b13-23: 25

192b20-2: 21

194a18-21: 87, 95

194b13: 155

200a12-13: 25

200a12-15: 25

200a25: 26

200b12-13: 21

200b12-25: 25

200b15-16: 26

200b24-25: 26

200b25-201a9: 189

200b26-201a9: 86 n. 31

200b28: 86, 189 n. 50

200b33-34: 190

200b33-201a1: 10

201a8-9: 189 n. 50

202a7-8: 21

204a34-206a8: 21

206a16: 134 n. 57

206a25-25: 152 n. 26

208a31-32: 10 n. 3, 215

210b24-27: 50 n. 29

210b25-26: 106 n. 97

211a2: 77 n. 16

211a14-15: 75

211a15-17: 75

212b2-3: 101 n. 76

214b1-2: 109 n. 103

217b11-12: 102

217b16-18: 102

217b22-24: 101

220b26-201a9: 56

224a21-22: 27

224a21-24: 199

224a23-26: 77, 82

224a26-28: 199

224a35: 124 n. 24

224b1: 131 n. 47

224b8-10: 191

224b10-11: 26, 28

225a12-20: 91 n. 42, 191

225a17-18: 190

225a34-b3: 10 n. 1

225a34-b5: 187, 191

225b5-9: 56

226a23-25: 10 n. 1

226a29-32: 48

226a31-32: 200, 204 226b1-3: 47

226b8-10: 10 n. 1

226b16-17: 28

226b20-227a7: 51

226b34-227a4: 121

227a11-12: 119 n. 11

227a17-22: 121 n. 16

227b23-26: 124

227b29-30: 124

227b30-31: 124

227b31-228a1: 82, 124

228a1-2: 124

228a20: 119

228a21-22: 82, 124

228a27-28: 125

228a29-30: 125 n. 32

228a31-b10: 124

229a5-6: 121 n. 17

229a30-229b10: 133 n. 54

229b6-10: 135

231a22: 119

231a23: 121

231b15-16: 119

233a31-4: 21

240a29-b7: 79 n. 21

241a17: 131 n. 47

241a26-28: 131

241a26-b20: 29

241a33-b2: 55, 200, 204

241b18-20: 29

241b34-35: 50

242a26-b11: 37

243a11-244b2: 51 n. 32

243a34-35: 51 n. 32

243a39-40: 10

243b7-12: 96

244b2-5: 50

244b2-245a10: 50 n. 28

245a10-11: 50

245a11-16: 51 n. 32

245b3-246a9: 195

246a4-9: 195, 196 n. 65

248a6-9: 195

251a8-10: 21, 26

252b5-6: 32 n. 67, 116

252b7-12: 29

252b9-10: 131

252b9-12: 37

252b9-13: 137

252b9-28: 32

252b10: 131 n. 47 
252b10-12: 37

252b17-28: 60-61

253a1-2: 37

253a7-21: 60-61

253a14-15: 62

253a23-b2: 32

253a32-b2: 32 n. 63

253b2-6: 32

253b7-9: 21

254a27-30: 32 n. 63

254a35-b4: 32, 33

254b4-6: 33, 35

255a5-7: 58

255b29-31: 58

256a2-3: 50

256a3: 33

256a4-21: 52

256a13-21: 58, 62 n. 65

256b1-3: 58, 62 n. 65

258a1-2: 33

258b4-9: 33

259a6-20: 33, 52

259a10-12: 127 n. 36

259a13-20: 33, 37, 147

259a15-18: 122

259a16-18: 122 n. 20

259b1-16: 214 n. 2

259b1-20: 60-61, 66

259b6-7: 62 n. 64

259b11-13: 65

259b32-260a10: 140

260a1-5: 154

260a5-10: 155

260a11-19: 33, 35

260a17-19: 33

260a20-23: 37

260a20-26: 34-35

260a20-261a26: 39

260a21-22: 35

260a21-23: 128

260a22-23: 35

260a23-24: 35

260a23-26: 39 n. 99

260a26-29: 10, 44, 45, 58, 66, 67

260a26-31: 53

260a26-b7: 12, 42

260a29-30: 44, 68

260a29-32: 55

260a30-33: 45

260a34: 47

260b1: 50 260b1-3: 51

260b1-5: 50-51

260b2: 50

260b4-5: 50, 68

260b5-7: 66-67

260b7-15: 12, 71, 98

260b8: 103

260b8-10: 100

260b11: 110

260b11-13: 89, 96

260b13-15: 74

260b15-19: 10, 167 n. 8

260b15-29: 12

260b16-18: 214 n. 2

260b16-19: 67

260b17-19: 68, 137

260b19-29: 115

260b20-21: 118

260b21-22: 119

260b22-24: 127

260b23-25: 128

260b25-26: 116, 127, 128, 130, 139, 141

260b26-28: 141

260b26-29: 10

260b28-29: 141

260b29-30: 146, 209

260b29-261a12: 12, 144-145

260b30-32: 148, 165

260b30-33: 150 n. 19, 185

260b32-33: 68-69, 165

261a1: 151

261a1-2: 150-151

261a1-3: 158 n. 45

261a1-12: 150

261a2: 151 n. 23,157 n. 42

261a2-3: 151

261a3-5: 150

261a6: 151 n. 21

261a6-7: 152, 158

261a7: 151, 157-158

261a7-12: 161

261a7-265a12: 128-129

261a8: 161 n. 49

261a13: 174 n. 20

261a13-15: 167 n. 8

261a13-20: 164, 175

261a13-23: 13, 68 n. 68

261a14: 167

261a14-15: 172

261a14-19: 68-69

261a15-17: 171, 173 
261a15-18: 174 n. 20

261a19: 174 n. 20

261a19-20: 167 n. 8, 186

261a19-23: 186-187

261a20-23: 146

261a21-22: 189

261a21-23: 201

261a22: 188 n. 49

261a23-26: 214 n. 2

261a27: 10

261a27-28: 214

261a27-31: 130 n. 46

261a28-265a12: 217

261a31-261b3: 52 n. 35

261a32-33: 132, 149

261a34-36: 132

261b3-15: 133 n. 53

261b5-7: 132

261b15: 132 n. 51

261b28-30: 134

261b28-265a12: 38 n. 87

261b32: 134

261b34-36: 135

261b36-262a5: 124

262a6-8: 135 n. 59

264a28-29: 132 n. 51

264b9-265a12: 135

264b10-11: 135

264b10-17: 136

264b17-18: 136

265a10-12: 137

265b17-32: 90

265b19-20: 97 n. 67

265b19-21: 90

265b30-31: 101

265b30-32: 90

266a1-2: 10 n. 3, 215 n. 3

266b25-7: 21

266b30-31: 101

267b20-2: 21

Top.

144b32: 206

144b37-145a1: 206

145a3-12: 193 n. 60

145a4: 204

Philoponus

In Gen.

71. 25-31: 76 n. 14

232. 9-12: 104 n. 87
In Phys.

2. 16-17: 22

895. 4-5: 36 n. 79

896: 72 n. 2,90 n. 39,101 n. 73

897. 17-18: 116 n. 2

897. 19: 122 n. 19

899. 18: 141 n.77

899. 24-25: 150 n. 19

899. 26-28: 155 n. 35

900. 6-8: 158 n. 48

900. 18-901. 3: 208 n. 87

Porphyry

Vit. Plot.

24. 6-11: 16 n. 6

Simplicius

In Cael.

226. 19-23: 23

In Phys.

6. 9-10: 17 n. 12

801. 14-16: 17 n. 12

802. 7-13: 22

923. 7-8: 18

923. 8: 17 n. 12

923. 9-11: 19

923. 11-16: 19

923. 16-924. 5: 21

924. 5-12: 21

924. 12-14: 21

924. 15-16: 20

924. 16-23: 22

1036. $8-17: 23$

1036. 11-15: 23

1037. $3: 24$

1037. 5-6: 15

1264. 23-27: 36 n. 79

1265. 16-20: 68 n. 79

1265. 17-19: 68 n. 80

1265. 26-28: 53 n 37

1265-1266: 51 n. 33

1266. 10-1267. $28: 90$ n. 39

1269. 6-10: 138 n. 68

1269. 10-12: 167 n. 8

1269. $15-16: 140 \mathrm{n} .74$

1269. 17-18: 116 n. 2

1269. 34-35: 128 n. 40

1270. $17: 150$ n. 19 
1270. $37: 155$ n. 35

1271. 23-28: 167 n. 8

1271. 30-31: 173 n. 18

1271. 35-37: 208 n. 87

1272. 23-25: 208 n. 87

\section{Themistius}

In Phys.

225. 11-16: 36 n. 79

225. 26-226. 7: 72 n. 2

226. 6-13: 150 n. 19 


\section{Index Nominum}

Alexander of Aphrodisias $23 \mathrm{n} .34$

Andronicus of Rhodes 16-24, 16 n. 5, 17 n. 11,19 n. 15

Aquinas 36 n. 79,39 n. 88,48 n. 20, 72 n. 2, 76 n. 13, 90-91 n. 39,116 n. 2, 122 n. 19, 147 n. 8,150 n. 19,208 n. 87

von Arnim, H. 16 n. 4, 32 n. 62

Averroes 76 n. 13, 80 n. 24

Balme, D.M. 178 n. 37, 179 n. 38, n. 39

Barnes, J. 16 n. 5-8, 17 n. 10-12, 19 n. 15, 20 n. 19, n. 22,22 n. 30,23 n. 33,26 n. 46

Beere, J. 167 n. 5, n. 6, 169 n. 10

Blackwell, R.J. 122 n. 19

Bodnàr, I. 152 n. 26

Bonitz, H. 127 n. 36

Brunschwig, J. 16 n. 5, 16-17 n. 9, 17 n. 1012, 18 n. 13,23 n. 33 , n. 34,24 n. 38,26 n. 46

Buchheim, T. 63 n. 67,76 n. 13, 95-96 n. 63, 104 n. 87,156 n. 39

Carteron, H. 26 n. 46, 37 n. 82,95 n. 62,96 n. 64

Cleary, J. 72 n. 2

Code, A. 54 n. 39, 75 n. 9, 76-77, 76 n. 13, 77 n. 15

Diogenes Laertius 24 n. 39

Damas 21, 21 n. 27, 23-24, 24 n. 38

Drossaart Lulofs, H.J. 22 n. 30

Düring, I. 16 n. 7, 17 n. 10, 19 n. 15, 24 n.39

Eudemus 18-24, 23 n. 34, 24 n. 38

Flashar, H. 16 n. 4, 32 n. 65

Graham, D.W. 15 n. 2, 16 n. 4, 30 n. 60, 36 n. 79, 48 n. 20, 53-54 n. 37, 72 n. 2, n. 3, 85-86 n. 30, 90-91, 90-91 n. 39, 91 n. 40, n. 41,101 n. 73, n. 75,102 n. 78, n. 81,110 n. 106,120 n. 14,141 n. 78, n. 79,147 n. 8 , 148 n. 12,150 n. 19,155 n. 35,161 n. 51 , 165-166 n. 4, 189-190 n. 53, 208 n. 87

Hagen, C. 15 n. 3

Hardie, R.P. / Gaye, R.K. 26 n. 46, 55 n. 42, 124 n. 29,152 n. 26,155 n. 35,192 n. 59

Hesychius 24 n. 39

Hussey, E. 26 n. 46,75 n. 8

Jaeger, W. 16 n. 4, n. 5, 23 n. 33, n. 34, 30 n. 60

Joachim, H.H. 54 n. 39, 76 n. 13, n. 14, 80 n. $24,95-96$ n. 63,160 n. 40

Kirwan, C. 147 n. 9

Konstan, D. 18 n. 14

Kupreeva, I. 76 n. 13

Lang, H.S. 32 n. 65

Lennox, J.G. 57 n. 48,178 n. 32

Makin, S. 167 n. 6

Mansion, A. 23 n. 34

Moraux, P. 20 n. 23

Morison, B. 10 n. 3, 17 n. 12,25 n. 40, 61 n. 62,62 n. $64,64-65,65$ n. 71,72 n. 2,89 n. $35,90-91$ n. 39,177 n. 28,215 n. 3

Neleus 17

Nicolaus of Damascus 22

Nussbaum, M.C. 57 n. 49, 58 n. 53

Panayides, C.Y. 167 n. 6

Peramatzis, M. 208 n. 87

Philoponus 22-24, 22 n. 31, 36 n. 79, 48 n. 20,72 n. 2,76 n. 13 , n. $14,90-91$ n. 39, 101 n. 73,104 n. 87,116 n. 2, 122 n. 19,141 n. 77,147 n. 8,150 n. 19,155 n. $35,158-$ 159 n. 48,208 n. 87

Pickard-Cambridge, W.A. 206 n. 84

Plato 68 n. 79 
Plutarch 16

Porphyry 16-17, 16 n. 6, 22, 22 n. 31

Ptolemy 24 n. 39

Rashed, M. 76 n. 13, 95-96 n. 63, 104 n. 87

Ross, W.D. 10 n. 1,11 n. 6,15 n. 1,16 n. 4 , 20-21, 20 n. 20 , n. 21,21 n. 26,22 n. 28 , n. 31,23 n. 34,24 n. 39,29 n. 56,31 n. 61, 36 n. 79,48 n. 20,72 n. 2, 90-91 n. 39,147 n. 8,150 n. 19,155 n. 33, n. $35,158-159$ n. 48,167 n. 7,168 n. 9,174 n. 20,179 n. 39

Simplicius 15 n., 17 n. 12, 18-24, 19 n. 15, 20 n. 23,22 n. 31,23 n. 32, n. 33, n. 34,36 n. 79,48 n. 20,51 n. $33,53-54$ n. 37,68 n. 79, n. 80,72 n. 2,76 n. $13,90-91$ n. 39 , 116 n. $2,128-129$ n. 40,138 n. 68,140 n. 74,147 n. 8,150 n. 19,155 n. $35,167-$ 168 n. 8,173 n. 18,208 n. 87

Solmsen, F. 32 n. 65, 90-91 n. 39, 208 n. 87

Stocks, J.L. 102 n.79

Strabo 16
Themistius 23 n. 34,36 n. 79, 72 n. 2, 147 n. 8,150 n. 19

Theophrastus 17-22, 89 n. 35

Wagner, H. 15 n. 2, 16 n. 4, n. 5, 17 n. 12, 23 n. 34,25 n. 40,26 n. 46,36 n. 79,48 n. 20 , 53-54 n. 37, 59, 59 n. 55, n. 56, 72 n. 2, 8586 n. 30, 90-91 n. 39,101 n. 73 , n. 75,116 n. 2,141 n. 78,147 n. 8,150 n. 19,189 n. $51,192-193,192$ n. 59, 208 n. 87

Wardy, R. 23 n. 35

Waterlow, S. 10 n. 1,23 n. 35

Wehrli, F. 21 n. 27,24 n. 38

Wieland, W. 25 n. 40, 156 n. 39, 197 n. 69

Williams, C.J.F. 63 n. 67, 64 n. 69,76 n. 13, n. 14,95 n. 63,104 n. 87

Witt, C. 167 n. 6

Zekl, H.G. 16 n. 4, 26 n. 46, 48 n. 20, 72 n.2, 85-86 n. 30, 90-91 n. 39, 101 n. 73, n. 75, 158-159 n. 48,174 n. 20

Zeno 28, 36, 120, 137 n. 67, 211 


\section{Index Rerum}

aggregation \& segregation (diakrisis \& sugkrisis) 71, 89-98, 109-112

Aristotelian examples of 92

mixture and 94, 112

relation to generation \& corruption $89-98$

air, see elements

alloiōsis, see alteration

alteration (alloiōsis) 49-53, 71, 98-113, 115,

$144,148,161,164,177-179,187-190$,

195-199

as change in density 102,110

as change in hexis 50-51 n.29, 106

as change in perceptible qualities 104-107

as part of change in essence 195-199

as part of generation \& corruption 195 199

involving change in place $49-52,53,73$, 112-113

involving condensation \& rarefaction 108-110

may result in a change in essence 202-206

anapnoē, see respiration

archē, see principle / source

atoms $84,86,92$

auxēsis \& phthisis, see growth \& diminution

categories 56 n. $45,86,189$

cause

of all change $35,38,153-154,161$ n. 49

of generation of living things 151-162

sun as, see sun as a cause of generation

change

count noun- vs. mass term-usage 118-119

eternal 29-30, 32, 36-37, 66-67, 115-116,

$118-123,125,130-137,142,147,159$,

162,216

extremes and limits of 125-126, 131, 134-

137 , see also change, starting point and endpoint of

general theory of 27-31, 211, 219

in being 188-194

in essence 190-206 in magnitude, see growth \& diminution; magnitude, non-organic change in

in place, see locomotion

in size, see growth \& diminution; magnitude, non-organic change in

in substance, see change, in essence; generation \& corruption

narrow vs. wide notion of $120-121$

of $x$ as a whole 75-82,149, 203

of $x$ with respect to parts $76-81,86-88$, 97, 199, 202-203

predecessors' views on $72,85-88,90-96$, 114

starting point and endpoint of 37, 55, 131-132, 134-137, 191, 200, see also

change, extremes and limits of

three factors of 124

unity of, see unity of change

cold (psuchron), see quality, four basic kinds of

coming-to-be, see generation \& corruption concoction (pepsis) 47, 196-197

condensation \& rarefaction (puknōsis \&

manōsis) 71, 89, 98-113, 195

as aggregation \& segregation $110-112$

as principles of qualities and their changes $98,108-110$

contact of alterer and altered 50, $51 \mathrm{n} .32$

continuous (suneches) 34-36, 54, 115-117,

$118-127,132$ n. $52,137,141$

one- vs. two-place use 119

sunechōs (adv.) 115, 118-121, 136 n. 64

suneches (adj.) vs. sunechōs (adv.) 115, 118-121

deductive proof 217

denaturation of proteins 197

density \& rarity $99-103,109-110$

departing Berlin 205

diakrisis \& sugkrisis, see aggregation \& segregation

dialectical inquiry 217 
diminution $48-49,53,200,204$, see also growth \& diminution

domino 123

dry (xēron), see quality, four basic kinds of

dunamis, see priority, of energeia over dunamis

earth, see elements

to elaunomenon (what is beaten out) 76

elements / elemental bodies (fire, water, earth, air) 89, 92-97, 105-107, 108-109

transformation of 108-109, 111

energeia, see priority, of energeia over dunamis

ephexēs 115, 118, 121, 126, 144-145, 161

eschata, see change, extremes and limits of

essence $87,146,169-170,182-183,187-188$, 190-194

change with respect to, see change, in essence

$x$ departs from its (existatai tēs ousias) 146, 187, 190-194, 198, 202-207

eternal things 141 n. 77, 144-148, 153-154,

156-157, 160-162, 207-209

existatai tēs ousias, see essence, $x$ departs from its

explanation of change in the cosmos 30-32, $155,157,211,215-218$

fire, see elements

food (trophē) 45-46 , 51-52, 54 n. 39, 65

form $87,93-95,167$ n. 5, 168-169, 171, 183, 195

generation \& corruption (genesis \& phthora)

$38,59,66,71,89-97,115,144,148-150$,

154-162, 190-191, 195-199

accompanied by change in place 96-97, see also locomotion, as part of change in essence

as a change in hexis 195

endpoint of 164, 167-171, 174 n. 20

of living things 150-162

of man 151-161, 196-197

genesis \& phthora, see generation \& corruption

goal 55, 166-167, 185, 200 growth \& diminution (auxēsis \& phthisis) 42, 44-49, 53-57, 62-61, 71, 73-88, 115, $144,149,161,164,177-179,187-190$, see also magnitude, non-organic change in as change of place $73-88$

as part of change in essence 199-201

as part of generation \& corruption 200201

by means of acceding matter 63-64

"by what is like" / "unlike" 45

in living vs. non-living things 53-54

involving locomotion of subject's parts 44-52, 53

may result in a change in essence 202-206 starting point and endpoint of 55, 200, 204

hama, see together

haptesthai, see touching

hard (sklēron) 102, 104

heavy (baru) 101-104

homoeomeres 47, 94

hot (thermon), see quality, four basic kinds of

hule, see matter

infant, growing 78-81, 87

inner spatial order of parts 82-85, 201

kinds of change 10, 27-28, 39, 56 n. 45, 74, 85-88, 177 n. 28, 189, 219

in place, see locomotion, kinds of

non-substantial 10 n. 1, 23 n. 35, 42-44, 51

n. $32,53,57$ n. $48,64,67,133$ n. 54,177 , 188-192

kinēsis, see change

vs. metabolē 10 n. 1, 189 n. 50, 192 n. 58

light (kouphon) 101-104

limit (peras), see change, extremes and limits of

locomotion (phora)

as last kind of change 148, 150, 154-162, $164-165,175-176$

as part of change in essence 201-202, 205-206

as weakest kind of change, see preservation of essence

capacity for, see locomotive capacity of the soul 
circular 28 n. 54, 29, 38-39, 80 n. 24, 130 $131,134-137,146$ n. 3, 153, 156 n. 39, 217-218

different uses of the term 75 n. 7, 76 n. 12, 149, 173-175

has ontological priority $67-69,88,97-98$, 113-117, 130, 137-142, 181-184, 212213

has priority in essence $164-166,171-173$, 187, 206-210, 213

has priority in nature 164,167 n. 8 , see also locomotion, has priority in essence has priority in time 145-147, 159-162, 213

kinds of $75,81,134$

mixed 134

of $x$ as a whole, see change of $x$ as a whole of $x$ with respect to parts, see change, of $x$ with respect to parts

rectilinear 80 n. 24, 134-137

locomotive capacity of the soul 177-183, see also soul, capacities of

magnitude (megethos) 53-54, 71, 74, 134 n. 57, 200, 204

change in, see growth \& diminution non-organic change in 53-56

"man is begotten by man" 155

manōsis, see condensation \& rarefaction matter 63-64, 87, 93, 94 n. 56, 155 n. 36, 195-199

megethos, see magnitude

metabolē 10, 37 n. 84, 42, 45 n. 8, 47, 132

n. 52,137 n. 65,189 n. 50,192 n. 58

mixis, see mixture

mixture (mixis) 94, 102

moist (hugron), see quality, four basic kinds of

nature (phusis) 25-27, 55-57, 59, 115, 127$129,164,169,174$ n. 20,177 n. $28,182-$ 183,200

priority in, see priority, in nature

science of 20, 28, 196, 217, see also Physics, aim of

what is better is always the case in 115 , 127-129

nutritive capacity of the soul 177-182, see also soul, capacities of ontological dependency $68,116,138-139$, 181

outermost sphere 39, 153-155, 209-210, 216-217

pathos, see quality

pepsis, see concoction

peras, see change, extremes and limits of

Peri kinèseōs (On Change) 18-24, 26-31, 218

perishable things 148-150, 154-162, 207

phora, see locomotion

phusis, see nature

Physics

aim of 25-31

arrangement of 15-22

Book VII as a misplacement in 23-24, 29

Book VIII 31-34

connection between Books VI and VIII 29-30

two parts of $17-18$

place (topos) 74-77

change with respect to, see locomotion

looser sense 76

strict or primary sense 76-77

poson, see quantity

preservation of essence 146, 188-196, 201206

primum mobile 147, 154-155, 209, 212-214

principle / source $(\operatorname{arch} \bar{e})$

as endpoint of coming to be 164, 167171,174 n. 20

of bodies 104-106

of change $56-57,62,154,217$, see also self-mover

of qualities 98, 100-104, 108-110

principle of irreducibility 86,104

priority

explanatory 166

in coming to be 172

in essence 13, 68 n. 79, 138, 167 n. 8, 169$172,181-184,206-210$

in nature 68 n.79, 139 n.70, 140 n. 74, 164, 167 n. 8

in time $67,128,147$

of energeia over dunamis 167-172

ontological $42-43,68-69,71-72,73,88-$ $89,113-115,137-142,167$ n. 8

senses of 137-139, 167 n. 8,

phthisis, see growth \& diminution

phthora, see generation \& corruption

proteron $137-138$, see also priority 
puknōsis \& manōsis, see condensation \& rarefaction

quality (pathos) 98, 100-103, 104-107

change in 50-51 n.29, 53, see also alteration

four basic kinds of (hot-cold, dry-moist) 51 n. 33, 103-110

of colour and taste 105-107

psychological 106-107

quantity $53-55,74,186$,

change in, see growth \& diminution; magnitude, non-organic change in

respiration (anapnōe) 61

reversed priority claim 167-172

\section{Scepsis 17}

seasons 156

self-mover(s) $33,58,65,149$

living beings as $57-60,63,149,176-179$, 213-214

sensory capacity of the soul 177-182, see also soul, capacities of

soft (malakon) 102, 104

soul

as the source of change $56-57,60,149$, 176-179 capacities of 176-186

sphere, revolving 79-81, 85

substance 10,51 n. $33,71,89,94,97,105-$

$107,171,203-204,206$, see also essence change in $10-11,91,93$ n. 51,95 , see also change, in essence; generation \& corruption

sugkrisis, see aggregation \& segregation sun as a cause of generation 154-162 suneches / sunechōs, see continuous

Third eternity-objection 60-66

together (hama) 50-51, 51 n.30

topos, see place

touching (haptesthai) 50-52

trophe, see food

unity of change $82,121-127,130-137$

different ways of 124

unmoved mover 31, 33-34, 37, 52, 66, 115$117,122,140-142,154-162,209-211$, 215-219

as principle, source or cause of change 156-162

water, see elements

Zeno's paradoxes 28, 36, 137 n. 67, 211 